\title{
Effects of the novel mitochondrial protein mimitin in insulin-secreting cells
}

\author{
Von der Naturwissenschaftlichen Fakultät \\ der Gottfried Wilhelm Leibniz Universität Hannover \\ zur Erlangung des Grades \\ Doktorin der Naturwissenschaften \\ Dr. rer. nat. \\ genehmigte Dissertation \\ von \\ Katarzyna Joanna Hanzelka, Magister \\ geboren am 27 April 1984 \\ in Kraków, Polen
}


Referent: Prof. Dr. Sigurd Lenzen

Korreferent: Prof. Dr. Georgios Tsiavaliaris

Tag der Promotion: 10. Oktober 2012 
For my Family 


\section{TABLE OF CONTENTS}

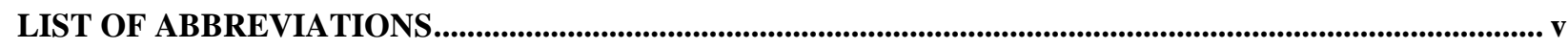

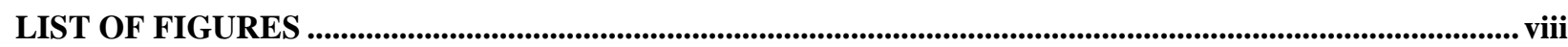

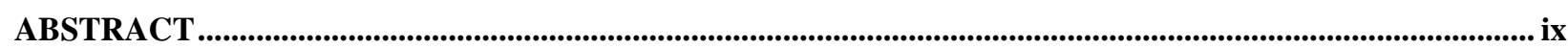

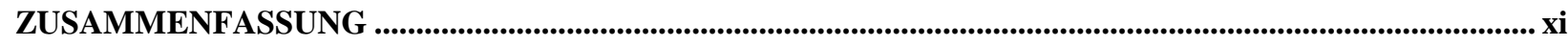

1. INTRODUCTION

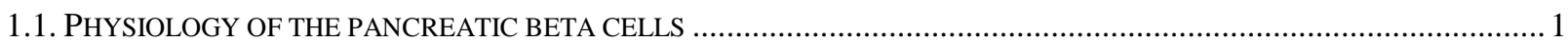

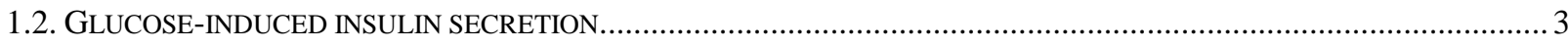

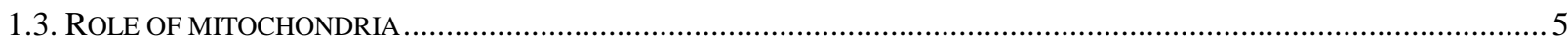

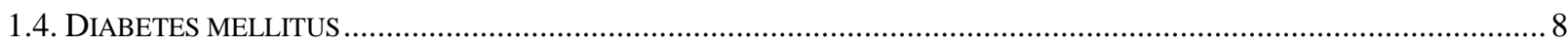

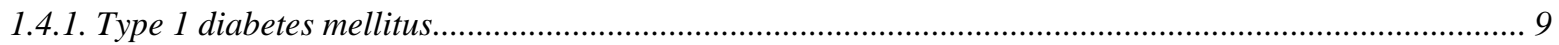

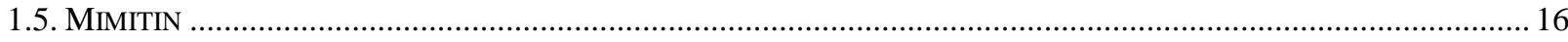

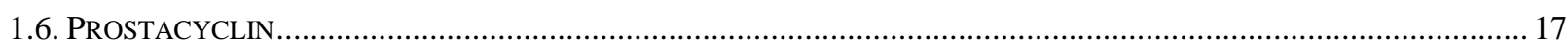

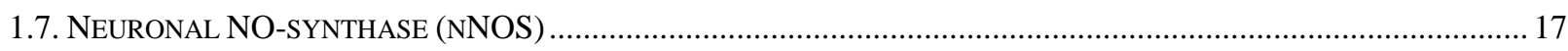

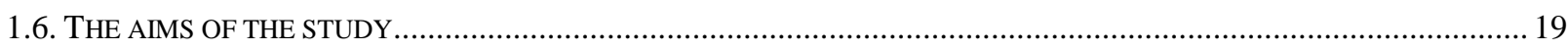

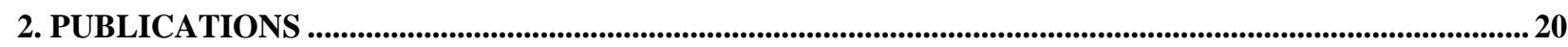

2.1. EFFECTS OF THE NOVEL MITOCHONDRIAL PROTEIN MIMITIN IN INSULIN-SECRETING CELLS ..............................21

2.2. MECHANISM OF PROSTACYCLIN-INDUCED POTENTIATION OF GLUCOSE-INDUCED INSULIN SECRETION............. 32

2.3. IS THERE A ROLE FOR NEURONAL NITRIC OXIDE SYNTHASE (NNOS) IN CYTOKINE TOXICITY TO PANCREATIC

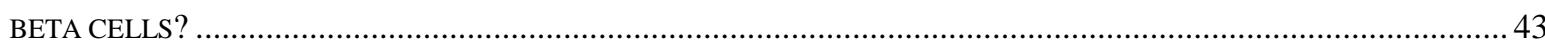

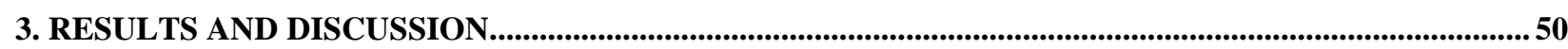

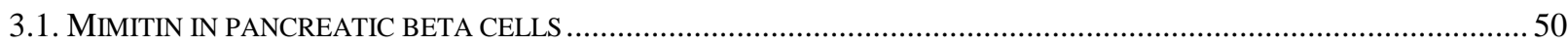

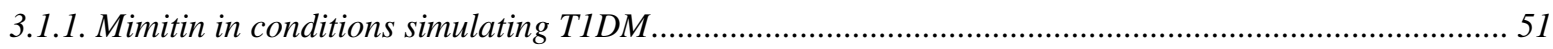

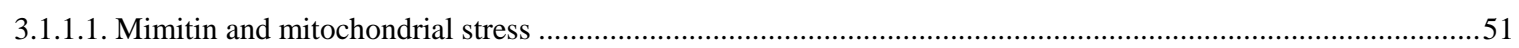

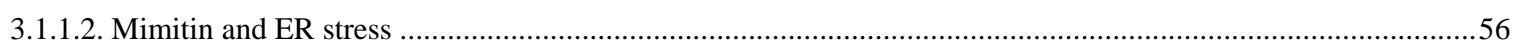

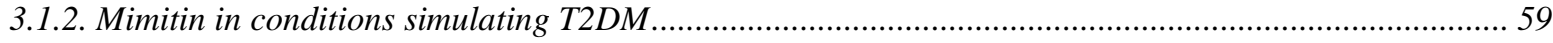

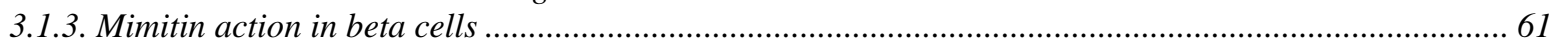

3.2. PROTECTIVE STRATEGIES, COMPARISON BETWEEN MIMITIN AND PROSTACYCLIN SYNTHASE

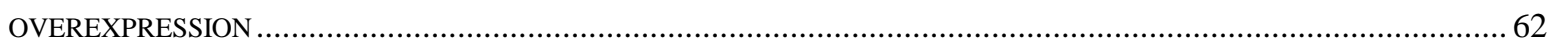

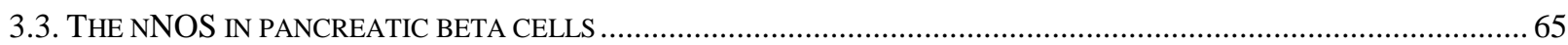

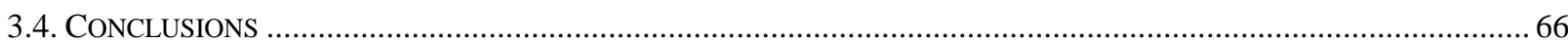

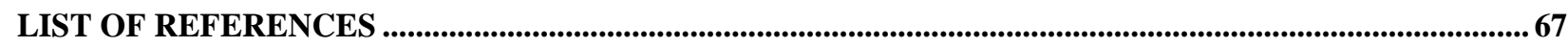

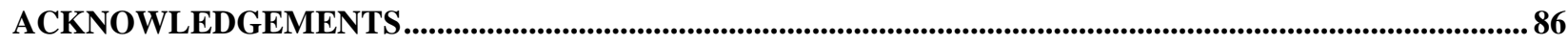

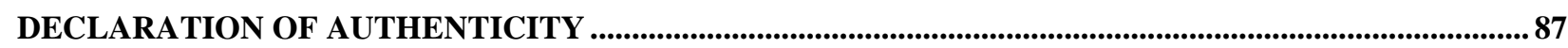

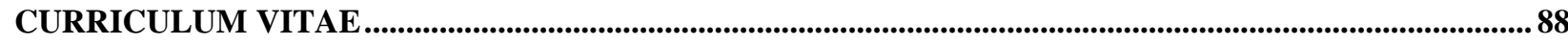

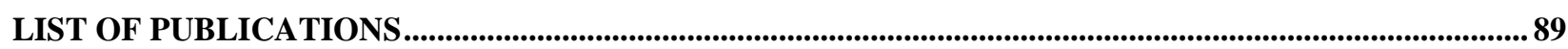

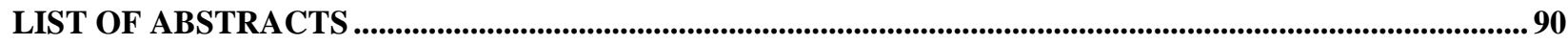




\section{LIST OF ABBREVIATIONS}

ADP

AIF

ANOVA

AP-1

APAF1

ATF6

ATP

BCA

Bip

bp

BrdU

cAMP

CD

cDNA

CoA

CHOP

DAG

DCFDA

DD

DNA

eNOS

ETC

eIF $2 \alpha$

Epac2

ER

ERAD

ERK1

ERK2

FACS

FADD

$\mathrm{FADH}_{2}$

FasL

FFA

GAD

GK adenosine diphosphate

apoptosis-inducing factor

analysis of variance

activator protein-1

apoptotic protease activating factor 1

activating transcription factor 6

adenosine triphosphate

bicinchoninic acid

binding immunoglobulin protein

base pair

5-bromo-2'-deoxyuridine

cyclic adenosine monophosphate

cluster of designation

complementary DNA

coenzyme A

C/EBP homologous protein

diacylglycerol

dichlorofluorescein diacetate

death domain

deoxyribonucleic acid

endothelial nitric oxide synthase

electron transport chain

eukaryotic initiation factor $2 \alpha$

exchange protein directly activated by cAMP 2

endoplasmic reticulum

ER-associated degradation

extracellular-signal regulated kinase 1

extracellular-signal regulated kinase 2

fluorescence-activated cell sorting

Fas-associated death domain

flavin adenine dinucleotide

Fas ligand

free fatty acid

glutamate decarboxylase

glucokinase 


\begin{tabular}{|c|c|}
\hline Glc & glucose \\
\hline Glc-6P & glucose-6-phosphate \\
\hline GLP-1 & glucagon-like-peptide 1 \\
\hline GLUT1 & glucose transporter 1 \\
\hline GLUT2 & glucose transporter 2 \\
\hline GSIS & glucose-stimulated insulin secretion \\
\hline GTP & guanosine triphosphate \\
\hline IAAs & autoantibodies to insulin \\
\hline ICAs & islet cell autoantibodies \\
\hline IDDM & insulin-dependent diabetes mellitus \\
\hline $\mathrm{IFN} \gamma$ & interferon $\gamma$ \\
\hline IFN $\gamma \mathrm{R} 2$ & IFN $\gamma$ receptor 2 \\
\hline IKK & inhibitory $\kappa \mathrm{B}(\mathrm{I} \kappa \mathrm{B})$ kinase \\
\hline IL-1 $\beta$ & interleukin $1 \beta$ \\
\hline iNOS & inducible nitric oxide synthase \\
\hline IRF & interferon regulatory factor \\
\hline JAK $1 / 2$ & Janus tyrosine kinases 1 and 2 \\
\hline JNK & c-Jun $\mathrm{NH}_{2}$-terminal kinase \\
\hline $\mathrm{K}_{\mathrm{ATP}}$ & ATP-sensitive potassium channel \\
\hline LADA & latent autoimmune diabetes in adults \\
\hline L-NARG & L-nitroarginine \\
\hline MAP1S & microtubule-associated protein $1 \mathrm{~S}$ \\
\hline MAPK & mitogen-activated protein kinase \\
\hline MHC & major histocompatibility complex \\
\hline MODY & maturity onset diabetes of the young \\
\hline MOMP & mitochondrial outer membrane permeabilization \\
\hline mRNA & messenger RNA \\
\hline mtDNA & mitochondrial DNA \\
\hline MTT & 3-(4, 5-dimethylthiazol-2-yl)-2, 5-diphenyl-tetrazolium bromide \\
\hline NADH & nicotinamide adenine dinucleotide \\
\hline n.d. & not detectable \\
\hline $\mathrm{NF} \kappa \mathrm{B}$ & nuclear factor $(\mathrm{NF})-\kappa \mathrm{B}$ \\
\hline NIK & nuclear factor- $\kappa \mathrm{B}$ inducing kinase \\
\hline NK cells & natural killer cells \\
\hline NO & nitric oxide \\
\hline NOS & nitric oxide synthase \\
\hline nNOS & neuronal nitric oxide synthase \\
\hline
\end{tabular}




\begin{tabular}{|c|c|}
\hline NOD & non-obese diabetic \\
\hline PC1 & prohormone convertase 1 \\
\hline PC2 & prohormone convertase 2 \\
\hline PGI2 & prostacyclin \\
\hline PGIS & prostacyclin synthase \\
\hline PI3K & phopshatidylinositol-3 kinase \\
\hline PKA & protein kinase A \\
\hline PKB & protein kinase $\mathrm{B}$ \\
\hline PKC & protein kinase $\mathrm{C}$ \\
\hline PLA2 & phospholipase $\mathrm{A}_{2}$ \\
\hline PP & pancreatic polypeptide \\
\hline PP1 & protein phosphatase 1 \\
\hline PP2 & protein phosphatase 2 \\
\hline PT & permeability transition \\
\hline Pyr & pyruvate \\
\hline RNS & reactive nitrogen species \\
\hline ROS & reactive oxygen species \\
\hline SAPK & stress-activated protein kinase \\
\hline siRNA & small interfering RNA \\
\hline STAT & signal transducer and activator of transcription \\
\hline T1DM & type 1 diabetes mellitus \\
\hline T2DM & type 2 diabetes mellitus \\
\hline TCA & tricarboxylic acid \\
\hline $\mathrm{TNF} \alpha$ & tumour necrosis factor $\alpha$ \\
\hline TRADD & TNF-receptor-associated death domain \\
\hline TRAF2 & TNF-receptor-associated factor 2 \\
\hline TRAF6 & TNF-receptor-associated factor 6 \\
\hline TRAIL & TNF related apoptosis inducing ligand \\
\hline UPR & unfolded protein response \\
\hline XBP1 & $\mathrm{X}$-box binding protein 1 \\
\hline
\end{tabular}




\section{LIST OF FIGURES}

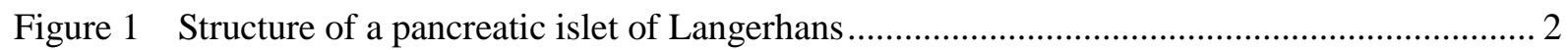

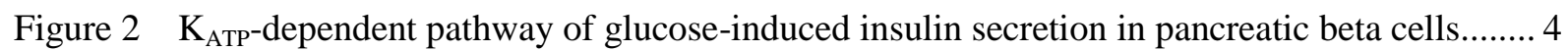

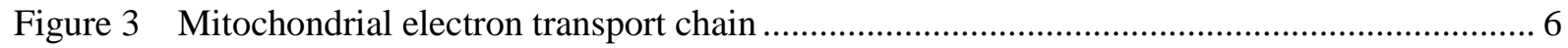

Figure 4 Signal cascades initiated by proinflammatory cytokines in pancreatic beta cells................ 11

Figure 5 Endoplasmic reticulum stress signal transduction .......................................................... 14

Figure 6 A possible place of mimitin action in the cell ............................................................... 17

Figure 7 Effects of mimitin overexpression on cytokine-stimulated DCFDA- $\mathrm{H}_{2}$ oxidation in

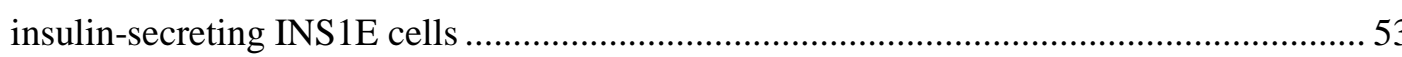

Figure 8 Effects of mimitin overexpression on iNOS protein expression in insulin-secreting INS1E cells

Figure 9 Effects of mimitin overexpression on cytokine-induced ER stress in insulin-secreting INS1E cells 58

Figure 10 Mimitin overexpression protects pancreatic beta cells against cytokine toxicity 62 


\section{ABSTRACT}

During type 1 diabetes development insulin-secreting cells are specifically destroyed by proinflammatory cytokines. This destruction involves the nitrooxidative stress induction, which leads to a severe mitochondrial dysfunction with a concomitant loss of glucose-induced insulin secretion and at the later stage to beta cell death.

Mimitin is a novel mitochondrial protein, which is believed to be involved in the control of cell proliferation and death. Mimitin was also described as a new chaperone for the mitochondrial complex I, thereby modulating ATP formation.

The main aim of this dissertation was to elucidate a possible role of mimitin in insulin-secreting cells. For this purpose a screening for the mimitin expression pattern in different rat and mouse tissues was performed, which revealed a moderate level of mimitin expression in rat and a higher level in mouse islets. Mimitin was expressed in all cell types in the pancreatic islets. Mimitin expression was decreased by proinflammatory cytokines. In the $o b / o b$ mouse, an animal model of insulin resistance and obesity, mimitin expression was not altered in islets, but significantly different in other tissues when compared to the lean litter mates.

To elucidate the role of mimitin in insulin-secreting cells in detail, two cell lines, one with a low expression level (INS1E) and the second with a higher expression level (MIN6), were selected for further studies. Mimitin overexpression increased proliferation of INS1E cells and counteracted its cytokine-mediated inhibition. The cytokine-induced activation of caspase- 9 and -12 was significantly reduced in INS1E-mimitin cells, almost leading to the full prevention of the effector caspase-3 activation. Mimitin overexpression did not affect cytokine-induced NFKB activation and nitrite production. Nevertheless, it reduced the cytokine-mediated ER stress response. The ATP content was significantly higher in mimitin overexpressing INS1E cells and was not diminished by proinflammatory cytokines. In addition, the mitochondrial membrane potential was also not affected by cytokines. Mimitin overexpression led to a higher insulin secretion even in the presence of a basal glucose concentration. The glucose-induced insulin secretion was significantly higher in mimitin overexpressing cells, also after exposure to proinflammatory cytokines. Conversely, mimitin knockdown in MIN6 cells resulted in the opposite effects, when compared to the overexpression. The cytokine-mediated caspase-3 activation was significantly increased, while ATP formation and glucoseinduced insulin secretion (both in the presence and absence of cytokines) were notably reduced.

Overall, these results identified mimitin as a novel protective protein, preventing mitochondrial and ER stresses in insulin-secreting cells exposed to cytokines. Moreover, the data revealed that mimitin overexpression reduces the cytokine-mediated inhibition of glucose induced-insulin secretion, most probably through the maintenance of mitochondrial function. Nevertheless, an increased mimitin expression may constitute a possible threat of a mild but undesirable hypoglycaemia. This observation 
underlines the compromise which pancreatic beta cells must make between a properly controlled glucose responsiveness of insulin secretion and protection against cytokine-mediated toxicity.

Furthermore, the role of prostacyclin (PGI2) in glucose-induced insulin secretion was analyzed. Pancreatic beta cells express prostacyclin synthase (PGIS), the enzyme synthesizing PGI2, on a relatively low level. Therefore PGIS was overexpressed in insulin-secreting INS1E cells and the effects on beta cell function were studied. Interestingly, in contrast to other prostaglandins, prostacyclin was found to be a strong potentiator of glucose-induced insulin secretion. This potentiating effect was dependent on the release of PGI2 from the cell of origin and activation of prostacyclin receptors, leading to a strong rise in cAMP formation, followed by the activation of the PKA-independent and Epac2-mediated pathway.

Moreover, the present study strongly suggests that a low level of nitric oxide (NO) is not deleterious for the pancreatic beta cells. While the high amounts of NO originating from the inducible NO synthase (iNOS) activity mediate the inhibitory actions of proinflammatory cytokines on beta cell function, the low concentrations of NO produced by the neuronal NO synthase (nNOS) seem to be involved in the physiology of pancreatic beta cells. Proinflammatory cytokines significantly reduced the expression of nNOS in insulin-secreting INS1E cells as well as in rat islets. Therefore, the observed modest basal level of nNOS expression in pancreatic beta cells does not mediate the cytokine toxicity in beta cells.

Keywords: Diabetes, Insulin-secreting cell, Cytokines, ATP 


\section{ZUSAMMENFASSUNG}

Die insulinproduzierenden Betazellen werden während der Typ 1 Diabetes Entwicklung durch proinflammatorische Zytokine selektiv zerstört. Diese Zerstörung geht mit der Induktion des nitrooxidativen Stresses einher, die zu einer mitochondrialen Dysfunktion und dem damit verbundenen Verlust der glukoseinduzierten Insulinsekretion und letztlich zum Betazelltod führt.

Mimitin, ein mitochondriales Protein, scheint in der Zellproliferation und beim Zelltod eine wichtige Rolle zu spielen. Darüber hinaus wurde Mimitin als ein neues Chaperon für den mitochondrialen Komplex I beschrieben, wodurch die ATP-Produktion moduliert wird.

Das Ziel der vorliegenden Arbeit war es, die Funktion von Mimitin in insulinsezernierenden Zellen aufzuklären. Hierfür wurde zunächst das Expressionsmuster von Mimitin in verschiedenen Geweben der Ratte und Maus untersucht. Isolierte Langerhans'sche Inseln der Ratte zeigten eine mäßige Mimitin-Expression, wohingegen die Expression in Inseln der Maus deutlich höher war. Mimitin konnte in allen Zellen der Langerhans'schen Inseln nachgewiesen werden. Die Wirkung proinflammatorischer Zytokine reduzierte die Expression des Mimitins innerhalb der Ratteninseln. In pankreatischen Inseln von ob/ob Mäusen, einem Tiermodell für Insulinresistenz und Adipositas, konnten keine Expressionsunterschiede von Mimitin im Vergleich von übergewichtigen mit normalgewichtigen Tieren nachgewiesen werden. Allerdings zeigten sich bei der Mimitin-Expression in anderen Geweben signifikante Unterschiede im Vergleich beider Gruppen.

Für eine detaillierte Darstellung der Rolle des Mimitins in insulinsezernierenden Zellen wurden zwei Betazellinien verwendet. Die INS1E Zellen wiesen dabei ein niedriges Expressionsniveau an Mimitin auf, während die MIN6 Zellen eine höhere Mimitin-Expression zeigten. Die Überexpression von Mimitin in INS1E Zellen führte zu einer Erhöhung der Proliferationsrate und verhinderte die zytokinvermittelte Hemmung der Zellproliferation. Die zytokininduzierte Aktivierung der mitochondrialen Caspase-9 und der ER Stress-assoziierten Caspase-12 war in INS1E-Mimitin Zellen signifikant reduziert und infolgedessen auch die Aktivierung der Effektor-Caspase-3. Zusätzlich blieben jedoch die zytokininduzierte NFkB-Aktivierung sowie die Nitritproduktion unverändert. Dennoch ergab sich eine Verminderung der zytokinvermittelten ER-Stress Antwort. Die ATP Konzentration war in Mimitin-überexprimierenden INS1E Zellen signifikant erhöht und wurde auch durch proinflammatorische Zytokine nicht beeinflusst. Zudem konnte das mitochondriale Membranpotential gegenüber einer zytokinvermittelten Verminderung geschützt werden. Die Überexpression von Mimitin führte selbst bei einer basalen Glukosekonzentration zu einer erhöhten Insulinsekretion. Die Mimitin-überexprimierenden Zellen wiesen auch unter dem Einfluss von proinflammatorischen Zytokinen eine signifikant erhöhte glukoseinduzierte Insulinsekretion auf. Ein „knock-down“ von Mimitin in MIN6-Zellen führte im Vergleich zu Mimitin-überexprimierenden Zellen zu gegenteiligen Effekten. In diesen Zellen konnte eine signifikant erhöhte Aktivierung der 
Caspase-3 nach einer Zytokinexposition mit einer Reduktion der glukoseinduzierten Insulinsekretion sowie der ATP Produktion (in Abwesenheit oder Anwesenheit von Zytokinen) nachgewiesen werden.

Diese Ergebnisse verdeutlichen die Rolle von Mimitin als neues protektives Protein, welches einem zytokinvermittelten mitochondrialen und ER Stress in insulinproduzierenden Zellen entgegen wirkt. Darüber hinaus führte eine erhöhte Expression von Mimitin zu einer reduzierten zytokinvermittelten Inhibierung der glukoseinduzierten Insulinsekretion, was wahrscheinlich durch die Aufrechterhaltung der mitochondrialen Funktion gewährleistet wird. Dennoch könnte die erhöhte Mimitin-Expression zu einer unerwünschten milden Hypoglykämie führen. Die Ergebnisse dieser Arbeit verdeutlichen, dass die Mimitin-Expression in pankreatischen Betazellen einen Kompromiss zwischen der Glukoseresponsivität und dem Schutz gegenüber einer Zytokintoxizität darstellt.

Außerdem wurde die Bedeutung von Prostacyclin (PGI2) für die glukoseinduzierte Insulinsekretion analysiert. Pankreatische Betazellen exprimieren die Prostacyclinsynthase (PGIS), das PGI2-synthetisierende Enzym, auf einem relativ niedrigen Niveau. Um die Bedeutung für die Betazellfunktion zu untersuchen, wurde PGIS in insulinproduzierenden INS1E Zellen überexprimiert. Es konnte gezeigt werden, dass Prostacyclin im Gegensatz zu den anderen Prostaglandinen die glukoseinduzierte Insulinsekretion verstärkt. Diese Verstärkung war von der Freisetzung des PGI2 und Aktivierung des Prostacyclinrezeptors abhängig, wodurch es zu einer starken Erhöhung der cAMPBildung und anschließenden Aktivierung des PKA-unabhängigen bzw. des Epac2-vermittelten Signalweges kam.

Darüber hinaus konnte gezeigt werden, dass niedrige Konzentrationen von Stickstoffmonoxid (NO) keine schädliche Wirkung auf pankreatische Betazellen haben. Während hohe NOKonzentrationen, gebildet durch die induzierbare NO-Synthase (iNOS), die inhibierende Wirkung von proinflammatorischen Zytokinen auf die Betazellfunktion vermitteln, scheinen niedrige NOKonzentrationen, die durch die neuronale NO-Synthase (nNOS) generiert werden, in der Physiologie der pankreatischen Betazellen beteiligt zu sein. Die Inkubation von insulinproduzierenden INS1E Zellen und Ratteninseln mit proinflammatorischen Zytokinen führte zu einer signifikanten Abnahme der nNOS-Expression, was darauf hindeutet, dass die beobachtete moderate nNOS-Expression in pankreatischen Betazellen nicht die Zytokintoxizität vermittelt.

Schlüsselwörter: Diabetes, insulinsezernierenden Zellen, Zytokine, ATP 


\section{INTRODUCTION}

One of the most essential functions of the endocrine system is to maintain body homeostasis. The endocrine system is composed of glands, which produce and secrete hormones directly into the bloodstream. Hormones serve as chemical messengers, transferring the information to target tissues and regulating the whole body metabolism, growth, and development as well as reproductive processes. The endocrine system consists of the hypothalamus, pituitary gland, thyroid, parathyroids, adrenal gland, pineal body, reproductive organs (ovaries and testes), and endocrine pancreas. In contrast to other glands the pancreas has a dual function, reflected by the presence of endocrine and exocrine compartments, the latter of which secretes digestive enzymes. The pancreas is responsible for controlling the blood glucose level. Among many disorders caused by dysfunction of the pancreas, diabetes is the most common one, affecting millions of people worldwide (Eisenbarth 2006).

\subsection{Physiology of the pancreatic beta cells}

The human endocrine pancreas is composed of nearly one million pancreatic islets, scattered over the glandular exocrine tissue (Eisenbarth \& Lafferty 1996; Eisenbarth 2006; Lenzen 2011; MandrupPoulsen et al. 2010; Waldhäusl \& Lenzen 2007). Each of the islets of Langerhans (Figure 1), named after their discoverer Paul Langerhans (1869), contains around 1000-2000 secretory cells arranged in clusters (Ravier \& Rutter 2010). Human islets, varying considerably in terms of size, comprise 1-2 \% of the total mass of the pancreas (Eizirik et al. 2009). A capsule composed of connective tissue fibres and glial-like cells separates richly vascularized (the endocrine cells have direct contact with the bloodstream) and innervated islets from the exocrine tissue (Eisenbarth \& Lafferty 1996; Eisenbarth 2006). Approximately 60-80\% of endocrine cells present in the islets are insulin-producing beta cells, the rest consists of glucagon-producing alpha cells (10-20\% of the endocrine cell mass), somatostatinreleasing delta cells $(\sim 5 \%)$, pancreatic polypeptide-producing PP cells $(<1 \%)$, and ghrelin-producing epsilon cells (Ashcroft \& Rorsman 1989; Eisenbarth \& Lafferty 1996; Eisenbarth 2006; MandrupPoulsen et al. 2010). The communication between endocrine cells occurs either in a paracrine fashion or directly via gap junctions (Mandrup-Poulsen et al. 2010). The architecture of islets varies between the species; however, most mammalian islets have a beta cell rich core surrounded by a demarcated margin composed of alpha-, delta-, and PP-cells.

Pancreatic beta cells secrete insulin, which is the most potent anabolic hormone (Eisenbarth \& Lafferty 1996; Eisenbarth 2006; Lenzen 2011). Insulin production by beta cells represents almost $50 \%$ of their total protein production (Schuit et al. 1988). Insulin biosynthesis is regulated by various factors like glucose, amino acids, cytokines, and insulin itself. In some animals two insulin genes are present; however, in most of them (including humans) only one gene is found. The human insulin gene is located on chromosome 11 and encodes 3 exons and 2 introns (Owerbach et al. 1980). The final spliced messenger RNA transcript is 446 base pairs (bp) long. Insulin mRNA is translated to the pre- 
proinsulin. The formation of proinsulin from pre-proinsulin takes place in the rough endoplasmic reticulum upon the cleavage of the $\mathrm{N}$-terminal signal peptide. Proinsulin contains a 21 amino acid-long alpha and a 30 amino acid-long beta chain, which are linked by a highly charged C-peptide (Eisenbarth \& Lafferty 1996; Eisenbarth 2006; Owerbach et al. 1980). Proinsulin is transported through the Golgi apparatus where it is further processed in the maturing granule to insulin and stored in complexes with zinc. Transformation from proinsulin into insulin occurs via excision of the C-peptide carried out by the endopeptidases PC1 and PC2 (prohormone convertases) and carboxypeptidase H (Eisenbarth \& Lafferty 1996; Eisenbarth 2006). The biologically inactive C-peptide is co-secreted in equimolar amounts with insulin from the mature secretory granule. In the bioactive insulin both alpha and beta chains are linked intramolecularly by two disulfide bridges. The third disulfide bridge is located on the alpha chain. The molecular weight of insulin is $5.8 \mathrm{kDa}$.

Pancreatic beta cells secrete insulin in response to increased circulating levels of glucose. Released insulin exerts its action via binding to and following by the activation of its highly specific and highaffinity cell-surface receptors which are virtually present on all cells of the body, including pancreatic beta cells themselves (Hirayama et al. 1999). Consequently, insulin influences the function of almost all tissues. However, the major insulin-sensitive tissues (target tissues) are liver, adipose tissue, and skeletal muscle.

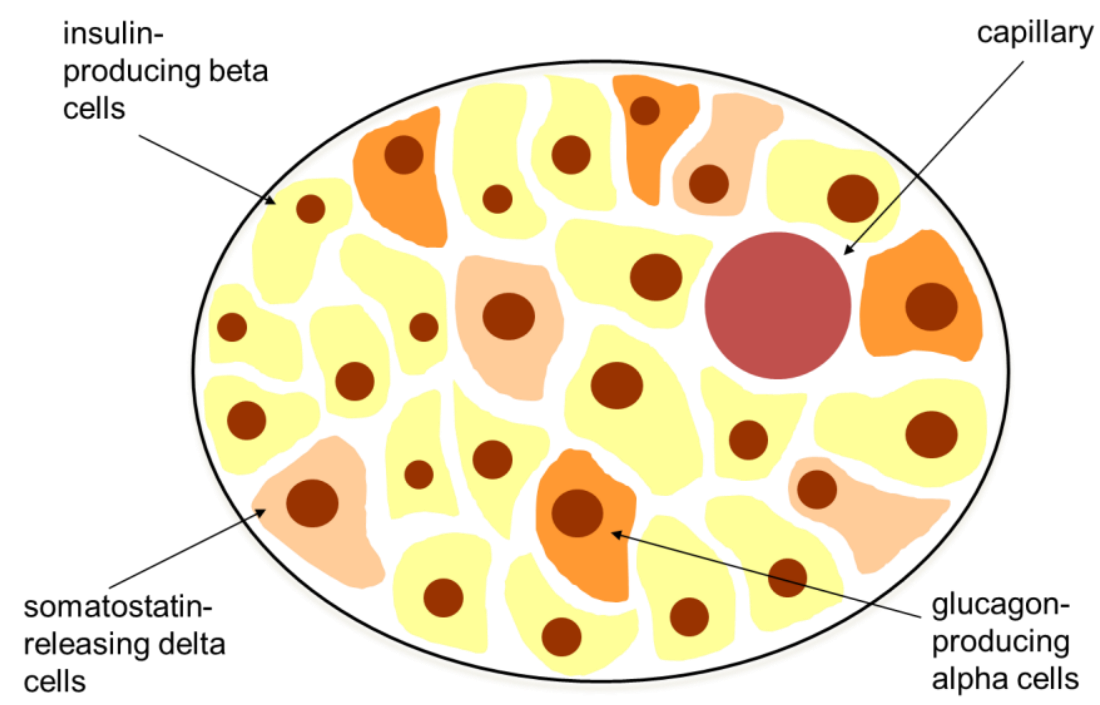

Figure 1 Structure of a pancreatic islet of Langerhans [adapted from (Waldhäusl \& Lenzen 2007)]. 


\subsection{Glucose-induced insulin secretion}

Glucose is the most potent stimulator of insulin secretion (Malaisse et al. 1977; Matschinsky \& Ellerman 1968). Additionally, several other nutrients act as insulin secretagogues, including some amino acids and non-esterified fatty acids (Broca et al. 2003; MacDonald et al. 2005; Newsholme et al. 2005). Pancreatic beta cells are responsible for maintaining the body's glucose concentration within a very narrow range to preserve euglycaemia (Bonner-Weir 2000). Moreover, insulin action on its target tissues, mainly on liver and muscle, enables a tight control of blood glucose level and metabolism.

Since the intra-islet glucose concentration reflects the glucose concentration in the extracellular fluid and closely follows the blood glucose concentration within its physiological range (Matschinsky \& Ellerman 1968), the insulin secretory and biosynthetic activity of pancreatic beta cells is thought to be primarily regulated by the glucose concentration in the circulation (Lenzen \& Panten 1988). In insulin-producing pancreatic beta cells glucose plays a dual role of fuel and physiological stimulus for the initiation of insulin secretion and the regulation of insulin biosynthesis (Ashcroft 1980; Lenzen \& Panten 1988; Schuit et al. 2002; Welsh et al. 1986). The stimulatory effect of glucose on insulin biosynthesis is achieved via concentration-dependent recruitment of pancreatic beta cells to biosynthetic activity (Schuit et al. 1988; Schuit et al. 2002; Weksler-Zangen et al. 2008). The pancreatic beta cell population seems to be composed of cells which differ in their sensitivity to the stimulatory action of glucose. This heterogeneity explains the sigmoidal concentration-response curve for the glucose-induced total protein and proinsulin biosynthesis (Schuit et al. 1988).

In rodent beta cells glucose is transported across the plasma membrane via the high capacity, lowaffinity glucose transporter GLUT2, using the mechanism of facilitated diffusion (Lenzen \& Panten 1988; Maechler 2002; Newgard \& McGarry 1995). However, in human beta cells GLUT2 is only moderately expressed, while the expression of another glucose transporter GLUT1 is predominant (De Vos et al. 1995; Schuit 1997). GLUT1 is characterized by high-affinity for glucose (Boden et al. 1994). Glucose is quickly phosphorylated by the low-affinity glucose phosphorylating enzyme glucokinase (GK) (Ferber et al. 1994; Moukil et al. 2000; Newgard \& McGarry 1995; Purrello et al. 1993). This step leads to the production of glucose-6-phosphate (Glc-6P) and determines the rate of glycolysis and pyruvate generation (Matschinsky 1990; Matschinsky 1996; Newgard \& McGarry 1995; Wiederkehr \& Wollheim 2006). GK activity is present only in the liver and in the islets of Langerhans of the pancreas, where its expression is restricted to beta cells (Iynedjian et al. 1989; Jetton \& Magnuson 1992; Johnson et al. 1990; Lenzen \& Panten 1988; Magnuson \& Shelton 1989). When the blood glucose concentration is high, the rate of glycolysis in the beta cell increases. Electron transfer from the tricarboxylic acid (TCA) cycle to the mitochondrial respiratory chain facilitated by $\mathrm{NADH}$ and $\mathrm{FADH}_{2}$ enables the generation of ATP, which is then exported into the cytosol. An increase in the cytosolic ATP/ADP ratio causes closure of ATP-sensitive $\mathrm{K}^{+}\left(\mathrm{K}_{\mathrm{ATP}}\right)$ channels, which in 
turn depolarizes the plasma membrane. This results in the opening of voltage-sensitive $\mathrm{Ca}^{2+}$ channels and evokes $\mathrm{Ca}^{2+}$ to enter into the cell. In the presence of ATP, $\mathrm{Ca}^{2+}$ stimulates exocytosis of insulincontaining secretory granules (Lang 1999). Although an increase in cytosolic $\mathrm{Ca}^{2+}$ is the main trigger for exocytosis, glucose is also capable of stimulating insulin secretion in a manner not involving $\mathrm{K}_{\mathrm{ATP}}$ channels and $\mathrm{Ca}^{2+}$ influx (Henquin 1988; Lenzen \& Panten 1988). However, the exact mechanism underlying the $\mathrm{K}_{\mathrm{ATP}}$-channel independent pathway is still unclear (Sato \& Henquin 1998). The current hypothesis involves an increased level of cytosolic long-chain acyl-CoA forms, glutamate export from mitochondria, elevated ATP, GTP, and DAG binding protein concentrations as well as activation of PKA and PKC (Bratanova-Tochkova et al. 2002; Prentki 1996; Straub \& Sharp 2002). The $\mathrm{K}_{\text {ATP- }}$ dependent and -independent insulin secretion both require mitochondrial metabolism (Detimary et al. 1994; Taguchi et al. 1995; Wiederkehr \& Wollheim 2006). The $\mathrm{K}_{\mathrm{ATP}}$-dependent pathway of glucoseinduced insulin secretion in pancreatic beta cells is illustrated in Figure 2.

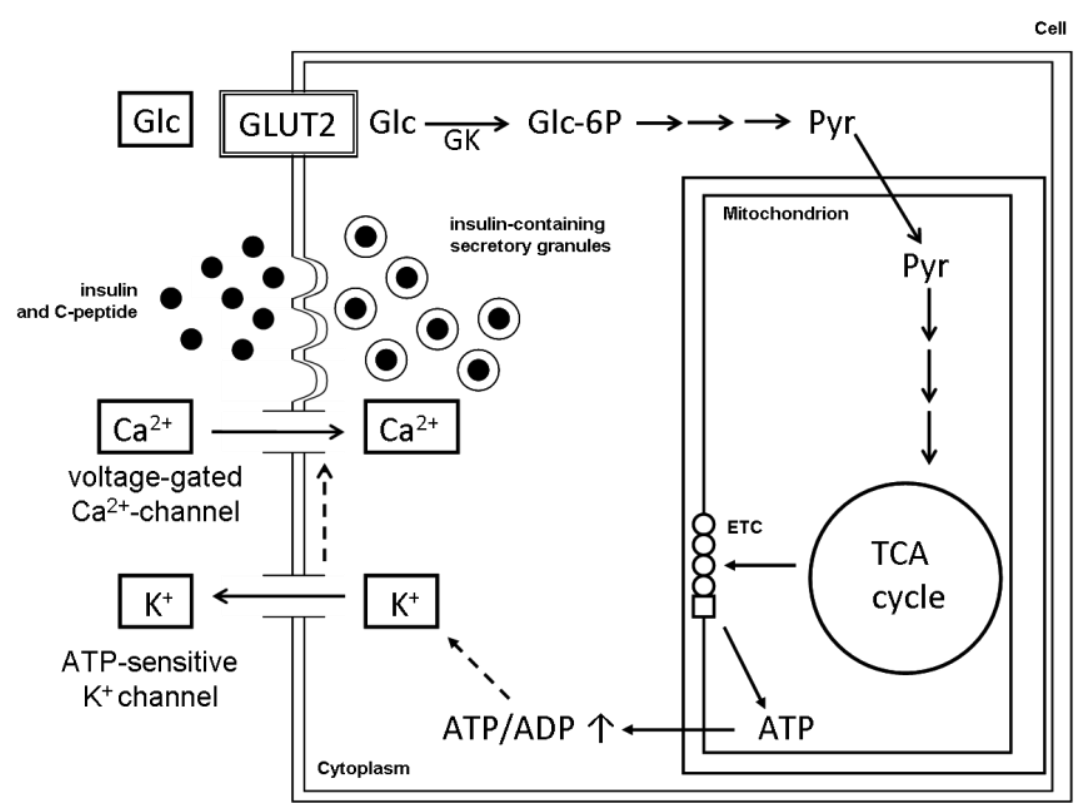

Figure $2 \mathrm{~K}_{\mathrm{ATP}}$-dependent pathway of glucose-induced insulin secretion in pancreatic beta cells [adapted from (Maechler 2002)].

- Glucose (Glc) is taken up by low-affinity GLUT2 glucose transporter in response to hyperglycaemia.

- Glucose is rapidly phosphorylated to glucose-6 phosphate (Glc-6P) by low-affinity glucose phosphorylating enzyme glucokinase (GK) and further converted to pyruvate (Pyr) by glycolysis (Walter \& Ron 2011).

- Pyruvate preferentially enters the mitochondrion and fuels the TCA (Krebs) cycle, leading to the generation of ATP through electron transport chain (ETC), which in turn causes an increase of the ATP/ADP ratio.

- The increased cellular ATP/ADP ratio closes $\mathrm{K}_{\mathrm{ATP}}$-sensitive channels, resulting in membrane depolarization, followed by $\mathrm{Ca}^{2+}$ influx through voltage-gated-Ca ${ }^{2+}$ channels.

- A raise in cytosolic $\mathrm{Ca}^{2+}$ concentration triggers exocytosis of insulin.

Insulin secretion occurs in two phases, though there are significant differences across the species (Grodsky et al. 1967; Henquin et al. 2002; Lenzen 1979; Rorsman et al. 2000). This biphasic response consists of an immediate first phase followed by a sustained second phase. The immediate transient release begins after a short period of 1 to 2 minutes and upon reaching the peak it declines rapidly. The long lasting second phase of insulin secretion begins within 5 minutes after glucose stimulation and is 
characterized by a gradual increase of insulin secretion to a plateau level, though there are significant species differences (Lenzen 1979). Insulin released in the first immediate phase originates from the readily releasable pool of mature granules, whereas the second phase release involves induction of insulin biosynthesis (Bratanova-Tochkova et al. 2002; Henquin 2000; Schuit et al. 2002).

\subsection{Role of mitochondria}

Mitochondria are rod-shaped organelles surrounded by a double membrane present in most eukaryotic cells (with the exception of the red blood cells). The number of mitochondria present within a cell depends on its metabolic requirements and can vary significantly (Robin \& Wong 1988; Wallace 1999). With $4 \%$ the mitochondrial volume is rather low in the beta cells (Dean 1973; Lenzen \& Panten 1988). The unique mitochondrial genome in the form of circular DNA is transcribed and translated within the mitochondrion. Human mitochondrial DNA (mtDNA) comprises only 37 genes (16 $569 \mathrm{bp}$ ), the most important of which are those encoding subunits of the electron transport chain (Wallace 1999). Therefore any defect in mitochondrial DNA results in an impaired oxidative phopshorylation (de Andrade et al. 2006; Jacobsen et al. 2009; Jacobson et al. 1993; Kennedy et al. 1998; Marchetti et al. 1996; Wiederkehr \& Wollheim 2006). Other enzyme subunits as well as mitochondrial proteins are encoded by the nuclear genome (Maechler \& Wollheim 2001; Wiederkehr \& Wollheim 2006). In contrast to nuclear DNA mtDNA consists only of coding sequences, and is not protected by histones. Additionally its repair mechanisms are very poor, which makes it highly susceptible to mutation and oxidative stress (Maechler \& Wollheim 2001).

Mitochondria represent the central crossroad of metabolic pathways and are the main source of energy, primarily ATP, which is required for the maintenance of transmembrane ion gradients, protein synthesis, and vesicular transport (Green \& Reed 1998; Maechler \& Wollheim 2000; Maechler \& Wollheim 2001; Maechler 2002; Maechler \& de Andrade 2006; Newmeyer \& Ferguson-Miller 2003; Skulachev 1999). Three classes of fuel are able to activate mitochondria: amino acids, fatty acids, and carbohydrates, the latter of which are fundamental in pancreatic beta cells under normal physiological conditions (Maechler \& Wollheim 2001). The principal mitochondrial substrate pyruvate, essentially generated by glycolysis, is transported to the mitochondria and provides substrates to the Krebs cycle. This in turn leads to the production of the reducing equivalents, $\mathrm{NADH}$ and $\mathrm{FADH}_{2}$, in the mitochondrial matrix, which are used by complexes I and II in the mitochondrial electron transport chain (ETC). Both complexes I (NADH) and II $\left(\mathrm{FADH}_{2}\right)$ enable electrons to enter the respiratory chain (Maechler \& Wollheim 2001) (Figure 3). Consequently, complexes I, III, and IV of the respiratory chain create an electrochemical proton gradient across the inner mitochondrial membrane. The condensation of ADP with inorganic phosphate is catalyzed by the ATP synthase (complex V). As a result ATP is generated via a process which is powered by the diffusion of protons back into the matrix through the ATP synthase. The adenine nucleotide translocator facilitates the transfer of ATP to the cytoplasm in exchange of ADP. The second complex of the respiratory chain in the mitochondrion, 
namely the $\mathrm{FADH}_{2} /$ succinate dehydrogenase, is also an integral part of the Krebs cycle (Maechler \& Wollheim 2001). The entire process is regulated not only by substrate flux, but also by the $\mathrm{Ca}^{2+}$ concentration, which is able to increase the activity of several mitochondrial dehydrogenases.

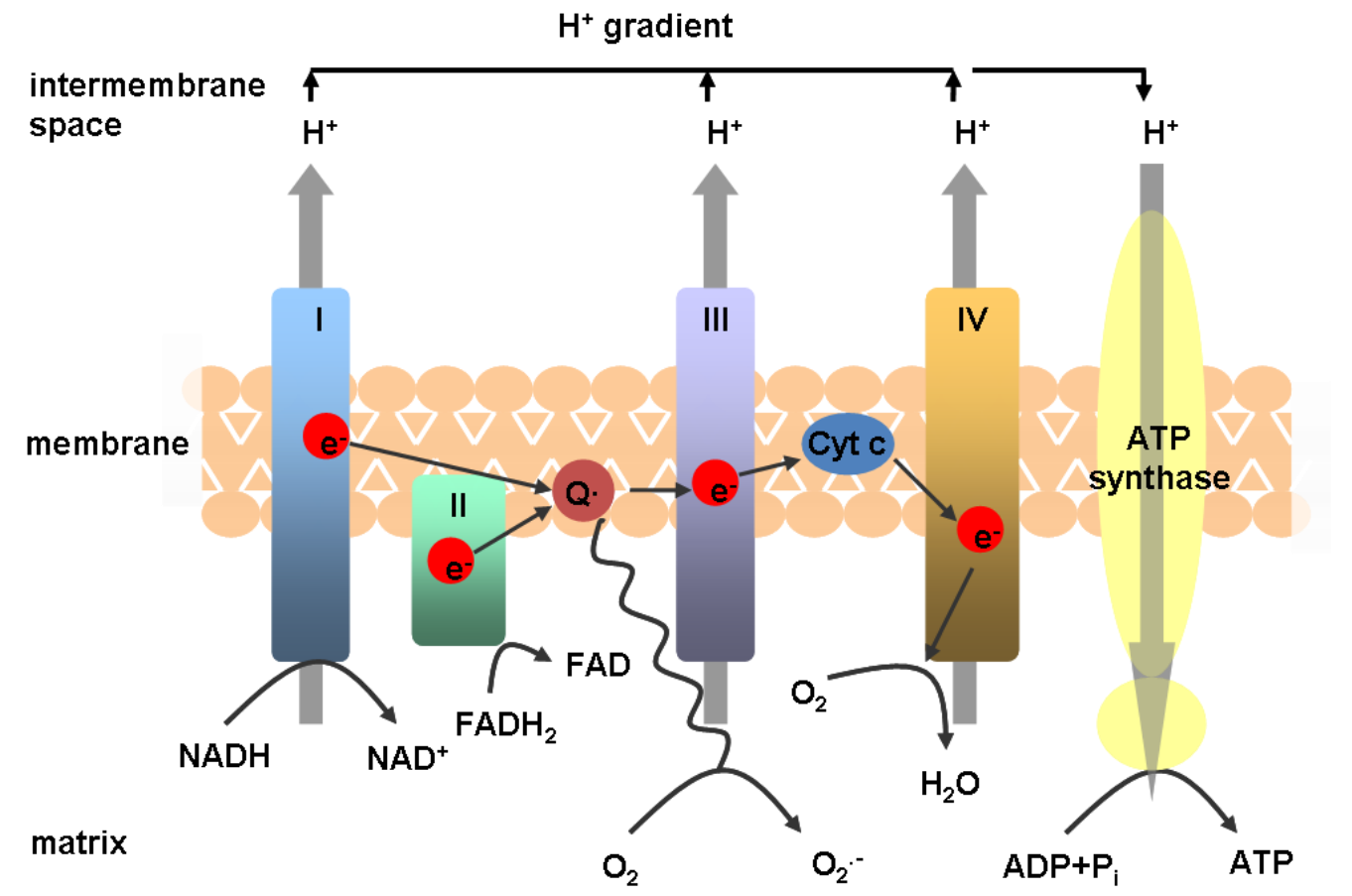

Figure 3 Mitochondrial electron transport chain [adapted from (Brownlee 2005)].

The enzyme complexes I-V are located in the inner mitochondrial membrane. The flux of electrons along the respiratory chain enables complexes I, III and IV to create an electrochemical proton gradient across the inner mitochondrial membrane. This gradient serves as a source of energy to drive ATP synthesis via a process which is powered by the diffusion of protons back to the matrix through the ATP synthase (complex V).

Mitochondria are of particular importance for pancreatic beta cell function. They play an essential role in insulin secretion, coupling nutrient metabolism to insulin secretion (Duchen et al. 1993; Lenzen \& Panten 1988; Maechler 2002; Maechler et al. 2010; Mehmeti et al. 2011; Wiederkehr \& Wollheim 2006; Wollheim 2000). This crucial importance is underscored by the fact that a defective respiratorychain activation as well as the loss of mitochondrial ATP production lead to the inhibition of glucoseinduced insulin release (Maechler \& de Andrade 2006; Maechler et al. 2010; Sakai et al. 2003; Soejima et al. 1996; Tsuruzoe et al. 1998).

Besides having a pivotal role in ATP generation, an increasing amount of evidence also points to the involvement of mitochondria in the regulation of the programmed cell death (Duchen 2004; Green \& Reed 1998; Lee \& Wei 2000; Newmeyer \& Ferguson-Miller 2003; Petit et al. 1996). This has been demonstrated by disruption of the electron transport, oxidative phosphorylation, and ATP production as well as by a release of proteins (such as cytochrome c) triggering the activation of caspases and alteration of cellular redox potential. For most cells the mitochondrial outer membrane permeabilization (MOMP) is the actual point of no return for cell survival, as cells die irrespective of the following caspase activation (Gottlieb et al. 2003). Moreover, it has been demonstrated that in 
nearly all cells MOMP can initiate from a defined point or points in the cell and further proceed in a wave-like manner across all mitochondria (Bhola et al. 2009; Lartigue et al. 2008; Rehm et al. 2003; Tait \& Green 2010). A collapse of the mitochondrial transmembrane potential contributes to cell death mainly via loss of mitochondrial functions: ATP synthesis, ion homeostasis, and protein transport into the mitochondrial matrix (Tait \& Green 2010). Discontinuity of the outer mitochondrial membrane causes a release of intermembranous proteins including cytochrome $\mathrm{c}$ and apoptosis-inducing factor (AIF). After translocation from mitochondria to the cytosol cytochrome $\mathrm{c}$ binds to the apoptosisprotease activating factor-1 (APAF-1). In the presence of ATP the so-called apoptosome is formed, which in turn recruits procaspase 9. The initiator caspase-9 becomes activated and released upon proteolytic cleavage from a multimeric complex. The active caspase 9 then activates the effector caspase- 3 and caspase- 7.

Permeabilization of the outer mitochondrial membrane and the subsequent release of cytochrome $\mathrm{c}$ from the intramembraneous space are firmly regulated by the Bcl-2 family of proteins (Newmeyer \& Ferguson-Miller 2003). The Bcl-2 protein family comprises pro- and antiapoptotic members (Wang et al. 2011). Although the exact mechanisms responsible for cell death controlled by Bcl-2 proteins remain elusive, it appears that the fate of cells exposed to apoptotic stimuli is determined by the interaction between the $\mathrm{Bcl}-2$ family proteins.

The mitochondrial respiratory chain has been defined as the main source of reactive oxygen species (ROS) formation within the cell (Lee \& Wei 2000; Maechler \& de Andrade 2006; Turrens 2003). Under normal conditions only $0.1 \%$ of the total oxygen consumption leaks to ROS generation, which results from an imperfect electron transport (Chance et al. 1979; Raha \& Robinson 2000). However, it has been demonstrated that the magnitude of this leak increases in ageing tissues and in a variety of pathological conditions (Beckman \& Ames 1998). Under physiological conditions ROS are effectively scavenged by different components of the antioxidative defence, often restricted to particular cell compartments. Superoxide radicals were identified as the initial ROS species formed continually by the mitochondrial electron transport chain through the one-electron reduction of molecular oxygen. Even though superoxide radicals are not very toxic, they are precursors of most other ROS. Mitochondria are not only the main source of ROS, they are also the primary target of their action. A number of distinct factors (e.g. UV radiation, proinflammatory cytokines, and environmental toxins) may disturb the equilibrium between production and scavenging of ROS causing a significant increase of the ROS intracellular concentration. A persistent imbalance between excessive formation of ROS and a limited antioxidant defence leads to oxidative stress which eventually damages mitochondria and causes cell death (Crawford et al. 1998; Gehrmann et al. 2010; Maechler \& de Andrade 2006; Mandrup-Poulsen 2001).

Beta cells are known for their limited antioxidant capacity, which makes them particularly susceptible to oxidative damage (Lenzen et al. 1996; Lenzen 2008; Tiedge et al. 1997). This vulnerability mainly relates to beta cell mitochondria characterized by a modest antioxidant defence 
capacity (Lenzen 2008). It has been shown that mitochondria are the main source of cytokine-derived ROS formation (Gurgul et al. 2004; Maechler et al. 2010) and also the main targets of cytokine toxicity (Azevedo-Martins et al. 2003; Drews et al. 2010; Green \& Reed 1998; Grunnet et al. 2009; Gurgul-Convey et al. 2011; Lortz et al. 2005).

\subsection{Diabetes mellitus}

Diabetes mellitus is a chronic metabolic disorder, developing when the beta cells of the pancreas are unable to meet the insulin demand of the body (Hutton \& Eisenbarth 2003), and characterized by hyperglycaemia resulting from defects in insulin secretion, insulin action or both. Over the past 50 years the incidence of diabetes mellitus has been doubled in Western societies (Hutton \& Eisenbarth 2003).

The two main forms of diabetes mellitus, type 1 and type 2 (T1DM and T2DM respectively; Table 1) are characterized by a progressive beta cell dysfunction and loss (Chandra et al. 2001; Cnop et al. 2005). Although the mechanisms involved in T1DM and T2DM development are different, apoptosis is the predominant mode of beta cell death (Chandra et al. 2001; Mandrup-Poulsen 2001). It has been shown that augmented oxidative damage as well as inadequate antioxidant defence significantly contribute to the pathogenesis of diabetes (West 2000).

\begin{tabular}{lll}
\hline \multicolumn{1}{c}{ Type 1 diabetes mellitus (T1DM) } & \multicolumn{1}{c}{ Type 2 diabetes mellitus (T2DM) } \\
\hline- & autoimmune disease & insulin resistance and/or beta cell \\
- & absolute lack of insulin (beta cell & dysfunction \\
destruction) & - & relative insulin deficiency in late disease \\
- & obligatory and permanent insulin & stages, when reduced beta cell mass occurs \\
& substitution & (insulin substitution) \\
- & $5-10 \%$ of all diabetics & $90-95 \%$ of all diabetics \\
\hline
\end{tabular}

Table 1 The two main forms of diabetes mellitus [based on (Lenzen 2011)].

Type 1 diabetes mellitus, also known as insulin-dependent diabetes mellitus, is a polygenic autoimmune disorder and accounts for around 5-10\% of all cases (Daneman 2006). It results from a cellular-mediated autoimmune destruction of beta cells in the pancreas, which leads to the absolute deficiency of insulin secretion (Atkinson \& Maclaren 1994; Donath et al. 2003; Hutton \& Eisenbarth 2003). This complete lack of endogenous insulin production makes a life-long insulin substitution the absolute requirement for T1DM patients. The susceptibility to T1DM is inherited (Atkinson \& Maclaren 1994) indicating a strong genetic background. However, environmental factors were also described as relevant in the aetiology of T1DM (Donath et al. 2003). Moreover, some nutritional factors such as early exposure to cow's milk protein, or gluten may also contribute to the development of type 1 diabetes (Virtanen \& Knip 2003). 
T2DM is characterized by the combination of resistance to insulin action and an inadequate insulin secretory response (Gehrmann et al. 2010; Greenberg \& McDaniel 2002; Pickup \& Crook 1998). The loss of beta cells in T2DM is much slower than in T1DM and is typically preceded by a long phase of beta cell dysfunction characterized by a defective insulin secretion in response to glucose (Lenzen 2011; Newgard \& McGarry 1995). Insulin resistance accompanied by normal glucose levels, glucose intolerance, and clinical diabetes are the three recognized stages described in the development of T2DM with the first two being reversible (Durruty \& Garcia de los Rios 2001). The diminished responsiveness to insulin in the periphery, particularly in muscle, adipose tissue, and liver, seems to be the first demonstrable abnormality in the development of T2DM (Häring \& Mehnert 1993). The risk of developing T2DM increases with age, obesity, and lack of physical activity (Ammon 1997; Durruty \& Garcia de los Rios 2001). T2DM is also genetically influenced (Bonnefond et al. 2010; Cauchi \& Froguel 2008; Froguel et al. 1992; Hertel et al. 2008; Lyssenko et al. 2007; McCarthy 2010; McCarthy 2011), as it has been shown in the study carried out in 200 pairs of identical twins (Barnett et al. 1981).

Besides the types described above there are also several other specific forms of diabetes. A few of them are associated with a monogenic defect in beta cell function. They are referred to as maturityonset diabetes of the young (MODY). MODY is a monogenic autosomal dominant early onset form of non-insulin dependent diabetes mellitus, which was first described in 1975 (Tattersall \& Fajans 1975). It is characterized by an impaired insulin secretion with minimal or no defects in insulin action and accounts for only 1-2 \% of all diabetic cases (Gardner \& Tai 2012).

Latent autoimmune diabetes in adults (LADA), also known as diabetes type 1.5, is characterized by the presence of islet antibodies with simultaneous slow progression of autoimmune beta cell failure (Grant et al. 2010; Stenström et al. 2005; Tuomi et al. 1993). Therefore, LADA patients are not requiring insulin at least during the first 6 months after diagnosis (Stenström et al. 2005). The prevalence of LADA was assessed to be around $10 \%$ among incident case subjects of diabetes aged 40-75 years (Nambam et al. 2010; Wroblewski et al. 1998). Although LADA is initially well manageable with diet and oral hypoglycaemic agents, beta cell function becomes severely impaired within years, which eventually leads to insulin dependency in most patients (Naik et al. 2009; Tuomi et al. 1993; Zimmet et al. 1994).

\subsubsection{Type 1 diabetes mellitus}

Type 1 diabetes has been classified as a chronic autoimmune disease (Castaño \& Eisenbarth 1990; Pipeleers et al. 2001). In this form of diabetes insulin producing beta cells are selectively destroyed by the autoimmune process (Eizirik et al. 2009; Nerup et al. 1994). In contrast endocrine islet cells secreting glucagon, somatostatin, or pancreatic polypeptide are preserved (Atkinson \& Maclaren 1994; Newgard \& McGarry 1995).

Type 1 diabetes occurs mainly in childhood and adolescence; however, it can also occur at a later age (then typically as LADA). The classic manifestation of type 1 diabetes mellitus appears late in the 
course of the disease after most of the beta cells have been destroyed (Atkinson \& Maclaren 1994). Pathological studies of subjects recently diagnosed with T1DM indicate that the symptoms of this disease appear when $~ 70-80 \%$ of beta cells are destroyed (Cnop et al. 2005; Eizirik et al. 2009; Foulis et al. 1986; Klöppel et al. 1985). Since at the time of the onset of T1DM or shortly after most islets are deficient in beta cells and they are characterized by an abnormally small size (Klöppel et al. 1985). The remaining beta cell-positive islets contain cells with enlarged nuclei and variable numbers of degranulated beta cells (Klöppel et al. 1985).

It has been speculated that a developing pattern of epitope-specific autoantibodies, which are detectable at the time of diagnosis, predicts future development of insulin-dependent diabetes in individuals at risk (Mandrup-Poulsen et al. 1985; Pihoker et al. 2005; Roep \& De Vries 1992; Roep 2000; Taplin \& Barker 2008). Those markers of the immune destruction of beta cells include islet cell autoantibodies (ICAs), autoantibodies to insulin (IAAs), autoantibodies to glutamic acid decarboxylase (GAD65), and autoantibodies to the thyrosine phosphatase IA-2 (Atkinson et al. 1986; Pihoker et al. 2005). The presence of multiple autoantibodies is considered to have the highest positive predictive value for T1DM (Pihoker et al. 2005).

Both genetic and environmental factors were found to play a role in T1DM development. T1DM is a polygenic disease and the genetic susceptibility to this form of diabetes is conferred by loci closely related to immune-response genes (Pociot \& McDermott 2002). The major susceptibility to T1DM lies in the major histocompatibility complex (MHC) localized on chromosome 6 in the region associated with the genes for the highly polymorphic immune-system-recognition molecules HLA (Bluestone et al. 2010; Pirot et al. 2008). Autoimmune destruction of beta cells is also considered to be related to environmental factors (Castaño \& Eisenbarth 1990). For instance viral infections, toxins, and certain dietary proteins were found as possible contributors in the pathogenesis of T1DM (Jun \& Yoon 2001; Yoon \& Jun 1999).

Most of the pathological processes occurring in the early phase of T1DM take place in the islets and pancreas draining lymph nodes (Eizirik et al. 2009). Pancreatic islets of patients with T1DM are infiltrated with immune cells, a condition referred to as insulitis (Atkinson \& Maclaren 1994). CD8 ${ }^{+}$ cells, $\mathrm{CD}^{+}$cells, B lymphocytes, macrophages, and natural killer (NK) cells are the major constituents of this inflammatory infiltrate (Atkinson \& Maclaren 1994). Among them macrophages are the main antigen presenting cells, which infiltrate the islets first and induce the beta cell apoptosis via release of proinflammatory cytokines such as IL-1 $\beta$ and TNF $\alpha$ as well as nitric oxide and other free radicals (Eizirik \& Mandrup-Poulsen 2001). Furthermore, increasing evidence indicates that macrophages provide important costimulatory signals for T-cell activation (Jun et al. 1999; Jun et al. 1999). T-cells, following macrophages during insulitis, produce upon activation proinflammatory cytokines in particular IL-1 $\beta$, TNF $\alpha$, and IFN $\gamma$ (Mosmann \& Coffman 1989; Rabinovitch 1998; Rabinovitch \& Suarez-Pinzon 1998). Moreover, they also express the ligand of the Fas receptor (FasL) present on beta cells and the tumour necrosis factor related apoptosis inducing ligand (TRAIL) both of 
which are able to induce apoptosis via the activation of effector caspases-3 and -7 (Kreuwel \& Sherman 2001).

Proinflammatory cytokines are thought to be direct mediators and main effectors of pancreatic beta cell apoptosis (Grunnet \& Mandrup-Poulsen 2011; Nerup et al. 1994). Their cytotoxic effects were reported to be counteracted by the antiinflammatory cytokine-mediated reduction of nitrosative stress, which indicates that the balance between pro- and antiinflammatory cytokines plays a crucial role in the prevention of pancreatic beta cell destruction (Souza et al. 2008). The beta cell damage and apoptosis occurring during T1DM development are induced by IL-1 $\beta, \mathrm{TNF} \alpha$, and IFN $\gamma$ (MandrupPoulsen et al. 1985). Although IL-1 $\beta$ was found to be the most beta cell toxic cytokine being able to inhibit beta cell function and often sufficient to promote apoptosis (Corbett et al. 1992; Jörns et al. 2005; Maedler et al. 2002; Mandrup-Poulsen et al. 1987; Nerup et al. 1988; Sandler et al. 1987), the massive induction of pancreatic beta cell death usually requires a combination of IL-1 $\beta$, TNF $\alpha$, and IFN $\gamma$ (Cetkovic-Cvrlje \& Eizirik 1994; Nerup et al. 1994; Saldeen 2000). The signal transduction by these proinflammatory cytokines involves binding and activation of specific receptors, triggering the signal via cytosolic kinases and/or phosphatases, and mobilization or de novo synthesis of various transcription factors, which next up- or down-regulate gene transcription (Delaney et al. 1997; Eizirik et al. 1996; Eizirik \& Mandrup-Poulsen 2001; Mandrup-Poulsen 2003; Rabinovitch 1998; Rabinovitch \& Suarez-Pinzon 1998; Rabinovitch et al. 1999). The cytokine crosstalk in pancreatic beta cells is shown in Figure 4.

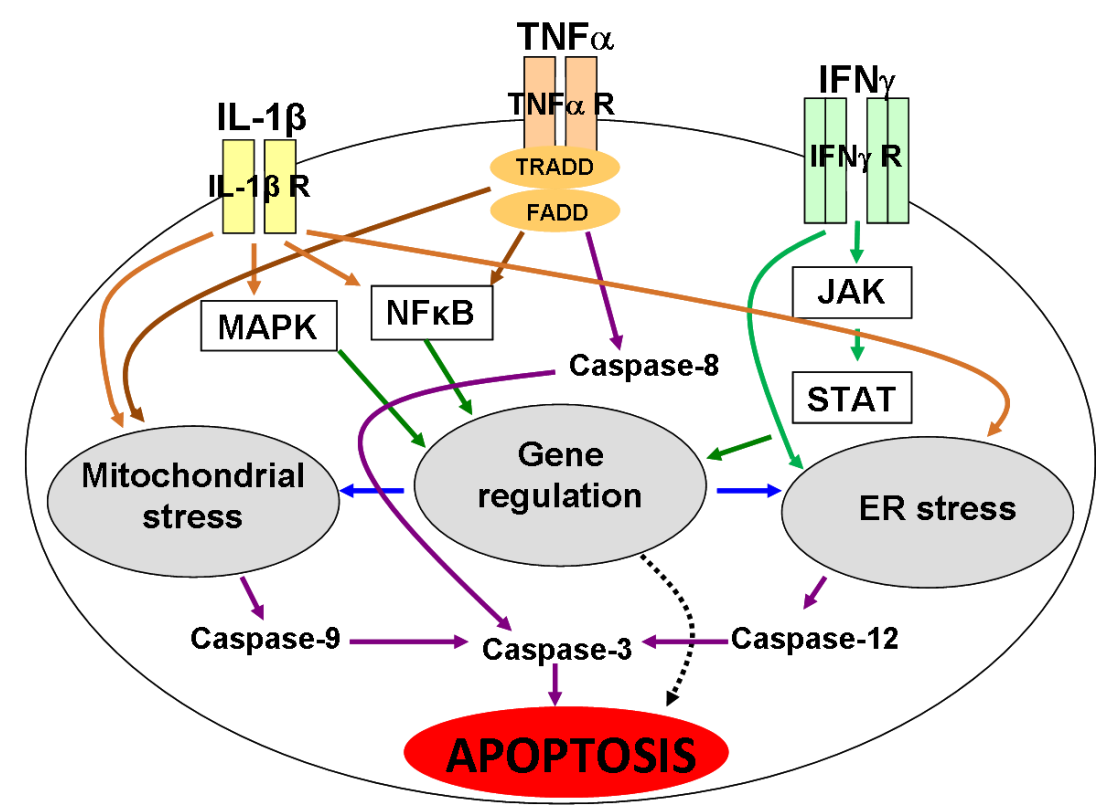

Figure 4 Signal cascades initiated by proinflammatory cytokines in pancreatic beta cells [adapted from (Cnop et al. 2005; Donath et al. 2003; Eizirik \& Mandrup-Poulsen 2001)].

The beta cell damage and apoptosis occurring during T1DM development are induced by three proinflammatory cytokines, namely IL-1 $\beta$, TNF $\alpha$ and IFN $\gamma$. IL- $1 \beta$ activates the transcription factors NFKB and MAPK, which further regulate the gene expression. IL-1 $\beta$ leads to the induction of mitochondrial and ER stress in beta cells. TNF $\alpha$ signals via activating NFKB. Moreover, TNF $\alpha$ can directly induce the caspase- 8 activation. TNF $\alpha$ 
contributes to the mitochondrial stress. IFN $\gamma$ signalling leads to the activation of the JAK/STAT pathway. IFN $\gamma$ contributes to ER stress.

Beta cells express both IL-1 $\beta$ receptors, namely IL-1R1 and IL-1R2 (Dinarello 1997; Eizirik \& Darville 2001). Three major pathways are involved in signal transduction induced by IL-1 $\beta$ : the activation of nuclear factor $\kappa \mathrm{B}(\mathrm{NF \kappa B})$, the activation of mitogen-activated protein kinase (MAPK), and the activation of protein kinase C (PKC) (Eizirik \& Mandrup-Poulsen 2001). MAPKs comprise extracellular signal-regulated kinase (ERK), p38, and c-Jun $\mathrm{NH}_{2}$-terminal kinase (JNK) (Eizirik \& Mandrup-Poulsen 2001; Larsen et al. 2005). ERK, p38, and JNK have been suggested as crucial for excitatory effects of cytokines in beta cells (Eizirik \& Mandrup-Poulsen 2001). They regulate cytokine-induced nitric oxide production. However, MAPK signalling was also implicated in nitric oxide independent events (Eizirik \& Mandrup-Poulsen 2001; Makeeva et al. 2006; Mokhtari et al. 2008; Saldeen \& Welsh 2004; Størling et al. 2005). Upon IL-1 $\beta$ binding conformational changes occur and IL-1R1-activated kinase (Tsuruzoe et al. 1998) is recruited to the receptor complex. IRAK recruitment is thought to be crucial for IL-1 $\beta$-induced signalling, since it interacts with and activates

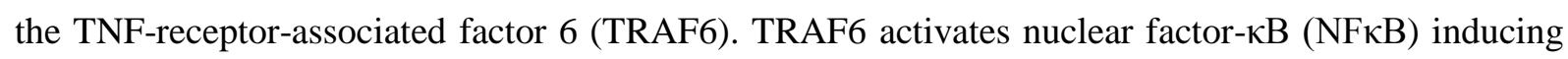
kinase (NIK), which in turn leads to the activation of inhibitory $\kappa \mathrm{B}$ (IкB) kinase (IKK). This causes phosphorylation and eventually degradation of the inhibitory subunits of the NFאB complex, called

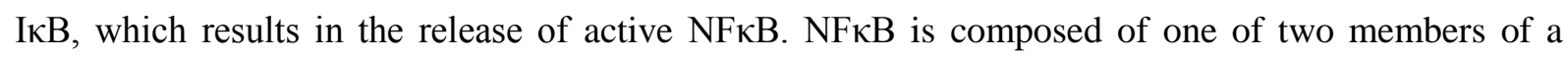
family comprising five proteins that form homo- or heterodimers, depending on stimulus and cell type (Larsen et al. 2005; Ortis et al. 2006; Ortis et al. 2008). Active NFKB is then translocated to the nucleus, where it induces gene transcription. $\mathrm{NF \kappa B}$ is for instance required for cytokine-induced inducible nitric oxide synthase expression (Cetkovic-Cvrlje \& Eizirik 1994; Corbett \& McDaniel 1995; Eizirik \& Darville 2001). It was shown that IL-1 $\beta$ can also activate phosphatidylinositol-3 kinase (PI3K), which similarly to NFאB and AP-1 activation can affect the PKC and protein kinase $\mathrm{B}$ (PKB) activity. IL-1 $\beta$ can also induce mitochondrial and ER stress in pancreatic beta cells (Gurzov et al. 2009; Lee et al. 2010) (Figure 4).

The TNF $\alpha$ signalling occurs through the two different receptors p60 and p80 (Figure 4). Whereas the p60 receptor is ubiquitously expressed in all cell types the p80 is restricted to immune and endothelial cells. The two receptors share a similarity of extracellular domains, but have different intracellular domains. The cytosolic portion of p60 contains the death domain (DD) crucial for transmitting the death signal, while p80 lacks it (Rath \& Aggarwal 1999). After ligand binding the p60 receptor undergoes conformational changes and trimerizes. The DD of the activated receptor interacts with the TNF-receptor-associated death domain (TRADD) which subsequently recruits the Fasassociated death domain (FADD). As a consequence TNF-receptor-associated factor 2 (TRAF2) and a receptor-interacting protein bind to the p60/TRADD/FADD complex (Saklatvala et al. 1999). Eventually $\mathrm{TNF} \alpha$ signalling leads to the activation of phospholipases and sphingomyelinases, 


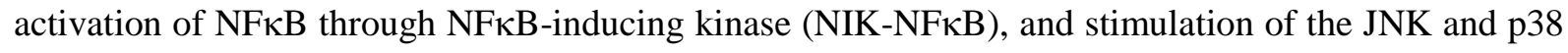
MAP/SAPK pathways, which are also activated by IL-1 $\beta$ (Andersen et al. 2000). Moreover, TNF $\alpha$ is also capable of directly activating the caspase cascade triggered by FADD activation of caspase-8, eventually leading to the final effector caspases (Rath \& Aggarwal 1999) (Figure 4). TNFo also contributes to mitochondrial stress (Cnop et al. 2005; Gurgul-Convey et al. 2011) (Figure 4).

In contrast to IL-1 $\beta$ signalling interferon- $\gamma$ (IFN $\gamma$ ) exerts its action more straightforward. IFN $\gamma$ binds to the IFN $\gamma$ receptor 1 (IFN $\gamma \mathrm{R} 1$ ), which leads to dimerization of the receptors. Subsequently two identical membrane-associated accessory factor proteins (IFN $\gamma$ receptor 2, IFN $\gamma \mathrm{R} 2$ ) are recruited. Both, IFN $\gamma \mathrm{R} 1$ and IFN $\gamma \mathrm{R} 2$ are on their cytoplasmic side associated with the Janus tyrosine kinases 1 and 2 (JAK1/2). When after complex formation two IFN $\gamma$ receptors are brought into close proximity, JAK1/2 becomes activated via auto-phosphorylation and trans-phosphorylation. This further allows docking of two signal transducers and activators of transcription 1 molecules (STAT1), which are next phosphorylated by JAK2. Activated STAT1 homodimerizes and translocates into the nucleus, where through binding to DNA at $\gamma$-activated sites, it regulates the expression of more than a hundred different genes (Eizirik \& Mandrup-Poulsen 2001; Stephanou et al. 2000; Tau \& Rothman 1999). Moreover, STAT1 binds to and activates members of the interferon regulatory factor (IRF) family of transcription factors (Stark et al. 1998; Tau \& Rothman 1999). The activation of STAT1 as a consequence of the IFN $\gamma$ action was found to occur upon cytokine incubation in both insulin-secreting and primary islet cells (Heitmeier et al. 1999; Stark et al. 1998). STAT1 modulates caspase expression and thus regulates the cellular response to pro-apoptotic stimuli (Stephanou et al. 2000). JAKs in turn can activate the extracellular signal-regulated kinase (ERK) MAPK, PI3K, and phospholipase $\mathrm{A}_{2}$ (PLA2), which accounts for a crosstalk with the IL-1 $\beta$ signalling pathway (Stark et al. 1998).

The number of known cytokine-responsive beta cell genes has recently increased to more than 100 by the use of DNA microarrays (Cardozo et al. 2000). Moreover, nearly 20 of them, several with a putative pro-apoptotic role, seem to be NFkB-regulated (Cardozo et al. 2001), which suggests an important role of this transcription factor in the process of beta cell death.

An increasing amount of evidence indicates that mitochondrial stress plays a crucial role in proinflammatory cytokine-induced beta cell death (Figure 4). Mitochondria are known to be the major source of ROS production (Green \& Reed 1998) and the main intracellular target of ROS toxicity (Lee \& Wei 2000; Turrens 2003). The cytokine-induced mitochondrial dysfunction mediated by ROS has been identified as the central event in beta cell death (Gurgul-Convey et al. 2011; Mehmeti et al. 2011). The extraordinary sensitivity of pancreatic beta cells to oxidative stress results from the low expression of antioxidant enzymes (Lenzen et al. 1996; Lenzen 2008; Tiedge et al. 1997), especially those detoxifying $\mathrm{H}_{2} \mathrm{O}_{2}$. Moreover, it was shown that proinflammatory cytokines influence the expression as well as activities of antioxidant enzymes and by that are able to further promote the imbalance in redox status of insulin-producing cells (Bigdeli et al. 1994; Borg et al. 1992; Lortz et al. 
2005; Sigfrid et al. 2003; Souza et al. 2008). The synergism between NO and reactive oxygen species (ROS) action in pancreatic beta cell death has recently been confirmed (Gurgul-Convey et al. 2011). Generation of peroxynitrite from NO and superoxide radicals was commonly thought to be the main cause of cytokine toxicity (Delaney \& Eizirik 1996; Lakey et al. 2001; Suarez-Pinzon et al. 1997; Suarez-Pinzon et al. 2001). However, recent studies demonstrated that it is the nitro-oxidative stressmediated hydroxyl radical formation in the mitochondria that underlies the proinflammatory cytokinemediated beta cell death during T1DM development (Gurgul-Convey et al. 2011).

Lately published reports implicate that the crosstalk between the mitochondrial intrinsic pathway of apoptosis and the endoplasmic reticulum (ER) stress plays a role in the cytokine induced beta cell death (Verma \& Datta 2012). The ER accounts for half of the total protein production in pancreatic beta cells and is an important cellular compartment for insulin biosynthesis (Fonseca et al. 2011). The great secretory demand of beta cells requires a very well developed and highly active endoplasmic reticulum (Eizirik et al. 2008; Eizirik \& Cnop 2010; Laybutt et al. 2007). Recent studies indicate that the ER stress response (Figure 5) is involved in the pathogenesis of diabetes, contributing to pancreatic beta cell loss and insulin resistance (Eizirik et al. 2008; Gurzov et al. 2009; Linssen et al. 2011; Oyadomari et al. 2002; Tabas \& Ron 2011).

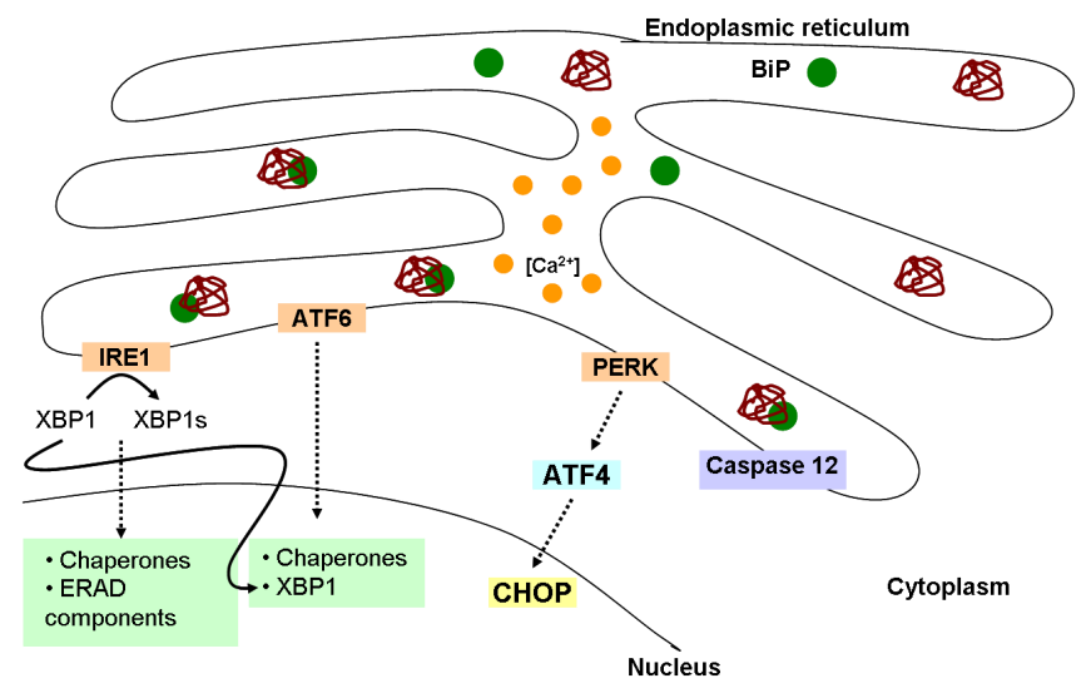

Figure 5 Endoplasmic reticulum stress signal transduction [adapted from (Fonseca et al. 2011; Verma \& Datta 2012; Walter \& Ron 2011)].

Accumulation of misfolded proteins leads to their aggregation within the ER lumen. The ER chaperone Bip dissociates from the luminal side of the ER stress transducer proteins namely IRE1, ATF6, and PERK, leading to their activation. IRE1 splices the mRNA encoding XBP1 and by this generates XBP1s mRNA which in turn encodes the transcription factor regulating the expression of chaperone proteins as well as components of ERassociated degradation (ERAD). ATF6 induces transcription of ER chaperones and XBP1. Activation of the PERK pathway induces overexpression of ATF4 and consequently leads to the induction of transcription factor CHOP. Exposure to cytokines and NO deplete ER calcium stores, leading to ER stress, accompanied by increased levels of IRE1, CHOP and ATF4. 
Accumulation of misfolded proteins, resulting from an imbalance between the protein folding capacity of the ER and the protein load, leads to their aggregation within the ER lumen (Cnop et al. 2012; Eizirik \& Cnop 2010; Kim et al. 2008; Oslowski \& Urano 2010). This causes the loss of ER homeostasis, also known as unfolded protein response (UPR) (Szegezdi et al. 2006; Walter \& Ron 2011). The aim of UPR, serving as an adaptive mechanism, is to alleviate ER stress, restore ER homeostasis, and prevent cell death (Cnop et al. 2012; Eizirik et al. 2008). To achieve this UPR induces: a) a decrease in the arrival of new proteins into the ER (prevention against additional protein misfolding and overloading of the organelle); b) an increase in the amount of ER chaperones (augmentation of the folding capacity of the ER); c) an increase in the extrusion of irreversibly misfolded proteins from the ER (Cnop et al. 2012; Eizirik et al. 2008). Accumulation of unfolded or misfolded proteins in the lumen of the ER induces the activation of three transmembrane ER proteins, which mediate signalling from the ER to the nucleus. Those so-called ER stress transducers, the inositol-requiring enzyme 1 (IRE1), the PKR-like ER kinase (PERK), and the activating transcription factor 6 (ATF6), trigger the main pathways of UPR. Under nonstressed conditions they remain inactive due to binding to the ER chaperone BiP (immunoglobulin heavy chain binding protein). However, in the presence of ER stress mediators the expression of $\mathrm{BiP}$ is decreased and its binding to luminal misfolded proteins is increased, which in turn activates the above mentioned transducers (Bertolotti et al. 2000; Oyadomari et al. 2002). In case the UPR fails to solve ER stress, it generates pro-apoptotic signals to eliminate the diseased cell (Oyadomari et al. 2002). A prolonged and excessive ER stress may trigger apoptosis by various pathways, including activation of some of the key regulators of the UPR. Among them IRE1 $\alpha$ was shown to recruit the adaptor molecule TNF receptor-associated factor 2 (TRAF2) and activate c-Jun N-terminal kinase (JNK) (Urano et al. 2000). The IRE1 $\alpha /$ TRAF2 complex can cause NFkB activation, which leads to the activation of proapoptotic mechanisms in pancreatic beta cells (Ortis et al. 2006). Moreover, the IRE1 $\alpha$ /TRAF2 association is also required for the activation of procaspase 12, specifically related to ER stress (Morishima et al. 2002; Nakagawa et al. 2000). Under ER stress conditions activated IRE1 $\alpha$ cleaves an intron from the mRNA encoding X-box protein binding 1 (XBP1) (Oslowski \& Urano 2010; Yoshida et al. 2001). The spliced variant of XBP1 mRNA (XBP1s) encodes a transcriptional factor, which regulates the protein expression of chaperones and components of ER-associated degradation, ERAD (Lee et al. 2003). ATF6 induces transcription of XBP1 (Oslowski \& Urano 2010; Yoshida et al. 2001).

Beta cell death can also be induced via the activation of the PERK pathway leading to overexpression of the activating transcription factor 4 (ATF4) and consequently to the induction of C/EBP homologous protein (CHOP). CHOP, also known as GADD153, is a member of the C/EBP family of transcription factors (Ron \& Habener 1992). Under normal physiological conditions this putative regulator of ER stress-mediated apoptosis is either not expressed or its expression level is very low (Lawrence et al. 2007; Wang \& Ron 1996). Suppression of the pro-survival protein Bcl-2 and induction of oxidative stress are the most widely cited mechanisms implicated in the CHOP- 
induced apoptosis (Marciniak et al. 2004; McCullough et al. 2001; Tabas \& Ron 2011). Studies performed in beta cells demonstrated that a blockade of NO formation partially prevented IL-1 $\beta$ induced CHOP expression (Kacheva et al. 2011; Oyadomari et al. 2001). In contrast TNF $\alpha$ and IFN $\gamma$ are not involved in the induction of CHOP expression in beta cells (Kacheva et al. 2011).

\subsection{Mimitin}

Mimitin, a Myc-induced mitochondrial protein, has been discovered in human glioblastoma cells and has been shown to be involved in cell proliferation (Tsuneoka et al. 2005). Human mimitin is a small $20 \mathrm{kDa}$ protein, comprising 169 amino acids, the sequence of which is highly conserved between human and mouse ( $80 \%$ homology), suggesting an important function of mimitin in mammals (Tsuneoka et al. 2005). A specific c-myc binding site was identified in the promoter region of the mimitin gene, which clearly indicates that mimitin is a direct transcriptional target of c-myc (Tsuneoka et al. 2005). Mimitin contains an ATP/GTP binding motif and a domain called Complex 1_17_2 kDa. The latter was found in the NADH-ubiquinone oxidoreductase subunit B17.2, originally identified as a subunit of complex I involved in oxidative phosphorylation in bovine heart mitochondria (Tsuneoka et al. 2005). Mimitin is thought to play the role of a molecular chaperone for assembly of the mitochondrial complex I (Ogilvie et al. 2005) and to be involved in ATP metabolism in mitochondria (Tsuneoka et al. 2005). Studies performed in human hepatoma cells (HepG2) confirmed the mitochondrial association of mimitin and revealed that mimitin may modulate cell death (Wegrzyn et al. 2009). It was shown that upon exposure to IL-1 $\beta$ and IL-6 the level of mimitin expression in HepG2 cells was increased more than 1.6-fold, with the highest level achieved after 18-24 hours of cytokine addition (Wegrzyn et al. 2009).The NFkB signalling pathway did not appear to be involved in the IL-1 $\beta$-dependent activation of the mimitin gene, while the MAP kinase pathway was identified as being involved in cytokine-induced stimulation of mimitin. Among human tissues the heart was found to contain the highest level of mimitin mRNA followed by considerably lesser amounts detected in the liver, skeletal muscle, and kidney (Wegrzyn et al. 2009). Furthermore, reduction of mimitin expression by the siRNA approach had no direct effects on the basal activities of caspase-3 and -7. However, when apoptosis was induced by TNF $\alpha$ and cycloheximide, mimitin knock-down led to a significant increase in apoptosis (Wegrzyn et al. 2009). Consistently, overexpression of mimitin resulted in a 2-fold decrease of caspase-3 and -7 activities in HepG2 cells treated with TNF $\alpha$ and cycloheximide (Wegrzyn et al. 2009). The mimitin knock-down slightly decreased the rate of DNA replication and cell proliferation in HepG2 cells, whereas mimitin overexpression did not seem to influence cell proliferation (Wegrzyn et al. 2009). 


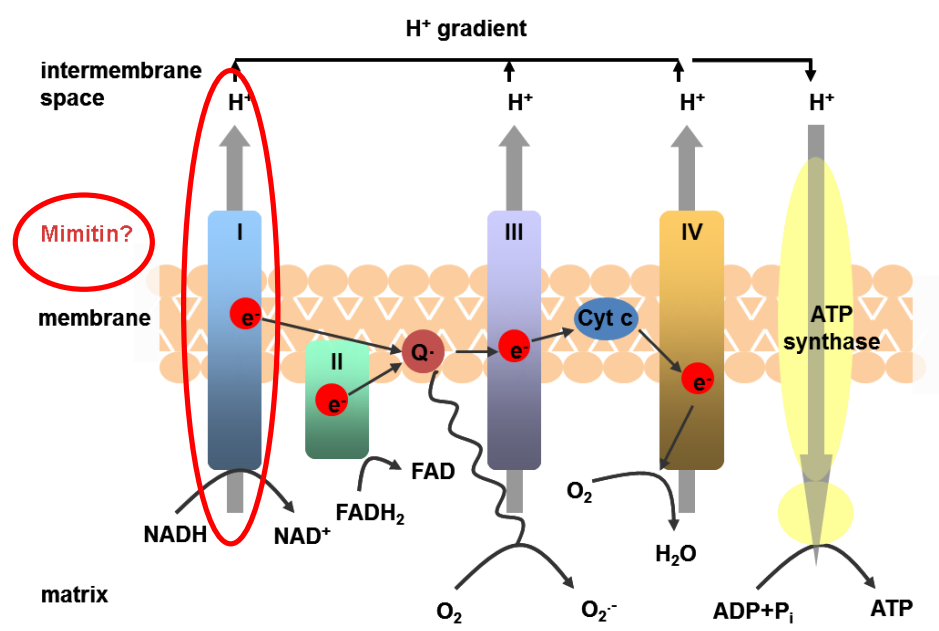

Figure 6 A possible place of mimitin action in the cell [adapted from (Brownlee 2005)].

\subsection{Prostacyclin}

Prostacyclin belongs to the family of eicosanoids, lipid mediators and signalling molecules (Hatae et al. 2001). It is produced by the action of a specific prostacyclin synthase (Hatae et al. 2001; Wu \& Liou 2005). Prostacyclin serves as a crucial vasodilator (Hatae et al. 2001) and prevents platelet cloth formation (DeWitt et al. 1983; Weiss \& Turitto 1979). Stable analogues have been successfully used to treat patients with hypertension (Miyata et al. 1996; Otsuki et al. 2005).

Prostacyclin has been reported to provide beneficial effects during islet isolation and cryopreservation (Arita et al. 1997; Arita et al. 1998; Arita et al. 1999; Arita et al. 2001; Yegen et al. 1994). The molecular mechanisms underlying the protective effect of PGI2 were recently clarified (Gurgul-Convey \& Lenzen 2010). They involve the prevention of the cytokine-induced mitochondrial and ER stress responses (Gurgul-Convey \& Lenzen 2010). The protective action of prostacyclin is strongly mediated by inhibition of the cytokine-activated NFKB pathway (Gurgul-Convey \& Lenzen 2010).

Many arachidonic acid metabolites have been shown to act as negative regulators of glucoseinduced insulin-secretion (Tran et al. 1999), but the role of PGI2 in this context is unclear.

\subsection{Neuronal NO-synthase (nNOS)}

Under normal physiological conditions NO is present at low concentrations and plays a role of the messenger molecule, mediating diverse biological functions (Hill et al. 2010; Zhou \& Zhu 2009). Three types of nitric oxide synthase (NOS) serve as a source of NO, generated by the conversion of Larginine to L-citrulline (Zhou \& Zhu 2009). They comprise two constitutively expressed isoenzymes, namely neuronal NO synthase (nNOS) and endothelial NO synthase (eNOS), as well as inducible NO synthase (iNOS), the expression of which is stimulated in the presence of different cytokines and endotoxin (Zhou \& Zhu 2009). The eNOS and nNOS account for the production of low concentrations of NO, which are relevant under physiological conditions (Zhou \& Zhu 2009), whereas the large 
amounts produced by iNOS over prolonged time are attributed to pathological situations (Holohan et al. 2008). During T1DM development proinflammatory cytokines induce iNOS expression in pancreatic beta cells (Cnop et al. 2005; Eizirik \& Pavlovic 1997; Gurgul-Convey et al. 2011). The nNOS isoform, expressed preferentially in the brain, was also shown to be present in insulin secreting cells, where it was suggested to regulate the beta cell response to glucose (Lajoix et al. 2001; Liu et al. 2000). Moreover, NO may regulate gene transcription and nearly $50 \%$ of the genes modified by cytokines and related to beta cell death were shown to be NO-dependent, clearly indicating the pivotal role of this free radical in cytokine-mediated cell toxicity (Kutlu et al. 2003; Li \& Mahato 2008; Liu et al. 2000). Noteworthy it has been shown that NO contributes to cytokine-induced beta cell death via its interaction with hydrogen peroxide in beta cell mitochondria, leading to the production of highly toxic hydroxyl radicals (Gurgul-Convey et al. 2011). 


\subsection{The aims of the study}

During T1DM development proinflammatory cytokines cause pancreatic beta cell dysfunction and death by affecting several signalling and metabolic pathways, exerting their deleterious effects in all cell compartments.

Mitochondria play a central role in the regulation of glucose-induced insulin secretion and are therefore of crucial importance for pancreatic beta cell function. During type 1 diabetes development proinflammatory cytokines cause pancreatic beta cell dysfunction and destruction through nitrooxidative stress, induced mainly in the mitochondria. Mitochondrial dysfunction also occurs during development of other diabetes subforms, especially with regard to an impaired ATP generation.

Mimitin was reported to be a new chaperone for the mitochondrial complex I, to modulate ATP production, and to be involved in the control of cell proliferation and death. So far there has been no information about mimitin in pancreatic beta cells.

Thus, the aims of this study regarding mimitin were:

1. to uncover mimitin expression regulation by proinflammatory cytokines in insulin-secreting cells,

2. to analyze the role of mimitin in beta cell function with special reference to the regulation of glucose-induced insulin secretion,

3. to elucidate the molecular mechanisms underlying mimitin effects on beta cell function,

4. to confirm the findings in primary islet cells,

5. to investigate mimitin expression in the mouse model of insulin resistance and obesity, the $o b / o b$ mouse.

Moreover, the current study attempted to compare the beneficial effects of mimitin and prostycyclin synthase (PGIS) overexpression.

Furthermore, the role of neuronal NOS (nNOS) in cytokine-mediated beta cell dysfunction and death was analyzed. 


\section{PUBLICATIONS}

1. Hanzelka K., Skalniak L., Jura J., Lenzen S., Gurgul-Convey E. (2012) Effects of the novel mitochondrial protein mimitin in insulin-secreting cells. Biochem J 445: 349-359. ${ }^{1}$

2. Gurgul-Convey E., Hanzelka K., Lenzen S. (2012) Mechanism of prostacyclin-induced potentiation of glucose-induced insulin secretion. Endocrinology 153:2612-22. ${ }^{2}$

3. Gurgul-Convey E., Hanzelka K., Lenzen S. (2012) Is there a role for neuronal nitric oxide synthase (nNOS) in cytokine toxicity to pancreatic beta cells? Nitric oxide $27: 235-241 .^{3}$

\footnotetext{
${ }^{1}$ Reproduced with permission, from Hanzelka K., Skalniak L., Jura J., Lenzen S., Gurgul-Convey E., (2012), (Biochemical Journal), (445), (349-359). @ 0 the Biochemical Society.

${ }^{2}$ Copyright 2012, The Endocrine Society

${ }^{3}$ Reprinted from the Nitric oxide, Vol. 27, Gurgul-Convey E., Hanzelka K., Lenzen S., Is there a role for neuronal nitric oxide synthase (nNOS) in cytokine toxicity to pancreatic beta cells? Pages No. 235-241 Copyright (2012), with permission from Elsevier.
} 


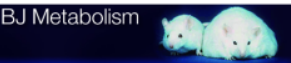

Biochem. J. (2012) 445, 349-359 (Printed in Great Britain) doi:10.1042/BJ20111920

\section{Effects of the novel mitochondrial protein mimitin in insulin-secreting cells}

Katarzyna HANZELKA* ${ }^{*}$ Lukasz SKALNIAK ${ }^{\dagger}$, Jolanta JURA ${ }^{*}$, Sigurd LENZEN* and Ewa GURGUL-CONVEY*1

*Institute of Clinical Biochemistry, Hannover Medical School, 30625 Hannover, Germany, and †Department of General Biochemistry, Faculty of Biochemistry, Biophysics and

Biotechnology, Jagiellonian University, 30387 Krakow. Poland

Mimitin, a novel mitochondrial protein, has been shown to act as a molecular chaperone for the mitochondrial complex I and to regulate ATP synthesis. During Type 1 diabetes development, pro-inflammatory cytokines induce mitochondrial damage in pancreatic $\beta$-cells, inhibit ATP synthesis and reduce glucoseinduced insulin secretion. Mimitin was expressed in rat pancreatic islets including $\beta$-cells and decreased by cytokines. In the ob/ob mouse, a model of insulin resistance and obesity, mimitin expression was down-regulated in liver and brain, up-regulated in heart and kidney, but not affected in islets. To further analyse the impact of mimitin on $\beta$-cell function, two $\beta$-cell lines, one with a low (INS1E) and another with a higher (MIN6) mimitin expression were studied. Mimitin overexpression protected

\section{INTRODUCTION}

Mimitin is a small $20 \mathrm{kDa}$ mitochondrial protein that is a direct target for c-Myc and is involved in cell proliferation [1] Mimitin contains an ATP/GTP-binding motif and a domain called Complex1_17_2 kDa [1]. Mimitin is thought to play the role of a molecular chaperone for assembly of the mitochondrial respiratory chain complex I and to be involved in ATP generation in mitochondria [1]. Previous studies have shown that mimitin may modulate cell death [2]. In hepatoma cells, the expression of mimitin was found to be increased upon exposure to IL (interleukin)$1 \beta$ and IL-6 [2]. It has also been shown that blockade of mimitin expression by siRNA (small interfering RNA) technology leads to a decrease in HepG2 cell proliferation and accelerates TNF $\alpha$ (tumour necrosis factor $\alpha$ ) and cycloheximide-induced apoptosis [2]

Synthesis of ATP is crucial for glucose-induced insulin secretion [3], and since this process is disturbed by cytokines during Type 1 diabetes development [4], mimitin attracted our attention. So far there is no information about mimitin in pancreatic islets. It was therefore the aim of the present study to elucidate the role of mimitin in primary islet cells and in insulinsecreting cell lines with special reference to its effects on the action of pro-inflammatory cytokines, which are responsible for pancreatic $\beta$-cell damage during Type 1 diabetes developmen $[5,6]$. Moreover, the influence of mimitin on $\beta$-cell function with special emphasis on the regulation of glucose-induced insulin secretion was studied. We show that mimitin can act as a modulator of glucose-induced insulin secretion and prevent its inhibition by pro-inflammatory cytokines

\section{MATERIALS AND METHODS}

\section{Chemicals}

Cytokines and the dNTP mixture were obtained from PromoCell The jetPEI ${ }^{\mathrm{TM}}$ transfection reagent was purchased from PEQLAB
INS1E cells against cytokine-induced caspase 3 activation, mitochondrial membrane potential reduction and ATP production inhibition, independently from the NF- $\kappa \mathrm{B}$ (nuclear factor $\kappa \mathrm{B}$ )iNOS (inducible NO synthase) pathway. Mimitin overexpression increased basal and glucose-induced insulin secretion and prevented cytokine-mediated suppression of insulin secretion. Mimitin knockdown in MIN6 cells had opposite effects to those observed after overexpression. Thus mimitin has the capacity to modulate pancreatic islet function and to reduce cytokine toxicity.

Key words: ATP, cytokine, diabetes, insulin-secreting cell, mimitin, mitochondrion.

Biotechnologie, and Biotherm ${ }^{\mathrm{TM}}$ Taq polymerase was from GeneCraft. The SuperScript II RT ${ }^{\mathrm{TM}}$ reverse transcriptase and all tissue culture equipment were from Invitrogen. Primers were from Invitrogen. Hybond $\mathrm{N}$ nylon membranes and the ECL (enhanced chemiluminescence) detection system were from Amersham Biosciences, and Immobilon-P PVDF membranes were from Millipore. All other reagents were from SigmaAldrich.

\section{Rat and mouse tissue preparation}

Pancreatic islets and other tissues were from $250-300 \mathrm{~g}$ male Lewis rats or from ob/ob mice (50-70 g) or their lean littermates $(25-30 \mathrm{~g})$ bred in our institution according to German animal law. The ob/ob mice [7] used in the present study originate from a colony described previously [8] and are characterized by a moderate hyperglycaemia together with hyperinsulinaemia due to islet hypertrophy, without any defects in $\beta$-cells.

\section{Rat islet isolation, culture and treatment}

Pancreatic islets were isolated by collagenase digestion and handpicked under a stereomicroscope. Isolated islets were cultured on $35 \mathrm{~mm}$ ECM (extracellular matrix)-coated plates (Novamed), the ECM being derived from bovine corneal endothelial cells, in RPMI 1640 tissue culture medium containing $5 \mathrm{mM}$ glucose, $10 \%$ FBS (fetal bovine serum), 200 units $/ \mathrm{ml}$ penicillin and $0.2 \mathrm{mg} / \mathrm{ml}$ streptomycin at $37^{\circ} \mathrm{C}$ in a humidified atmosphere of $5 \% \mathrm{CO}_{2}$. For immunofluorescence studies, islets were allowed to adhere and to spread for 10-12 days on the ECM plates. After transfer on to collagen-coated chamber slides, they were allowed to attach for $24 \mathrm{~h}$. The islets were treated with IL- $1 \beta$ $(600 \mathrm{units} / \mathrm{ml})$ or a cytokine mixture [IL- $1 \beta, 60 \mathrm{units} / \mathrm{ml} ; \mathrm{TNF} \alpha$, $185 \mathrm{units} / \mathrm{ml}$; and IFN $\gamma$ (interferon $\gamma$ ), 14 units/ml] for $24 \mathrm{~h}[5,6]$.

Abbreviations used: AMPK, AMP-activated protein kinase; BrdU, bromodeoxyuridine; ECL, enhanced chemiluminescence; ECM, extracellular matrix; FBS, fetal bovine serum; FW, forward; IL, interleukin; IFN $\gamma$, interferon $\gamma$; iNOS, inducible NO synthase; Ins2, insulin 2; NF- $k \mathrm{~B}$, nuclear factor $\kappa \mathrm{B}$; REV, reverse; RT, reverse transcription; SEAP, secreted alkaline phosphatase; shRNA, short hairpin RNA; siRNA, small interfering RNA; TNF $\alpha$, tumour necrosis factor $\alpha$.

To whom correspondence should be addressed (email Gurgul-Convey.Ewa@mh-hannover.de). 


\section{Immunofluorescence}

For immunofluorescence staining, rat islet cells or INS1E cells were seeded on to collagen-coated glass slides and incubated as described above following an overnight fixation with $4 \%$ $(\mathrm{w} / \mathrm{v})$ paraformaldehyde in PBS. After fixation, cells were washed three times with PBS for 5 min. After a 20 min blocking in PBS with $0.1 \%$ Triton $\mathrm{X}-100$ and $1 \%(\mathrm{v} / \mathrm{v})$ BSA at room temperature $\left(20^{\circ} \mathrm{C}\right)$ and washed again as above. The slides were incubated with primary antibodies diluted in PBS with $0.1 \%$ Triton X-100 and $0.1 \%$ BSA at room temperature for $1 \mathrm{~h}$ \{rabbit polyclonal anti-mimitin antibody, 1:100 dilution, selfmade [2]; guinea pig polyclonal anti-insulin antibody, 1:100 dilution (Abcam); or mouse monoclonal anti-glucagon antibody, 1:250 dilution (Abcam) $\}$ and then washed three times with PBS The cells were incubated with secondary antibodies for $1 \mathrm{~h}$ [FITC-conjugated anti-(rabbit $\mathrm{IgG}$ ), 1:200 dilution; Texas Redconjugated anti-(guinea pig IgG), 1:200 dilution; or Texas Red-conjugated anti-(mouse IgG), 1:200 for $1 \mathrm{~h}$ at room temperature (all from Dianova)]. For nuclear counterstaining, $300 \mathrm{nM}$ DAPI (4,6-diamidino-2-phenylindole) was used for $5 \mathrm{~min}$ at room temperature. Slides were thereafter mounted with Mowio (Merck) plus $0.6 \%$ Dabco (Sigma-Aldrich). Images were captured and analysed using a Cell ${ }^{\circledR} /$ Olympus X 81 inverted microscope system.

\section{Cell culture and cytokine incubation}

Insulin-secreting INS1E cells were cultured as described previously [9] in fully supplemented RPMI 1640 medium, with $10 \mathrm{mM}$ glucose, $10 \%$ (v/v) FBS, 100 units $/ \mathrm{ml}$ penicillin and $0.1 \mathrm{mg} / \mathrm{ml}$ streptomycin in a humidified atmosphere at $37^{\circ} \mathrm{C}$ and $5 \% \mathrm{CO}_{2}$. Insulin-secreting MIN6 cells were grown in DMEM (Dulbecco's modified Eagle's medium) medium supplemented with $25 \mathrm{mM}$ glucose, $10 \%$ (v/v) FBS, 100 units $/ \mathrm{ml}$ penicillin and $0.1 \mathrm{mg} / \mathrm{ml}$ streptomycin in a humidified atmosphere at $37^{\circ} \mathrm{C}$ and $5 \% \quad \mathrm{CO}_{2}$. IL- $1 \beta$ was used at a concentration of 600 units/ml, and the cytokine mixture contained IL-1 $\beta$ (60 units/ml), TNF $\alpha$ (185 units/ml) and IFN $\gamma$ (14 units/ml).

\section{Overexpression of mimitin in insulin-secreting INS1E cells}

Human mimitin cDNA was stably overexpressed in insulinsecreting INS1E cells using the jetPE ${ }^{\mathrm{TM}}$ transfection reagent. INS1E cells transfected with an empty pcDNA3 vector were used as a control (two clones). Positive clones were selected against $\mathrm{G} 418(125 \mu \mathrm{g} / \mathrm{ml})$ and the mimitin expression levels were confirmed by Western blotting.

\section{Knockdown of mimitin in insulin-secreting MIN6 cells}

MIN6 cells were infected with lentiviral particles (self-made [9a]) containing mouse mimitin or control shRNA (short hairpin RNA both vectors from Santa Cruz Biotechnology) and the success of the knockdown was verified by Western blotting.

\section{Confirmation of mitochondrial localization of mimitin}

Insulin-secreting INS1E cells transfected with pmaxFPTM - green mimitin were seeded on to Mat-Tek dishes (MatTek) $24 \mathrm{~h}$ before loading with MitoTracker Deep Red (Invitrogen) for $15 \mathrm{~min}$ at $37^{\circ} \mathrm{C}$. Images were captured and analysed using a Cell ${ }^{\mathrm{R}} / \mathrm{Olympus}$ IX81 inverted microscope system.

\section{Proliferation assay}

The proliferation rate of INS1E cells was quantified by a colorimetric method using the Cell Proliferation BrdU (bromodeoxyuridine) ELISA (Roche). Cells were seeded at a concentration of $4 \times 10^{4}$ cells/well in 96-well microtitre plates and allowed to attach for $24 \mathrm{~h}$. Thereafter cells were incubated with IL- $\beta$ ( 600 units/ml) or a cytokine mixture (IL- $1 \beta, 60$ units $/ \mathrm{ml}$, TNF $\alpha, 185$ units $/ \mathrm{ml}$ and IFN $\gamma, 14$ units/ml) for $24 \mathrm{~h}$. The assay was performed according to the manufacturer's instructions. $A_{450}$ (reference wavelength of $650 \mathrm{~nm}$ ) was measured. Results were expressed as the percentage of untreated cells.

\section{NF- $k$ B (nuclear factor $\kappa$ B) reporter gene assay}

For the NF- $k$ B enhancer element activity studies, $2 \times 10^{4}$ cells $/$ well were seeded in 96 -well plates $24 \mathrm{~h}$ before transient transfection was performed (jetPEI ${ }^{\mathrm{TM}}$ transfection reagent) and $48 \mathrm{~h}$ before addition of cytokines for $24 \mathrm{~h}$. The pSEAP-NF- $\kappa$ B construct was used as described previously [10]. SEAP (secreted alkaline phosphatase) was measured using the Phospha-Light ${ }^{\mathrm{TM}}$ System kit (Applera).

\section{Nitrite measurement}

Nitrite accumulation after $24 \mathrm{~h}$ of cytokine treatment was determined spectrophotometrically at $562 \mathrm{~nm}$ by the Griess reaction [11].

\section{Activity assay of caspases 3 and 9}

INS1E cells were seeded at a density of $5 \times 10^{5}$ cells/well on to six-well plates $24 \mathrm{~h}$ before addition of cytokines. MIN 6 cells were seeded at a density of $3 \times 10^{5}$ cells/well on to six-well plates 2 days before lentiviral particles were added. After a $4 \mathrm{~h}$ incubation with lentivirus, the medium was changed and the experiments were started on the following day. Activation of caspases 3 and 9 was quantified after a $24 \mathrm{~h}$ exposure to cytokines, using red caspase 3 and green caspase 9 staining kits (PromoCell) according to the manufacturer's instructions. After staining and washing, cell suspensions were promptly read in the CyFlow ML cytometer (Partec). A total of $2 \times 10^{4}$ events were acquired. Non-labelled cells were used as a negative control and for the determination of the gates. Data were analysed by the FlowJo software (Tree Star). Results are expressed as the percentage of positive cells without exposure to cy tokines.

\section{RNA isolation and CDNA preparation}

For RNA extraction, cells were plated at a density of $6 \times 10^{5}$ cells/well on to six-well plates and grown to confluence within 2 days. Total RNA from insulin-secreting INS1E cells or rat tissues was obtained using Nucleo-Spin RNA columns (Macherey-Nagel). The quality of the total RNA was verified by agarose gel electrophoresis. RNA was quantified spectrophotometrically at $260 / 280 \mathrm{~nm}$. Thereafter, $2 \mu \mathrm{g}$ of RNA was reverse-transcribed into cDNA using Random-Hexamer primers and a reverse transcriptase.

\section{Real-time RT (reverse transcription)-PCR}

The QuantiTect SYBR Green ${ }^{\mathrm{TM}}$ technology (Qiagen) based on a fluorescent dye that binds only double-stranded DNA was employed. The reactions were performed using the DNA Engine Opticon $^{\mathrm{TM}}$ Sequence Detection System (Biozym Diagnostik). A total volume of $25 \mu 1$ was used for the PCR reactions. Samples 
were first denatured at $94^{\circ} \mathrm{C}$ for $3 \mathrm{~min}$ followed by up to 40 PCR cycles. Each PCR cycle comprised a melting at $94^{\circ} \mathrm{C}$ for $30 \mathrm{~s}$, an annealing at $62^{\circ} \mathrm{C}$ [mimitin and Ins2 (insulin 2)] for $30 \mathrm{~s}$ and an extension at $72^{\circ} \mathrm{C}$ for $30 \mathrm{~s}$. Each PCR amplification was performed in triplicate. The optimal parameters for the PCR reactions were defined empirically. The purity of the amplified products was verified by melting curves. Results for human mimitin, rat mimitin, mouse mimitin and rat Ins 2 were normalized to $\beta$-actin. The sequences of the primers used in the present study were as follows: human mimitin, FW (forward), $5^{\prime}$ AGGAACTCCTGCCTCCACCA-3', and REV (reverse), 5'-CTCGTGGCATCCAGGATCCT-3'; rat mimitin, FW, 5'-GGGAGTGGTGCGCTCTGTTT-3', and REV, 5'-CGCATAGTCTGCCCTCTCCA-3'; mouse mimitin, FW, 5'-ATGAGCTGGTGGTCCGGTGT-3', and REV, 5'-CGAATAGTCTGCCCTCTCCA-3'; rat Ins2, FW, 5'-AGGACCCACAAGTGGCACAA-3', and REV 5'-AGCACTGATCCACGATGC-3'; rat $\beta$-actin, FW, 5 -GAACACGGCATTGTAACCAACTGG-3', and REV, 5'-GGCCACACGCAGCTCATTGTA- $3^{\prime}$; mouse $\beta$-actin, FW, $5^{\prime}$-AGAGGGAAATCGTGCGTGAC-3', and REV, 5'-CAATAGTGATGA CCTGGCCGT-3'.

\section{Western blot analysis of mimitin}

For protein analysis cells were plated at a density of $6 \times 10^{5}$ cells/well on to six-well plates and grown to confluence within 2 days. Cells were exposed to the desired concentrations of cytokines for $24 \mathrm{~h}$. Thereafter, cells were homogenized in ice-cold PBS using short bursts $(10 \mathrm{~s}$ using a Braun-Sonic 125 Homogenizer). Protein content was determined by the BCA (bicinchoninic acid) assay (Pierce). For Western blotting, $10 \mu \mathrm{g}$ of total protein was resolved by SDS/PAGE $(10 \% \mathrm{gel})$ and then electroblotted on to membranes. Immunodetection was performed using specific primary antibodies against mimitin (polyclonal, self-made [2]) followed by exposure to secondary peroxidase-conjugated AffiniPure donkey anti-[rabbi IgG $(\mathrm{H}+\mathrm{L})]$ (Dianova). Hybridized antibodies were visualized through chemiluminescence using the ECL detection system and captured by the INTAS ${ }^{(B)}$ chemiluminescence detection system (Intas Science Imaging Instruments). The blots were stripped (ReBlot Plus Strong Solution, Millipore), blocked and incubated with primary antibodies against actin (goat polyclonal, Santa Cruz Biotechnology), followed by exposure to secondary peroxidaseconjugated anti-goat antibodies (Dianova) and analysed as described above.

\section{Mitochondrial membrane potential estimation}

Cells were seeded at a density of $4 \times 10^{4}$ cells/well on to black 96 -well plates $24 \mathrm{~h}$ before addition of cytokines. Thereafter cells were incubated for $20 \mathrm{~min}$ with rhodamine $123(50 \mu \mathrm{M})$ (Invitrogen). After washing, plates were analysed at $480 / 520 \mathrm{~nm}$ excitation/emission using a Victor2 1420 Multilabel Counter fluorescence reader (PerkinElmer). Each condition was measured at least in duplicate. Results were expressed as the percentage of untreated cells.

\section{ATP measurements}

ATP was determined using the ATPlite Detection Assay System (PerkinElmer) [12]. INS1E cells were seeded at a density of $4 \times 10^{4}$ cells/well and MIN6 cells at a density of $2 \times 10^{4}$ cells/well on to black 96 -well plates $24 \mathrm{~h}$ before the addition of cytokines. After $24 \mathrm{~h}$, cells were cultured in the absence of glucose for $1 \mathrm{~h}$ followed by a $2 \mathrm{~h}$ incubation with $10 \mathrm{mM}$ glucose. Cells were then lysed and used for ATP concentration measurements according to the manufacturer's instructions. Results were normalized to protein content.

\section{Insulin secretion and content}

Insulin secretion and content in control and mimitinoverexpressing insulin-secreting INS1E and MIN6 cell clones were measured by radioimmunoassay [13]. INS1E cells were seeded at a density of $3.5 \times 10^{5}$ cells/well on to six-well plates 2 days before test components were added. MIN6 cells were seeded at a density of $3 \times 10^{5}$ cells/well on to six-well plates 2 days before lentiviral particles were added. After a $4 \mathrm{~h}$ incubation with lentivirus, the medium was changed and the experiments were started on the following day. A $24 \mathrm{~h}$ incubation with cytokines was followed by a $1 \mathrm{~h}$ incubation without glucose and a $2 \mathrm{~h}$ stimulation with glucose $(3,10$ or $30 \mathrm{mM})$. Thereafter supernatants were collected for radioimmunoassay. Insulin values were normalized to the DNA content of the incubated cells.

\section{Data analysis}

Analyses of the real-time RT-PCR data were performed using the Opticon Monitor v.1.07 (MJ Research). All results are means \pm S.E.M. Statistical analyses were performed using the Prism analysis program (GraphPad); $P<0.05$ was considered significant.

\section{RESULTS}

\section{Expression of mimitin in rat and mouse tissues}

The mimitin gene expression level in rat liver was set as $100 \%$. In testis and pancreas mimitin expression was higher than in liver (Table 1). In all other tissues analysed, including pancreatic islets, the expression was significantly lower than in liver (Table 1). Particularly in heart muscle, brain and kidney, mimitin expression was extremely low in the range of $1 \%$ of the liver (Table 1). Mimitin gene expression in the mouse insulinproducing MIN6 cell line was strong (Figure 1A). In contrast, the gene expression of mimitin in the rat insulin-secreting cell lines INS1E, INS 1 and RINm5F was lower than in rat pancreatic islets (Figure 1A). To address whether native pancreatic $\beta$-cells express mimitin, a detailed immunofluorescence analysis of the mimitin distribution in rat islet cells was performed showing expression in all islet cell types (Figure 2B). The mimitin expression level was

\section{Table 1 Mimitin gene expression in different rat tissues}

Mimitin expression in different tissues was determined by quantitative real-time PT-PCR and nomalized to $\beta$-actin. Results are means + S. EM. with the numbers of experiments given in nomalized to $\beta$-actin. Results are means \pm S. E.M. with the numbers of experiments given in ${ }_{*} P<0.05$ compared with liver; ANOVA tollowed by a Bonterroni test.

\begin{tabular}{lc}
\hline Tissue & Mimitin (\%) \\
\hline Testis & $300 \pm 21(5)^{*}$ \\
Pancreas & $260 \pm 19(6)^{*}$ \\
Liver & $100 \pm 9(8)$ \\
Intestine & $49 \pm 5(4)^{*}$ \\
Lung & $35 \pm 4(5)^{*}$ \\
Pancreatic islets & $23 \pm 3(5)^{*}$ \\
Skeletal muscle & $18 \pm 1(5)^{*}$ \\
Heat muscle & $1 \pm 0(5)^{*}$ \\
Brain & $1 \pm 0(5)^{*}$ \\
Kidney & $1 \pm 0(5)^{*}$ \\
\hline
\end{tabular}



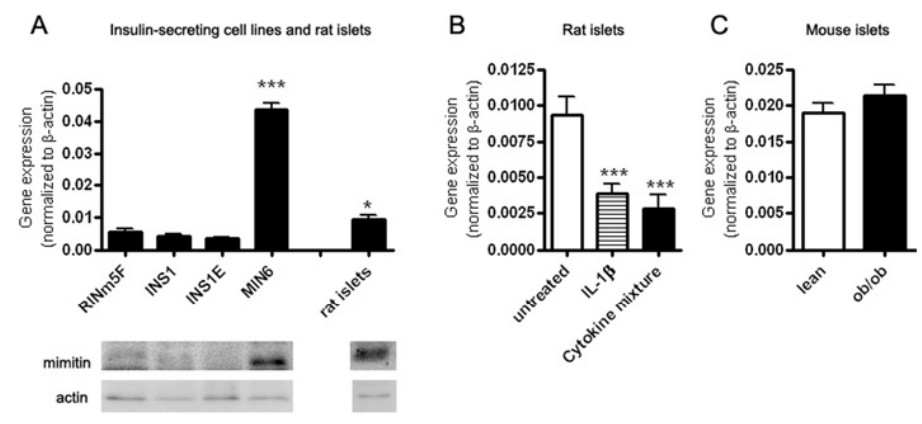

Figure 1 Mimitin expression in insulin-secreting cell lines and rat and mouse primary islet cells

RNA and protein was isolated from different insulin-secreting œell lines and from rat and mouse islets. (A) Upper panel: gene expression measured by quantitative real-time RT-PCR, $n=6$. Lower panel: a representative Western blot for four independent experiments. (B) Effects of a $24 \mathrm{~h}$ incubation with 600 units/ml IL-1, $\beta$ or with a cytokine mixture $(60$ units $/ m$ IL $\mathrm{L}-1, \beta, 185$ units/ml TNF $\alpha$, 14 units/ml IFN $\gamma$ ) on mimitin gene expression in rat islets, $n=6$. (C) Mimitin gene expression in islets isolated from lean or ob/ob mice, $n=10$. Results in (A-C) are means \pm S.E.M. In (A) ${ }^{*} P<0.05,{ }^{* * *} P<0.001$ compared with INS1E œells; in $(\mathbf{B}){ }^{* * *} P<0.001$ compared with untreated; ANOVA followed by a Bonferroni test.

higher in $\alpha$-cells than in $\beta$-cells, but nevertheless was clearly detectable, in contrast with the almost complete lack of expression in INS1E cells (Figures $2 \mathrm{~A}$ and $2 \mathrm{~B}$ ). Cells negative for both insulin and glucagon expressed more mimitin than $\alpha$ - or $\beta$-cells (Figure 2B)

A significant cytokine-induced reduction in mimitin gene expression was observed in rat islets (Figure 1B). The reduction in mimitin expression was particularly strong in rat $\alpha$ - and $\beta$-cell (Figure $2 \mathrm{~B}$ ), and somewhat weaker in other cell types (Figure 2B).

In isolated islets from spontaneously hyperglycaemic ob/ob mice, an animal model of insulin resistance and obesity, mimitin expression was comparable with that in islets from lean littermates (Figure $1 \mathrm{C}$ and Table 2). In contrast, a significant reduction of approximately $40 \%$ in mimitin expression in the liver as well as in the brain between ob/ob mice and their lean littermates was observed (Table 2). In the heart and the kidney of ob/ob mice, mimitin was expressed at a higher level when compared with the lean littermates (Table 2). The expression of mimitin in the skeletal muscle was 2 -fold higher than in the liver in both lean and ob/ob mice (Table 2).

To analyse the role of mimitin in pancreatic $\beta$-cells, the effect of mimitin overexpression and mimitin knockdown were analysed with special reference to cell function and insulin secretory capacity.

Stable overexpression of mimitin in insulin-secreting INS1E cells

The endogenous level of mimitin expression in the INS1E rat $\beta$-cell line was low, particularly when compared with the MIN6 mouse $\beta$-cell line (Figure 1A). So the INS1E insulinsecreting cell line can serve as a good model for studies on the effects of mimitin overexpression. Therefore cDNA for mimitin was introduced and several positive clones were obtained. To exclude a possible influence of clonal variation on the results, for further analyses three clones were selected, INS1Emimitin K1, K2 and K3 (Figure 3A). Mimitin expression was estimated at the protein level (Figure 3A). Insulin-secreting INS1E cells transfected with the empty pcDNA3 vector were used as control cells (two clones, INS1E-control 1 and INS1Econtrol 2). The mitochondrial localization of mimitin was confirmed using MitoTracker Deep Red staining (Figure 2C) Mimitin expression in untransfected and transfected INS1E- control as well as mimitin-overexpressing cells was only slightly affected by pro-inflammatory cytokines [for INS1E cells, IL-1 $\beta$ (600 units $/ \mathrm{ml}) 96+12 \%$, cytokine mixture $80+6 \%$; and for INS1E-control cells, IL-1 $\beta$ (600 units $/ \mathrm{ml}) 91 \pm 13 \%$, cytokine mixture $100 \pm 12 \%$; for INS1E-mimitin K3, IL- $1 \beta$ (600 units/ml) $87 \pm 4 \%$, cytokine mixture $89 \pm 8 \%$; compared with untreated $100 \%, n=14]$.

Effects of mimitin overexpression on cell viability and proliferation Caspase 3 was 1.5 -fold increased by IL- $1 \beta$ and even more by a cytokine mixture in INS1E-control 1 and 2 cell clones (Table 3). Importantly, mimitin overexpression abolished the activation of caspase 3 in the presence of cytokines (Table 3 ). The protective effects of mimitin were specific for cytokine-mediated toxicity, because the activation of caspase 3 by camptothecin $(0.5 \mu \mathrm{M})$ did not differ in INS1E-control 1 and 2 and INS1E-mimitin cells (results not shown).

The basal proliferation rate in untreated INS1E-mimitin cells was significantly higher in comparison with INS1E-control cells. The absolute absorbance values were in INS1E-control 1 cells $1.34 \pm 0.14$ and in INS1E-control 2 cells $1.35 \pm 0.08$. They increased significantly $(P<0.05)$ in the INS1E-mimitin $\mathrm{K} 1(1.37 \pm 0.09)$, INS1E-mimitin K2 $(2.58 \pm 0.14)$ and INS1Emimitin K3 $\left(2.28 \pm 0.17\right.$ ) clones (expressed as $\Delta A_{450650}, n=$ 4-13). Cytokines significantly decreased the proliferation of control INS1E cells, leading to a 55-60\% and $70 \%$ loss of proliferative capacity, in the case of $\amalg-1 \beta$ and the cytokine mixture, respectively (Table 3 ). INS1E cells overexpressing mimitin were protected against the cytokine-mediated reduction of proliferation capacity (Table 3 ). Thus mimitin overexpression protects insulin-secreting cells against cytokine-mediated viability and proliferation loss. Since the largest protective effects on cell viability as well as proliferation rate were seen in the case of the INS1E-mimitin K3 clone, the subsequent experiments were performed with this $\mathrm{K} 3$ clone.

Effects of mimitin overexpression on cytokine-stimulated mitochondrial dysfunction

Cytokines significantly activated mitochondrial caspase 9 in INS1E-control cells (Figure 3B). Mimitin overexpression 

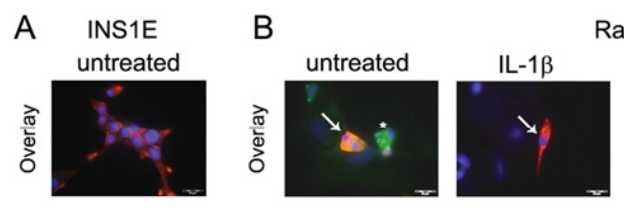

Rat islets
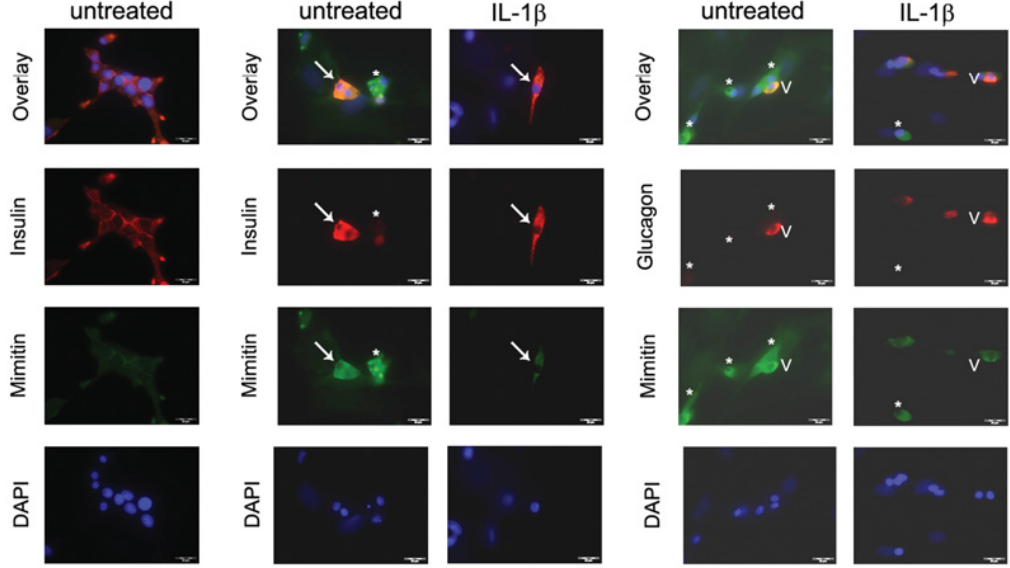

C INS1E-pmax ${ }^{\mathrm{FP}}$-green mimitin

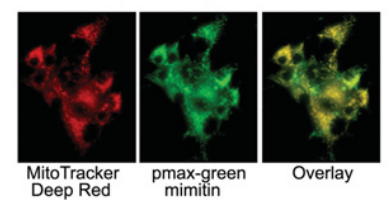

\section{Figure 2 Immunofluorescence analysis of mimitin expression in insulin-secreting cells and primary rat islet cells}

Insulin-secreting INS1E cells or rat islet œells were seeded on to chamber slides, fixed and immunostained. (A) INS1E œells, mimitin (green) and insulin (red). (B) Rat islet œells, mimitin

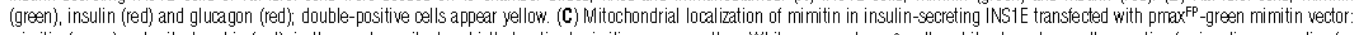
mimitin (green) and mitochondria (red); in the overlay, mitochondrially localized mimitin appears yellow. White arrows show $\beta$-cells, white stars show cells negative for insulin or negative for glucagon, and white $V$ indicates $\alpha$-cells.

attenuated cytokine-mediated caspase 9 activation (Figure 3B). The protective effect of mimitin was specific for cytokinemediated toxicity, because the activation of caspase 9 by camptothecin $(0.5 \mu \mathrm{M})$ did not differ in INS1E-control and INS1E-mimitin cells (Figure 3B).

Mitochondrial membrane potential in INS1E control and mimitin-overexpressing cells was identical under control conditions (results not shown). Exposure of INS1E-control cells to cytokines for $24 \mathrm{~h}$ reduced mitochondrial membrane potential (a $25 \%$ decrease after exposure to $\mathbb{L}-1 \beta$ and a nearly $40 \%$ decrease in the case of the cytokine mixture; Figure $3 \mathrm{C}$ ). The cytokine-mediated decrease in mitochondrial membrane potential was not present after IL-1 $\beta$ exposure and significantly smaller in the case of the cytokine mixture in INS1E-mimitin $\mathrm{K} 3$ cells when compared with control cells (Figure $3 \mathrm{C}$ ).

The ATP content in INS1E-control cells was $3.4 \pm 0.2$ (clone 1) and $3.2 \pm 0.3$ (clone 2; not depicted in Figure 3D) $\mathrm{nmol} / \mathrm{ms}$ of protein and was significantly decreased after a $24 \mathrm{~h}$ incubation with cytokines (Figure 3D). Interestingly, mimitin-overexpressing cells contained significantly more ATP than control cells (Figure 3D) and this ATP content was only very slightly reduced by cytokines (Figure 3D).
Table 2 Mimitin gene expression in different mouse tissues

Mimitin expression in different mouse tissues (from lean and ob/ob miœ) was determined by quantitative real-time RT-PCR and normalized to $\beta$-actin. The value for mouse liver from lean littermates was $0.044 \pm 0.004$ (arbitrary units) and was set as $100 \%$. Results are means $\pm S . E . M$. with the numbers of experiments given in parentheses (arbitrary units). $* P<0.05$ compared with liver in lean littermates; $\# P<0.05$ compared with the same tissue in lean littermates; Student's t test

\begin{tabular}{lcc}
\hline Tissue & Lean littermates (\% of liver) & ob/ob miœ (\% of liver in lean miœ) \\
\hline Liver & $100 \pm 9(23)$ & $63 \pm 5(22)^{*}$ \\
Pancreatic islets & $53 \pm 13(16)^{*}$ & $54 \pm 7(20)^{*}$ \\
Skeletal muscle & $245 \pm 71(4)^{*}$ & $206 \pm 71(6)^{*}$ \\
Heart muscle & $150 \pm 18(11)$ & $214 \pm 14(11)^{*} \#$ \\
Brain & $86 \pm 24(10)$ & $54 \pm 7(12)^{*} \#$ \\
Kidney & $72 \pm 4(4)^{*}$ & $100 \pm 11(6)^{*} \#$ \\
\hline
\end{tabular}

Effects of mimit in overexpression on cytokine-induced NF- $\kappa$ B activation and nitrite production

Incubation of insulin-secreting INS1E-control 1 cells with cytokines induced NF- $\kappa$ B activation (Table 4). A similar induction 
A Mimitin overexpression in INS1E cells

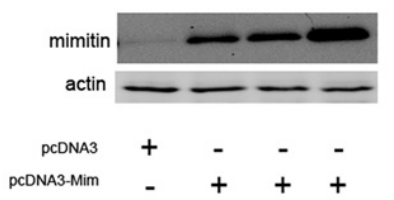

C

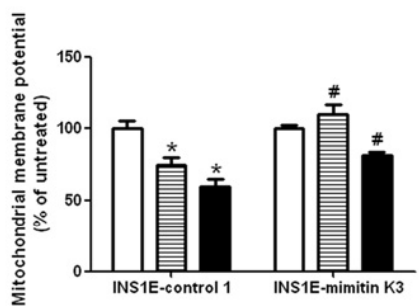

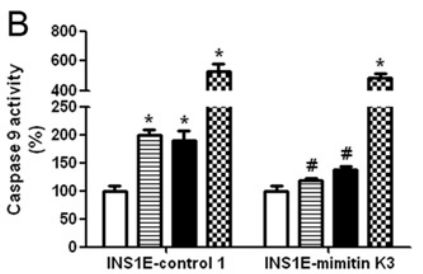

$\mathrm{D}$

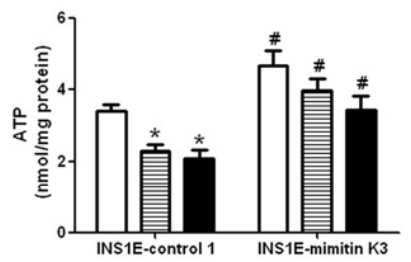

Figure 3 Effects of mimitin overexpression in insulin-secreting INS 1E cells on cytokine-mediated mitochondrial dysfunction

Insulin-secreting INSTE œells were incubated with either IL-1 $\beta$ alone ( 600 units/ml) or with a cytokine mixture ( 60 units/ml IL-1 $\beta, 185$ units/ml TNF $\alpha$ and 14 units/ml IFN $\gamma$ ), or camptothecin $(0.5 \mu M)$ for $24 \mathrm{~h}$ and thereafter: (A) overexpression of mimitin in insulin-secreting INSIE cells was confirmed by Western blotting; shown is a representative Western blot for four experiments; (B) caspase 9 activation was analysed by flow cytometry; (C) mitochondrial membrane potential was estimated using rhodamine 123; (D) ATP content was measured by a chemiluminescence method. White bars, untreated; striped bars, IL-1, ; black bars, cytokine mixture; checked bars, camptothecin. Pesults in (B-D) are means \pm S.E.M. ${ }^{*} P<0.05$ compared with untreated; $\# P<0.05$ compared with INSIE-control cells treated in the same way; ANOVA followed by a Bonferroni test

Table 3 Effects of mimitin overexpression in insulin-secreting INS1E cells on caspase 3 activation and cell proliferation after exposure to cytokines

Insulin-secreting INSIE œells overexpressing mimitin as well as control cells, were incubated for $24 \mathrm{~h}$ with either IL-1 $\beta$ (600 units/ml) alone or with a cytokine mixture $(60$ units/ml IL-1 $\beta$, 185 units/ml TNF $\alpha$ and 14 units/ml IFN $\gamma$ ). Caspase 3 activity was measured by flow cytometn and cell proliferation by a BrdU incorporation assay. Pesults are expressed as the percentage of untreated pells and are means \pm S.E.M. for the indicated numbers (in parentheses) of independent experiments, each measured for at least three repetitions. $* P<0.05$ compareed with untreated; $\# P<0.05$ compared with control clone 1 treated in the same way; $\& P<0.05$ compared with control clone 2 treated in the same way, ANOVA followed by a Bonterroni test. (a) Caspase 3 activity (\% of untreated)

\begin{tabular}{|c|c|c|c|}
\hline INS1E œll clone & Untreated & $\mathrm{IL}-1, \beta$ & Cytokine mixture \\
\hline $\begin{array}{l}\text { INS1E-control } 1 \\
\text { INS1E-control } 2 \\
\text { INS1E-mimitin K1 } \\
\text { INS1E-mimitin K2 } \\
\text { INS1E-mimitin K3 }\end{array}$ & $\begin{array}{l}100 \pm 7(10) \\
100 \pm 7(9) \\
100 \pm 9(11) \\
100 \pm 9(10) \\
100 \pm 8(9)\end{array}$ & $\begin{array}{l}157 \pm 9(9)^{\star} \\
166 \pm 10(9)^{*} \\
124 \pm 6(11) \# \S \\
120 \pm 7(12) \# \S \\
102 \pm 3(9)+\$\end{array}$ & $\begin{array}{l}162 \pm 10(10)^{*} \\
171 \pm 18(9)^{*} \\
108 \pm 10(11) \# \S \\
112 \pm 5(12) \# \S \\
106 \pm 7(9) \# \S\end{array}$ \\
\hline \multicolumn{4}{|c|}{ (b) Cell proliferation (\% of untreated) } \\
\hline INS1E œll clone & Untreated & $\mid \mathrm{L}-1, \beta$ & Cytokine mixture \\
\hline $\begin{array}{l}\text { INS1E-control } 1 \\
\text { INS1E-control } 2 \\
\text { INS1E-mimitin K1 } \\
\text { INS1E-mimimitin K2 } \\
\text { INS1E-mimimitin K3 }\end{array}$ & $\begin{array}{l}100 \pm 10(6) \\
100 \pm 10(7) \\
100 \pm 7(13) \\
100 \pm 5(4) \\
100 \pm 7(4)\end{array}$ & $\begin{array}{l}40 \pm 4(6)^{*} \\
54 \pm 5(7)^{\star} \\
74 \pm 5(13)^{\star} \# \$ \\
85 \pm 2(4) \# \$ \\
86 \pm 4(4) \# \$\end{array}$ & 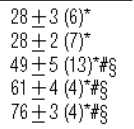 \\
\hline
\end{tabular}

was observed in cells overexpressing mimitin (Table 4). The iNOS (inducible NO synthase) protein expression analysis revealed a significant induction after exposure to cytokines in INS1Econtrol 1 as well as INS1E-mimitin K3 cells (results not shown). Measurements of nitrite production in INS1E-control 1
Table 4 Effects of mimitin overexpression on cytokine-induced NF- $\kappa$ B activation and nitrite production in insulin-secreting INS1E cells

For estimation of transcription factor activation, insulin-secreting INS1E œells were transfected $24 \mathrm{~h}$ prior to cytokine treatment and then incubated with either $\mathrm{L}-1 / 3$ ( $600 \mathrm{units} / \mathrm{m} / \mathrm{m})$ alone or with a cytokine mixture $(60$ units/ml IL-1 $\beta, 185$ units/ml TNF $\alpha$ and 14 units/ml IFN $\gamma$ ) for $24 \mathrm{~h}$. Thereafter the medium was collected and a SEAP-reporter gene assay was performed. Nitrite concentrations were determined by a Griess assay Pesults are means for the indicated numbers (in parentheses) of independent experiments, each measured for at least three repetitions $* P<0.05$ compared with untreated; ANOVA followed by a Bonferroni test. n.d., not detectable (a) NF- $\kappa$ B (\% of untreated)

\begin{tabular}{lll}
\hline INS1E œell clone & INS1E-control 1 & INS1E-mimitin K3 \\
\hline Untreated & $100 \pm 10(5)$ & $100 \pm 3(5)$ \\
IL-1 $\beta$ & $396 \pm 32(5)^{*}$ & $401 \pm 30(5)^{*}$ \\
Cytokine mixture & $219 \pm 22(5)^{\star}$ & $215 \pm 25(5)^{*}$ \\
\hline (b) Nitrite (pmol/ $\mu$ g of protein) & & \\
\hline INS1E œell clone & INS1E-control 1 & INS1E-mimitin K3 \\
\hline Untreated & n.d. (11) & n.d. (11) \\
IL-1 $\beta$ & $7 \pm 1(12)^{*}$ & $7 \pm 1(12)^{*}$ \\
Cytokine mixture & $10 \pm 1(12)^{*}$ & $11 \pm 1(11)^{*}$
\end{tabular}

as well as INS1E-mimitin K3 cells revealed no significant nitrite accumulation under control conditions (Table 4). Incubation of INS1E-control 1 as well as INS1E-mimitin K3 cells with cytokines induced NO production as documented by a significant rise in accumulated nitrite (Table 4). Thus mimitin overexpression did not block the NF- $\kappa \mathrm{B}-\mathrm{iNOS}$ pathway and therefore did not rescue insulin-producing cells from cytokine toxicity by reduction of NO production. 


\section{Glucose}

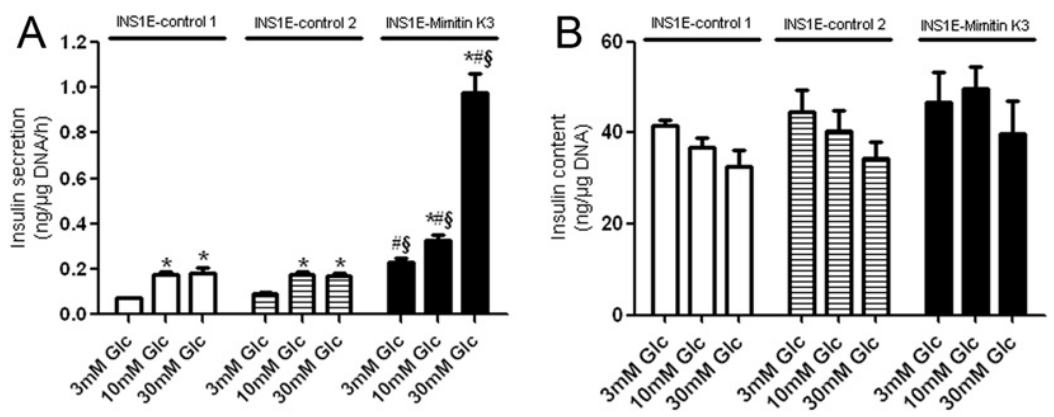

\section{Cytokines}

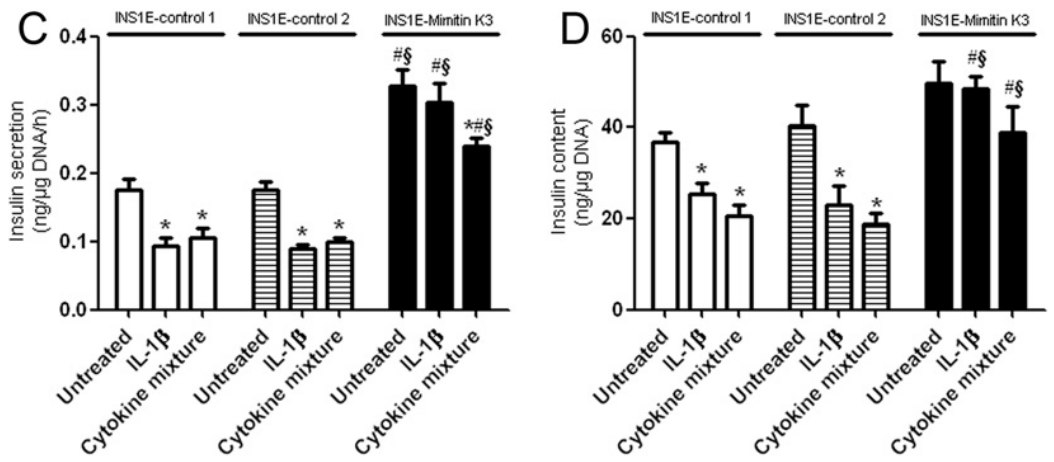

Figure 4 Effects of mimitin overexpression in insulin-secreting INS1E cells on insulin secretion and content

Insulin-secreting INS1E cells were incubated with either IL-1 $\beta$ alone ( 600 units/ml) or with a cytokine mixture ( $60 \mathrm{units} / \mathrm{ml} \mathrm{IL}-1, \beta, 185 \mathrm{hnits} / \mathrm{ml} \mathrm{TNF} \alpha$ and 14 units/ml IFNy) for $24 \mathrm{~h}$. Thereafter wells were cultured in the absence of glucose followed by a $1 \mathrm{~h}$ incubation with glucose $(3,10$ or $30 \mathrm{mM})$. Insulin was measured by radioimmunoassay: (A) glucase-induced insulin secretion; (B) insulin content; (C) glucose-induced insulin secretion at $10 \mathrm{mMM}$ glucose (Glc) in the absence or presenoe of cytokines; (D) insulin content at $10 \mathrm{mMM}$ glucose in the absence or presence of cytokines. White bars, INSTE-control 1 cells; striped bars, INSTE-control 2 cells, black bars, INSTE-mimitin K3 cells. Results are means $+S$ S.M.M. for six independent experiments. ${ }^{*} P<0.05$

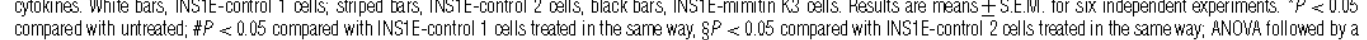
Bonferroni test.

Effects of mimitin over expression on Ins2 gene expression, insulin secretion and content

The expression of the Ins2 gene in insulin-secreting INS1Emimitin $\mathrm{K} 3$ cells did not significantly differ from control cells (INS1E-control 1 cells, untreated $6.0 \pm 0.6$, IL-1 $\beta \quad 2.4 \pm 0.2$ cytokine mixture $1.3+0.3$; compared with INS1E-mimitin K3 cells, untreated $7.2 \pm 1.0$, IL- $1 \beta 2.7 \pm 0.3$, cytokine mixture $1.8 \pm 0.3$; arbitrary units, $n=6$ ).

INS1E-control 1 cells secreted $0.09 \pm 0.01$ and INS1E-control 2 cells $0.07 \pm 0.01 \mathrm{ng} / \mu \mathrm{g}$ of DNA/h insulin at $3 \mathrm{mM}$ glucose (Figure 4A). Incubation in the medium containing $30 \mathrm{mM}$ glucose stimulated insulin secretion up to $0.17 \pm 0.01$ (INS1Econtrol 1) and $0.18 \pm 0.02$ (INS1E-control 2) $\mathrm{ng} / \mu \mathrm{gDNA} / \mathrm{h}$ (Figure 4A). The basal insulin secretion at $3 \mathrm{mM}$ glucose in INS1E-mimitin K 3 cells was $0.23 \pm 0.02 \mathrm{ng} / \mu \mathrm{gDNA} / \mathrm{h}$, approximately 2.5-fold higher than in controlINS1E cells (Figure 4A). Insulin secretion induced by $30 \mathrm{mM}$ glucose in INS1E-mimitin K3 cells reached $0.98 \pm 0.08 \mathrm{ng} / \mu \mathrm{g}$ of DNA/h and was significantly higher than glucose-induced insulin secretion in control cells.
Incubation of INS1E-control cells with $\mathbb{L}-1 \beta$ or a cytokine mixture significantly reduced insulin secretion $(10 \mathrm{mM}$ glucose; control 1 , $\mathbb{L}-1 \beta 0.09 \pm 0.01$, cytokine mixture $0.10 \pm 0.01$, compared with untreated $0.18 \pm 0.01 \mathrm{ng} / \mu \mathrm{g}$ of DNA/h; control 2 , IL- $1 \beta 0.09 \pm 0.01$, cytokine mixture $0.10 \pm 0.02$, compared with untreated $0.17+0.02 \mathrm{ng} / \mu \mathrm{g}$ of DNA/h; Figure $4 \mathrm{C}$ ). In INS1Emimitin $\mathrm{K} 3$ cells, IL-1 $\beta$ did not reduce insulin secretion and incubation with the cytokine mixture caused only a $28 \%$ decrease (Figure 4C). Although glucose-induced insulin secretion was decreased by cytokines in INS1E-mimitin K 3 cells, the amount of secreted insulin upon glucose stimulation was significantly higher than in control cells (IL-1 \& 3.3-fold higher, and cytokine mixture 2.4-fold higher, compared with INS1E-control cells treated in the same way, $P<0.05$; Figure $4 C$ ).

Insulin content in INS1E-control cells cultured at $3 \mathrm{mM}$ glucose was in the control 1 clone $45+5 \mathrm{ng} / \mu \mathrm{g}$ of DNA, in the control 2 clone $42 \pm 2 \mathrm{ng} / \mu \mathrm{g}$ of DNA, and was decreased in both clones after incubation at $30 \mathrm{mM}$ glucose (Figure $4 \mathrm{~B}$ ). INS1E-mimitin K3 cells had a similar insulin content to control cells ( $47 \pm 4 \mathrm{ng} / \mu \mathrm{g}$ of DNA), which was slightly reduced after 


\section{A Knockdown in MIN6 cells}
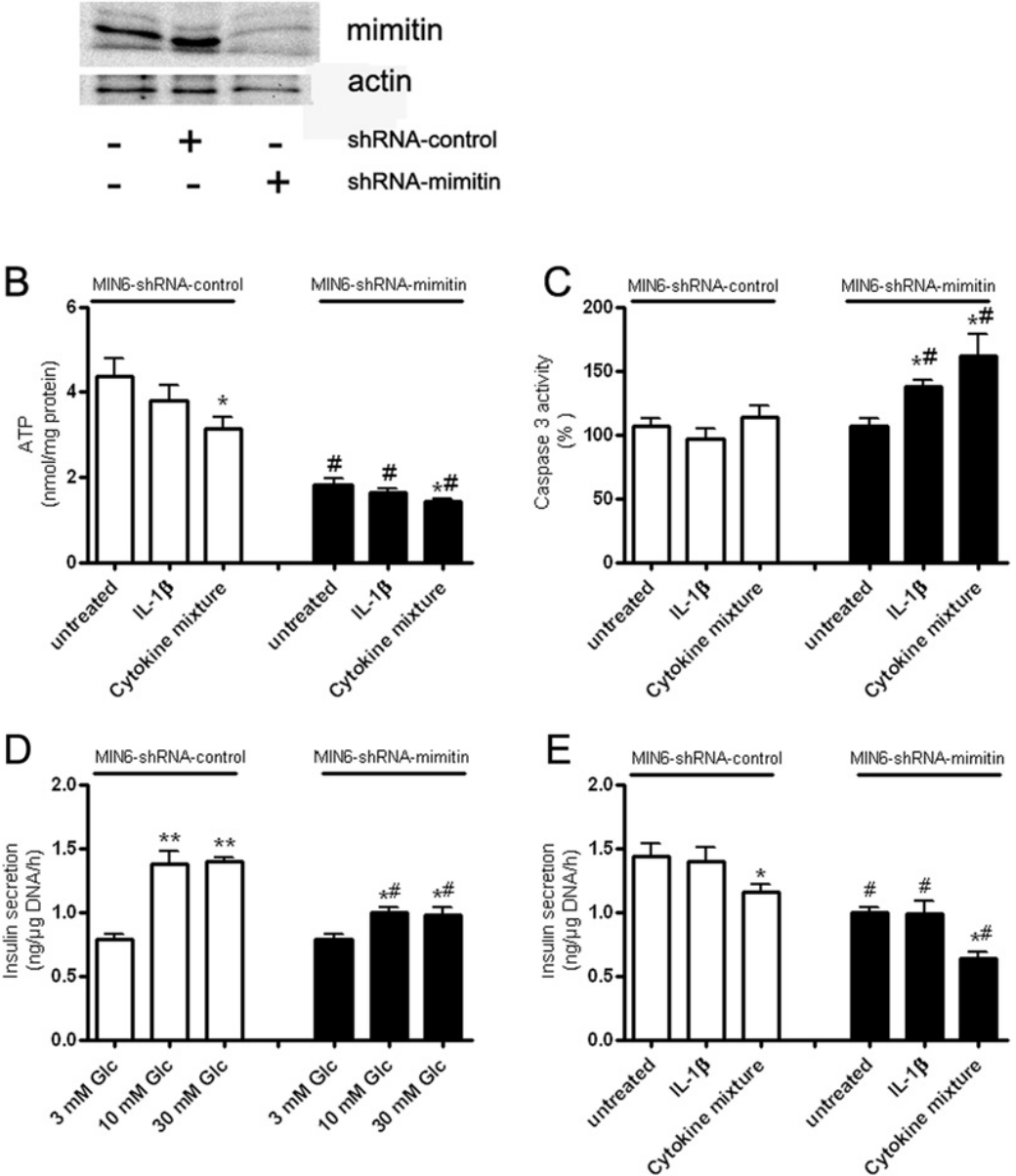

Figure 5 Effects of mimitin knockdown in insulin-secreting MIN6 cells

Insulin-secreting MIN6-shPNA-control and MIN6-ShRNA-mimitin œells were incubated with either IL-1 $\beta$ alone (600 units/ml) or with a cytokine mixture (60 units/ml IL-1 $\beta, 185$ units/ml TNF $\alpha$ and 14 units/ml IFN $\gamma$ ) for $24 \mathrm{~h}$. Thereafter: (A) knockdown of mimitin in insul in-secreting MIN 6 wells was confirmed by Western blotting; shown is a representative Western blot for three experiments; (B) ATP content was measured by a chemil uminesoenoe method, $n=6$, measured in triplicate; (C) caspase 3 activation wasaralysed by flow cytometry, $n=6$; (D) glucose (Glc)-induoed insulin secretion was measured by radioimmunoassay, $n=6$; (E) insulin secretion at $10 \mathrm{mMM}$ glucose in the absence or presenoe of cytokines was estimated by radioimmunoassay. White bars, MIN 6 -shRNA-control cells; black bars, MING-shRNA-mimitin œells. Results are means + S.E.M. ${ }^{*} P<0.05$ compared with untreated; ${ }^{* *} P<0.01$ compared with untreated; $\# P<0.05$ compared with MilNG-shRNA-control wells treated in the same way; ANOVA followed by a Bonferroni test

incubation at $30 \mathrm{mM}$ glucose (Figure $4 \mathrm{~B}$ ). A $24 \mathrm{~h}$ incubation of INS1E-control cells with $\amalg-1 \beta$ in the presence of $10 \mathrm{mM}$ glucose lowered insulin content (INS1E-control 1, from $41 \pm 4$ to $23 \pm 4 \mathrm{ng} / \mu \mathrm{g}$ of DNA; INS1E-control 2, from $37 \pm 2$ to $26 \pm 3 \mathrm{ng} / \mu \mathrm{g}$ of DNA) and exposure to the cytokine mixture caused an even stronger decrease (INS1E-control 1, $19 \pm 2 \mathrm{ng} / \mu \mathrm{g}$ of DNA; INS1E-control 2, $21 \pm 3 \mathrm{ng} / \mu \mathrm{g}$ of DNA) (Figure 4D) In INS1E-mimitin K3 cells exposure to cytokines only slightly reduced insulin content (Figure 4D).
Effects of mimitin knockdown in insulin-secreting MIN6 cells

In the mouse insulin-secreting MIN6 cells, mimitin was expressed, in contrast with the very weak expression in the rat insulin-secreting INS1E cell line (Figure 1A, Figure 3A and Figure 5A). Mimitin was successfully knocked down in MIN6 cells (Figure 5A). Mimitin expression in untransfected as well as transfected MIN6 cells was unaffected by proinflammatory cytokines (results not shown). The suppression 
of mimitin in MIN6 cells had opposite effects when compared with the effects observed after mimitin overexpression in INS1E cells.

The ATP content in the MIN6-shRNA-control cells was $4.4 \pm 0.4 \mathrm{nmol} / \mathrm{mg}$ of protein and was significantly reduced by a knockdown of mimitin to $1.8 \pm 0.2 \mathrm{nmol} / \mathrm{mg}$ of protein (Figure 5B). Pro-inflammatory cy tokines slightly decreased ATP content in MIN6-shRNA-control cells, reaching a significant effect in the case of the cytokine mixture (Figure 5B). In the case of MIN6-shRNA-mimitin cells, a further reduction in ATP content was also observed with cytokines, however, to a lesser extent than in the control cells (Figure 5B).

A $24 \mathrm{~h}$ incubation with IL- $\beta$ (600 units/ml) or a mixture of cytokines (IL-1 $\beta, \mathrm{TNF} \alpha$ and IFN $\gamma$ ) did not induce caspase 3 activation in MIN6-shRNA-control cells (Figure 5C). Mimitin knockdown resulted in increased cytokine-induced caspase 3 activation (Figure 5C)

The insulin content in MIN6-shRNA-control and in MIN6shRNA-mimitin cells was comparable $(3.0 \pm 0.3$ compared with $3.7 \pm 0.5 \mathrm{ng} / \mu \mathrm{g}$ of DNA respectively). The MIN6-shRNA-contro cells secreted significantly more insulin at the basal condition as well as upon stimulation with glucose when compared with insulin-secreting INS1E-control cells (Figure 5D and Figure 4A) Mimitin knockdown in MIN6 cells decreased glucose-induced insulin secretion (Figure 5D). The MIN6-shRNA-mimitin cells, however, did not lose their insulin secretory responsiveness to the glucose stimulus, indicating that mimitin acts as a potentiator of glucose-stimulated insulin secretion. Incubation of MIN6 shRNA-control cells with pro-inflammatory cytokines dampened glucose-induced insulin secretion very weakly (Figure $5 \mathrm{E}$ ). Vice versa, mimitin knockdown resulted in an enhancement of the cytokine-mediated inhibition of glucose-induced insulin secretion (Figure 5E).

\section{DISCUSSION}

Mimitin attracted our attention since it had been shown to act as a regulator of ATP synthesis [1] and the formation of ATP plays a crucial role in glucose-induced insulin secretion [3] and pancreatic $\beta$-cell survival upon exposure to pro-inflammatory cytokines [4].

Mimitin was expressed in different cell types of primary rat and mouse pancreatic islets. Pro-inflammatory cytokines significantly reduced mimitin expression in primary islet cells, but, however had a weaker effect in the insulin-secreting INS1E cell line, which is characterized by a very weak expression of mimitin. These dat indicate also that in a complex system composed of different cell types (islets) the regulation of mimitin expression can be influenced by additional yet-unknown modulatory factors.

Although the mimitin expression level of isolated islets fron ob/ob mice and their lean littermates did not differ, a significan difference was observed in the case of other tissues, suggesting a possible regulation of mimitin in this animal model of insulin resistance and obesity and the involvement of mimitin dysregulation in the development of metabolic disturbances. Because mimitin regulates the ATP production, one of the possible targets influenced by the changes in mimitin expression could be AMPK (AMP-activated protein kinase). AMPK is a central cellular energy sensor, activated by a decrease in ATP which controls whole-body energy homoeostasis [14] and which is an important target for diabetes therapy [15]. It has been shown that leptin reduces the AMPK activity in the brain [16 and that the inhibition of the hypothalamic AMPK leads to the reduction of food intake and the increase in energy expenditure [17]
It is possible therefore that a reduced mimitin level in the brain of ob/ob mice when compared with their lean littermates may, additionally to the lack of leptin, enable higher neuronal AMPK activity, which as a consequence fosters food intake and obesity in this animal model. On the other hand, the reduced mimitin level in the liver of ob/ob mice may serve as an adaptive response, since increased AMPK in hepatocytes (e.g. by the action of metformin) has been shown to improve insulin sensitivity and inhibit glucose production [18]. In the heart. AMPK has been shown to activate phosphofructokinase 2 and to stimulate the glycolytic flux [14]. The expression of mimitin in the heart of ob/ob mice was significantly higher than in lean littermates. Such an increased expression of mimitin may result in a higher ATP content and may disturb the AMP/ATP ratio in the cells, leading to a decreased AMPK activity. In pancreatic $\beta$-cells, AMPK overexpression has been shown to impair cell function [19]. The pancreatic $\beta$-cells of ob/ob mice are not defective in their function $[7,8]$ and in line with this we did not observe any differences between mimitin expression in islets isolated from lean and obese mice. Thus the mimitin data obtained from ob/ob mice and their lean littermates add a new aspect to the complex regulatory mechanisms in metabolic disorders

To analyse the impact of mimitin on $\beta$-cell function and susceptibility to pro-inflammatory cytokines we chose for the present study two $\beta$-cell lines, the INS1E with a low expression level of mimitin and the MIN6 with a higher expression level of this protein.

Insulin-secreting INS1E cells are known for their high sensitivity to pro-inflammatory cytokines [20], which we confirmed in the present study. Overexpression of mimitin in INS1E cells prevented cytokine-induced caspase 3 activation. In contrast, MIN6 cells, which are resistant to cytokine toxicity, achieved sensitivity to pro-inflammatory cytokines after a knockdown of mimitin. These findings are in line with a previous report in which reduction of mimitin expression in hepatoma cells by the siRNA approach resulted in a potentiation of cy tokine-induced apoptosis and inhibition of cell proliferation [2]. Overexpression of mimitin had opposite effects [2]. Moreover, the observed protective effect of mimitin overexpression is in line with reports showing that defects in the mitochondrial respiratory chain complex I are characteristic for many energy generation disorders and are possibly implicated in disturbed apoptotic signalling $[21,22]$.

Pro-inflammatory cytokines cause pancreatic $\beta$-cell death via induction of mitochondrial stress and other responses $[5,6,23]$ The results of the present study clearly show that mimitin overexpression protects insulin-secreting cells against cytokine toxicity via suppression of mitochondrial stress, however, without concomitant inhibition of the NF- $\kappa$ B-iNOS pathway. Similar protection against cytokine-induced mitochondrial stress was recently reported by overexpression of prostacyclin synthase in insulin-producing cells, but this protective effect strongly depended on inhibition of the NF- $\kappa \mathrm{B}$ signalling pathway [24]. Thus protection against cytokine toxicity via mimitin overexpression must involve other mechanisms.

Interestingly, mimitin-overexpressing cells exhibited a higher basal proliferation rate than control cells. This increased proliferative activity may result from an increased mitochondrial metabolism, as shown by a significantly higher ATP content in mimitin-overexpressing cells. This is in line with a previous report showing a correlation between a decreased rate of ATP production and a decreased $\beta$-cell proliferation [25]. It also confirms the results obtained in oesophageal carcinoma [1] and hepatoma cells [2], pointing to an important role of mimitin in cell proliferation. 
The elevated ATP content in mimitin-overexpressing cells is indicative of an increased ATP production. Indeed mimitin has been shown to act as a molecular chaperone for the assembly of the mitochondrial respiratory chain complex I [1] Therefore an increased level of mimitin may stimulate oxidative phosphorylation and raise ATP production. Our finding that mimitin knockdown in insulin-secreting MIN6 cells leads to decrease in ATP content confirms the role of mimitin in ATP production.

In pancreatic $\beta$-cells, an increased ATP production may support proper insulin secretory responsiveness $[3,25-27]$. In the present study, insulin-secreting INS1E cells overexpressing mimitin indeed exhibited greater insulin secretory responsiveness to the physiological stimulus glucose. The expression of the Ins2 gene as well as the insulin content were similar in control and mimitin-overexpressing cells, suggesting that the prominent effect of mimitin overexpression is a potentiation of glucose-induced insulin secretion. The results obtained in the MIN6-shRNAmimitin cells confirmed this observation, showing a decrease in overall insulin secretion, but no loss of glucose responsiveness. Thus mimitin seems to play a potentiating role in glucose-induced insulin secretion, but is not an obligatory component of it.

Importantly, mimitin overexpression counteracted cytokinemediated inhibition of glucose-induced insulin secretion, and this went along with a preservation of the ATP content. In line with this, mimitin knockdown led to stronger cytokine-mediated inhibition of glucose-induced insulin secretion. Therefore mimitin protects against adverse cytokine effects, most probably via its chaperone-mediated preservation of ATP production.

On the other hand, an increased basal insulin secretion at a low glucose concentration as observed in INS1E-mimitin cells with a high mimitin expression level is an indicator for a potential hypoglycaemia risk. Thus the rather moderate constitutive expression level of mimitin observed in primary $\beta$-cells might be necessary to avoid hypoglycaemic episodes, though on the other hand it may contribute to the extraordinary vulnerability of the pancreatic $\beta$-cells [28].

The present study identified a novel mitochondrial protein, mimitin, as a mild modulator of the glucose-induced insulin secretion pathway. Mimitin prevented mitochondrial stress upon exposure to cytokines, and this protective effect was delivered independent of a suppression of the NF- $k$ B pathway. Moreover, the data revealed that mimitin overexpression could prevent cytokine-induced inhibition of glucose-induced insulin secretion through maintenance of mitochondrial integrity.

\section{AUTHOR CONTRIBUTION}

Katarzyna Hanzelka engineered cell lines, performed experiments, analysed data and participated in writing the paper. Lukasz Skalniak prepared genetic constructs. Jolanta Jura discussed the data and revised the paper. Sigurd Lenzen provided conceptual advice, discussed the data and revised the paper. Ewa Gurgul-Conveydesigned the study, analysed and interpreted the data, supervised the proiect and wrote the paper.

\section{ACKNOWLEDGEMENTS}

We thank Professor Claes Wollheim (Department of Cell Physiology and Metabolism. University of Geneva Medical Center, Geneva, Switzerland) for providing insulin-secreting INS1E cells and Professor Jun-Ichi Miyazaki (Department of Molecular Therapeutic Osaka University Graduate School of Medicine, Osaka, Japan) for insulin-secreting MING cells. The excellent technical assistance of C. Heinrichs, M. Funck, J. Kresse and M. Wirth is gratefully acknowledged.

\section{FUNDING}

This work is part of the Ph.D. thesis of K.H. and was supported by the European Commission (E C) Framework Programme 6 STREP SaveBeta [orant number ISHM-
CT-2006-036903], and the E.C. Framework Programme 7, Collaborative Project NAlMIT [grant number 241447].

\section{REFERENCES}

1 Tsuneoka, M., Teye, K., Arima, N., Soejima, M., Otera, H., Ohashi, K., Koga, Y., Fujta, H., Shirouzu, K., Kimura, H. and Koda, Y. (2005) A novel Myc-target gene, mimitin, that is involved in cell proliferation of esophageal squamous cell carcinoma. J. Biol. Chem. 280, 19977-19985

2 Wegrzyn, P., Yarwood, S. J., Fiegler, N., Bzowska, M., Koj, A., Mizgalska, D., Malicki, S, Pajak, M., Kasza, A., Kachanakova-Trojanowska, N. et al. (2009) Mimitin: a novel cytokine-regulated mitochondrial protein. BMC Cell Biol. 10, 23

3 Ashcrott, S. J., Weerasinghe, L. C. and Rand le, P. J. (1973) Interrelationship of islet 3 Ashcroft, S. J., Weerasinghe, L. C. and Randle, P. J. (1973) Interrelationship of islet
metabolism, adenosine triphosphate content and insulin release. Biochem. J. 132, 223-231

4 Delaney, C. A. and Eizirik, D. L. (1996) Intracel lular targets tor nitric oxide toxicity to pancreatic $\beta$-cells. Braz. J. Med. Biol. Res. 29, 569-579

5 Cnop, M., Welsh, N., Jonas, J. C., Jöms, A., Lenzen, S. and Eizirik, D. L. (2005) Mechanisms of pancreatic $\beta$-cell death intype 1 and type 2 diabetes: many differences, few similarities. Dlabetes $\mathbf{5 4}$ (Suppl. 2), S97-S107

6 Gurgul-Convey, E., Mehmeti, I., Lortz, S. and Lenzen, S. (2011) Cytokine toxicity in insulin-produc ing cells is mediated by nitro-oxidative stress-induced hydroxyl radical formation in mitochondria. J. Mol. Med. 89, 785-798

7 Hellman, B. (1965) Studies in obese-hyperglycemic mice. Ann. N. Y. Acad. Sci. 131, $541-558$

8 Lenzen, S. and Panten, U. (1980) 2-oxocarboxylic acids and function of pancreatic islets in obese-hyperglycaemic mice. Insulin secretion in relation to ${ }^{45} \mathrm{Ca}$ uptake and metabolism. Biochem. J. 186, 135-144

9 Ximenes, H. M. Lortz, S., Jörns, A. and Lenzen, S. (2007) Triiodothyronine (T $\left.T_{3}\right)$-mediated toxicity and induction of apoptosis in insulin-producing INS-1 cells. Life Sci. 80, 2045-2050

ga Elsner, M., Gehmann, W. and Lenzen, S. (2011) Peroxisome-gererated hydrogen peroxide as important mediator of lipotoxicity in insulin-producing cells. Diabetes $\mathbf{6 0}$ 200-208

10 Azevedo-Martins, A. K., Lorz, S., Lenzen, S., Curi, R., Eizirik, D. L. and Tiedge, M. (2003) Improvement of the mitochondrial antioxidant detense status prevents cytokine-induced nuclear factor- $\alpha$ B activation in insulin-producing cells. Diabetes 52, 93-101

11 Tiedge, M., Lorz, S., Munday, R. and Lenzen, S. (1999) Protection against the co-operative toxicity of nitric oxide and oxygen free radicals by overexpression of antioxidant enzymes in bioengineered insul in-producing RINm5F cells. Diabetologia $\mathbf{4 2}$, $849-855$

12 Baltrusch, S., Langer, S., Massa, L., Tiedge, M. and Lenzen, S. (2006) Improved metabolic stimulus for glucose-induced insul in sec retion through GK and PFK-2/FBPase-2 coexpression in insulin-producing PINm5F cells. Endocrinology 147, 5768-5776

13 Tiedge, M. Höhne, M. and Lenzen, S. (1993) Insulin secretion, insul lin content and glucose phosphorylation in RINMm5F insulinoma cells after transfection with human GLUT2 glucose-transporter cDNA. Eiochem. J. 296, 113-118

14 Fryer, L. G. and Carling, D. (2005) AMP-activated protein kinase and the metabolic syndrome. Biochem. Soc. Trans. 33, 362-366

15 Rutter, G. A. and Leclerc, I. (2009) The AMP-regulated kinase tamily: enigmatic targets for diabetes therapy. Mol. Cell. Endocrinol. 297, 41-49

16 Andersson, U., Filinsson, K. Ahbott, C. R., Woods, A, Smith, K., Bloom, S. R, Carling, D. and Small, C. J. (2004) AMP-activated protein kinase plays a role in the control of food intake J. Biol. Chem. 279, 12005-12008

17 Small, C. J., Carl ling, D. and Bloom, S. R. (2004) Cellular energy sensor balances the scales. Nat. Med. 10, 681-682

18 Zhou, G., Myers, P., Li, Y., Chen, Y., Shen, X, Fenyk-Melody, J., Wu, M., Ventre, J, Doebber, T., Fujii, N. et al. (2001) Role of AMP-activated protein kinase in mechanism of mettomin action. J. Clin. Invest. 108, 1167-1174

19 Richards, S. K., Parton, L. E., Leclerc, I., Rutter, G. A. and Smith, R. M. (2005) Over-expression of AMP-activated protein kinase impairs pancreatic $\beta$-cell function in vivo. J. Endocrinol. 187, 225-235

20 Kacheva, S. Lenzen, S. and Gurgul-Convey, E. [2011] Differential effects of proinflammatory cytokines on cell death and ER stress in insulin-secreting INSTE cells and the involvement of nitric oxide. Cytokine $\mathbf{5 5}, 195-201$

21 Lazarou, M., McKenzie, M., Ohtake, A., Thorbum, D. R. and Ryan, M. T. (2007) Analysis of the assembly profiles formitochondrial- and nuclear-DNA-encoded subunits into complex I. Mol. Cell. Biol. 27, 4228-4237

22 Ogivie, I., Kennaway, N. G. and Shoubridge, E. A. (2005) A molecular chaperone for mitochondrial complex I assembly is mutated in a progressive encephalopathy. J. Clin. Invest. 115, 2784-2792 
23 Ezirik, D. L. and Cnon, M. (2010) ER stress in pancreatic $\beta$ cells: the thin red line between adaptation and failure. Sci. Signaling $\mathbf{3}$, pe 7

24 Gurgul-Convey, E. and Lenzen, S. (2010) Protection against cytokine toxicity through endop lasmic reticulum and mitochondrial stress prevention by prostacyc lin synthase overexpression in insulin-producing cells. J. Biol. Chem. 285, 11121-11128

25 Xu, J., Han, J., Long, Y. S., Epstein, P. N. and Liu, Y. Q. (2008) The role of pynuvate carboxylase in insulin secretion and proliteration in rat pancreatic $\beta$ cells. Diabetologia 51, 2022-2030
26 Ellasson, L., Renström, E., Ding, W. G., Proks, P. and Rorsman, P. (1997) Rapid ATP-dependent priming of secretory granules precedes $\mathrm{Ca}^{2}+$-induced exocytosis in mouse pancreatic $\beta$-cells. J. Physiol. 503, 399-412

27 Panten, U., Zünkler, B. J., Scheit, S., Kirchhoft, K. and Lenzen, S. (1986) Regulation of energy metabolism in pancreatic islets by glucose and tolbutamide. Diabetologia $\mathbf{2 9}$ 648-654

28 Lenzen, S. (2008) Oxidative stress: the vulnerable $\beta$-cell. Biochem. Soc. Trans. 36, $343-347$

Feceived 28 0ctober 2011/8 May 2012; accepted 16 May 2012

Fublished as BJ Immediate Publication 16 May 2012, doi:10.1042/BJ20111920 


\title{
Mechanism of Prostacyclin-Induced Potentiation of Glucose-Induced Insulin Secretion
}

\author{
Ewa Gurgul-Convey, Katarzyna Hanzelka, and Sigurd Lenzen \\ Institute of Clinical Biochemistry, Hannover Medical School, 30623 Hannover, Germany
}

\begin{abstract}
Arachidonic acid metabolites are crucial mediators of inflammation in diabetes. Although eicosanoids are established modulators of pancreatic $\beta$-cell function, the role of prostacyclin (prostaglandin 12) is unknown. Therefore, this study aimed to analyze the role of prostacyclin in $\beta$-cell function. Prostacyclin synthase (PGIS) was weakly expressed in rat islet cells but nevertheless significantly increased by incubation with $30 \mathrm{mM}$ glucose, especially in non- $\beta$-cells. PGIS was overexpressed in INS1E cells, and the regulation of insulin secretion was analyzed. PGIS overexpression strongly potentiated glucose-induced insulin secretion along with increased insulin content and ATP production. Importantly, overexpression of PGIS potentiated only nutrient-induced insulin secretion. The effect of PGIS overexpression was mediated by prostacyclin released from insulinsecreting cells and dependent on prostacyclin receptor (IP receptor) activation, with concomitant CAMP production. The CAMP-mediated potentiation of glucose-induced insulin secretion by prostacyclin was independent of the protein kinase A pathway but strongly attenuated by the knockdown of the exchange protein directly activated by CAMP 2 (Epac2), pointing to a crucial role for Epac2 in this process. Thus, prostacyclin is a powerful potentiator of glucose-induced insulin secretion. It improves the secretory capacity by inducing insulin biosynthesis and probably by stimulating exocytosis. Our findings open a new therapeutical perspective for an improved treatment of type 2 diabetes. (Endocrinology 153: 2612-2622, 2012)
\end{abstract}

$\mathbf{B}^{\circ}$ th type 1 and type 2 diabetes are metabolic diseases with a strong inflammatory component in their pathogenesis $(1,2)$. Activation of the arachidonic acid cascade by proinflammatory conditions leads to the production of active metabolites (eicosanoids), which play an important role in this context $(3,4)$. These eicosanoids are established modulators of pancreatic islet function $(5,6)$. Glucose stimulates the production of arachidonic acid metabolites, mainly prostaglandins, in pancreatic islets and affects insulin secretion (7). Although prostaglandin E2 is an inhibitor of glucose-induced insulin secretion (8), products of the lipooxygenase pathway of arachidonic acid metabolism have opposite effects (9). Lipooxygenase inhibitors decrease (10) and phospholipase activators increase cAMP and insulin secretion (11).

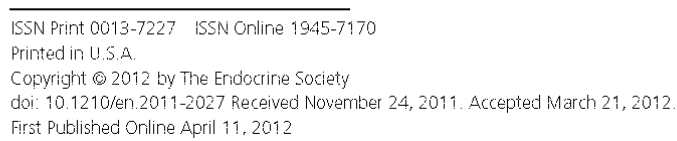

Eicosanoids comprise a wide range of lipid derivatives generated in arachidonic acid metabolism, which act as local hormones and signaling molecules. The intracellular concentrations of eicosanoids (prostaglandins, leukotrienes, and thromboxanes) are increased by cellular stress and participate in the inflammatory response (12). Prostaglandins also participate in the maintenance of cellular homeostasis. Prostacyclin [also called prostaglandin 12 [PGI2)] is synthesized from the precursor prostaglandin $\mathrm{H} 2$ by the heme-thiolate enzyme prostacyclin synthase (PGIS) (13). Prostacyclin can reportedly modulate the metabolism and function of the cell of origin or affect neighboring cells in a paracrine fashion after release. Prostacyclin receptors (IP receptors) belong to a $G$ protein-coupled receptor family and, upon activation, can induce adenyl cyclase, leading to the production of $\mathrm{cAMP}$.

Abbreviations: Bip, Binding immunoglobulin protein; BrdU, 5-bromo-2'-deoxyuridins

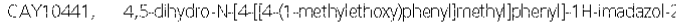
aminie; ECM, extracelluar matrix, EDac2, exchange protein directiy activated by CAMP 2. ER endoplasmic reticulum, GSIS, glucose stimulated insulin secretion; IP recentors, prostacydin

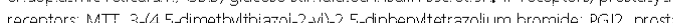

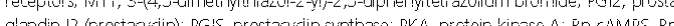
adenosine-3', $3^{\prime}$ cychicmonophosohiorothioate. 
Although beraprost, a stable synthetic analog of prostacyclin, has been shown to support $\beta$-cell viability and function during islet isolation (14) and the effects of prostacyclin administ ration have been reported in rats $(15,16)$ and humans (17), the mechanism used by prostacyclin remains unknown. In the present study, we identified the mechanism by which prostacyclin acts as a strong potentiator of glucose-induced insulin secretion. We demonstrate here that the overexpression of PGIS increases insulin biosynthesis and potentiates the secretory response of insulin-secreting cells to glucose stimulation through a cAMP-mediated and the exchange protein directly activated by CAMP 2 (Epac2)-dependent pathway.

\section{Materials and Methods}

\section{Chemicals}

Biotherm Taq polymerase was from GeneCraft (Münster, Germany). Hybond N nylon membranes, the enhanced chemiluminescence detection system, and autoradiography film were from Amersham Biosciences (Freiburg, Germany). Ilo prost (Ventavis) was a kind gift from Bayer Vital GmbH (Le verkusen, Germany).4,5-dihydro-N-[4-[[4-(1-methylethoxy) phenyl]methyl]phenyl]-1H-imadazol-2-amine (CAY10441) was from Biomol (Hamburg, Germany), and Rp-adenosine3',5' cyclicmonophosphorothioate (Rp-cAMPS) was from Santa Cruz Biotechnology (Heidelberg, Germany). All other reagents were from Sigma Chemicals (München, Germany).

\section{Animals and tissues}

Pancreatic islets and other tissues were derived from 250- to 300 -g adult male Lewis rats. Islets were isolated by collagenase digestion, separated by Ficoll gradient, and handpicked under a stereomicroscope.

\section{Cell culture}

Insulin-secreting INS1E cells were cultured as described (18) in fully supplemented RPMI 1640 medium, with $10 \mathrm{mM}$ glucose, $10 \%$ (vol/vol) fetal calf serum, penicillin, and streptomycin in a humidified atmosphere at $37 \mathrm{C}$ and $5 \% \mathrm{CO}_{2}$

\section{Rat islet isolation, culture, and treatment}

Pancreatic islets were isolated from 250- to 300-g adult male Lewis rats by collagenase digestion and handpicked under a stereomicroscope. Isolated islets were cultured on extracellular matrix (ECM)-coated plates (35 mm) Novamed, Jerusalem, Israel the ECM being derived from bovine corneal endothelial cells) in RPMI 1640 medium containing $5 \mathrm{mM}$ glucose, $10 \%$ fetal calf serum, penicillin, and streptomycin at $37 \mathrm{C}$ in a humidified at mosphere of $5 \% \mathrm{CO}_{2}$. For immunofluorescence studies, islet were cultured for $10-12 \mathrm{~d}$ on the ECM plates to adhere and spread before they were transferred onto collagen-coated chamber slides and let attach for $24 \mathrm{~h}$. The islets were then treated with $5 \mathrm{mM}$ or $30 \mathrm{mM}$ glucose for $24 \mathrm{~h}$. For RNA or protein measurements, islets were incubated overnight and then the incubation with 5 or $30 \mathrm{~mm}$ glucose was begun.

\section{Overexpression of PGIS in insulin-secreting cells}

Human PGIS cDNA ( $\mathrm{pcDNA3} .1(+)$ )-hPGIS vector, from Professor Rolf Müller, Marburg, Germany) was stably overexpressed in insulin-secreting INS1E cells using the Lipofectamine transfection method. Positive clones were selected against G418, and PGIS expression levels were confirmed by real-time PCR measurements and Western blotting.

\section{Suppression of Epac2 in insulin-secreting cells}

INS1E-control and PGIS-overexpressing cells were infected with lentiviral particles containing rat Epac2 short hairpin RNA (Santa Cruz. Biotechnology) and verified by Western blotting.

\section{MTT cell viability assay}

Viability of the cells was determined after a $24-h$ incubation with chemicals using a microplate-based 3-(4,5-dimethylthiazol2-yl)-2,5-diphenyltetrazolium bromide (MTT) assay (19). Viability was expressed as a percentage of the MTT absorbance at $550 \mathrm{~nm}$ in the absence of the test compounds.

\section{Proliferation assay}

The proliferation rate of INS1E cells was quantified by a colorimetric method using the cell proliferation 5-bromo- 2 '-deoxyuridine (BrdU)-ELISA (Roche, Mannheim, Germany). Cells were seeded at a concentration of 10,000 cells/well in 96-well microtiter plates and allowed to attach for $24 \mathrm{~h}$. Thereafter cells were incubated with the chemical compounds for $24 \mathrm{~h}$. The proliferation assay was performed as described (20). Absorbance was measured at $450 \mathrm{~nm}$ (reference wavelength $650 \mathrm{~nm}$ ). Data were expressed as percentage of untreated cells.

\section{RNA isolation, cDNA synthesis, and real-time PCR}

Total RNA from insulin-secreting cell clones or rat tissues was obtained using NucleoSpin RNA columns (Marcherey-Nagel, Düren, Germany). The quality of the total RNA was verified by agarose gel electrophoresis. RNA was quantified spectrophotometrically at $260 / 280 \mathrm{~nm}$. Thereafter $2 \mu \mathrm{g}$ of RNA was reverse transcribed into $\mathrm{CDNA}$ using a random hexamer primer and a reverse transcriptase. QuantiTect SYBR Green technology (QIAGEN, Hilden, Germany), which uses a fluorescent dye that binds only double-stranded DNA, was used. The reactions were performed using the DNA engine opticon sequence detection system (Biozym Diagnostik, Hess. Oldendorf, Germany), as described (21). The primer sequences were as follows: for rat PGIS, forward, ACGGCTTTCTGGCTCCTCCT, reverse, ATCTTCTGCGGGAGTGCGGT; for human PGIS, forward, CCT GGTTGGGGTATGCCTTG, reverse, TGTGGGTCCAGGAGAACGGT; for rat Ins2, forward, AGGACCCACAAGTGGCACAA, reverse, AGCACTGATCCACGATGC; for rat Binding immunoglobulin protein(Bip), forward, CCACCAGGATGCAGACATTG, reverse, AG GGCCTCCACTTCCATAGA; and for rat $\beta$-actin, forward, GAACACGGCATTGTAACCAACTGG, reverse, GGCCACACGCAGCTCATT GTA. The values for rat PGIS, human PGIS, rat Ins2, and rat Bip were normalized to $\beta$-actin.

\section{PGIS and Epac2 Western blot analysis}

PGIS protein expression was estimated according to GurgulConvey and Lenzen (21). For analysis of Epac2 protein expression, $60 \mu \mathrm{g}$ of total protein was resolved by SDS-PAGE and then 
electroblotted onto nitrocellulose membranes. Immunodetection was performed using specific primary antibodies against rat Epac2 (Santa Cruz Biotechnology) followed by exposition to secondary peroxidase-conjugated AffiniPure donkey antigoat IgG (heavy and light chains). The hybrids were visualized through chemiluminescence using the enhanced chemiluminescence detection kit and captured by the INTAS chemiluminescence detection system (Intas Science Imaging Instruments GmbH, Göttingen, Germany).

\section{Insulin secretion and content}

Insulin secretion and content in control and PGIS-overexpressing, insulin-secreting INS1E cell clones were measured by RIA (22). Cells were seeded at a density of $350,000 \mathrm{cells} / \mathrm{w}$ well onto six-well plates $2 \mathrm{~d}$ before the addition of chemicals. A 24-h incubation with the chemical compounds was followed by a $1-\mathrm{h}$ incubation without glucose and a 2 -h stimulation with glucose $(3,10$, or $30 \mathrm{~mm})$ or $\mathrm{KCl}(25 \mathrm{~mm})$ in the absence or presence of the chemical compounds. Thereafter supernatants were collected for RIA. Insulin values were normalized to the DNA content of the incubated cells.

\section{ATP measurements}

ATP levels were determined using the ATPlite detection assay system (PerkinElmer Life Sciences, Zaventem, Belgium), as described previously (23). Cells were seeded at a density of 40,000 cells/well onto black 96 -well plates $24 \mathrm{~h}$ before the addition of chemical compounds. Twenty-four hours later, cells were cultured in the absence of glucose for $1 \mathrm{~h}$, followed by a $2 \mathrm{~h}$ incubation with glucose and/or chemical compounds. Cells were then lysed and used for ATP concentration measurements. Data were normalized to the protein content.

\section{CAMP measurements}

The cAMP concentration was measured by the cAMP-Glo assay kit according to the manufacturer's instructions (Promega, Mannheim, Germany). Twenty thousand cells per well were seeded onto white 96 -well plates and allowed to attach for $48 \mathrm{~h}$ before the addition of chemical compounds. Twenty-four hours later, cells were cultured in the absence of glucose for $1 \mathrm{~h}$, and next a 2-h incubation with glucose and/or chemical compounds was performed. Cells were then lysed and used for cAMP concentration measurements.

\section{Immunostaining}

For immunofluorescence staining, rat islet cells were seeded onto collagen-coated glass slides and incubated as described above following an overnight fixation with $4 \%$ paraformaldehyde in PBS. After fixation cells were washed three times with PBS for 5 min. After a 20 -min blocking in PBS with $0.1 \%$ Triton $\mathrm{X}-100$ and $1 \% \mathrm{BSA}$ at room temperature, the cells were washed again as above. The slides were incubated with primary antibodies diluted in PBS with $0.1 \%$ Triton X-100 0.1\% BSA at room temperature for $1 \mathrm{~h}$ (mouse anti-PTGIS 1:100 from $\mathrm{Ab}$ nova, Aachen, Germany; guinea pig antiinsulin 1:200, from Abcam, Cambridge, UK) and then washed three times in PBS. The cells were incubated with secondary antibodies for $1 \mathrm{~h}$ (fluorescein isothiocyanate conjugated antimouse IgG, 1:200, TX red conjugated anti-guinea pig IgG, 1:500) for $1 \mathrm{~h}$ at room temperature (both from Dianova, Hamburg, Germany). For nuclear counterstaining, $300 \mathrm{nM}$ 4-,6-diamidino-2-phenylindole was used for $5 \mathrm{~min}$ at room temperature. Slides were thereafter mounted with Mowiol (Merck, Darmstadt, Germany) plus 0.6\% Dabco (Sigma, München, Germany). Images were captured and analyzed using a Cell/Olympus IX81 inverted microscope system (Olympus, Hamburg, Germany).

\section{Data analysis}

All data are expressed as means I SEM. Statistical analyses were performed using the Prism analysis program (GraphPad, San Diego, CA)

\section{Results}

\section{Expression of PGIS in rat tissues}

The enzyme PGIS was expressed in all rat tissues that were analyzed in this study (Table 1). The PGIS gene expression level in liver was set as $100 \%$. PGIS was expressed at a higher level in heart, lung, and pancreas than in liver (Table 1). The expression level in brain was comparable with that in liver. PGIS expression was lower in kidney and intestine than in liver (Table 1). Only in skeletal muscle and pancreatic islets was $P$ GIS expression very low (in the range of $5 \%$ of liver expression; Table 1). PGIS gene expression in the insulin-secreting INS1E cell line was even lower than in islets, $0.1 \%$ of liver expression, indicating that the higher expression level observed in islets may originate from the non- $\beta$-cells in the islets (Table 1 and Fig. 1A). PGIS expression in INS1E cells was not affected by glucose exposure, whereas in rat islets a significant increase in PGIS expression both on the gene and protein expression levels was observed (Fig. 1, A and B). A specific immunostaining for PGIS in isolated rat islet cells revealed that this protein is expressed in different types of islet cells, including $\beta$-cells (Fig. 1, C and Supplemental Fig. 1, published on The Endocrine Society's Jour-

\begin{tabular}{|c|c|}
\hline Tissue & rPGIS $(\%)$ \\
\hline $\begin{array}{l}\text { Heart muscle } \\
\text { Pancreas } \\
\text { Lung } \\
\text { Liver } \\
\text { Brain } \\
\text { Intestine } \\
\text { Kidney } \\
\text { Skeletal muscle } \\
\text { Pancreatic islets } \\
\text { INS1E cells }\end{array}$ & $\begin{array}{c}800 \pm 135(3)^{a} \\
264 \pm 39(8)^{a} \\
211 \pm 45(3)^{a} \\
100 \pm 17(8) \\
80 \pm 18(6) \\
54 \pm 11(4)^{a} \\
31 \pm 10(6)^{a} \\
6 \pm 1(6)^{a} \\
5 \pm 1(8)^{a} \\
0.1 \pm 0.0(4)^{a}\end{array}$ \\
\hline
\end{tabular}

Total RNA was isolated from different rat tissues. Next, real-time RTPCR was performed to determine rat PGIS expression. PGIS expression was normailzed to $\beta$-actin. Data are means \pm SEM, with the riumber of experiments provided in parentheses. The value for Iver was 0.312 I 0.052 (arbitrary units) and was set as $100 \%$. rPGIS, Rat PGIS a $P<0.05$ vs liver. ANOVA folliowed by Bonferroni 


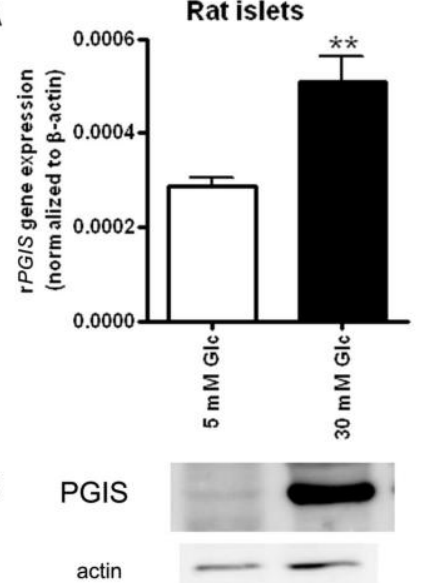

C

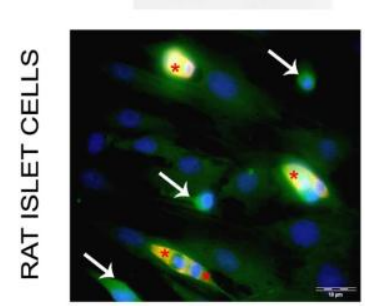

$5 \mathrm{mM}$ glucose

\section{D}

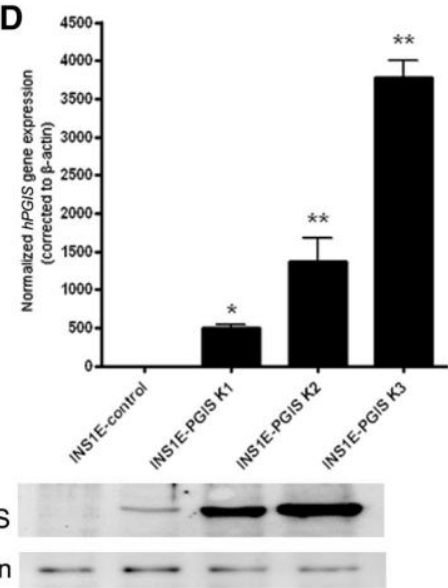

FIG. 1. PGIS expression in insulin-secreting INS1E cells and rat islets. The pCDNA3.1(+)hPGIS vector was used to obtain stably overexpressing INS1E cell clones. A, Real-time PCR analysis of rat PGIS expression in rat islets (left panel) and INS1E-control cells (right panel) after a 24-h incubation with different glucose concentrations. B. Western blot analysis of rat PGIS expression in rat islets and INS1Econtrol cells. C. Immunofluorescence staining for rat PGIS (green) and insulin (red) in rat islet cells exposed to 5 or $30 \mathrm{~mm}$ glucose for $24 \mathrm{~h}$. The merge is shown in yellow. $\beta$-Cells are marked with red asterisks. Non- $\beta$-cells strongly expressing PGIS marked with white arrows. Scale bar, $10 \mu \mathrm{m}$. D, upper panel, Human PGIS gene expression measured by means of real-time PCR; lower panel, a representative Western blot of four independent experiments. Data are mean values from four independent experiments. * $P<0.05$ and $* *, P<0.01$ vs. INS1E-control clone; ANOVA followed by Bonferroni. nals Online web site at http://endo.endojournals.org). The analysis of the PGIS expression pattern in primary rat islet cells after a $24-\mathrm{h}$ incubation with $30 \mathrm{~mm}$ glucose showed an induction of PGIS expression, mostly in non- $\beta$-cells (Fig. 1C and Supplemental Fig. 1).

Stable overexpression of PGIS in insulin-secreting INS1E cells

Because PGIS expression in rat islets was increased by exposure to a high glucose concentration, indicating a physiological role of PGIS in islet secretory function, we aimed to analyze in detail the effects of PGIS on $\beta$-cell function. The endogenous level of PGIS expression in insulin-secreting INS1E cells was extremely low (Table 1), so this insulin-secreting cell line can serve as a good model to study the effects of PGIS overexpression. Therefore, PGIS cDNA was introduced and several positive clones were obtained. To exclude the possible influence of clonal variation on the results, three clones were selected for further analyses: INS1EPGIS K1, with a relatively low expression level, and clones with medium (K2) and high (K3) expression levels (Fig. 1D). PGIS expression was estimated at RNA and protein levels (Fig. 1D). Insulin-secreting INS1E cells transfected with the empty pcDNA3 vector were used as control cells.

\section{Effects of PGIS overexpression on insulin secretion}

The magnitude of insulin secretion at $3 \mathrm{~mm}$ glucose was similar in insulinsecreting INS1E-control cells and in PGIS-overexpressing INS1E cells (Fig. 2A). After incubation of insulin-secreting INS1E cells with 10 and $30 \mathrm{~mm}$ glucose, glucose-induced insulin secretion was increased (Fig. 2A). Control experiments revealed that PGIS expression in INS1E-control (Fig. 1, A and B) as well as INS1E-PGIS overexpressing clones (not depicted in the figure) was not significantly affected by different glucose concentrations and by $\mathrm{KCl}$ (data not 
A

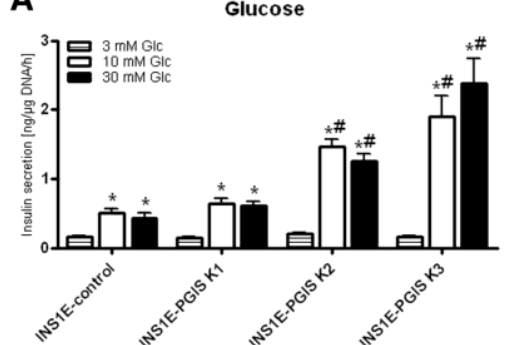

D INS1E-control

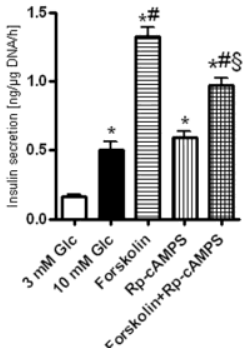

INS1E-PGIS K3

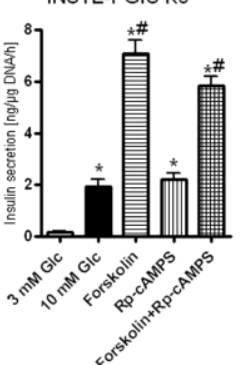

B

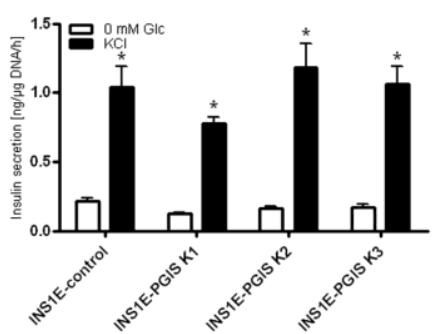

INS1E-PGIS K3

E

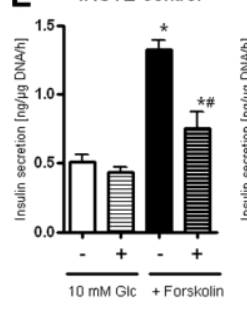

C

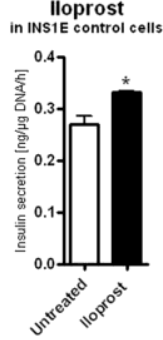

CAY 10441
INS1E-PGIS K3 cells

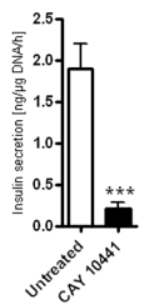

$\mathbf{F}$ Epac2 Knock-down

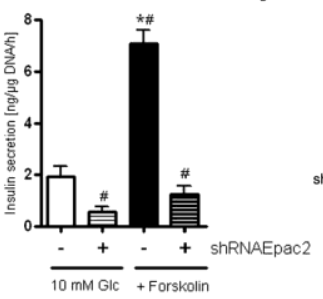

FIG. 2. Effects of PGIS overexpression on insulin secretion in insulin-secreting INS1E cells. INS1E-control and PGIS-overexpressing cells were

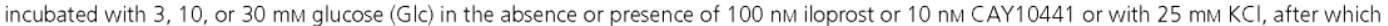
insulin secretion was measured. A, Insulin secretion from cells grown in $3 \mathrm{~mm} \mathrm{Glc} \mathrm{(striped} \mathrm{bars),} 10 \mathrm{~mm}$ Glc (open bars), or $30 \mathrm{~mm}$ Glc (black bars). $\mathrm{B}$, insulin secretion in the absence (white bars) and presence (black bars) of $\mathrm{KCl}$ in the cell culture medium without glucose. C, The effects of iloprost in the INS1E-control clone at $10 \mathrm{~mm}$ Glc and CAY10441 in the INS1E-PGIS K3 clone at $30 \mathrm{~mm}$ Glc. D, The effects of forskolin (10 $\mu \mathrm{M}$, horizontally striped bars) and Rp-CAMPS (10 $\mathrm{M}$, vertically striped bars) in INS1E-control and INS1E-PGIS K3 cells at $10 \mathrm{~mm}$ Glc (black bars), forskolin+Rp-cAMPS (grid bars). E, The effects of Epac2 knockdown in INS1E-control and INS1E-PGIS K3 cells treated with 10 mM Glc (white bars), $10 \mathrm{mM} \mathrm{Glc}$ in the presence of forskolin (black bars) $10 \mathrm{~mm} \mathrm{Glc} \mathrm{in} \mathrm{Epac2} \mathrm{knockdown} \mathrm{cells} \mathrm{(striped} \mathrm{bars),} \mathrm{and} 10 \mathrm{~mm}$ Glc in the presence of forskolin in Epac2 knockdown cells (black striped bars). F, Verification of Epac2 knockdown by Western blotting. Data are means from six to eight independent experiments, each performed in duplicate. ${ }^{*}, P<0.05$ and ${ }^{* * *}, P<0.001$ vs. control conditions; \#, $P<0.05$ vs. control clone treated identically; §, vs. forskolin; ANOVA followed by Bonferroni.

shown). PGIS overexpression significantly enhanced glucose-induced insulin secretion, and this effect was dependent on the magnitude of PGIS expression (Fig. 2A). In the INS1E-PGIS K3 clone with the highest PGIS overexpression, insulin secretion induced by incubation with $30 \mathrm{~mm}$ glucose was approximately 6 -fold higher than in INS1Econtrol cells (Fig. 2A). The stimulatory effect of PGIS overexpression on insulin secretion was glucose specific because there was no potentiation of $\mathrm{KCl}$-induced insulin secretion in INS1E PGIS-overexpressing clones in the absence of glucose (Fig. 2B).

Incubation with $100 \mathrm{~nm}$ iloprost, a stable analog of prostacyclin, enhanced glucose-induced insulin secretion in INS1E-control cells (Fig. 2C). In contrast, the IP receptor antagonist CAY10441 (10 nM) inhibited glucose-induced insulin secretion in the INS1E-PGIS K3 clone (Fig. $2 \mathrm{C})$. To address the question of which of the cAMP-dependent mechanisms causes the observed potentiation of glucose-induced insulin secretion, a competitive inhibitor of protein kinase A (PKA), namely Rp-cAMPS $(10 \mu \mathrm{M})$, was used. Rp-cAMPS did not affect glucose-induced insulin secretion in control INS1E cells in the absence of iloprost [Rp-cAMPS + 3 mM glucose: $98 \pm 2 \%$ (4); RpcAMPS + $10 \mathrm{~mm}$ glucose: $97 \pm 4 \%(\mathrm{n}=4)$; Rp-cAMPS + 30 mu glucose: $97 \pm 5 \%(\mathrm{n}=4)$; all $v$ s. glucose in the absence of Rp-cAMPS, set as $100 \%]$. In contrast, forskolin-potentiated, glucose-induced insulin secretion in INS1E cells was reduced by $45 \%$ after incubation with Rp-cAMPS (10 $\mu \mathrm{M})$ (Fig. 2D). Inhibition of the PKA pathway did not inhibit glucose-induced insulin secretion in INS1E-PGIS cells (Rp-cAMPS $+10 \mathrm{~mm}$ glucose: INS1E-PGIS K1 $96 \pm 9 \%$ (7); INS1E-PGIS K2: $102 \pm+6 \%(\mathrm{n}=7)$; INS1E-PGIS K3: $136 \pm 5 \%(\mathrm{n}=7)$; all $v$ s. glucose in the absence of Rp-cAMPS, set as $100 \%$; and Fig. 2D). In contrast the forskolin-potentiated glucose-stimulated insulin secretion (GSIS) in INS1E-PGIS overexpressing cells was reduced by Rp-cAMPS (Fig. 2D).

Next, we analyzed the effect of an Epac2 knockdown on glucose-induced insulin secretion. In control INS1E cells, reduced Epac2 expression significantly diminished 
TABLE 2. Effects of PGIS overexpression on Ins2 and Bip gene expression in insulin-secreting INS1E cells

\begin{tabular}{ccc}
\hline Cell clones & $\begin{array}{c}\text { Ins2 } \\
\text { (arbitrary units) }\end{array}$ & $\begin{array}{c}\text { Bip } \\
\text { (\% of INS1E-control) }\end{array}$ \\
\hline INS1E-Control & $4.9 \pm 0.5(6)$ & $100 \pm 1(7)$ \\
INS1E-PGIS K1 & $6.3 \pm 0.4(3)$ & $183 \pm 23(8)^{a}$ \\
INS1E-PGIS K2 & $7.7 \pm 1.2(4)^{a}$ & $215 \pm 28(6)^{a}$ \\
INS1E-PGIS K3 & $9.4 \pm 0.6(3)^{a}$ & $235 \pm 29(7)^{a}$ \\
\hline
\end{tabular}

Total RNA was isolated, and quantitative real-time RT-PCR was performed to determine the expression of rat Ins2 and Bip genes. Ins 2 and Bip expression was normalized to $\beta$-actin. Data are means \pm SEM, with the number of independent experiments provided in parentheses. a $P<0.05$ vs. INS1E-control cells, ANOVA followed by Dunnett's test,

glucose-inducer insulin secretion only in the presence of forskolin, a potent inducer of cAMP formation (Fig. 2E). Notably, the potentiating effect of PGIS overexpression on glucose-induced insulin secretion was lost in INS1E-PGIS K3 cells treated with short hairpin RNA-Epac2 (Fig. 2E). Indeed, the rate of glucose-induced insulin secretion was normalized to the level observed in INS1E-control cells (Fig. 2E). The forskolin-potentiated glucose-induced insulin secretion was significantly reduced by Epac2 knockdown. The Epac2 knock-down efficiency was verified by Western blotting (Fig. 2F).

Control experiments revealed no effects of exposure to different glucose concentrations as well as $\mathrm{KCl}$ on PGIS expression in INS1E-control as well as INS1E-PGIS overexpressing clones (data not shown).

Effects of PGIS overexpression on rat insulin gene expression and insulin content

Expression of the rat insulin (Ins2) gene was significantly higher in insulin-secreting INS1E-PGIS cells than in control cells (Table 2). Insulin-secreting INS1E cells contained 30 ng insulin per microgram DNA, and this insulin content was significantly reduced when $30 \mathrm{~mm}$ glucose was present in the culture medium (Fig. 3A). Insulin content was significantly higher in insulin-secreting INS1E cells overexpressing high levels of PGIS than in the control INS1E cells, reaching almost 50 ng insulin per microgram DNA (Fig. 3A). Although insulin content was significantly reduced in the INS1E-PGIS K3 clone after exposure to higher glucose concentrations, the remaining insulin content was still significantly higher compared with the control INS1E cells ( 36 vs. 15 ng insulin per microgram DNA, respectively; Fig. 3A). Incubation with $25 \mathrm{~mm} \mathrm{KCl}$ in the absence of glucose decreased insulin content both in control and PGIS-overexpressing clones, irrespective of the PGIS expression level (Fig. 3B). Incubation with a stable analog of prostacyclin, iloprost (100 nM), significantly increased insulin content in the INS1E-control cell clone (Fig. 3C). An opposite effect on insulin content was ob-
A

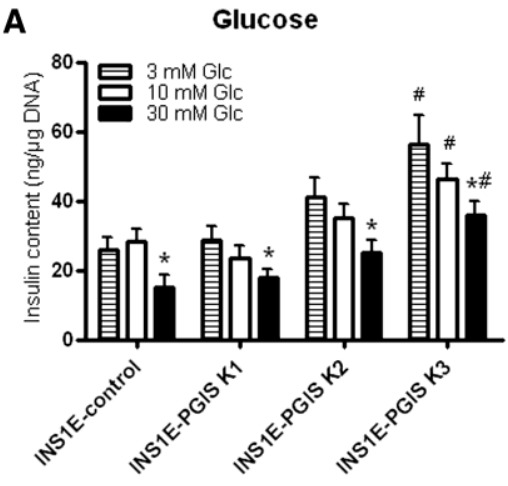

B

$\mathrm{KCl}$

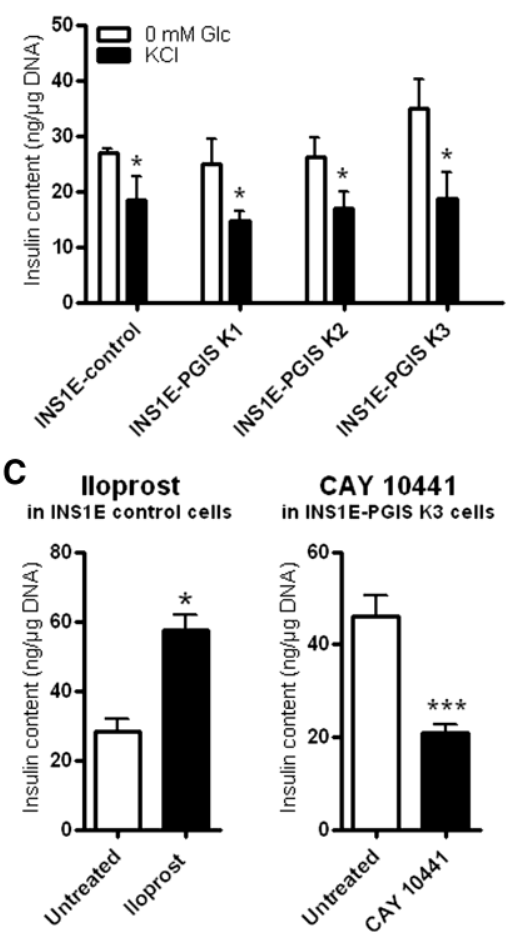

FIG. 3. Effects of PGIS overexpression on insulin content in insulinsecreting INS1E cells. INS1E insulin-secreting cells were incubated with 3,10 , or $30 \mathrm{~mm}$ glucose (Glc) in the absence or presence of $100 \mathrm{~nm}$ iloprost or $10 \mathrm{~nm} \mathrm{CAY} 10441$ or with $25 \mathrm{~mm} \mathrm{KCl}$. Next, insulin content was measured by RIA. A, Insulin content in cells treated with $3 \mathrm{~mm} \mathrm{GIc}$ (striped bars), $10 \mathrm{~mm}$ Glc (open bars), or $30 \mathrm{~mm}$ Glc (black bars). B, Insulin content in the absence (open bars) and presence (black bars) of $\mathrm{KCl}$ in the cell culture medium without glucose. C, The effects of iloprost in the INS1E-control clone and CAY10441 in the INS1E-PGIS $\mathrm{K} 3$ clone at $10 \mathrm{~mm}$ Glc. Data are means from six to eight independent experiments, each performed in duplicate. ${ }^{*}, P<0.05$ and ${ }^{* * *}, P<$ 0.001 vs. control conditions; \#, $P<0.05$ vs. control clone treated identically; ANOVA followed by Bonferroni. 
served in the INS1E-PGIS K3 clone, with the highest PGIS expression level after incubation with an IP receptor antagonist (10 nu CAY10441) (Fig. 3C).

\section{Effects of PGIS overexpression on Bip expression}

Expression of Bip was estimated by quantitative realtime PCR. The measurements revealed that Bip expression intensity correlated with the magnitude of PGIS overexpression (Table 2).

\section{Effects of PGIS overexpression on CAMP production}

The intracellular concentration of cAMP in insulin-secreting INS1E-control cells cultured in medium containing $10 \mathrm{~mm}$ glucose was $13 \pm 1 \mathrm{pmol} / \mathrm{mg}$ protein. Insulinsecreting INS1E-PGIS cell clones had a significantly higher level of cAMP under the same conditions when compared with the control cells (Fig. 4A). Incubation with $30 \mathrm{~mm}$ glucose caused a rise in cAMP content in all cell clones, irrespective of the PGIS expression level (Fig. 4A). Iloprost $(100 \mathrm{nM})$ significantly increased cAMP production in INS1E-control and INS1E-PGIS cell clones exposed to 10 mm glucose for $2 \mathrm{~h}$ (Fig. 4B). By contrast, CAY10441 (10 nM) significantly decreased cAMP production during exposure to $10 \mathrm{~mm}$ glucose (Fig. 4C). The most prominent decrease was observed in the INS1E-PGIS K2 and K3 clones with the highest PGIS expression levels (Fig. 4C).

\section{Prosurvival effects of PGIS overexpression in insulin-secreting cells}

None of the chemical compounds used in the insulin secretion studies affected the viability of INS1E-control or INS1E-PGIS overexpressing cells in the time loop chosen for GSIS experiments (data not shown). In the MTT assay, $24 \mathrm{~h}$ incubation with $100 \mathrm{~nm}$ iloprost did not affect the viability of insulin-secreting INS1E-control or PGIS-overexpressing cells (Fig. 5A). In contrast, a 24-h incubation with CAY10441 (10 $\mathrm{nm})$ resulted in strongly reduced cell viability, leading to $90 \%$ cell death in INS1E-control cells (Fig. 5A). In insulin-secreting INS1E-PGIS clones with a high level of overexpression, the CAY10441 toxicity was significantly reduced but remained strong (Fig. 5A). The MTT viability measurements were confirmed in the specific caspase-3 activation measurement, which demonstrated virtually no caspase- 3 activation after a $24-\mathrm{h}$ exposure of insulin-secreting INS1E-control cells to iloprost $(100 \mathrm{nM})$ and, in contrast, a 7-fold induction of caspase-3 activity after incubation with CAY10441 (10 nM) (Fig. 5B). Iloprost did not significantly affect the cell proliferation rate in any of the analyzed clones (Fig. 5C), although it was strongly inhibited by CAY10441 (Fig. 5C). The basal proliferation rate was significantly higher in un-

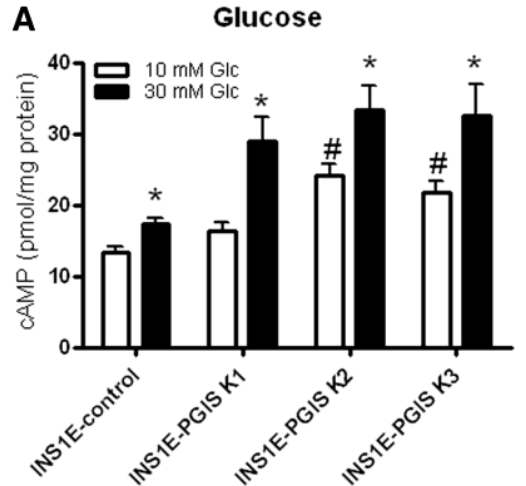

B

lloprost
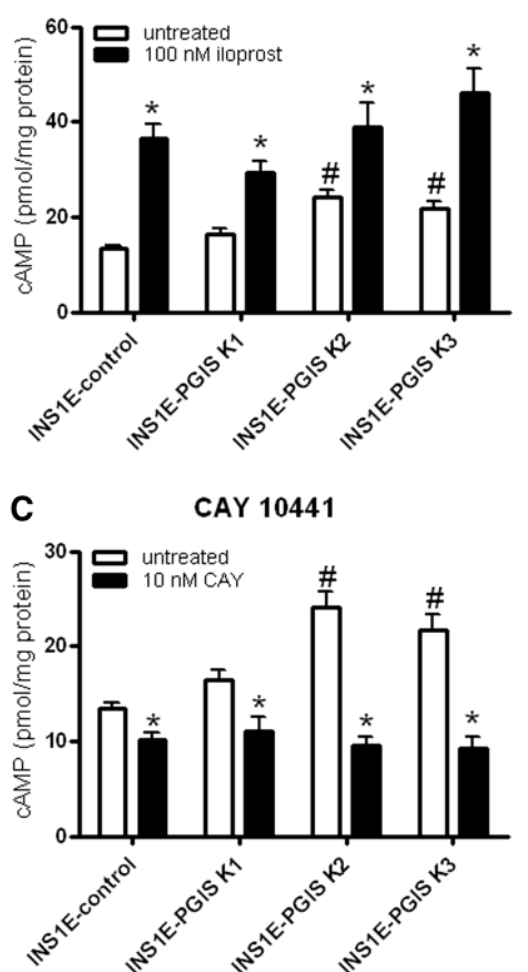

FIG. 4. Effects of PGIS overexpression on CAMP production in insulinsecreting INS1E cells. INS1E insulin-secreting cells were incubated for $24 \mathrm{~h}$ with 10 or $30 \mathrm{~mm}$ glucose, in the absence or presence of $100 \mathrm{~nm}$ iloprost or 10 nM CAY10441, after which intracellular CAMP concentration was measured. A, Ten and $30 \mathrm{~mm}$ glucose in cell culture medium. B, One hundred nanomoles of iloprost with $10 \mathrm{~mm}$ glucose in cell culture medium. C, Ten nanomoles of CAY 10441 with $10 \mathrm{~mm}$ glucose in cell culture medium. Open bars, Untreated in $10 \mathrm{~mm}$ glucose medium; black bars, treated with $30 \mathrm{~mm}$ Glc (A), iloprost (B), or CAY 10441 (C). Data are means from six independent experiments, each performed in triplicate. ${ }^{*}, P<0.05$ vs. untreated; $\#, P<0.05$ vs. control clone treated identically; ANOVA followed by Bonferroni. 
A

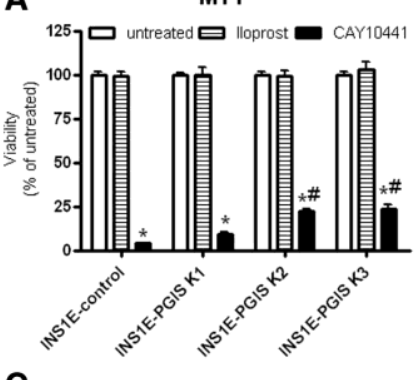

C

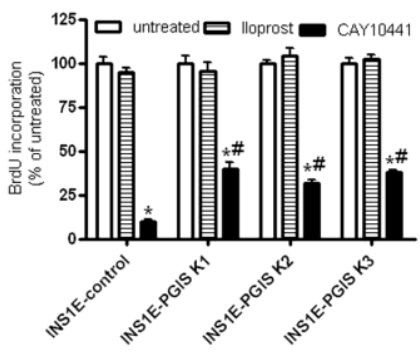

E

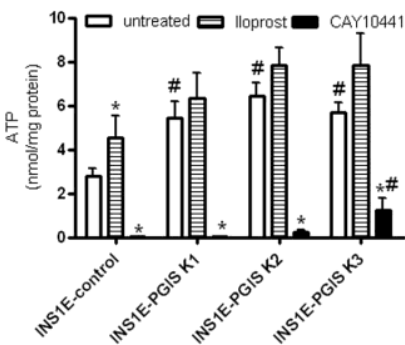

FIG. 5. Effects of PGIS overexpression on cell viability and metabolism in insulin-secreting INS1E cells. INS1E insulin-secreting cells were incubated for $24 \mathrm{~h}$ with $100 \mathrm{~nm}$ iloprost or $10 \mathrm{~nm}$ CAY10441. A, Cell viability, measured by MTT assay. B, Caspase-3 activation in INS1Econtrol cells, estimated by flow cytometry. C, Proliferation rate, measured by BrdU incorporation ELISA. D. Proliferation rate in untreated cell clones, estimated by BrdU ELISA and expressed as a percentage of the proliferation rate in INS1E-control cells. E, ATP content, measured by the ATPlite chemiluminescence assay (PerkinElmer Life Sciences). Open bars, Untreated; striped bars, iloprost; black bars, CAY10441. Data are means from six independent experiments. ${ }^{*}, P<0.05$ vs. untreated; $\#, P<0.05$ vs. control clone treated identically; ANOVA followed by Bonferroni.

treated INS1E-PGIS cell clones than in INS1E-control cells (Fig. 5D). Incubation with iloprost (100 nM) for $24 \mathrm{~h}$ slightly increased intracellular ATP concentrations in INS1E-control and PGIS-overexpressing cell clones (Fig 5E). However, a 24-h exposure to CAY10441 (10 nM) drastically reduced ATP content in all analyzed cell clones (Fig. 5E). INS1E-PGIS cell clones had a significantly higher intracellular ATP concentration than INS1E-control cells (Fig. 5E).

\section{Discussion}

The influence of arachidonic acid metabolites on glucoseinduced insulin secretion and their relevance to diabetes development have been studied over the last 3 decades $(5-10,24-26)$. Until now, most of the published data have been concerned with cyclooxygenase-derived metabolites, mostly E-series and J-series prostaglandins and products of the lipooxygenase pathway $(6-10,26)$. Data suggest that glucose-stimulated prostaglandin biosynthesis may modulate insulin secretion (7). Similarly, the products of the lipooxygenase pathway of arachidonic acid metabolism can reportedly act as modulators of glucose-induced insulin secretion (10). Prostaglandin E2 is a well-known inhibitor of glucose-induced insulin secretion (8), and the inhibition of prostaglandin $\mathrm{E}$ synthesis has been shown to augment glucose-induced insulin secretion (27). Prostaglandin synthesis inhibitors reportedly improve insulin secretion in diabetic patients (28).

In the present study, we observed a very low endogenous level of PGIS expression in rat pancreatic islets and in insulin-secreting cells compared with other tissues. Nevertheless, glucose stimulated PGIS expression in islets. This glucose-mediated prostacyclin formation in islets could possibly additionally, but weakly, potentiate pancreatic $\beta$-cells' response to the glucose stimulus. Our results show also that non- $\beta$-cells serve as a significant source of PGI2 in rat islets exposed to high-glucose concentrations. Although a negative correlation between PGI2 formation and glucose concentration has been shown before in other cell types (29-31), it remains unknown whether prolonged hyperglycemia also dampens PGIS expression and/or activity in islet cells in vivo.

PGIS overexpression specifically potentiated glucoseinduced insulin secretion. This increased glucose responsiveness of the insulin-secreting INS1E-PGIS cell clones was mimicked by the stable prostacyclin analog iloprost in INS1E-control cells, which express virtually no PGIS ( $0.1 \%$ of liver expression). Iloprost acts by activating IP receptors, and upon binding to these receptors, induces the cAMP formation (32). Iloprost also potentiated glucoseinduced insulin secretion in PGIS-overexpressing cells. The enhancement of glucose-induced insulin secretion by higher PGIS expression and by iloprost was accompanied by increased cellular cAMP concentrations. By contrast, experiments with the specific IP receptor antagonist CAY10441, which specifically blocks prostacyclin binding sites on the IP receptor, revealed that the beneficial effects of PGIS overexpression on insulin secretion originated from the action of secreted prostacyclin on IP receptors and led to adenyl cyclase activation and cAMP production. 
cAMP is an established potentiator of glucose-induced insulin secretion (33-38), and the present data demonstrate that the potentiation of insulin secretion in PGISoverexpressing cells also resulted from the strong $\mathrm{CAMP}$ increase in these cells. In pancreatic $\beta$-cells, cAMP exerts its modulatory effects on insulin secretion via PKA-dependent and/or PKA-independent mechanisms (36). Therefore, our study used the competitive PKA inhibitor RpcAMPS. Our results clearly show that the enhancement of glucose-induced insulin secretion in PGIS-overexpressing INS1E cells is not related to the PKA pathway because Rp-cAMPS did not significantly reduce glucose-induced insulin secretion. However, Rp-cAMPS reduced glucoseinduced insulin secretion by $50 \%$ in INS1E-control cells treated with forskolin, which is in agreement with earlier observations (36). As demonstrated recently, the effect of cAMP on glucose-induced insulin secretion is largely mediated by Epac2 (39), which acts via the small GTPase Ras-related protein-1, the regulatory SUR1 subunit of the ATP-sensitive potassium channel K(ATP) as well as via synaptosomal-associated protein 25, Rab3-interacting molecule 2, and Piccolo, which are proteins involved in exocytosis $(34,40-42)$. Indeed, the rate of glucose-induced insulin secretion in PGIS-overexpressing INS1E cells was normalized to the level observed in INS1E-control cells by knockdown of Epac2, clearly proving the crucial role of Epac2 in this process. Epac2 has been reported to mediate cAMP-related recruitment of insulin granules to the plasma membrane, stimulation of granule-granule fusion events together with PKA (43), and intracellular $\mathrm{Ca}^{2+}$ mobilization (44). In our experiments we observed a small tendency for reduction of glucose-induced insulin secretion in INS1E-control cells with a knock-down of Epac2. This is in line with the observed small increase of cAMP production by glucose in INS1E-control cells, which is in line with the weak involvement of the Epac2 pathway in GSIS in these cells in the absence of a potent source of CAMP. On the other hand, in experiments with forskolin, a potent inducer of cAMP formation, the knock-down of Epac2 strongly inhibited forskolin-potentiated glucose-induced insulin secretion in INS1E-control cells. Thus, the prostacyclin-mediated enhancement of glucose-induced insulin secretion in INS1E-PGIS cells can be assigned to the cAMP-dependent and PKA-independent activation of the Epac2 pathway, probably by stimulation of insulin granule priming and exocytosis together with a parallel increase in insulin biosynthesis.

PGIS overexpression also increased insulin content. Iloprost mimicked the effect of PGIS overexpression, albeit somewhat less than in the clones with high PGIS overexpression. In contrast, the IP receptor antagonist CAY10441 reduced insulin content. These data suggest that PGIS overexpression may modulate insulin transcription and/or translation [e.g. via cAMP responsive binding elements at the insulin gene promoter]. Indeed, Ins 2 gene expression correlated with the magnitude of PGIS overexpression. PGIS overexpression, which has been shown in insulin-producing RINm5F cells to protect against cytokine-induced (ER) stress (21), may also promote ER function and thereby improve insulin biosynthesis. Indeed, increased expression of one of the most important ER chaperones, Bip, provided evidence of significantly better ER function in PGIS-overexpressing INS1E cells. Similarly, increased Bitp expression in insulin-secreting cells has been observed with glucagon-like peptide- 1 agonists (45), which also act by inducing CAMP production.

Pancreatic $\beta$-cells possess a very well-developed ER (46), which is necessary for the proper synthesis and processing of insulin. ER homeostasis is disturbed by inflammatory processes in many pathologicalconditions, including obesity and diabetes (47). The protective effect of PGIS overexpression, along with the generation of the antiinflammatory eicosanoid prostacyclin, is in keeping with this information.

In addition to the potentiation of insulin secretion and increased cAMP formation, PGIS overexpression increased the ATP content and proliferation of INS1E-PGIS cells. Iloprost mimicked the effects of PGIS overexpression. This finding is in agreement with earlier observations describing increased $\beta$-cell replication after cAMP elevation (48), documenting an improved cell proliferative capacity in cells that overexpress PGIS $(21,49)$. It has been proposed that $\mathrm{AMP}$ may induce the activation of protein kinase $\mathrm{B}$, which in turn leads to a prosurvival response [e.g. inhibition of the proapoptotic Bcl-2 antagonist of cell death proteins or acceleration of cell proliferation $(50$, 51)]. Thus, insulin secretory capacity was increased by a prostacyclin-induced rise in CAMP concentration and decreased by the reduction of CAMP by the IP receptor antagonist CAY10441. PGIS overexpression, which increases cAMP content, counteracted CAY10441-induced toxicity. The observed reduction of the toxic effect of CAY10441 might also be a result of the action of the residual intracellular prostacyclin, which may induce antiapoptotic and suppress proapoptotic pathways within the cell of origin without being released and activating its extracellular receptors.

These results document the cytoprotective role of PGIS. It has been shown before that insulin-producing RINm5F cells that overexpress PGIS exhibit a significantly higher rate of glucose oxidation than control cells (21). This finding may explain the increased ATP content in PGIS-overexpressing INS1E cells. 
Insulin secretion is ATP dependent, and ATP acts as a coupling factor in the signaling pathway of glucose-induced insulin secretion in the pancreatic $\beta$-cells. ATP reduction accompanies decreased glucose-induced insulin secretion and biosynthesis (52). ATP is required for glucose-induced insulin secretion; it is needed to block ATP. sensitive $\mathrm{K}^{+}$channels (53), to foster the movement and processing of insulin secretory granules, and to prime the secretory granules for exocytosis $(54,55)$. The increased ATP content also enhances exocytosis in INS1E-PGIS cells by supporting CAMP generation to potentiate glucose-induced insulin secretion.

In conclusion, prostacyclin is a powerful potentiator of glucose-induced insulin secretion, and it improves secretory function by inducing insulin biosynthesis and probably by stimulating exocytosis. Thus, in addition to providing protection to insulin-secreting cells (21), increased PGIS expression may also strengthen physiological insulin secretory responsiveness to glucose.

Prostacyclin enrichment of insulin-secreting cells may represent an attractive strategy to maintain the insulin secretory responsiveness of $\beta$-cells, for example, during and after pancreatic islet transplantation. lloprost, a stable prostacyclin analog, can mimic the effects of prostacyclin overexpression through the same mechanism and therefore may also be able to preserve $\beta$-cell function, improving both glucose-induced insulin biosynthesis and secretion. Because stable prostacyclin analogs have been used as safe drugs for treatment of other diseases in man [e.g. hypertension (56)] and showed promising antidiabetic features in the rat model of type 2 diabetes mellitus (16) our findings may open new therapeutical perspectives for the treatment of diabetes. Stable prostacyclin analogs may represent a class of chemical compounds with an interesting antidiabetic potential.

\section{Acknowledgments}

We are grateful to Professor Rolf Müller (Marburg, Germany) for the pcDNA3.1(+)-hPGIS vector and to Professor Claes Wollheim (Geneva, Switzerland) for insulin-secreting INS1E cells. The excellent technical assistance of C. Heinrichs, M. Funck, J Kresse, and M. Wirth is gratefully acknowledged.

Address all correspondence and requests for reprints to: Dr. Ewa Gurgul-Convey, Institute of Clinical Biochemistry, Hannover Medical School, D-30623 Hannover, Germany. E-mail: gurgul-convey.ewa@mh-hannover.de.

This work was supported by grants from the Foundation "Das Zuckerkranke Kind" in the German Diabetes Foundation, and the European Union (STREP SaveBeta LSHM-CT-2006.
036903, FP6, and the Collaborative Project NAIMIT, Grant 241447, FP7).

Disclosure Summary: The authors have nothing to disclose.

\section{References}

1. McDaniel ML, Kwon G, Hill JR, Marshall CA, Corbett JA 1996 Cytokines and nitric oxide in islet inflammation and diabetes. Proc Soc Exp Biol Med 211:24-32

2. Wellen KE, Hotamisligil GS 2005 Inflammation, stress, and diabetes. J Clin Invest 115:1111-1119

3. Corbett JA, Kwon G, Turk J, McDaniel ML 1993 IL-1 $\beta$ induces the coexpression of both nitric oxide synthase and cyclooxygenase by islets of Langerhans: activation of cyclooxygenase by nitric oxide. Biochemistry 32:13767-13770

4. Tran PO, Gleason CE, Robertson RP 2002 Inhibition of interleukin1 beta-induced COX-2 and EP3 gene expression by sodium salicylate enhances pancreatic islet $\beta$-cell function. Diabetes 51:1772-1778

5. Robertson RP 1986 Arachidonic acid metabolite regulation of insulin secretion. Diabetes Metab Rey 2:261-296

6. Robertson RP 1988 Eicosanoids as pluripotential modulators of pancreatic islet function. Diabetes 37:367-370

7. Kelly KL, Laychock SG 1984 Activity of prostaglandin biosynthetic pathways in rat pancreatic islets. Prostaglandins 27:925-938

8. Robertson RP, Tsai P, Little SA, Zhang HJ, Walseth TF $1987 \mathrm{Re}-$ ceptor-mediated adenylate cyclase-coupled mechanism for PGE2 inhibition of insulin secretion in HIT cells. Diabetes 36:1047-1053

9. Metz SA, Fujimoto WY, Robertson RP 1984 Oxygenation products of arachidonic acid: third messengers for insulin release. J Allergy Clin Immunol 74:391-402

10. Metz S, VanRollins M, Strife R, Fujimoto W, Robertson RP 1983 Lipoxygenase pathway in islet endocrine cells. Oxidative metabolism of arachidonic acid promotes insulin release. J Clin Invest 71 : $1191-1205$

11. Landgraf R, Landgraf-Leurs MM 1979 The prostaglandins system and insulin release. Studies with the isolated perfused rat pancreas. Prostaglandins 17:599-613

12. Haeggström JZ, Rinaldo-Matthis A, Wheelock CE, Wetterholm A 2010 Advances in eicosanoid research, novel therapeutic implications. Biochem Biophys Res Commun 396:135-139

13. Wu KK, Liou JY 2005 Cellular and molecular biology of prostacyclin synthase. Biochem Biophys Res Commun 338:45-52

14. Arita $S$, Une $S$, Ohtsuka $S$, Kawahara $T$, Kasraie A, Smith CV, Mullen Y 2001 Increased islet viability by addition of beraprost sodium to collagenase solution. Pancreas 23:62-67

15. Sieradzki J, Wolan H, Szczeklik A 1984 Effects of prostacyclin and its stable analog, iloprost, upon insulin secretion in isolated pancreatic islets. Prostaglandins 28.289-296

16. Sato N, Kaneko M, Tamura M, Kurumatani H 2010 The prostacyclin analog beraprost sodium ameliorates characteristics of metabolic syndrome in obese Zucker (fatty) rats. Diabetes 59:10921100

17. Patrono C, Pugliese F, Ciabattoni G, Di Blasi S, Pierucci A, Cinotti GA, Maseri A, Chierchia S 1981 Prostacyclin does not affect insulin secretion in humans. Prostaglandins 21:379-385

18. Ximenes HM, Lortz S, Jörns A, Lenzen S 2007 Trïiodothyronine (T3)-mediated toxicity and induction of apoptosis in insulin-producing INS-1 cells. Life Sci 80:2045-2050

19. Mosmann T 1983 Rapid colorimetric assay for cellular growth and survival: application to proliferation and cytotoxicity assays. J Immunol Methods 65:55-63

20. Gurgul E, LortzS, Tiedge M, Jörns A, Lenzen S 2004 Mitochondrial catalase overexpression protects insulin-producing cells against tox- 
icity of reactive oxygen species and proinflammatory cytokines. Diabetes 53:2271-2280

21. Gurgul-Convey E, Lenzen S 2010 Protection against cytokine toxicity through endoplasmic reticulum and mitochondrial stress prevention by prostacyclin syn thase overexpression in insulin-producing cells. J Biol Chem 285:11121-11128

22. Tiedge M, Höhne M, Lenzen S 1993 Insulin secretion, insulin content and glucose phosphorylation in R N $5 \mathrm{~F}$ in su linoma cells after transfection with human GLUT2 glucose-transporter cDNA. Biochem J 296:113-118

23. Baltrusch S, Langer S, Massa L, Tiedge M, Lenzen S 2006 Improved metabolic stimulus for glucose-induced insulin secretion through $G K$ and PFK-2/FBPase-2 coexpression in insulin-producing RINmSF cells. Endocrinology 147:5768--5776

24. Robertson RP 1995 Molecular regulation of prostaglandin synthesis: implications for endocrine systems. Trends Endocrinol Metab 6:293-297

25. Robertson RP 1998 Dominance of cyclooxygenase- 2 in the regulation of pancreatic islet prostaglan din synthesis. Diabetes 47:13791383

26. Kelly KL, Laychock SG 1981 Prostaglandin synthesis and metabolism in isolated pancreatic islets of the rat. Prostaglandins 21:759769

27. Metz SA, Robertson RP, Fujimoto WY 1981 Inhibition of prostaglandin E synthesis augments glucose-induced insulin secretion is cultured pancreas. Diabetes 30:551-557

28. Robertson RP, Chen M, McRae JR, Metz SA 1979 Improvement of insulin secretion in diabetics by a prostaglandin syn thesis inhibitor. Adv Exp Med Biol 119:227-231

29. Gerrard JM, Stuart MJ, Rao GH, Steffes MW, Mauer SM, Brown DM, White JG 1980 Alteration in the balance of prostaglandin and thromboxane sunthesis in diabetic rats. JLab Clin Med 95:950 -..958

30. Giacco F, Brownlee $M 2010$ Oxidative stress and diabetic complications. Circ Res 107:1058-1070

31. Nie H, Wu JL, Zhang M, Xu J, Zou MH 2006 Endothelial nitric oxide synthase-dependent tyrosine nitration of prostacyclin synthase in diabetes in vivo. Diabetes 55:3133-3141

32. Sprague RS, Bowles EA, Hanson MS, DuFaux EA, Sridharan M, Adderley S, Ellsworth ML, Stephenson AH 2008 Prostacyclin analogs stimulate receptor-mediated CAMP synthesis and ATP release from rabbit and human erythrocytes. Microcirculation 15:461-471

33. MacDonald PE, Obermüller S, Vikman ], Galvanovskis I, Rorsman P, Eliasson L 2005 Regulated exocytosis and kiss-and-run of synaptic-like microvesicles in INS-1 and primary rat $\beta$-cells. Diabetes aptic-like micos $736-743$

34. Eliasson L, MaX, Renström E, Barg S, Berggren PO, Galvanovskis J, Gromada J, Jing X, Lundquist I, Salehi A, Sewing S, Rorsman P 2003 SUR1 regulates PKA-independent cAMP-induced granule priming in mouse pancreatic is-cells. J Gen Physiol 121:181-197

35. Gromada J, Ding WG, Barg S, Renström E, Rorsman P $1997 \mathrm{Mul}$ tisite regulation of insulin secretion by CAMP-increasing agonists: evidence that glucagon-like peptide 1 and glucagon act via distinet receptors. Pflugers Arch 434:515-524

36. Renström E, Eliasson L, Rorsman P 1997 Protein kinase A-dependent and -independent stimulation of exocytosis by cAMP in mouse pancreatic $\beta$-cells. J Physiol 502:105-118

37. Ammälä C, Ashcroft FM, Rorsman P 1993 Calcium-independent potentiation of in sulin release by cyclic AMP in single $\beta$-cells. Nature $363: 356-358$

38. Hanna ST, Pigeau GM, Galvanovskis I, Clark A, Rorsman P, MacDonald PE 2009 Kiss-and-run exocytosis and fusion pores of secretory vesicles in human $\beta$-cells. Pflugers Arch 457:1343-1350

39. Idevall-Hagren O, Barg S, Gylfe E, Tengholm A 2010 cAMP mediators of pulsatile insulin secretion from glucose-stimulated single B-cells. J Biol Chem 285:23007-23018
40. Fuịmoto K, Shibasaki T, Yokoi N, Kashima Y, Matsumoto $M$, Sasaki T, Tajima N, Iwanaga T, Seino S 2002 Piccolo, a Ca2+ sensor in pancreatic $\beta$-cells. Involvement of CAMP-GEFII. Rim2. Piccolo complex in cAMP-dependent exocytosis. J Biol Chem 277 50497-50502

41. Shibasaki 'T', Takahashi H, Miki T, Sunaga Y, Matsumura K, Yamanaka $M$, Zhang C, Tamamoto A, Satoh T, Miyazaki J, Seino S 2007 Essential role of Epac $2 / \mathrm{Rap} 1$ signaling in regulation of in sulin granule dynamics by cAMP. Proc Natl Acad Sci USA 104:1933319338

42. Vikman J, Svensson H, Huang YC, Kang Y, Andersson SA, Gaisano HY, Eliasson L 2009 Truncation of SNAP-25 reduces the stimulatory action of cAMP on rapid exocy tosis in insulin-secreting cells. Am J Physiol Endocrinol Metab 297:E4 52-E461

43. Kwan EP, Gao X, Leung YM, Gaisano HY 2007 Activation of ex change protein directly activated by cyclic adenosine monophosphate and protein kinase A regulate common and distinct steps in promoting plasma membrane exocytic and granule-to-granule fusions in rat islet $\beta$ cells. Pancreas $35: e 45-e 54$

44. Dzhura I, Chepurny OG, Kelley GG, Leech CA, Roe MW, Dzhura E, Afshari P, Maliks, Rindler MI Xu X, I Y SmrckaAV HolzGG 2010 Epac2-dependent mobilization of intracellular Ca2 + by glucagon-like peptide-1 receptor agonist exendin 4 is disrupted in $\beta$-cells of phospholipase C- $\epsilon$ knockout mice. J Physiol $588: 4871-$ 4889

45. Cunha DA, Ladrière L, Ortis F, Igoillo-Esteve M, Gurzoy EN, Lup R, Marchetti P, Eizirik DL, Cnop M 2009 Glucagon-like peptide-1 agonists protect pancreatic $\beta$-cells from lipotoxic endoplasmic reticulum stress through upregulation of BiP and JunB. Diabetes 58 2851-2862

46. Eizirik DL, Cnop M 2010 ER stress in pancreatic $\beta$ cells: the thin red line between adaptation and failure. Sci Signal 3:pe 7

47. Hotamisligil GS 2010 Endoplasmic reticulum stress and the inflammatory basis of metabolic disease. Cell 140:900-917

48. Rabinovitch A, Blondel B, Murray T, Mintz DH 1980 Cyclic aden osine- $3^{\prime}, 5^{\prime}$-monophosphate stimulates islet Beell replication in neonatal rat pancreatic monolayer cultures. I Clin Invest 66:1065-107

49. Kunugiza Y, Tomita N, Taniyama Y, Tomita T, Osako MK, Tamai K, Tanabe T', Kaneda Y, Yoshikawa H, Morishita R 2006 Acceleration of wound healing by combined gene transfer of hepatocyte growth factor and prostacyclin syn thase with Shima Jet. Gene Ther apy $13: 1143-1152$

50. Dalle S, Quoyer J, Varin E, Costes S 2011 Roles and regulation of the transcription factor $C R E B$ in pancreatic $\beta$-cells. Curr Mol Pharmacol 4:187-195

51. Lizcano JM, Morrice N, Cohen P 2000 Regulation of BAD by cAMP-dependent protein kinase is mediated via phosphorylation of a novel site, Ser155. Biochem J 349:547-.557

52. Ashcroft SJ, Weerasinghe LC, Randle PJ 1973 Interrelationship of islet metabolism, adenosine triphosphate content and insulin re lease. Biochem J 132:223--231

53. MeTaggart JS, Clark RH, Ashcroft FM 2010 The role of the KATP channel in glucose homeostasis in health and disease: more than meets the islet. J Physiol 588:3201-3209

54. Lang J 1999 Molecular mechanisms and regulation of insulin exocytosis as a paradigm of endacrine secretion. Eur J Biochem 259 : 3-17

55. Eliasson L, Renström E, Ding WG, Proks P, Rorsman P 1997 Rapid ATP-dependent priming of secretory granules precedes $\mathrm{Ca}(2+)$-induced exocytosis in mouse pancreatic B-cells. J Physiol 503:399 412

56. Otsuki M, Goya K, Kasayama S 2005 Vascular endothelium as a target of beraprost sodium and fenofibrate for antiatherosclerotic therapy in type 2 diabetes mellitus. Vase Health Risk Manag 1:209 215 


\section{Author's personal copy}

Nitric Oxide 27 (2012) 235-241

\section{Is there a role for neuronal nitric oxide synthase (nNOS) in cytokine toxicity to pancreatic beta cells?}

Ewa Gurgul-Convey*, Katarzyna Hanzelka, Sigurd Lenzen

Institute of Clinical Biochemistry, Hannover Medical School, Hannover, Germany

\section{A R T I C L E I N F O}

\section{Article history:}

Received 11 April 2012

Revised 17 July 2012

Available online 14 August 2012

\section{Keywords:}

Cytokines

Cytokines
Diabetes

Insulin-secreting cells

Islets

nNOS

iNOS

\section{Introduction}

Nitric oxide (NO) is a free radical, produced in many cell types under physiological conditions in low concentrations from L-arginine by a constitutive NO synthase and acting as an important signalling molecule $[1,2]$. There are three genetically different isoforms of NO synthase which can account for NO production. They comprise neuronal NO synthase (nNOS), inducible NO synthase (iNOS) and endothelial NO synthase (eNOS) [1]. Two isoforms, nNOS and eNOS, are expressed constitutively, nNOS preferentially in the brain and eNOS in the endothelium [1]. The activity of both of these isoforms is regulated by intracellular calcium concentration changes [1]. The expression of the iNOS isoform is induced by different cytokines and endotoxin, and is fully activated at basal calcium concentration [1].

Abbreviations: HEPES, 4-(2-hydroxyethyl)-piperazine-1-ethanesulfonic acid; IFN $\gamma$, interferon gamma; iNOS, inducible nitric oxide synthase; IL-1 $\beta$, interleukin 1 beta; eNOS, endothelial nitric oxide synthase; ER, endoplasmic reticulum; nNOS, neuronal nitric oxide synthase; NO, nitric oxide; TNF- $\alpha$, tumor necrosis factor alpha. * Corresponding author. Address: Institute of Clinical Biochemistry, Hannover Medical School, Carl-Neuberg-Str. 1, 30625 Hannover, Germany. Fax: +49 5115323584

E-mail address: Gurgul-Convey.Ewa@mh-hannover.de (E. Gurgul-Convey).

1089-8603/\$ - see front matter $\odot 2012$ Elsevier Inc. All rights reserved. http://dx doi.org/10.1016/jniox 2012.08.075
The neuronal isoform is the predominant source of NO in neurons, but it is also expressed in skeletal muscle, heart and smooth muscle, where NO controls blood flow and muscle contractility [1] The nNOS enzyme is localized in the cytoplasmic, mitochondrial or nuclear compartment of the cell, displaying diverse intracellula functions depending on its localization [1]. The activity of nNOS can be modulated on different levels, e.g. by calmodulin binding. dimerization, protein-protein interactions or phosphorylation [1].

Reactive oxygen and nitrogen species can impair the function of a variety of biomolecules and lead to dysfunction of cellular organelles, thereby causing various disorders [3-7]. The cytokine-mediated iNOS induction together with an excessive NO generation in pancreatic beta cells is a crucial element of cytokine toxicity during type 1 diabetes development $[4,7,8]$. In insulin-secreting cells $\mathrm{NO}$ is a partner molecule for two important chemical reactions occurring during exposure to proinflammatory cytokines and yielding toxic end products. On the one hand, NO can react with superoxide radicals resulting in production of peroxynitrite [7]. On the other hand, the reaction between $\mathrm{NO}$ and hydrogen peroxide in the presence of trace metals forms hydroxyl radicals [7]. Although both reactions take place in pancreatic beta cells exposed to cytokines, only the latter one is responsible for cytokine-induced beta cell destruction and death [7]. Moreover, NO is also involved in 


\section{Author's personal copy}

cytokine-induced ER stress in insulin-secreting cells $[8,9]$ and the inhibition of insulin secretion [10-12].

Pancreatic beta cells express the neuronal, constitutive isoform of NOS (nNOS) [13]. It resides mainly in secretory granules and has been shown to modulate insulin secretion [13]. Recently Bachar et al. [14] proposed that nNOS may protect pancreatic beta cells from glucolipotoxicity-induced ER stress and apoptosis. Because the influence of cytokines on nNOS expression in insulin-secreting cells remains unknown, the aim of this study was to analyze the effects of IL- $1 \beta$, TNF- $\alpha$ and IFN $\gamma$ on nNOS.

\section{Materials and methods}

Cell culture and cytokine incubation

Insulin-secreting INS1E cells were cultured as described $[15,16]$. Concentrations for $24 \mathrm{~h}$ incubation with cytokines (all from Promokine, Heidelberg, Germany) were: $60 \mathrm{U} / \mathrm{ml}$ of $\mathrm{IL}-1 \beta(4.4 \mathrm{ng} / \mathrm{ml})$; $600 \mathrm{U} / \mathrm{ml}$ of IL-1 $\beta(44 \mathrm{ng} / \mathrm{ml}), 185 \mathrm{U} / \mathrm{ml}$ of TNF- $\alpha(8.7 \mathrm{ng} / \mathrm{ml})$; $1850 \mathrm{U} / \mathrm{ml}$ of TNF- $\alpha(87 \mathrm{ng} / \mathrm{ml}) ; 14 \mathrm{U} / \mathrm{ml}$ of IFN $\gamma(10.3 \mathrm{ng} / \mathrm{ml})$; $140 \mathrm{U} / \mathrm{ml}$ of IFN $\gamma(103 \mathrm{ng} / \mathrm{ml})$. All chemicals used in this study were from Sigma.

Rat tissue isolation and treatment

Pancreatic islets and other tissues were isolated from 250 to $300 \mathrm{~g}$ adult male Lewis rats ( $70-80$ days old). Islets were isolated by collagenase digestion and handpicked under a stereo microscope. Isolated islets were cultured overnight in RPMI-1640 medium containing $5 \mathrm{mmol} / \mathrm{l}$ glucose, $10 \% \mathrm{FCS}$, penicillin, and streptomycin at $37{ }^{\circ} \mathrm{C}$ in a humidified atmosphere of $5 \% \mathrm{CO}_{2}$ as described before [17]. The islets were then treated with $600 \mathrm{U} / \mathrm{ml} \mathrm{IL-}$ $1 \beta$ or a mixture of the three proinflammatory cytokines for $24 \mathrm{~h}$ following RNA extraction.

RNA isolation, CDNA preparation and real-time PCR

RNA isolation, cDNA production and quantitative real-time PCR measurements were performed as described [9]. The primers used in this study are shown in Table 1 . Data were normalized to $\beta$-actin. The primers were designed to detect the following sequences: eNOS 73-241 bp (containing the Aval restriction site), iNOS 11011192 bp (containing the Ncol restriction site) and nNOS 375506 bp (no restriction sites). Restriction analysis was performed using the Aval and the Ncol restriction enzymes (Fermentas) according to the manufacturer's protocol. DNA electrophoresis was done in $1 \%$ agarose gels.

iNOS and nNOS Western blot analyses

INS1E cells were incubated for $24 \mathrm{~h}$ with cytokines, washed with ice-cold PBS and homogenized using short bursts (Braun-Sonic 125 Homogenisator, Quigley-Rochester, Inc., Rochester, NY, USA). Protein content was determined by the BCA assay (Pierce, Rockford, IL, USA). $40 \mu \mathrm{g}$ of total protein was resolved in SDS poly-

Table 1

Primer sequences for quantitative real-time PCR.

\begin{tabular}{lll}
\hline Gene & Forward primer & Reverse primer \\
\hline Rat eNOS & CTAGGGCTATGCGGCAAGCA & TGATGCTGCCCACTTCCAG \\
Rat iNOS & TCGTACTTGGGATGCTCCATGG & TCCTGCAGGCTCACGGTCAA \\
Rat nNOS & CACGTGGTCCTCATTCTGAG & CAGATCGACGGCTTTGGT
\end{tabular}

\begin{tabular}{lll} 
Rat nNOS & CACGTGGTCCTCATTCTGAG & CAGATCGACGGCTTTGGT \\
Rat $\beta$-actin & GAACACGGCATTGTAACCAACTGG & GGCCACACGCAGCTCATTGTA \\
\hline
\end{tabular} acrylamide gel electrophoresis and then electroblotted onto membranes. Immunodetection was performed using specific primary antibodies against nNOS (catalog number 4234, Cell Signalling; overnight incubation), iNOS (sc-650, overnight incubation) or $\beta$ actin (sc-1619, 2 h incubation) (both from Santa Cruz Biotechnology, Heidelberg, Germany) followed by exposure to secondary peroxidase-conjugated AffiniPure antibodies (Dianova, Hamburg, Germany). The immunoreactive bands were visualized through chemiluminescence using the ECL detection system and the INTAS ${ }^{R}$ chemiluminescence detection system (Intas Science Imaging Instruments $\mathrm{GmbH}$, Göttingen, Germany).

Insulin secretion and content

Insulin secretion and content in insulin-secreting INS1E cells were measured by radioimmunoassay (RIA) [18]. Cells were seeded at a density of 350,000 cells/well onto 6 -well plates 2 days before the addition of cytokines. A 24-h incubation with cytokines was followed by a 1-h incubation without glucose and a 2-h stimulation with $10 \mathrm{mM}$ glucose. Thereafter, samples were collected for RIA. Insulin values were normalized to the DNA content of the incubated cells.

Immunofluorescence

For immunofluorescence staining INS1E cells were seeded onto collagen-coated glass slides and incubated for $24 \mathrm{~h}$ with a cytokine mixture as described above following an overnight fixation with $4 \%$ paraformaldehyde in PBS. After fixation cells were washed three times with PBS for $5 \mathrm{~min}$. After a $20 \mathrm{~min}$ blocking in PBS with $0.1 \%$ Triton X-100 and $1 \%$ bovine serum albumin (BSA) at room temperature the cells were washed again as above. The slides were incubated with primary antibodies diluted in PBS with $0.1 \%$ Triton $\mathrm{X}-100$ and $0.1 \% \mathrm{BSA}$ at room temperature for $1 \mathrm{~h}$ (rabbit polyclonal anti-nNOS 1:200 (catalog number 4234, Cell Signalling), or guinea pig polyclonal anti-insulin 1:100 (catalog number AB7842, Abcam, Cambridge, UK)) and then washed three times with PBS. The cells were incubated with secondary antibodies (FITC-conjugated antirabbit IgG $1: 200$, or Texas red-conjugated anti-guinea pig IgG $1: 200$ ) for $1 \mathrm{~h}$ at room temperature (all from Dianova, Hamburg, Germany). For nuclear counterstaining, $300 \mathrm{nM}$ 4-6-diamidino-2phenylindole (DAPI) was used for $5 \mathrm{~min}$ at room temperature. Slides were thereafter mounted with Mowiol (Merck, Darmstadt, Germany) plus 0.6\% Dabco (St. Louis, MO, USA). Images were captured $\left(60 \times\right.$ oil objective) and analyzed using a Cell ${ }^{R} /$ Olympus IX81 inverted microscope system (Olympus, Hamburg, Germany).

Data analysis

Analyses of the real-time RT-PCR data were performed using the Opticon Monitor v. 1.07 software (MJ Research Inc., Waltham, MA, USA). All data are expressed as means \pm SEM. Statistical analyses for each group were performed using the Prism analysis program (Graphpad, San Diego, CA, USA), the Kruskal-Wallis nonparametric test was employed. $P$ values $<0.05$ were considered statistically significant.

\section{Results}

eNOS, iNOS and nNOS transcript expression

To assess the gene expression levels of different NOS isoforms in insulin-secreting INS1E cells and rat islets specific primers for each gene were designed. The specificity of the primers was assured by a choice of sequences of the lowest identity between isoforms 


\section{Author's personal copy}

A

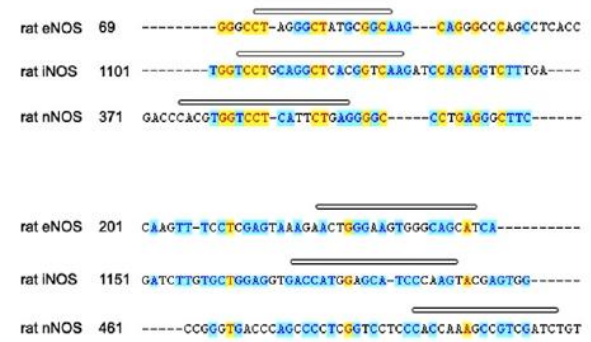

B Melting curve analysis of real-time PCR products

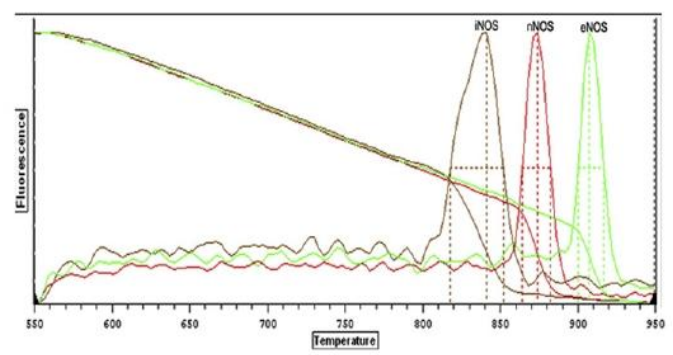

C Gel electrophoresis of real-time PCR end products

D

Restriction analysis of real-time PCR products
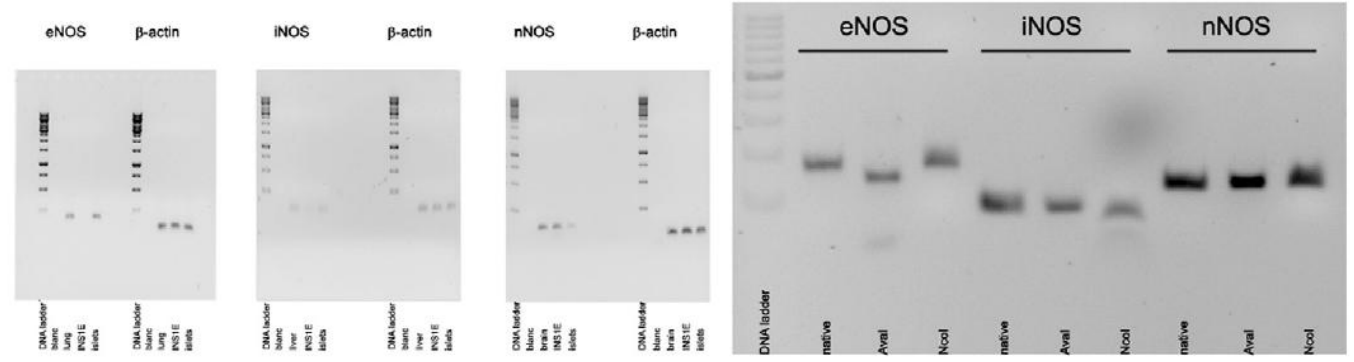

Fig. 1. The analysis of the specificity of real-time PCR primers used for the detection of different NOS isoform-coding transcripts. (A) Alignment of partial mRNA sequences of transcripts encoding three isoforms of NOS proteins. For each sequence a pair of primers was chosen for real-time PCR studies: (B) melting curve analysis of three primer sets: (C) DNA gel electrophoresis of real-time PCR end products for all three pairs of designed primers (after 40 cycles); (D) restriction analysis of real-time PCR end products of

(Fig. 1A). The analysis of melting curves as well as the end products of real-time PCR reactions for each primer set clearly showed a specific product formation (Fig. 1B-D). The appearance of specific products was also confirmed using positive controls (for eNOS: rat lung, for nNOS: rat brain, Fig. 1C). Noteworthy the restriction analysis of the real-time PCR products for each primer set revealed the specificity of the primers used (Fig. 1D).

Quantitative real-time PCR analysis of gene expression of eNOS, iNOS and nNOS in insulin-secreting INS1E cells revealed a significant nNOS expression, similar to that found in rat brain, and no expression of the two other isoforms. In contrast to INS1E cells pancreatic islets expressed the eNOS isoform (Fig. 1C). None of the used cytokines induced eNOS transcription in INS1E cells (data not shown). Transcription of iNOS, however, was dramatically increased upon exposure to IL-1 $\beta$ (both by $60 \mathrm{U} / \mathrm{ml}$ as well as by $600 \mathrm{U} / \mathrm{ml}$ ) and its combinations with TNF- $\alpha$ and/or IFN $\gamma$ (Fig. 2A), and only marginally affected by TNF- $\alpha$ or IFN $\gamma$ alone (Fig. 2A), confirming earlier observations [9]. In contrast, IL-1 $\beta$ influenced nNOS transcription only mildly (Fig. $2 \mathrm{~B}$ ), whereas there was no effect at all by TNF- $\alpha$ or IFN $\gamma$ alone (Fig. 2B). Interestingly, the combinations of IL- $1 \beta$ with the two other proinflammatory cytokines decreased the nNOS expression (Fig. 2B). The inhibitory effect on the nNOS transcription was especially strong in the case of a mixture of IL$1 \beta+$ TNF- $\alpha+\operatorname{IFN} \gamma$ (Fig. 2B).

eNOS, iNOS and nNOS protein expression

No basal or induced eNOS protein expression was detected in INS1E cells (data not shown). iNOS protein expression was not detectable in untreated insulin-secreting INS1E cells. An
IL-1 $\beta$-dependent pattern of iNOS expression similar to the gene expression was observed on the protein level (Fig. 3A). High concentrations of TNF- $\alpha(1850 \mathrm{U} / \mathrm{ml})$ as well as of IFN $\gamma(140 \mathrm{U} / \mathrm{ml})$ alone were ineffective with respect to iNOS induction (Fig. $3 \mathrm{~A}$ ) in the same way as the 10 times lower concentrations of the two proinflammatory cytokines (data not shown). The densitometric analysis of the blots revealed a 5 -fold induction of iNOS protein by $60 \mathrm{U} / \mathrm{ml} \mathrm{IL-1 \beta}$ and a 6 -fold induction by $600 \mathrm{U} / \mathrm{ml} \mathrm{IL-} 1 \beta$ (Fig. 3A). No significant additive effects of the other two tested proinflammatory cytokines TNF- $\alpha$ or IFN $\gamma$ were observed. The incubation with a mixture of all three cytokines led to a massive 12 -fold increase in iNOS protein expression (Fig. 3A). TNF- $\alpha$ as well as IFN $\gamma$ alone did not induce iNOS protein expression, what suggests that the observed weak iNOS gene transcription led to a weak translation providing extremely low levels of iNOS protein. INS1E cells expressed the nNOS protein as shown in Fig. 3B. The nNOS protein expression was decreased in the same fashion as on the transcriptional level, however to a lesser extent (Fig. 3B). The mixture of the three proinflammatory cytokines IL- $1 \beta$, TNF- $\alpha$ and IFN $\gamma$ caused a significant, nearly $50 \%$ reduction of nNOS protein expression as determined by quantitative densitometric analysis (Fig. 3B) and confirmed by immunofluorescence staining (Fig. 4).

Thus, the translation fashion of eNOS, iNOS and nNOS proteins correlates very well with the transcription pattern of the respective genes.

nNOS expression in rat islets

The expression level of nNOS in rat islets was lower than in INS1E cells (Fig. 1C) in line with earlier studies [13]. Exposure to 


\section{Author's personal copy}
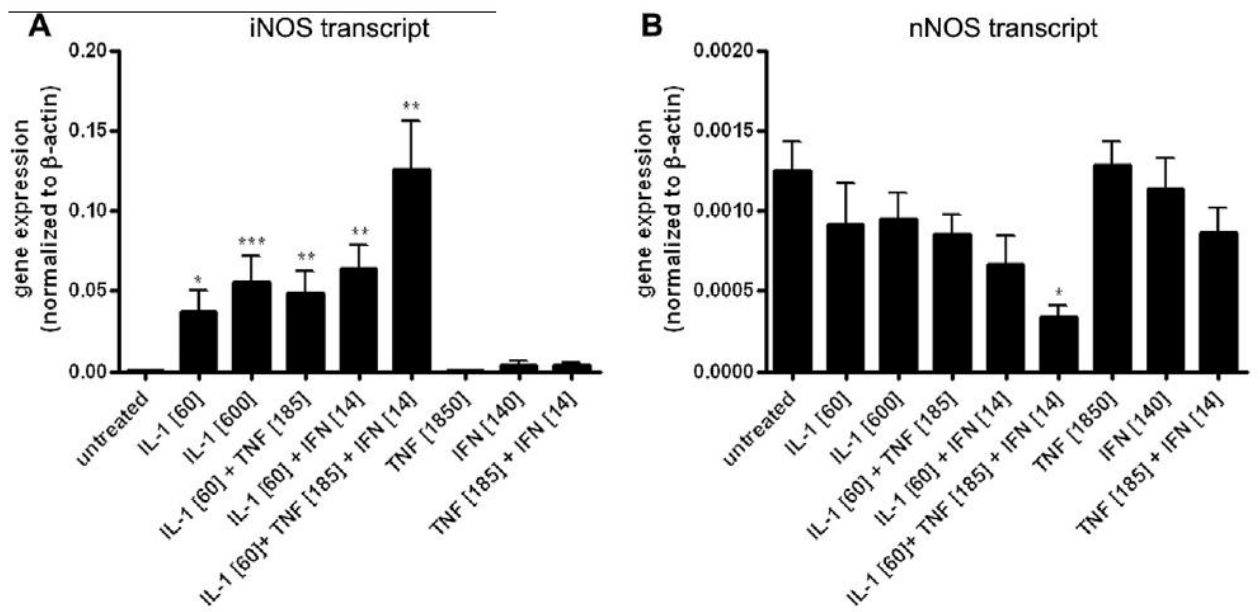

Fig. 2. iNOS and nNOS gene expression in insulin-secreting INS1E cells after exposure to cytokines. Insulin-secreting INS1E cells were seeded onto 6-well plates at a density of 500,000 cells $/$ well and allowed to attach for $24 \mathrm{~h}$. Thereafter various combinations of cytokines were added $(60 \mathrm{U} / \mathrm{ml} \mathrm{IL-1 \beta ,600} \mathrm{U/ml} \mathrm{IL-1 \beta ,} 60 \mathrm{U} / \mathrm{ml} \mathrm{IL}-1 \beta+185 \mathrm{U} / \mathrm{ml} \mathrm{TNF}-\alpha$,

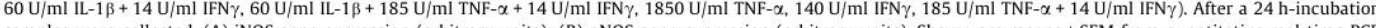
samples were collected. (A) iNOS gene expression (arbitrary units); (B) nNOS gene expression (arbitrary units). Shown are means \pm SEM from quantitative real-time PCR
analysis $(n=12$ ). Data were normalized to $\beta$-actin. $p<0.05, \cdots p<0.01, \cdots p<0.001$ vs. untreated. ANOVA followed by a nonparametric Kruskal-Wallis test.

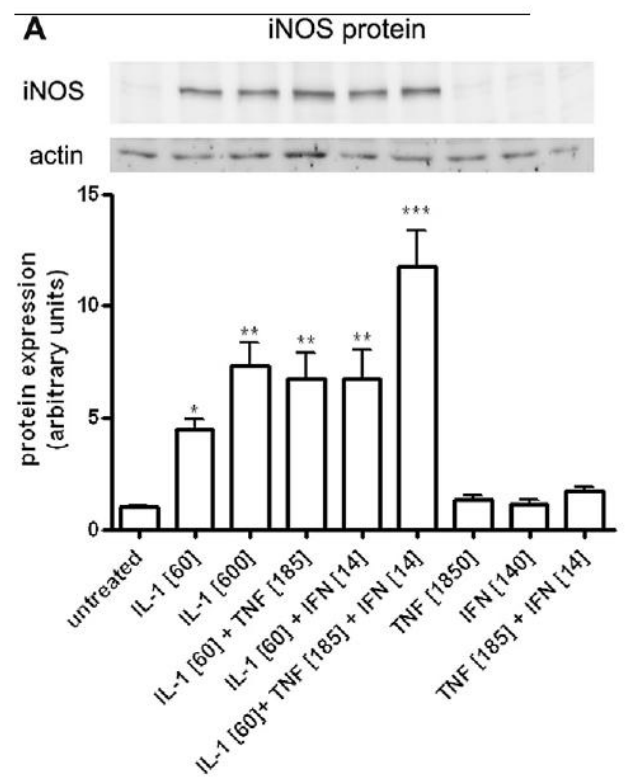

B
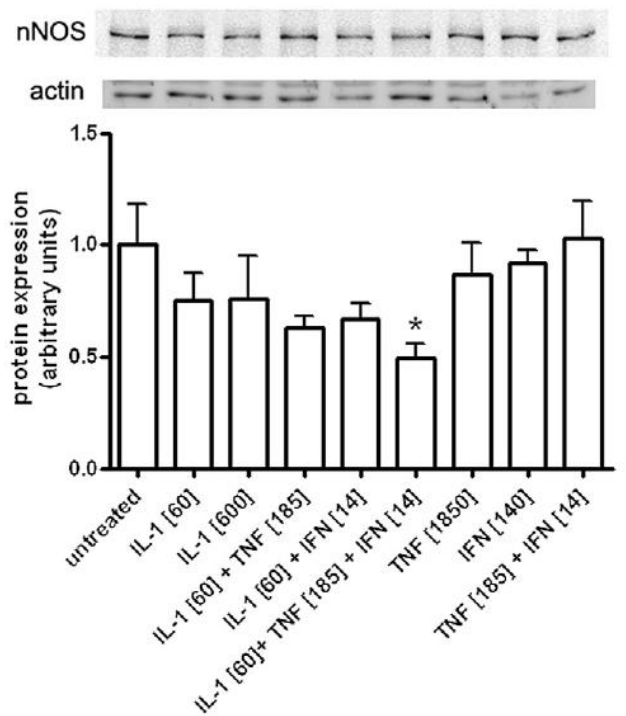

Fig. 3. iNOS and nNOS protein expression in insulin-secreting INS1E cells after exposure to cytokines. Insulin-secreting INS1E cells were seeded onto 6-well plates at a density of 500,000 cells/well and allowed to attach for $24 \mathrm{~h}$. Thereafter various combinations of cytokines were added $(60 \mathrm{U} / \mathrm{ml} \mathrm{IL}-1 \beta, 600 \mathrm{U} / \mathrm{ml} \mathrm{IL}-1 \beta, 60 \mathrm{U} / \mathrm{ml} \mathrm{IL}-1 \beta+185 \mathrm{U}$ $\mathrm{ml} \mathrm{TNF}-\alpha, 60 \mathrm{U} / \mathrm{ml} \mathrm{IL-}-1 \beta+14 \mathrm{U} / \mathrm{ml}$ IFN $\gamma, 60 \mathrm{U} / \mathrm{ml}$ IL- $1 \beta+185 \mathrm{U} / \mathrm{ml}$ TNF- $\alpha+14 \mathrm{U} / \mathrm{ml}$ IFN $\gamma, 1850 \mathrm{U} / \mathrm{ml} \mathrm{TNF}-\alpha, 140 \mathrm{U} / \mathrm{ml}$ IFN $\gamma, 185 \mathrm{U} / \mathrm{ml}$ TNF- $\alpha+14 \mathrm{U} / \mathrm{ml}$ IFN $\gamma$ ). After a $24 \mathrm{~h}-$ incubation samples were collected. (A) iNOS protein expression; (B) nNOS protein expression. Shown are representative blots and quantitative densitometric analyses of 8 independent experiments (means \pm SEM, arbitrary units, normalized to $\beta$-actin). " $p<0.05,{ }^{*} p<0.01, \cdots p<0.001$ vs. untreated. ANOVA followed by a nonparametric KruskalWallis test. 


\section{Author's personal copy}

E. Gurgul-Convey et al./Nitric Oxide 27 (2012) 235-241
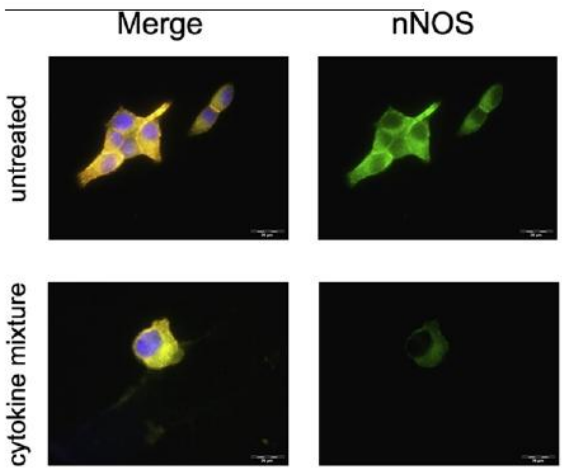

$\mathrm{nNOS}$

Insulin
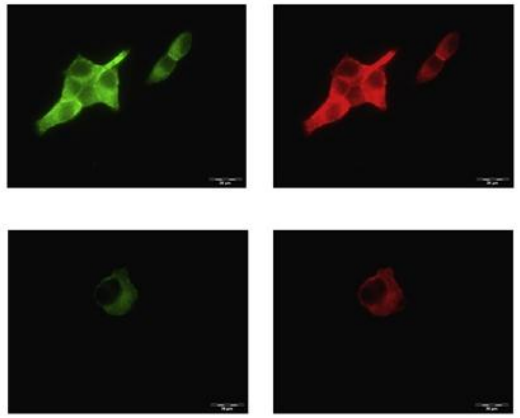

DAPI
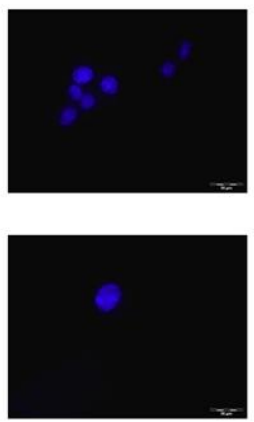

Fig. 4. Immunofluorescence analysis of nNOS expression in insulin-secreting INS1E cells after exposure to cytokines. Insulin-secreting INS1E cells were incubated with $60 \mathrm{U} / \mathrm{ml} \mathrm{IL}-1 \beta+185 \mathrm{U} / \mathrm{ml}$ TNF- $\alpha+14 \mathrm{U} / \mathrm{ml}$ IFN $\gamma$ for $24 \mathrm{~h}$ and thereafter fixed and immunostained for nNOS (green) and insulin (red). Double positive cells appear in yellow. Scale bar: $20 \mu \mathrm{m}$.

IL- $1 \beta$ or a cytokine mixture (IL- $1 \beta$, TNF- $\alpha$ and IFN $\gamma$ ) caused a significant reduction of nNOS expression (to $38 \pm 11 \%$ after IL- $1 \beta$ and $18 \pm 6 \%$ after cytokine mixture compared to the $100 \%$ control value, $n=4, p<0.05$

Glucose-induced insulin secretion and insulin content after cytokine incubation

Insulin secretion in the presence of $10 \mathrm{mM}$ glucose was analyzed after a $24 \mathrm{~h}$ exposure of INS1E cells to different cytokines and their combinations (Fig. 5A). The experiments revealed a strong IL-1 $\beta$-dependent inhibition of glucose-induced insulin secretion, which was slightly potentiated by TNF- $\alpha$ (Fig. $5 \mathrm{~A}$ ). In contrast the incubation of INS1E cells even with high concentrations of IFN $\gamma$ did not result in insulin secretion inhibition (Fig. 5A). Moreover, IL-1 $\beta$ significantly reduced insulin content, an effect potentiated by TNF- $\alpha$, but, again, not by IFN $\gamma$ (Fig. 5B).

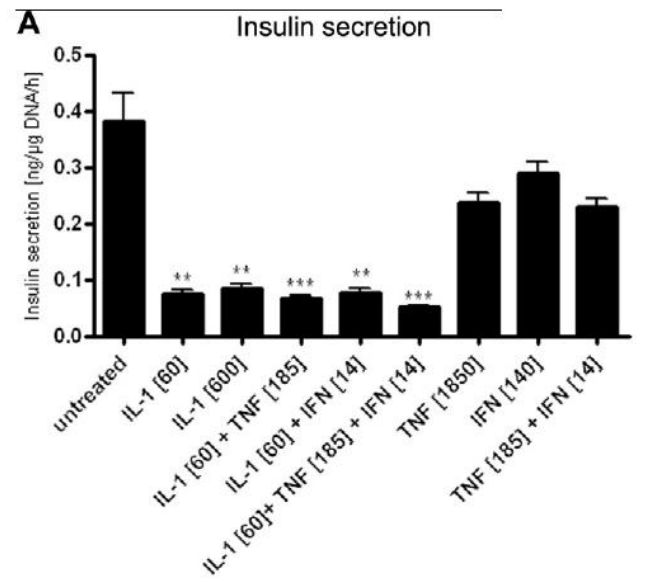

\section{Discussion}

Nitric oxide (NO) produced in low concentrations by constitutive nitric oxide synthases plays a signalling role in different tissues, however an excessive production of NO, driven by iNOS, is thought to underlie the development of various diseases [3-7]. The expression of different NOS isoforms is specifically and tightly regulated by various mechanisms. The expression of iNOS in pancreatic beta cells crucially depends on the activation of the transcription factor NF- $\kappa B$ and, to a lesser extent, on the JAK/STAT pathway [19]. The inhibition of NF-KB signalling via e.g. JANEX-1 [20], antiinflammatory cytokines [21], prostacyclin [22] or some plant extracts [23] prevents cytokine-induced iNOS expression and cytokine toxicity in insulin-secreting cells [1,24,25]. The expression of nNOS is controlled by alternative splicing and the transcription factor CREB [26] and its activity can be regulated by Hsp90, calmodulin and other factors $[1,26,27]$.

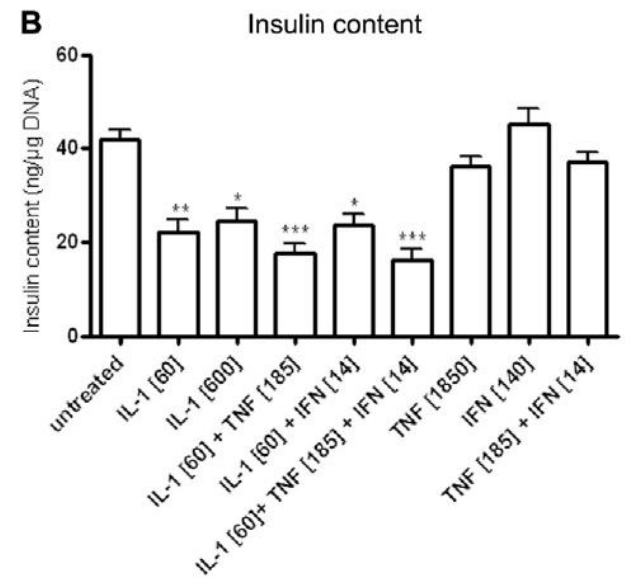
Fig. 5. Insulin secretion and content in the presence of $10 \mathrm{mM}$ glucose in insulin-secreting INS1E cells after exposure to cytokines. Insulin-secreting INS1E cells were seeded $60 \mathrm{U} / \mathrm{ml}$ IL- $1 \beta+185 \mathrm{U} / \mathrm{ml} \mathrm{TNF}-\alpha, 60 \mathrm{U} / \mathrm{ml} \mathrm{IL}-1 \beta+14 \mathrm{U} / \mathrm{ml} \mathrm{IFN} \gamma, 60 \mathrm{U} / \mathrm{ml} \mathrm{IL-}-1 \beta+185 \mathrm{U} / \mathrm{ml} \mathrm{TNF}-\alpha+14 \mathrm{U} / \mathrm{ml} \mathrm{IFN} \gamma, 1850 \mathrm{U} / \mathrm{ml} \mathrm{TNF}-\alpha, 140 \mathrm{U} / \mathrm{ml}$ IFN $\gamma, 185 \mathrm{U} / \mathrm{ml}$ TNF- $\alpha+14 \mathrm{U} / \mathrm{m} /$ IFN $\gamma$ ). After a $24 \mathrm{~h}$-incubation samples were collected and measured by RIA; (A) insulin secretion (B) insulin content. Mean values of 8 independent experiments $( \pm S E M$, normalized to the DNA content). $p<0.05, " p<0.01, \cdots p<0.001$ vs. untreated. ANOVA followed by a nonparametric Kruskal-Wallis test. 


\section{Author's personal copy}

The present study showed that in insulin-secreting INS1E cells only the nNOS isoform was expressed constitutively, thus confirming earlier reports [13]. The observed eNOS expression in rat islets originates most likely from glucagon and somatostatin-secreting cells, in which the expression of eNOS was reported earlier [13]. Cytokines significantly reduced nNOS expression both on the transcriptional and translational level. The expression level of nNOS in rat islets was lower, but the results from the rat islet cells treated with cytokines confirmed the data obtained from INS1E cells regarding the decrease of nNOS expression upon exposure to cytokines. Interestingly, the cytokine-mediated changes of nNOS expression closely match the pattern of cytokine toxicity in insulin-secreting cells, which we reported earlier [9]. It is possible that either the induction of pro-apoptotic and/or the reduction of prosurvival pathways may influence the transcriptional control of nNOS expression and/or its translation and activity. As recently shown the activation of the JNK pathway may lead to the reduction of nNOS protein expression [27], therefore the observed decrease in nNOS protein expression after a cytokine mixture treatment may result, at least partially, from the cytokine-induced JNK activation, a well established phenomenon in pancreatic beta cells $[28-30]$. Other possible regulatory mechanisms could also include changes in the alternative splicing of nNOS mRNA as well as inactivation of nNOS activity, for instance by disturbances in the intracellular calcium pool and Hsp90 availability.

As we have recently shown IL- $1 \beta$ alone or in combination with TNF- $\alpha$ and/or IFN $\gamma$ is able to induce a strong rise in NO formation in insulin-secreting INS1E cells, while TNF- $\alpha$ and IFN $\gamma$ do not stimulate iNOS and NO production [9]. In contrast to a strong activation of NF- $\kappa B$ by IL- $1 \beta[21,31]$, TNF- $\alpha$ is known to induce NF- $\kappa B$ only mildly $[21,31]$. Since the transcription factor NF- $\kappa B$ is crucial for cytokine-induced iNOS expression, the observed lack of iNOS induction by TNF- $\alpha$ is not surprising. Moreover, it is also possible that TNF- $\alpha$ may stimulate some alternative signalling pathways which in turn reduce iNOS expression. A significantly higher induction of iNOS expression by the mixture of IL- $1 \beta$, TNF- $\alpha$ and IFN $\gamma$ as compared to IL-1 $\beta$ alone, indicates that in the late stages of islet infiltration during T1DM development, when all three cytokines are produced by activated immune cells in the vicinity of beta cells, insulin-secreting cells face a massive generation of NO. This favors the reaction between NO and the hydrogen peroxide produced in parallel, and leads to formation of highly toxic hydroxyl radicals, which ultimately cause pancreatic beta cell death [6].

The present study showed a strong inhibition of glucose-induced insulin secretion as well as insulin content by IL- $1 \beta$ or its combinations with TNF- $\alpha$ or IFN $\gamma$. A slight potentiating effect of TNF- $\alpha$ alone and no influence of IFN $\gamma$ were observed. This is in line with earlier reports demonstrating a strong deleterious effect of IL$1 \beta$ on islet cell function and a weaker effect of TNF- $\alpha$. It has been shown that this inhibitory effect of IL- $1 \beta$ strongly depends on NO formation derived from iNOS induction [10-12,32-34].

The present study shows that cytokine-mediated NO production in pancreatic beta cells can originate only from the cytokineinduced iNOS expression, and not from any other NOS isoform. The results indicate that a basal level of NO (produced by nNOS) is apparently not deleterious to the beta cells. nNOS has even been shown to prevent iNOS induction in some cell types [35,36] and a partial nNOS knock-down has been shown to result in increased JNK phosphorylation and CHOP production, leading to apoptosis [14]. Thus a reduction of nNOS expression by cytokines might be unfavorable for beta cell function. A little NO formation through a mild iNOS induction by low concentrations of IL- $1 \beta$ in insulinsecreting cells might compensate this negative effect. Indeed, it has been shown before that IL-1 $\beta$ in very low concentrations can potentiate glucose-induced insulin secretion [37] rather than causing damage to the beta cells.
We showed that insulin-secreting INS1E cells and rat islets constitutively express nNOS confirming earlier observations $[13,38]$. INS1E cells are known for their excellent glucose responsiveness [15], which we confirmed in this study. Pancreatic beta cell nNOS is thought to exert two different catalytic activities and the balance between NO production and a nonoxidating calmodulin-dependent reductase activity is required for the biphasic response of beta cells to glucose stimulation [13]. Moreover, it has been shown that a pharmacological inhibition of nNOS in insulin-secreting INS1E cells and rat islets enhances glucose-induced insulin secretion $[13,38]$. Therefore the earlier observations together with our present data indicate that the basal nNOS expression plays a regulatory role in insulin secretion, probably by preventing possible episodes of hyperinsulinemia, but is not disadvantageous for the beta cell function or does not promote beta cell vulnerability. A decreased catalytical activity of nNOS and its relocalization have been shown to be involved in the hyperactivity of beta cells from insulinresistant rats and also from human islets isolated from obese individuals [39].

The present data strongly indicate that a very small rate of NO formation, derived either from a basal nNOS expression under physiological conditions or from a very weak iNOS expression, which may originate from IL- $1 \beta$ present in beta cells at very low concentrations [9], as e $g$ in a type 2 diabetes situation $[8,40]$, will not account for beta cell damage and death. The very low IL- $1 \beta$ expression in beta cells in animal models of type 2 diabetes as well as in patients with type 2 diabetes, as reported earlier [40-42], will be insufficient to induce iNOS expression significantly, which would be a prerequisite for $\mathrm{NO}$ production that can cause apoptotic beta cell death.

Thus, NO is toxic to beta cells only when generated in high concentrations by cytokine-induced iNOS, as occurs in the type 1 diabetes situation [8]. The constitutive expression of $\mathrm{nNOS}$ in pancreatic beta cells, on the other hand, represents rather a protective element against cytokine toxicity, in particular in a type 2 diabetes setting. The present data virtually exclude the concept of a significant role of very low IL- $1 \beta$ concentrations generated in pancreatic beta cells in the type 2 diabetes etiopathology as proposed a number of years ago [41].

\section{Conflict of interest}

The authors declare no financial or commercial conflict of interest

\section{Acknowledgments}

This work was supported by a grant from the European Union (Collaborative Project NAIMIT in the 7th Framework Programme, Grant Agreement No. 241447). We would like to thank very much Prof. Claes B. Wollheim (Department of Cell Physiology and Metabolism, University of Geneva, Geneva, Switzerland) for providing insulin-secreting INS1E cells for this study. The excellent technical assistance of $\mathrm{Ch}$. Heinrichs is gratefully acknowledged.

\section{References}

[1] L. Zhou, D.Y. Zhu, Neuronal nitric oxide synthase: structure, subcellular localization, regulation, and clinical implications, Nitric Oxide 20 (2009) 223230.

[2] B.G. Hill, B.P. Dranka, S.M. Bailey, J.R. Lancaster Jr., V.M. Darley-Usmar, What part of NO don't you understand? Some answers to the cardinal questions in

[3] W. Dröge, Free radicals in the physiological control of cell function, Physiol Rev. 82 (2002) 47-95.

Eizirik, D. Pavlovic, Is there a role for nitric oxide in beta-cell dysfunction and damage in IDDM?, Diabetes Metab Rev. 13 (1997) 293-307. 


\section{Author's personal copy}

[5] A.M. Briones, R.M. Touyz, Oxidative stress and hypertension: current concepts, Curr. Hypertens. Rep. 12 (2010) 135-142.

[6] D.G. Hirst, T. Robson, Nitric oxide physiology and pathology, Methods Mol. Biol. 704 (2011) 1-13.

[7] E. Gurgul-Convey, I. Mehmeti, S. Lortz, S. Lenzen, Cytokine toxicity in insulinproducing cells is mediated by nitro-oxidative stress-induced hydroxyl radical formation in mitochondria, J. Mol. Med. 89 (2011) 785-798. [8] M. Cnop, N. Welsh, J.C. Jonas. A. Jörns, S. Lenzen, D.L. Eizirik, Mechanisms of
pancreatic beta cell death in type 1 and type 2 diabetes: many differences, few similarities, Diabetes 54 (Suppl. 2) (2005) S97-S107.

[9] S. Kacheva, S. Lenzen, E. Gurgul-Convey, Differential effects of proinflammatory cytokines on cell death and ER stress in insulin-secreting [10] J.A. Corbett, M.A. Sweetland, J.R. Lancaster Jr., M.L. McDaniel, A 1-hour pulse
with IL-1 beta induces formation of nitric oxide and inhibits insulin secretion ting by rat islets of Langerhans: evidence
mechanism, Faseb J. 7 (1993) 369-374.

[11] J.A. Corbett, M.A. Sweetland, J.L. Wang, J.R. Lancaster Jr., M.L. McDaniel, Nitric oxide mediates cytokine-induced inhibition of insulin secretion by human islets of Langerhans, Proc .Natl. Acad. Sci. USA 90 (1993) 1731-1735.

[12] C.A. Delaney, D.L. Eizirik, Intracellular targets for nitric oxide toxicity to pancreatic beta-cells, Braz. J. Med. Biol. Res. 29 (1996) 569-579.

[13] A.D. Lajoix, H. Reggio, T. Chardes, S. Peraldi-Roux, F. Tribillac, M. Roye, S. Dietz, C. Broca, M. Manteghetti, G. Ribes, C.B. Wollheim, R. Gross, A neuronal isoform of nitric oxide synthase expressed in pa

[14] E. Bachar, Y. Ariav, E. Cerasi, N. Kaiser, G. Leibowitz, Neuronal nitric oxide synthase protects the pancreatic beta cell from glucolipotoxicity-induced synthase protects the pancreatic beta cell from glucolipotoxicity-induced
endoplasmic reticulum stress and apoptosis, Diabetologia $53(2010) 2177-$ 2187.

[15] M. Asfari, D. Janjic, P. Meda, G. Li, P.A. Halban, C.B. Wollheim, Establishment of 2-mercaptoethanol-dependent differentiated insulin-secreting cell lines, Endocrinology 130 (1992) 167-178.

[16] H.M. Ximenes, S. Lortz, A. Jörns, S. Lenzen, Triiodothyronine (T3)-mediated toxicity and induction of apoptosis in insulin-producing INS-1 cells, Life Sci. 80 (2007) 2045-2050

[17] E. Gurgul-Convey, K. Hanzelka, S. Lenzen, Mechanism of prostacyclin-induced potentiation of glucose-induced insulin secretion, Endocrinology 153 (2012) 2612-2622.

18] M. Tiedge, M. Höhne, S. Lenzen, Insulin secretion, insulin content and glucose phosphorylation in RINm5F insulinoma cells after transfection with hum

[19] M.I. Darville, D.L. Eizirik, Regulation by cytokines of the inducible nitric oxide synthase promoter in insulin-producing cells, Diabetologia 41 (1998) 11011108.

20] N. Lv, E.K. Kim, M.Y. Song, H.N. Choi, W.S. Moon, S.J. Park, J.W. Park, K.B. Kwon, B.H. Park, JANEX-1, a JAK3 inhibitor, protects pancreatic islets from cytokine toxicity through downregulation of NF-kB activation and the JAK/STAT pathway, Exp. Cell Res. 315 (2009) 2064-207

[21] K.L. Souza, E. Gurgul-Convey, M. Elsner, S. Lenzen, Interaction between proinflammatory and anti-inflammatory cytokines in insulin-producing cells, J.

[22] E. Gurgul-Convey, S. Lenzen, Protection against cytokine toxicity through endoplasmic reticulum and mitochondrial stress prevention by prostacyclin synthase overext $11121-11128$.

[23] M.Y. Song, E.K. Kim, H.J. Lee, J.W. Park, D.G. Ryu, K.B. Kwon, B.H. Park, Fructus Xanthii extract protects aga cells through suppression of NF-kB activation, Int. J. Mol. Med. 23 (2009) 547 553.

[24] D.S. Bredt, Endogenous nitric oxide synthesis: biological functions and pathophysiology, Free Radic. Res. 31 (1999) 577-596.
[25] B.C. Kone, Protein-protein interactions controlling nitric oxide synthases, Acta Physiol. Scand. 168 (2000) 27-31.

26] C.X. Luo, D.Y. Zhu, Research progress on neurobiology of neuronal nitric oxide synthase, Neurosci. Bull 27 (2011) 23-35.

[27] L.L. Wang, X.C. Zhao, L.F. Yan, Y.Q. Wang, X. Cheng, R. Fu, L.H. Zhou, C-jun phosphorylation contributes to down regulation of neuronal nitric oxide synthase protein and motoneurons death in injured spinal cords following root-avulsion of the brachial plexus, Neuroscience 189 (2011) 397-407,

[28] A. Ammendrup, A. Maillard, K. Nielsen, N. Aabenhus Andersen, P. Serup, O. Dragsbaek Madsen, T. Mandrup-Poulsen, C. Bonny, The c-Jun amino-terminal kinase pathway is preferentially activated by interleukin-1 and controls 1476.

[29] N.A. Andersen, C.M. Larsen, T. Mandrup-Poulsen, TNF-a and IFNg potentiate IL$1 \mathrm{~b}$ induced mitogen activated protein kinase activity in rat pancreatic islets of Langerhans, Diabetologia 43 (2000) 1389-1396.

[30] J. Størling, J. Binzer, A.K. Andersson, R.A. Zullig, M. Tonnesen, R. Lehmann, G.A. Spinas, S. Sandler, N. Billestrup, T. Mandrup-Poulsen, Nitric oxide contributes to cytokine-induced apoptosis in pancreatic beta cells via potentiation of JNK activity and inhibition of Akt, Diabetologia 48 (2005) 2039-2050.

31] F. Ortis, P. Pirot, N. Naamane, A.Y. Kreins, J. Rasschaert, F. Moore, E. Theatre, C. Verhaeghe, N.E. Magnusson, A. Chariot, T.F. Orntoft, D.L. Eizirik, Induction of nuclear factor-kappaB and its downstream genes by TNF-a and IL-1b has a proapoptotic role in pancreatic beta cells, Diabetologia $51(2008) 1213-1225$. Nielsen Affinitysen, K. Bendtzen, J. Nerup, C.A. Dinarello, M. Svenson, J.H. Nielsen, Affinity-purified human interleukin 1 is cytor

S. Sandler, A. Andersson, C. Hellerstrom, Inhibitory effects of interleukin 1 on
insulin secretion, insulin biosynthesis, and oxidative metabolism of isolated insulin secretion, insulin biosynthesis, and oxidative metab
rat pancreatic islets, Endocrinology 121 (1987) 1424-1431.

[34] J.A. Corbett, J.L. Wang. T.P. Misko, W. Zhao, W.F. Hickey, M.L. McDaniel, Nitric oxide mediates IL-1b-induced islet dysfunction and destruction: prevention by dexamethasone, Autoimmunity 15 (1993) 145-153.

[35] R. Perez-Rodriguez, C. Roncero, A.M. Olivan, M.P. Gonzalez, M.J. Oset-Gasque, Signaling mechanisms of interferon gamma induced apoptosis in chromaffin cells: involvement of nNOS, iNOS, and NF-kB, J. Neurochem. 108 (2009) 1083

[36] H. Togashi, M. Sasaki, E. Frohman, E. Taira, R.R. Ratan, T.M. Dawson, V.L. Dawson, Neuronal (type I) nitric oxide synthase regulates nuclear factor $\mathrm{kB}$ activity and immunologic (type II) nitric oxide synthase expression. Proc. Natl. Acad. Sci. USA 94 (1997) 2676-2680.

[37] D.L. Eizirik, N. Welsh, C. Hellerstrom, Predominance of stimulatory effects of interleukin-1b on iso
76 (1993) $399-403$.

[38] P. Beffy, A.D. Lajoix, P. Masiello, S. Dietz, S. Peraldi-Roux, T. Chardes, G. Ribes, R. Gross, A constitutive nitric oxide synthase modulates insulin secretion in the INS-1 cell line, Mol. Cell Endocrinol. 183 (2001) 41-48.

39] K. Mezghenna, P. Pomies, A. Chalancon, F. Castex, J. Leroy, N. Niclauss, B. Nadal, L. Cambier, C. Cazevieille, P. Petit, R. Gomis, T. Berney, R. Gross, A.D. Lajoix, Increased neuronal nitric oxide synthase dimerisation is involved in rat and 2856-2866.

A. Jörns, KJ. Rath, O. Bock, S. Lenzen, Beta cell death in hyperglycaemic
Psammmomys obesus is not cytokine-mediated, Diabetologia 49 (2006) 27042712 .

[41] K. Maedler, P. Sergeev, F. Ris, J. Oberholzer, H.I. Joller-Jemelka, G.A. Spinas, N. Kaiser, P.A. Halban, M.Y. Donath, Glucose-induced beta cell production of IL-1b contributes to glucotoxicity in human pancreatic islets, J. Clin. Invest. 110

(2002) $851-860$.
42] M.Y. Donath, S.E. Shoelson, Type 2 diabetes as an inflammatory disease, Nat. Rev. Immunol. 11 (2011) 98-107. 


\section{RESULTS AND DISCUSSION}

The present work provided the analysis of the role of three different proteins, namely mimitin, PGIS and nNOS, in deleterious effects of proinflammatory cytokines against pancreatic beta cells. These three proteins are distinct in their subcellular localizations and their mechanisms of action as well as intracellular functions. They exert their effects against cytokine toxicity by distinct mechanisms; however, they share the common final outcome, namely the beta cell protection.

Mimitin is a novel mitochondrial protein, involved in the control of cell proliferation and death (Tsuneoka et al. 2005; Wegrzyn et al. 2009). It has been shown that mimitin may act as a molecular chaperone for the assembly of the mitochondrial complex I and be implicated in ATP production in mitochondria (Tsuneoka et al. 2005). In pancreatic beta cells the formation of ATP is essential for glucose-stimulated insulin secretion (GSIS) (Ashcroft et al. 1973; Rodriguez Candela \& GarciaFernandez 1963). During type 1 diabetes development proinflammatory cytokines inhibit ATP synthesis, leading to the impairment of GSIS (Ashcroft et al. 1973; Delaney \& Eizirik 1996). Mitochondrial metabolism is also affected by chronic hyperglycaemia and hyperlipidemia (Jitrapakdee et al. 2010). Until now there has been no information regarding the role of mimitin in pancreatic beta cell function and in diabetes development and the present study was therefore aiming to elucidate this issue.

Prostacyclin synthase is a cytoplasmic heme-thiolate enzyme catalysing the conversion of PGH2 into prostacyclin (Siegle et al. 2000) and has been reported to be modestly expressed in pancreatic beta cells (Gurgul-Convey et al. 2012). Prostacyclin analogues as well as PGIS overexpression in insulinsecreting cells provide protection against environmental insults as well as proinflammatory cytokines (Gurgul-Convey \& Lenzen 2010). Many prostaglandins have been previously shown to act as negative regulators of glucose-induced insulin secretion (Tran et al. 1999). Until now the role of PGI2 in glucose-induced insulin secretion remained unclear.

The neuronal NO-synthase is a constitutive isoform of NOS localized in the cytoplasmic compartment and responsible for the production of low concentrations of NO (Zhou \& Zhu 2009). It has been recently shown that nNOS plays a protective role against lipotoxicity in pancreatic beta cells (Bachar et al. 2010). The role of nNOS in cytokine toxicity to pancreatic beta cells is unknown.

\subsection{Mimitin in pancreatic beta cells}

Mimitin expression was analyzed in different rat and mouse tissues with a special focus on primary pancreatic islets. The results revealed a lower expression level of mimitin in rat compared to mouse tissues. Further studies demonstrated that beta cell function and susceptibility towards proinflammatory cytokines were both influenced by the mimitin expression level. Moreover, expression of mimitin was shown to vary significantly between different tissues from $o b / o b$ mice, a model of insulin resistance and obesity, compared to their lean litter mates. Therefore, it is proposed 
that mimitin exerts its action as a modulator of beta cell function and its impact seems to differ in type 1 and type 2 diabetes situations.

\subsubsection{Mimitin in conditions simulating T1DM}

Proinflammatory cytokines IL-1 $\beta$, TNF $\alpha$, and IFN $\gamma$ play a crucial role in T1DM development (Grunnet \& Mandrup-Poulsen 2011; Mandrup-Poulsen et al. 1985; Mandrup-Poulsen 1990). Insulinsecreting INS1E cells are known for their particular sensitivity to proinflammatory cytokines (Kacheva et al. 2011). According to gene expression studies INS1E cells were characterized by the lowest endogenous level of mimitin expression among all insulin-secreting rat cell lines that were examined. This low level of mimitin makes them well suited for investigations on the effects of mimitin overexpression in pancreatic beta cells. Therefore, the cDNA coding of human mimitin was introduced and several positive clones were obtained. Insulin-secreting INS1E cells transfected with a vector lacking insert were used as control cells.

\subsubsection{Mimitin and mitochondrial stress}

Ectopic expression of mimitin significantly decreased cytokine-induced caspase- 3 activation in INS1E cells (Hanzelka et al. 2012). Moreover, it attenuated the cytokine-mediated decrease of mitochondrial membrane potential and caspase-9 activation (Hanzelka et al. 2012). Interestingly, caspase- 8 triggering the extrinsic apoptotic pathway was also significantly downregulated by mimitin overexpression (caspase-8 after 24 h, INS1E-control: IL-1 $\beta 172 \pm 17$, cytokine mixture $146 \pm 8$; INS1E-mimitin IL-1 $103 \pm 5$, cytokine mixture $103 \pm 10 \%$ vs. untreated $100 \%, \mathrm{p}<0.05$ ). Mimitin overexpression also improved cell viability of INS1E cells treated with cytokines (Table 2). A $24 \mathrm{~h}$ incubation of insulin-secreting INS1E control cells with cytokines caused $\sim 45$ or $60 \%$ of cell viability loss after exposure to IL-1 $\beta$ alone or to a cytokine mixture, respectively (Table 2 ). Those findings are in line with results previously obtained in INS1E cells (Kacheva et al. 2011), pointing to the high sensitivity of this cell line towards proinflammatory cytokines. Mimitin overexpression resulted in a protection against cytokine-induced viability loss in all analyzed clones, with the most pronounced effect reported in the clone with the highest mimitin expression level, namely INS1E-mimitin K3 cells. While mimitin overexpression provided a nearly-full prevention of cytokine-induced caspase-3 activation, it afforded only a partial protection against the cytokine-mediated loss of cell viability in the MTT assay. This implies that a necrotic component of beta cell death cannot be prevented by mimitin action. 


\begin{tabular}{lccc}
\hline INS1E cell clone & Untreated & IL-1 & Cytokine mixture \\
\hline INS1E-control 1 & $100 \pm 12(10)$ & $56 \pm 3(10)^{*}$ & $48 \pm 3(10)^{*}$ \\
INS1E-control 2 & $100 \pm 10(13)$ & $55 \pm 5(13)^{*}$ & $43 \pm 5(13)^{*}$ \\
INS1E-mimitin K1 & $100 \pm 10(6)$ & $68 \pm 5(6)^{*}$ & $58 \pm 6(6)^{*}$ \\
INS1E-mimitin K2 & $100 \pm 8(8)$ & $75 \pm 4(8)^{* \# \S}$ & $64 \pm 7(8)^{*}$ \\
INS1E-mimitin K3 & $100 \pm 7(8)$ & $84 \pm 3(8)^{\# \S}$ & $67 \pm 6(8)^{\# \S}$ \\
\hline
\end{tabular}

Table 2 Effects of mimitin overexpression in insulin-secreting INS1E cells on cell viability after exposure to IL-1 $\beta$ alone or to a cytokine mixture (Hanzelka 2012, unpublished).

INS1E insulin-secreting cells overexpressing mimitin as well as control cells were incubated with IL-1 $\beta$ (600 $\mathrm{U} / \mathrm{ml})$ or a cytokine mixture $(60 \mathrm{U} / \mathrm{ml} \mathrm{IL}-1 \beta, 185 \mathrm{U} / \mathrm{ml} \mathrm{TNF} \alpha$, and $14 \mathrm{U} / \mathrm{ml} \mathrm{IFN} \gamma)$ for $24 \mathrm{~h}$. The viability of the cells was determined by the 3-(4,5-dimethylthiazol-2-yl)-2,5-diphenyltetrazolium bromide assay and expressed as a percentage of the untreated cells. Data are means \pm SEM with the number of independent experiments in parentheses, each measured in at least three repetitions. ${ }^{\mathrm{p}}<0.05$ vs. untreated; \#p $<0.05$ vs. control clone 1 treated in the same way; $\$ p<0.05$ vs. control clone 2 treated in the same way; ANOVA followed by Bonferroni.

Recent studies performed on animal models of T1DM underlined apoptosis as the main form of beta cell death occurring in this disease (Jörns et al. 2004; Jörns et al. 2005; Lenzen et al. 2001; Mauricio \& Mandrup-Poulsen 1998). Apoptosis was also demonstrated to be the predominant form of cytokine-induced beta cell death in human islets, although necrosis could also be involved (Delaney et al. 1997; Eizirik \& Darville 2001; Eizirik \& Mandrup-Poulsen 2001; Liu et al. 2000; Pipeleers et al. 2001; Saldeen 2000). Mimitin overexpression prevented cytokine-induced caspase-3 activation. Those data confirm previous findings based on studies in hepatoma (HepG2) cells, where overexpression of mimitin significantly decreased cytokine-induced apoptosis (Wegrzyn et al. 2009). Furthermore the observed protective effect of mimitin overexpression corresponds with reports demonstrating that defects in human complex I of the respiratory chain account for many energy generation disorders and may be implicated in disturbed apoptosis signalling (Lazarou et al. 2007; Ogilvie et al. 2005).

Proinflammatory cytokines induce nitrosative and oxidative stresses, collectively known as nitrooxidative stress, which contributes to pancreatic beta cell death during T1DM development (Bast et al. 2002; Eizirik et al. 1996; Eizirik \& Mandrup-Poulsen 2001; Gurgul-Convey et al. 2011; Gurgul et al. 2004; Lortz et al. 2000; Lortz \& Tiedge 2003; Storling et al. 2005). Since mitochondria represent the main source and target of the hydroxyl radical formation and action, playing the fundamental role in this stress response, we have examined whether mimitin overexpression affects overall oxidative and nitrosative stress in INS1E cells. For this purpose the widely used fluorescent ROS indicator dichlorodihydrofluorescein diacetate $\left(\right.$ DCFDA- $\mathrm{H}_{2}$ ) was employed. DCFDA- $\mathrm{H}_{2}$ is a cell-permeable fluorogenic probe cleaved by esterases within the cell (Eruslanov \& Kusmartsev 2010). In the presence of different ROS (hydroxyl radical, peroxyl radical, hydrogen peroxide, and superoxide anion) and RNS (peroxynitrite anion and nitric oxide) DCFDA- $\mathrm{H}_{2}$ is rapidly oxidized to its fluorescent form DCF (Degli Esposti 2002). Incubation of control as well as mimitin overexpressing INS1E cells with IL-1 $\beta$ significantly induced oxidation of DCFDA- $\mathrm{H}_{2}$ to DCF $(173 \%$ and $206 \%$ respectively, vs. 
untreated cells set as $100 \%$; Figure 7). Correspondingly, the exposure to the cytokine mixture also caused a significant increase in DCFDA- $\mathrm{H}_{2}$ oxidation, clearly indicating an increasing oxidative and nitrosative stress response. Noteworthy, the combination of cytokines augmented DCFDA- $\mathrm{H}_{2}$ oxidation to a greater extent than exposure to IL- $1 \beta$ alone. DCFDA- $\mathrm{H}_{2}$ oxidation was comparable in control and mimitin overexpressing cells (INS1E-control $185 \%$, INS1E-mimitin K3 $229 \%$ vs. $100 \%$ untreated; Figure 7). These results indicate that the protective action of mimitin in beta cells is not due to prevention of oxidative stress.

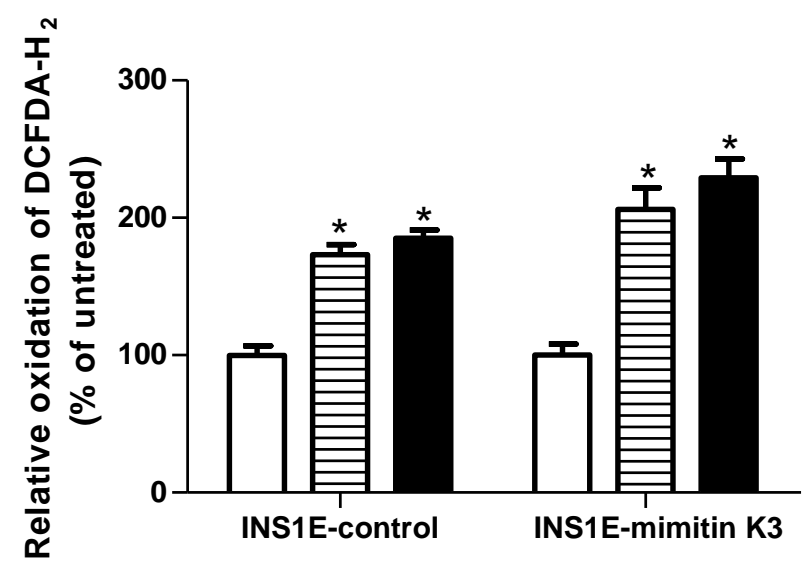

Figure 7 Effects of mimitin overexpression on cytokine-stimulated DCFDA- $\mathrm{H}_{2}$ oxidation in insulinsecreting INS1E cells (Hanzelka 2012, unpublished).

INS1E cells were incubated for $72 \mathrm{~h}$ with $600 \mathrm{U} / \mathrm{ml} \mathrm{IL}-1 \beta$ (striped bars) or a cytokine mixture (60 U/ml IL-1 $185 \mathrm{U} / \mathrm{ml} \mathrm{TNF} \alpha, 14 \mathrm{U} / \mathrm{ml}$ IFN $\gamma$ ) (black bars). The overall oxidative and nitrosative stress was estimated by the DCFDA- $\mathrm{H}_{2}$ oxidation assay and expressed as a percentage of untreated cells. Results were normalized to cell viability estimated by MTT assay. Data are means \pm SEM from 5 independent experiments; each measurement was performed in at least three repetitions and is reported as the percentage of untreated cells, set as $100 \%$. ${ }^{*} \mathrm{p}<0.05$ vs. untreated; $\# \mathrm{p}<0.05$ vs. control clone treated in the same way; ANOVA followed by Bonferroni.

The results obtained in this study also show no beneficial effects of mimitin overexpression against cytokine-induced nitrooxidative stress. Mimitin overexpression did not prevent the cytokinestimulated NFKB activation (Hanzelka et al. 2012) and as a consequence failed to reduce cytokineinduced iNOS expression (Figure 8). The analysis of iNOS protein expression revealed a comparable induction by cytokines in control and mimitin overexpressing cells (Figure 8). Moreover, the concentrations of accumulated nitrite in control and mimitin overexpressing cells were similar (Hanzelka et al. 2012). Overall, because mimitin overexpression did not downregulate the cytokineinduced NFKB-iNOS pathway, those findings provide further evidence that mimitin action cannot prevent a necrotic component of beta cell death. The results suggest that other yet uncovered mechanisms must be involved in the protective action of mimitin. 


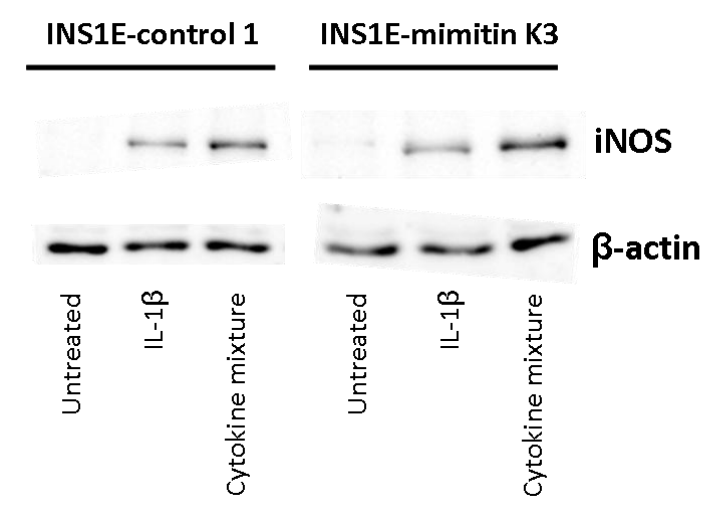

Figure 8 Effects of mimitin overexpression on iNOS protein expression in insulin-secreting INS1E cells (Hanzelka 2012, unpublished).

Insulin-secreting INS1E cells were incubated with either IL-1 $\beta$ alone $(600 \mathrm{U} / \mathrm{ml})$ or with a cytokine mixture $(60$ $\mathrm{U} / \mathrm{ml} \mathrm{IL}-1 \beta, 185 \mathrm{U} / \mathrm{ml} \mathrm{TNF} \alpha, 14 \mathrm{U} / \mathrm{ml} \mathrm{IFN} \gamma$ ) for $24 \mathrm{~h}$ and thereafter $40 \mu \mathrm{g}$ of total protein was resolved in $7.5 \%$ SDS polyacrylamide gel electrophoresis and then electroblotted onto membranes. Shown is a representative Western blot of 6 independent experiments.

Since cytokines only slightly affected the proliferation rate of insulin-secreting INS1E cells highly overexpressing mimitin, the protective action of mimitin cannot only result from a decreased cell death rate but also from preserved proliferative capacity. The increased proliferative activity found in mimitin overexpressing cells compared to control cells may arise from an increased mitochondrial metabolism. This in turn was demonstrated by a significantly higher ATP content in mimitin overexpressing cells. The correlation between ATP production and proliferative capacity was previously shown in pancreatic beta cells (Xu et al. 2008). Moreover, the results are also in agreement with data obtained in hepatoma (HepG2) cells, where reduction of mimitin expression by the siRNA approach inhibited cell proliferation (Wegrzyn et al. 2009). This indicates a relevant role of mimitin in cell proliferation. The elevated ATP content in mimitin overexpressing cells, implying their increased rate of ATP production, correlates well with the formerly reported role of mimitin as a molecular chaperone for the assembly of the mitochondrial respiratory chain complex I (Tsuneoka et al. 2005). Accordingly, an increased mimitin expression level may favour oxidative phosphorylation and thus enhance ATP production. ATP synthesis in pancreatic beta cells is of crucial importance in the regulation of glucose-induced insulin secretion and may protect accurate insulin secretory responsiveness (Ashcroft et al. 1973; Eliasson et al. 1997; Moreira et al. 1991; Panten et al. 1986; Rodriguez Candela \& Garcia-Fernandez 1963; Xu et al. 2008). Studies performed on permeabilized insulin-secreting cells have clearly indicated that withdrawal of ATP from the cytoplasmic compartment results in a strong ( $90 \%)$ inhibition of exocytosis (Regazzi et al. 1995). In line with those findings insulin-secreting INS1E cells overexpressing mimitin demonstrated an improved insulin secretory responsiveness to glucose. It is noteworthy that insulin secretion stimulated by $25 \mathrm{mM} \mathrm{KCl}$, which causes an increase in the cytosolic $\mathrm{Ca}^{2+}$ concentration independently of the mitochondrial activation, did not differ between control and mimitin overexpressing cells (Hanzelka et al. 2012). 
Because the expression of the Ins2 gene as well as the insulin content were similar in both control and mimitin overexpressing rat cells, it seems that INS1E-mimitin cells do not generate more insulin, but instead secrete it more rapidly upon glucose stimulation. Furthermore, the protective effect of mimitin against cytokine-mediated inhibition of glucose-induced insulin secretion was accompanied by a preservation of ATP content (Hanzelka et al. 2012). Therefore mimitin overexpression protects against detrimental cytokine effects most probably via its chaperone function-mediated conservation of ATP production.

Aside from the above described favourable effects of mimitin overexpression it is important to emphasize that an increased basal insulin secretion at low glucose concentration $(3 \mathrm{mM})$, as found in INS1E-mimitin cells, may constitute a possible threat of hypoglycaemia episodes. Thus, the observed rather moderate level of mimitin expression found in primary beta cells seems to be necessary to avoid hypoglycaemic episodes, though on the other hand it may account for the remarkable vulnerability and sensitivity of the pancreatic beta cells (Lenzen 2008).

To confirm the role of mimitin in the protection against cytokines and as a modulatory factor in GSIS, another beta cell line with a high mimitin expression level was analyzed. The MIN6 cell line has been extensively used for studies unravelling mechanisms involved in insulin secretion in pancreatic beta cells, since it is characterized by a notable ability to respond to glucose (Ishihara et al. 1993; Minami et al. 2000; Miyazaki et al. 1990). Mimitin knock-down in insulin-secreting MIN6 cells caused opposite effects to those obtained in the overexpression studies. A decreased mimitin expression augmented sensitivity to proinflammatory cytokines in MIN6 cells (Hanzelka et al. 2012), known for their weak sensitivity to cytokine toxicity. An increased cytokine-induced caspase-3 activation in MIN6-shRNA-mimitin cells is consistent with previous findings obtained in hepatoma cells, according to which a reduction of mimitin expression by the siRNA approach potentiated cytokine-induced apoptosis (Wegrzyn et al. 2009). Moreover, knock-down of mimitin reduced ATP formation which was accompanied by a decrease in glucose-induced insulin secretion in the absence and presence of cytokines. The differences in the amount of secreted insulin in response to glucose between MIN6-shRNA-control and MIN6-shRNA-mimitin cells could not be ascribed to differences in the insulin content, which was comparable in both cases (Hanzelka et al. 2012). However, it should be pointed out that the decreased ability to secrete insulin in MIN6-shRNA-mimitin cells was not associated with the full loss of glucose responsiveness, since these cells exhibited glucose-induced insulin secretion in a concentration-dependent manner (Hanzelka et al. 2012).

Overall, our findings indicate that mimitin only potentiates glucose-induced insulin secretion. Expression of mimitin is not obligatory for GSIS, since INS1E cells, which are characterized by a low endogenous mimitin expression, still respond normally to glucose and display a classical pattern of insulin secretion (Hanzelka et al. 2012). Thus, mimitin is not a mandatory component, but only a mild regulator of the glucose-induced insulin secretion pathway. 
Immunofluorescence analysis of the mimitin distribution in primary rat islets revealed an evident expression of mimitin in all cell types (Hanzelka et al. 2012). Mimitin expression in beta cells was lower when compared with alpha cells. The magnitude of mimitin expression was decreased by cytokine treatment (Hanzelka et al. 2012). The observed reduction in mimitin expression may represent an additional deleterious element in the action of cytokines. The cytokine-mediated decrease in mimitin expression may render beta cells more vulnerable to cytokine-induced GSIS impairment and mitochondrial damage.

\subsubsection{Mimitin and ER stress}

Proinflammatory cytokines were shown to induce ER stress (Allagnat et al. 2012; Eizirik et al. 2008). ER stress is believed to contribute to the cytotoxic effects of cytokines in pancreatic beta cells (Cardozo et al. 2005; Eizirik et al. 2008); however, only to some extent (Akerfeldt et al. 2008; Chambers et al. 2008; Gurgul-Convey \& Lenzen 2010; Mehmeti et al. 2011; Satoh et al. 2011). Therefore, the effects of mimitin overexpression on cytokine-induced ER stress in insulin-secreting INS1E cells were also examined in this study.

Caspase-12 localized mainly on the cytoplasmic side of the ER, specifically mediates the apoptosis pathway downstream of this organelle (Lamkanfi et al. 2004; Momoi 2004). Its activation occurs upon ER stress conditions comprising the disruption of ER calcium homeostasis and the accumulation of excess proteins in the ER (Nakagawa et al. 2000). It has been shown that prevention of caspase-12 activation only partially counteracts cytokine toxicity in beta cells (Gurgul-Convey \& Lenzen 2010). For this reason it is believed that the ER stress pathway contributes to cytokine-induced pancreatic beta cell death, but it is not able to induce it in the absence of activation of other stress pathways (Akerfeldt et al. 2008). Cytokines caused a significant induction of caspase-12 activity in INS1Econtrol cells (IL-1 $135 \pm 7$, cytokine mix $204 \pm 16 \%$ vs. untreated $100 \%$; Figure 9A). In contrast, mimitin overexpression greatly reduced cytokine-mediated caspase-12 activation (IL-1 $\beta$ 107 \pm 6 , cytokine mix $115 \pm 13 \%$; Figure 9A). The protective effect of mimitin was specific for cytokinemediated toxicity, because the activation of this ER stress related caspase by camptothecin $(0.5 \mu \mathrm{M})$ did not differ between INS1E-control and INS1E-mimitin cells (Figure 9A).

Since mimitin overexpression caused a significant prevention of caspase-12 activation, in the next step the expression of ER stress markers was analyzed. The basal expression of the ER chaperone Bip in INS1E-mimitin cells was significantly higher in comparison to INS1E-control cells (Figure 9B). The high secretory capacity of insulin-secreting cells requires a very well developed ER. An increased expression of Bip would support the proper function of ER in beta cells. The incubation with $600 \mathrm{U} / \mathrm{ml}$ IL-1 $\beta$ or a cytokine mixture for $24 \mathrm{~h}$ caused a significant decrease in the Bip transcription in both INS1E-control as well as INS1E-mimitin cells (Figure 9B). Those findings correspond with previous observations, demonstrating that cytokines significantly diminish the expression of Bip (Kacheva et al. 2011; Pirot et al. 2006). 
The transcription factor CHOP is considered to be a crucial component of ER stress-induced apoptosis (Gupta et al. 2010; Pirot et al. 2007). In untreated control as well as mimitin overexpressing INS1E cells an extremely low expression level of CHOP was observed (Figure 9C), which is in agreement with earlier studies (Kacheva et al. 2011; Oyadomari \& Mori 2004). Proinflammatory cytokines induced CHOP transcription in INS1E-control cells (IL-1 $\beta$ : 2-fold induction, cytokine mix: 6.5-fold induction) (Figure 9C), thus confirming earlier reports (Kacheva et al. 2011; Kharroubi et al. 2004). Interestingly, this cytokine-stimulated CHOP gene expression was either significantly abolished (incubation with IL-1 $\beta$ alone) or strongly reduced (cytokine mix: 2.5-fold induction) in mimitin overexpressing cells (Figure 9C).

Although it has been shown that inhibition of the NFKB activation may lead to a reduction of ER stress (Chambers et al. 2008; Tonnesen et al. 2009), the present results show that cytokine-induced ER stress in insulin-secreting cells may be effectively inhibited without simultaneous NFkB blockade (Hanzelka et al. 2012).

It remains unclear how the mitochondrial protein mimitin is able to counteract the cytokineinduced ER stress in beta cells. One of the possible mechanisms involved could be an interaction with the ER stress related microtubule-associated protein 1S (MAP1S). Recent studies performed in hepatoma HepG2 cells identified MAP1S as one of the proteins interacting with mimitin (Wegrzyn et al. 2009). This potential partner protein for mimitin is a proapoptotic cytoplasmic protein, which was shown to be upregulated upon cytokine treatment (Zou et al. 2008). Cytokine treatment led to a significant increase in MAP1S expression in insulin-secreting cells (Gurgul-Convey 2009). Moreover, it was also reported that MAP1S may be involved in ER stress induction and caused swelling of mitochondria (Xie et al. 2011). Therefore, it seems possible that mimitin may downregulate cytokinemediated ER stress in insulin-secreting cells via inhibition of the MAP1S action. It is assumed to be possible that this interaction may serve as a potential link between mitochondrial and cytoplasmic stress responses and eventually modulate cell death. However this hypothesis still requires further investigation. 

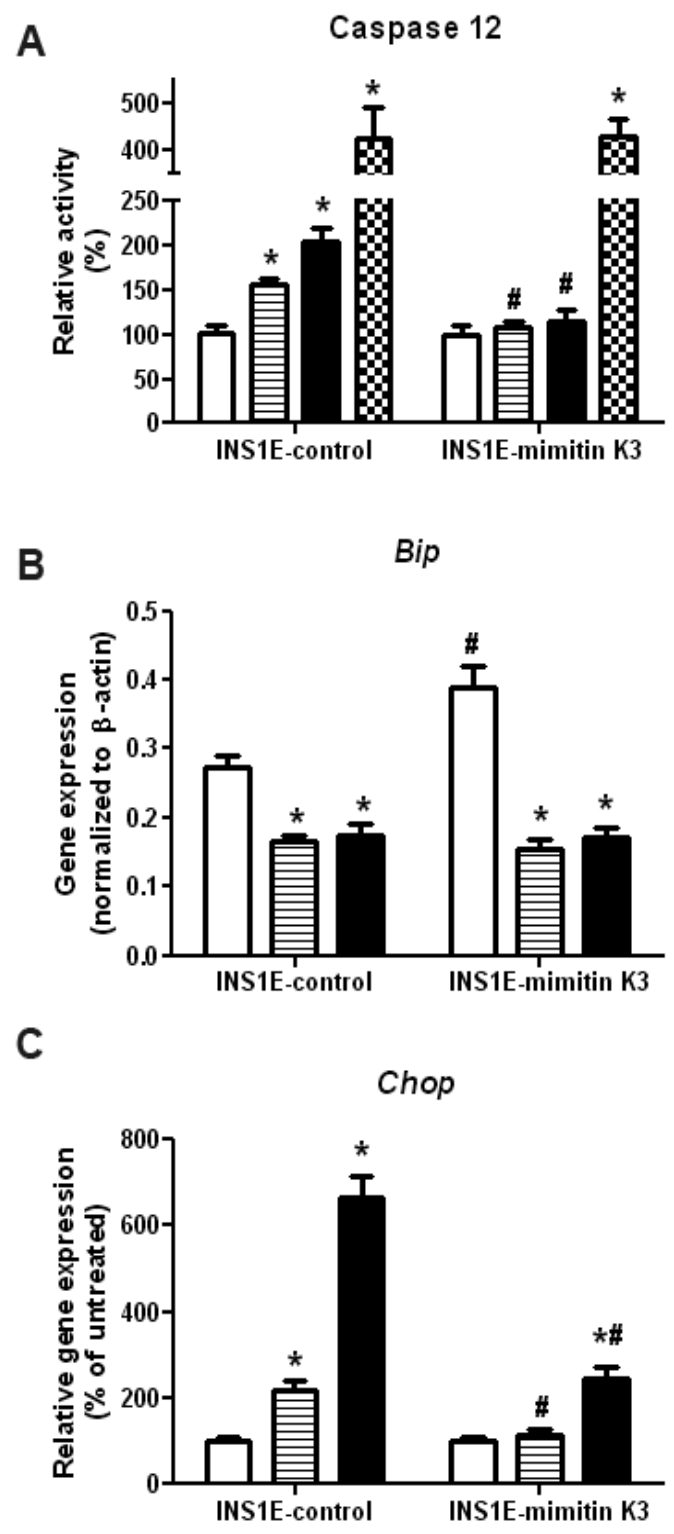

Figure 9 Effects of mimitin overexpression on cytokine-induced ER stress in insulin-secreting INS1E cells (Hanzelka 2012, unpublished).

INS1E cells were incubated with either IL-1 $\beta$ alone $(600 \mathrm{U} / \mathrm{ml})$ (striped bars) or with a cytokine mixture (60 $\mathrm{U} / \mathrm{ml} \mathrm{IL}-1 \beta, 185 \mathrm{U} / \mathrm{ml} \mathrm{TNF} \alpha, 14 \mathrm{U} / \mathrm{ml}$ IFN $\gamma$ ) (black bars) or camptothecin $(0.5 \mu \mathrm{M})$ (chequered bars) for $24 \mathrm{~h}$ and thereafter: A. Caspase-12 activation was analyzed by flow-cytometry; B. Bip gene expression was estimated by quantitative Real-Time PCR; C. Chop gene expression was measured by quantitative real-time PCR. The CHOP gene expression in each cell clone under untreated control conditions was set as $100 \%$. The data were normalized to the expression of the house-keeping gene $\beta$-actin. The sequences of the primers used are: rat Chop FW: CAGCAGAGGTCACAAGCAC, REV: CGCACTGACCACTCTGTTTC, rat Bip FW: CCACCAGGATGCAGACATTG, REV: AGGGCCTCCACTTCCATAGA; rat $\beta$-actin FW: GAACACGGCATTGTAACCAACTGG, REV: GGCCACACGCAGCTCATTGTA. Data are mean values from 6 independent experiments. p $^{*}<0.05$ vs. untreated, \#p $<0.05$ vs. INS1E-control cells treated in the same way; ANOVA followed by Bonferroni. 


\subsubsection{Mimitin in conditions simulating T2DM}

To study a possible role of mimitin in the T2DM situation mimitin expression was analyzed in the animal model of insulin resistance and obesity, the $o b / o b$ mouse. Mimitin expression was detected in mouse pancreatic islets. These $o b / o b$ mice carry a genetic mutation resulting in an inability to express functional leptin protein (Lam et al. 2004; Lindström 2007). Leptin is an adipocyte-derived hormone, which, by transferring information to the appetite centres in hypothalamic regions of the brain, regulates energy intake and expenditure (Ahima \& Flier 2000; Flier 1997; Friedman 1997; Friedman \& Halaas 1998; Lam et al. 2004; Trayhurn et al. 1999; Tritos \& Mantzoros 1997; Zhang et al. 1994). Both the increased food intake as well as the reduced energy expenditure of $o b / o b$ mice is a direct consequence of leptin deficiency. The $o b / o b$ mice are spontaneously hyperglycaemic, hyperinsulinemic, and grossly overweight (Campfield et al. 1995; Garthwaite et al. 1980; Halaas et al. 1995; Hellman 1965; Lenzen \& Panten 1980; Mayer et al. 1953; Pelleymounter et al. 1995). Moreover, their pancreatic islets are relatively large and contain a high proportion of insulin-producing beta cells (Hellman 1965; Lindström 2007). Therefore, ob/ob mice are often used as a source of pancreatic islets in order to investigate beta cell function. The present study did not reveal any significant difference considering mimitin expression levels between islets from $o b / o b$ mice and their lean litter mates (Hanzelka et al. 2012). Conversely, pronounced variation in mimitin expression was observed in other analyzed tissues, indicating a potential regulation of this protein in $o b / o b$ mice and its role in the development of metabolic disorders.

Since mimitin is involved in the synthesis of ATP a variation of its expression level may influence the AMP-activated protein kinase (AMPK). AMPK is one of the intracellular energy sensors and was proposed to provide a link in metabolic defects underlying progression to the metabolic syndrome (Carling 2004; Hardie et al. 1998; Kumar \& Peers 2006). Impairment of AMPK function is associated with metabolic alterations, insulin resistance, obesity, hormonal disorders, and cardiovascular disease (Kumar \& Peers 2006; Lage et al. 2008). AMPK acts as a "fuel gauge" and is activated by an increasing cellular AMP/ATP ratio, indicating a decrease in energy, resulting either from diminished ATP production or from augmented ATP consumption (Fryer \& Carling 2005; Hardie et al. 1998). Once activated the enzyme switches off anabolic and triggers catabolic pathways, resulting in the generation of ATP (Hardie 2011). The control of AMPK activity provides an attractive target for the development of new therapeutic strategies in metabolic disorders such as obesity and T2DM (Rutter \& Leclerc 2009; Viollet et al. 2007; Zhang et al. 2009).

AMPK was shown to be one of the main elements involved in leptin signalling (Frühbeck 2006; Sweeney 2002). An increase in its hypothalamic activity causes enhanced food intake and decreased energy expenditure, while inhibition of AMPK in the brain by leptin leads to opposite effects (Andersson et al. 2004; Kim et al. 2004; Minokoshi et al. 2004; Small et al. 2004). The present study showed a reduced mimitin level in the brain of $o b / o b$ mice. Therefore, the lower mimitin expression 
seems to potentiate the consequences of the lack of leptin by increasing AMPK activity resulting in higher food intake.

Liver AMPK controls glucose homeostasis mostly by reducing gluconeogenesis (Horike et al. 2008; Lage et al. 2008; Viana et al. 2006; Zhang et al. 2009). Moreover, it was demonstrated that AMPK activation mediated by the antidiabetic drug metformin suppresses glucose production and improves insulin sensitivity in hepatocytes (Viollet et al. 2006; Zhang et al. 2009; Zhou et al. 2001). The observed reduced level of mimitin found in the liver of the $o b / o b$ mouse may contribute to AMPK activation and preserve glucose homeostasis in liver as an adaptive response. Those findings may open new therapeutic perspectives, since AMPK activation in liver has recently been shown to be a useful approach for the treatment of hyperglycaemia and diabetes (Rutter \& Leclerc 2009).

AMPK is highly expressed in the kidney, where it is involved in the regulation of many physiological and pathological processes, including ion transport and diabetic renal hypertrophy (Hallows et al. 2010; Lee et al. 2007). AMPK activity was reported to be reduced in the diabetic kidney (Guo \& Zhao 2007). Moreover, recent studies strongly indicate that a high-fat diet decreases renal AMPK activity which eventually leads to the initiation of kidney disease (Declèves et al. 2011). In view of those findings an increased level of mimitin in $o b / o b$ mouse kidney, when compared to their lean litter mates, may contribute to renal dysfunction reported in this mouse model (Sharma et al. 2002).

The role of AMPK in the heart is of particular relevance, because of its high energy demand (Dyck \& Lopaschuk 2006). AMPK phosphorylates and activates phosphofructokinase-2, thus enhancing glycolytic flux (Fryer \& Carling 2005; Marsin et al. 2000). This pathway is suggested to be responsible for the increased rate of glycolysis in the heart during ischemic conditions (Marsin et al. 2000). The activation of AMPK may raise energy production and inhibit apoptosis, thereby protecting the heart during the ischemic stress (Dyck \& Lopaschuk 2006). The higher mimitin expression in the heart of $o b / o b$ mice compared with their lean litter mates may indicate increased ATP synthesis. An elevated ATP content in turn depresses the AMP/ATP ratio in the cells, which eventually could diminish AMPK activity.

It has been shown that AMPK contributes to the regulation of insulin secretion as well as insulin gene expression in pancreatic beta cells (Rutter \& Leclerc 2009). Overexpression of AMPK in those cells was reported to impair beta cell function and enhance cell death through apoptosis (Kefas et al. 2003; Richards et al. 2005; Rutter \& Leclerc 2009). Furthermore, activation of AMPK in isolated rodent and human islets was demonstrated to suppress glucose metabolism and glucose-induced insulin secretion (da Silva Xavier et al. 2000; da Silva Xavier et al. 2003; Eto et al. 2002; Leclerc et al. 2004). The pancreatic beta cells of $o b / o b$ mice were reported to respond adequately to most stimuli (Hellman 1965; Lenzen \& Panten 1980). Their proper function correlates with a similar level of mimitin expression in islets isolated from $o b / o b$ mice and their lean litter mates indicating comparable AMPK activity. 
The data obtained from spontaneously hyperglycaemic $o b / o b$ mice imply that mimitin is involved in the development of metabolic disorders. Thus, the present study opens new avenues to understand the complexity of mechanisms involved in the pathogenesis of metabolic disorders.

\subsubsection{Mimitin action in beta cells}

In summary the present study demonstrates that the novel mitochondrial protein mimitin may act as a mild modulator of beta cell function. The current findings indicate that mimitin is not an obligatory component of GSIS, but only potentiates it. Furthermore an increased mimitin expression level prevents inhibition of GSIS in the presence of cytokines. Overexpression of mimitin counteracts mitochondrial and ER stress and the preservation of mitochondrial integrity in conjunction with ER stress down-regulation underlie the protective anti-apoptotic effect of mimitin in beta cells. On the other hand, mimitin overexpression did not seem to counteract the necrotic component of cytokine toxicity and this was related to the lack of prevention of the cytokine-induced NFKB-iNOS pathway.

It remains unclear how mimitin overexpression inhibits the ER stress response and whether mimitin affects other cytokine-dependent signalling pathways in beta cells. A mechanistic model of mimitin action in pancreatic beta cells is shown in Figure 10. 


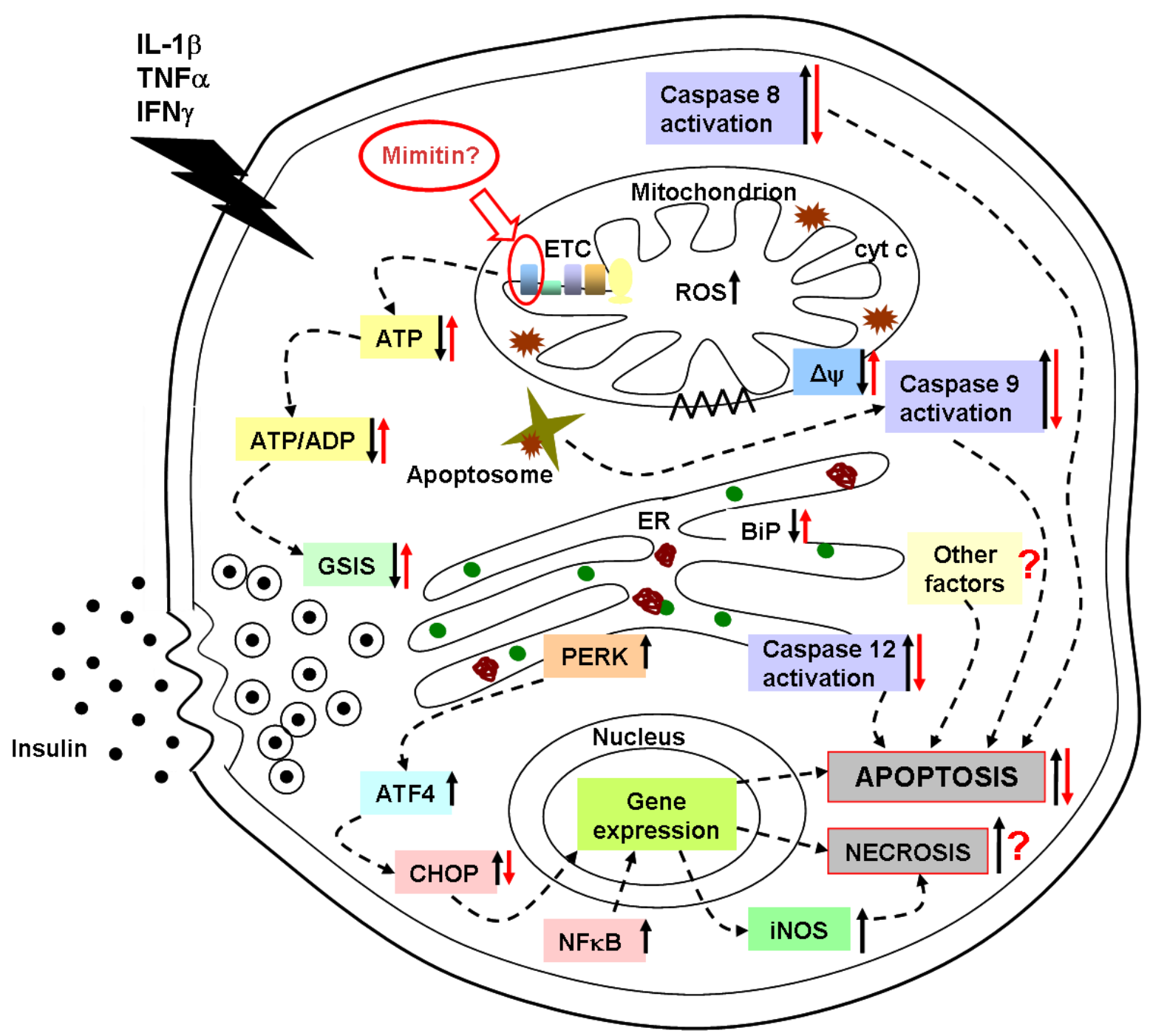

Figure 10 Mimitin overexpression protects pancreatic beta cells against cytokine toxicity.

Mimitin overexpression protects insulin-secreting cells against cytokine-induced mitochondrial and ER stress: cytokine-induced caspase- 9 activation is inhibited; mitochondrial membrane potential $(\Delta \psi)$ is not affected by cytokines, the ATP content is not reduced by cytokines, cytokine-stimulated caspase-12 activation and cytokinemediated induction of $\mathrm{CHOP}$ expression are reduced, basal expression of BiP is increased. Moreover overexpression of mimitin results in augmented basal insulin secretion and protects cells against cytokinemediated suppression of glucose-stimulated insulin secretion (GSIS). Black arrows: cytokine-mediated effects, red arrows: mimitin action. Abbreviations: cyt c-cytochrome, ETC-electron transport chain.

\subsection{Protective strategies, comparison between mimitin and prostacyclin synthase overexpression}

The two main forms of diabetes mellitus T1DM and T2DM are both characterized by a progressive beta cell failure and apoptosis is considered to be the main form of beta cell death (Cnop et al. 2005). Over the last decades research efforts focused on searching for potential protective strategies that could counteract the action of pathological factors leading to beta cell dysfunction and death. Pancreas transplantation, correlated with surgical morbidity and the detrimental effects of chronic immunosuppression, is not the method of choice in diabetic patients, especially since the reservoir of 
pancreases for transplantation is restricted. Therefore, there is a need for alternative approaches to restore functional beta cell mass in patients with diabetes. Currently the strategy of transplantation of insulin-secreting cells generated in vitro either from autologous adult stem cells or from nonautologous embryonic stem cells is extensively studied (Portha et al. 2011). Moreover, the attempts to promote regeneration of beta cell function from patients' endogenous sources have also been made (Portha et al. 2011; Robertson 2000).

Nitro-oxidative stress plays a critical role in the impairment of pancreatic beta cell function and cytokine-induced beta cell death occurring during diabetes development (Gurgul-Convey et al. 2011). Low antioxidant capacity of beta cells, particularly with respect to the $\mathrm{H}_{2} \mathrm{O}_{2}$-detoxifying enzymes, renders them extraordinarily sensitive towards oxidative stress and cytokine toxicity (AzevedoMartins et al. 2003; de Andrade et al. 2006; Drews et al. 2010; Green \& Reed 1998; Gurgul-Convey et al. 2011; Lenzen 2008; Lortz et al. 2005; Maechler \& de Andrade 2006; Petit et al. 1996; Turrens 2003). Therefore, improving the antioxidant defence presents a promising strategy to slow down the progression of diabetes. Studies employing insulin-secreting cell lines and animal models of diabetes provided a strong support for this therapeutical approach (de Cavanagh et al. 2001; Green et al. 2004; Hotta et al. 1998; Wolff 1993). It has been demonstrated that overexpression of antioxidant enzymes (particularly $\mathrm{H}_{2} \mathrm{O}_{2}$-detoxifying) in the mitochondrial compartment protects insulin-secreting cells against cytokine-induced oxidative stress (Gurgul et al. 2004).

The fundamental characteristic of pancreatic beta cells is their ability to secrete insulin in response to glucose. Therefore, maintenance of physiological GSIS is of particular importance in developing new strategies to treat diabetes.

The present study identified the novel mitochondrial protein, mimitin, as a protective factor diminishing cytokine-mediated mitochondrial and ER stress (Hanzelka et al. 2012). Mimitin overexpression was also shown to reduce cytokine-induced inhibition of GSIS, most probably by preserving the mitochondrial function. A similar protection against cytokine-induced mitochondrial and ER stress was recently demonstrated via overexpression of the enzyme prostacyclin synthase (PGIS) in insulin-secreting cells (Gurgul-Convey \& Lenzen 2010). PGIS synthesizes the antiinflammatory prostaglandin I2 (PGI2), also known as prostacyclin. After being released, prostacyclin binds to specific cell surface receptors (IP receptors), leading to their activation and production of cAMP (Sprague et al. 2008). PGI2 can also influence the metabolism and cell function by directly affecting intracellular pathways, without being released from the cell of origin. Likewise in mimitin overexpressing cells, also in those with PGIS overexpression, cytokine-induced activation of caspase-9 and caspase-12 was significantly diminished, which was further associated with the prevention of caspase- 3 activation. However, in contrast to mimitin overexpression, the protective effect of PGIS overexpression was reported to be strongly dependent on the inhibition of the NFkB signalling pathway (Gurgul-Convey \& Lenzen 2010). Consequently, stimulation of the inducible NO synthase promoter significantly declined, resulting in a reduced iNOS protein expression and nitrite 
production (Gurgul-Convey \& Lenzen 2010). The enhancement of glucose-induced insulin secretion, resulting from higher mimitin and PGIS expression, was in both cases accompanied by an increased intracellular ATP content. In mimitin overexpressing cells the observed increased ATP content originated from improved electron transport chain activity, as mimitin was shown to be a part of the mitochondrial complex I. On the other hand, a significantly higher rate of glucose oxidation, previously demonstrated in insulin-producing RINm5F cells overexpressing PGIS, may explain the ATP elevation triggered by PGI2 (Gurgul-Convey \& Lenzen 2010). A high ATP content also enables an efficient generation of cAMP in PGIS overexpressing cells. cAMP is a well-established potentiator of GSIS (Ammälä et al. 1993; Eliasson et al. 2003; Gromada et al. 1997; Hanna et al. 2009; MacDonald et al. 2005; Renström et al. 1997). It has been demonstrated that PGI2 acts via specific IP receptors, leading to the activation of adenyl cyclase and resulting in cAMP production (GurgulConvey et al. 2012). Therefore, an increased formation of cAMP was the major factor responsible for the potentiation of glucose-induced insulin secretion in PGIS overexpressing cells. A detailed analysis of cAMP action in INS1E-PGIS cells revealed that its enhancing effects on insulin secretion are exerted via the PKA-independent pathway (Gurgul-Convey et al. 2012). The Epac2 protein is crucially involved in this process (Gurgul-Convey et al. 2012). A similar mechanism of potentiation of GSIS has been described for GLP-1 (Holst 2007; Kielgast et al. 2009; Portha et al. 2011; Vilsbøll \& Garber 2012).

In contrast to insulin-secreting INS1E-mimitin cells, INS1E cells overexpressing PGIS were characterized by a higher insulin (Ins2) transcript level as well as insulin content, compared to INS1E control cells. The insulin content remained elevated along with a rising level of glucose concentrations. These findings implicate that PGIS overexpression may influence the transcription and/or translation of insulin. Protection against cytokine-induced ER stress previously demonstrated in insulin-secreting RINm5F cells overexpressing PGIS (Gurgul-Convey \& Lenzen 2010) additionally supports this hypothesis, pointing to the possible role of PGIS in maintaining ER biosynthetic capacity. A similar increase in Bip expression, however to a lesser extent, was also observed in mimitin overexpressing INS1E cells.

Moreover, overexpression of PGIS does not pose a threat of hypoglycaemic episodes, the risk of which was implied in the case of a high mimitin expression level. The magnitude of insulin secretion at the basal glucose concentration $(3 \mathrm{mM})$ was comparable in INS1E-control and PGIS-overexpressing INS1E cells, while INS1E cells overexpressing mimitin demonstrated significantly increased basal insulin secretion (Gurgul-Convey et al. 2012; Hanzelka et al. 2012).

Furthermore, in line with the proven correlation between beta cell proliferation and ATP production, an increased ATP content improved proliferative capacity in PGIS- and mimitinoverexpressing cells. In conclusion, prostacyclin seems to represent a more favourable approach to maintain the insulin secretory responsiveness of beta cells when compared with mimitin overexpression. 


\subsection{The nNOS in pancreatic beta cells}

At low concentrations NO plays a role in a number of physiological processes involving different tissues of nervous, cardiovascular and immune system. The constitutive forms of NOS synthases account for these small amounts of NO, however from among them only nNOS was shown to be present in pancreatic beta cells. The second constitutively expressed NOS isoform, namely eNOS was shown to be exclusively expressed in secretory granules of glucagon- and somatostatin-secreting cells (Spinas et al. 1986). The results obtained in this study further confirmed the presence of nNOS in insulin-secreting cells, which is in agreement with previous reports (Lajoix et al. 2001). The expression of nNOS was shown to be decreased upon cytokine treatment in INS1E cells as well as in rat islets, although the latter one was characterized by a lower expression level of this enzyme.

According to recent studies the activation of the JNK pathway can cause the reduction of nNOS protein expression (Wang et al. 2011). Therefore the decrease in the enzyme protein level observed after treatment with a cytokine mixture may, at least to a certain extent, stem from the JNK activation evoked by cytokines. Those mediators of pancreatic beta cell death lead also to the induction of iNOS expression, resulting mainly from the activation of transcription factor $\mathrm{NF \kappa B}$. This in turn is caused primarily by IL-1 $\beta$, since TNF $\alpha$ has been shown to prompt only moderate induction of NFkB. Consequently, it seems possible that during the late stages of islet infiltration, in the course of T1DM development and characterized by the presence of all three proinflammatory cytokines, pancreatic beta cells are exposed to large amounts of NO. Subsequently, the reaction between NO and the hydrogen peroxide is boosted, causing the formation of highly toxic hydroxyl radicals, which eventually leads to pancreatic beta cell death (Gurgul-Convey et al. 2011). NO formation originating from the induction of iNOS was also demonstrated to inhibit glucose-induced insulin secretion, with a parallel decrease in insulin content (Henningsson et al. 2002). Those findings were confirmed in the present study, pointing to the potent deleterious effects of IL-1 $\beta$, further potentiated by TNF $\alpha$. Overall the present study strongly indicates that NO production induced by cytokines originates solely from the activity of iNOS, without concomitant contribution of any other NOS isoform. Further, our findings provide a clear implication that a low basal level of NO, synthesized by nNOS, does not exert detrimental effects on pancreatic beta cells. The nNOS is able to prevent iNOS induction in some cell types and its partial knock down increased JNK phosphorylation and CHOP production, eventually leading to apoptosis (Bachar et al. 2010). Therefore it seems possible that a reduction of nNOS expression, caused by cytokines might be adverse for pancreatic beta cells. 


\subsection{Conclusions}

The results presented in this study provide new knowledge about the action of proinflammatory cytokines in pancreatic beta cells. This work confirms the importance of mitochondrial and, to a lesser extent, ER stresses in cytokine toxicity. It describes for the first time a new modulator of pancreatic beta cell function, mimitin.

Moreover, the study presents a novel powerful potentiator of glucose-induced insulin secretion, prostacyclin, and shows that its stable analogues, already commonly used to treat hypertension, could serve as potential anti-diabetic drugs.

The results show also the existence of a firm balance between the activity of nNOS and iNOS and its important role for pancreatic beta cell life and death.

Thus, the present study opens new therapeutic perspectives for the treatment of T1DM. 


\section{LIST OF REFERENCES}

Ahima RS, Flier JS: Leptin. Annu Rev Physiol 2000; 62: 413-437

Akerfeldt MC, Howes J, Chan JY, Stevens VA, Boubenna N, McGuire HM, King C, Biden TJ, Laybutt DR: Cytokine-induced beta-cell death is independent of endoplasmic reticulum stress signaling. Diabetes 2008; 57: 3034-3044

Allagnat F, Fukaya M, Nogueira TC, Delaroche D, Welsh N, Marselli L, Marchetti P, Haefliger JA, Eizirik DL, Cardozo AK: C/EBP homologous protein contributes to cytokine-induced proinflammatory responses and apoptosis in [beta]-cells. Cell Death Differ 2012; doi: 10.1038/cdd.2012.67

Ammälä C, Ashcroft FM, Rorsman P: Calcium-independent potentiation of insulin release by cyclic AMP in single beta-cells. Nature 1993; 363: 356-358

Ammon HP: Hyper- and hypoinsulinemia in type-2 diabetes: what may be wrong in the secretory mechanism of the B-cell. Exp Clin Endocrinol Diabetes 1997; 105: S43-47

Andersen NA, Larsen CM, Mandrup-Poulsen T: TNFalpha and IFNgamma potentiate IL-1beta induced mitogen activated protein kinase activity in rat pancreatic islets of Langerhans. Diabetologia 2000; 43: 1389-1396

Andersson U, Filipsson K, Abbott CR, Woods A, Smith K, Bloom SR, Carling D, Small CJ: AMP-activated protein kinase plays a role in the control of food intake. J Biol Chem 2004; 279: 12005-12008

Arita S, Kasraie A, Une S, Ohtsuka S, Kawahara T, Shevlin L, Matusda N, Amirmoazzami S, Mullen Y: Beraprost sodium improves islet yield and viability in canine islet cryopreservation. Transplant Proc 1997; 29: 1977

Arita S, Une S, Ohtsuka S, Kawahara T, Kasraie A, Shevlin L, Mullen Y: The islet protective effect of beraprost sodium during collagenase digestion. Transplant Proc 1998; 30: 366

Arita S, Kasraie A, Une S, Ohtsuka S, Kawahara T, Smith CV, Mullen Y: Improved recovery of cryopreserved canine islets by use of beraprost sodium. Pancreas 1999; 19: 289-296

Arita S, Une S, Ohtsuka S, Kawahara T, Kasraie A, Smith CV, Mullen Y: Increased islet viability by addition of beraprost sodium to collagenase solution. Pancreas 2001; 23: 62-67

Ashcroft FM, Rorsman P: Electrophysiology of the pancreatic beta-cell. Prog Biophys Mol Biol 1989; 54: 87-143

Ashcroft SJ, Weerasinghe LC, Randle PJ: Interrelationship of islet metabolism, adenosine triphosphate content and insulin release. Biochem J 1973; 132: 223-231

Ashcroft SJ: Glucoreceptor mechanisms and the control of insulin release and biosynthesis. Diabetologia 1980; 18: 5-15

Atkinson MA, Maclaren NK, Riley WJ, Winter WE, Fisk DD, Spillar RP: Are insulin autoantibodies markers for insulin-dependent diabetes mellitus? Diabetes 1986; 35: 894-898

Atkinson MA, Maclaren NK: The pathogenesis of insulin-dependent diabetes mellitus. N Engl J Med 1994; 331: 1428-1436

Azevedo-Martins AK, Lortz S, Lenzen S, Curi R, Eizirik DL, Tiedge M: Improvement of the mitochondrial antioxidant defense status prevents cytokine-induced nuclear factor-kappaB activation in insulin-producing cells. Diabetes 2003; 52: 93-101

Bachar E, Ariav Y, Cerasi E, Kaiser N, Leibowitz G: Neuronal nitric oxide synthase protects the pancreatic beta cell from glucolipotoxicity-induced endoplasmic reticulum stress and apoptosis. Diabetologia 2010; 53: 2177-2187 
Barnett AH, Eff C, Leslie RD, Pyke DA: Diabetes in identical twins. A study of 200 pairs. Diabetologia 1981; 20: 87-93

Bast A, Wolf G, Oberbäumer I, Walther R: Oxidative and nitrosative stress induces peroxiredoxins in pancreatic beta cells. Diabetologia 2002; 45: 867-876

Beckman KB, Ames BN: Mitochondrial aging: open questions. Ann N Y Acad Sci 1998; 854: 118 127

Bertolotti A, Zhang Y, Hendershot LM, Harding HP, Ron D: Dynamic interaction of BiP and ER stress transducers in the unfolded-protein response. Nat Cell Biol 2000; 2: 326-332

Bhola PD, Mattheyses AL, Simon SM: Spatial and temporal dynamics of mitochondrial membrane permeability waves during apoptosis. Biophys J 2009; 97: 2222-2231

Bigdeli N, Niemann A, Sandler S, Eizirik DL: Dissociation between interleukin-1 beta-induced expression of mRNA for superoxide dismutase and nitric oxide synthase in insulin-producing cells. Biochem Biophys Res Commun 1994; 203: 1542-1547

Bluestone JA, Herold K, Eisenbarth G: Genetics, pathogenesis and clinical interventions in type 1 diabetes. Nature 2010; 464: 1293-1300

Boden G, Murer E, Mozzoli M: Glucose transporter proteins in human insulinoma. Ann Intern Med 1994; 121: 109-112

Bonnefond A, Froguel P, Vaxillaire M: The emerging genetics of type 2 diabetes. Trends Mol Med 2010; 16: 407-416

Bonner-Weir S: Life and death of the pancreatic beta cells. Trends Endocrinol Metab 2000; 11: 375378

Borg LA, Cagliero E, Sandler S, Welsh N, Eizirik DL: Interleukin-1 beta increases the activity of superoxide dismutase in rat pancreatic islets. Endocrinology 1992; 130: 2851-2857

Bratanova-Tochkova TK, Cheng H, Daniel S, Gunawardana S, Liu YJ, Mulvaney-Musa J, Schermerhorn T, Straub SG, Yajima H, Sharp GW: Triggering and augmentation mechanisms, granule pools, and biphasic insulin secretion. Diabetes 2002; 51: S83-90

Broca C, Brennan L, Petit P, Newsholme P, Maechler P: Mitochondria-derived glutamate at the interplay between branched-chain amino acid and glucose-induced insulin secretion. FEBS Lett 2003; 545: 167-172

Brownlee M: The pathobiology of diabetic complications: a unifying mechanism. Diabetes 2005; 54 : $1615-1625$

Campfield LA, Smith FJ, Guisez Y, Devos R, Burn P: Recombinant mouse OB protein: evidence for a peripheral signal linking adiposity and central neural networks. Science 1995; 269: 546-549

Cardozo AK, De Meirleir L, Liebaers I, Lissens W: Analysis of exonic mutations leading to exon skipping in patients with pyruvate dehydrogenase E1 alpha deficiency. Pediatr Res 2000; 48: 748-753

Cardozo AK, Kruhøffer M, Leeman R, Orntoft T, Eizirik DL: Identification of novel cytokineinduced genes in pancreatic beta-cells by high-density oligonucleotide arrays. Diabetes 2001; 50: 909920

Cardozo AK, Ortis F, Storling J, Feng YM, Rasschaert J, Tonnesen M, Van Eylen F, MandrupPoulsen T, Herchuelz A, Eizirik DL: Cytokines downregulate the sarcoendoplasmic reticulum pump $\mathrm{Ca}^{2+}$ ATPase $2 \mathrm{~b}$ and deplete endoplasmic reticulum $\mathrm{Ca}^{2+}$, leading to induction of endoplasmic reticulum stress in pancreatic beta-cells. Diabetes 2005; 54: 452-461

Carling D: The AMP-activated protein kinase cascade-a unifying system for energy control. Trends Biochem Sci 2004; 29: 18-24

Castaño L, Eisenbarth GS: Type-I diabetes: a chronic autoimmune disease of human, mouse, and rat. Annu Rev Immunol 1990; 8: 647-679 
Cauchi S, Froguel P: TCF7L2 genetic defect and type 2 diabetes. Curr Diab Rep 2008; 8: 149-155

Cetkovic-Cvrlje M, Eizirik DL: TNF-alpha and IFN-gamma potentiate the deleterious effects of IL-1 beta on mouse pancreatic islets mainly via generation of nitric oxide. Cytokine 1994; 6: 399-406

Chambers KT, Unverferth JA, Weber SM, Wek RC, Urano F, Corbett JA: The role of nitric oxide and the unfolded protein response in cytokine-induced beta-cell death. Diabetes 2008; 57: 124132

Chance B, Sies H, Boveris A: Hydroperoxide metabolism in mammalian organs. Physiol Rev 1979; 59: 527-605

Chandra J, Zhivotovsky B, Zaitsev S, Juntti-Berggren L, Berggren PO, Orrenius S: Role of apoptosis in pancreatic beta-cell death in diabetes. Diabetes 2001; 50: S44-47

Cnop M, Welsh N, Jonas JC, Jörns A, Lenzen S, Eizirik DL: Mechanisms of pancreatic beta-cell death in type 1 and type 2 diabetes: many differences, few similarities. Diabetes 2005; 54: S97-107

Cnop M, Foufelle F, Velloso LA: Endoplasmic reticulum stress, obesity and diabetes. Trends Mol Med 2012; 18: 59-68

Corbett JA, Wang JL, Hughes JH, Wolf BA, Sweetland MA, Lancaster JR, Jr., McDaniel ML: Nitric oxide and cyclic GMP formation induced by interleukin 1 beta in islets of Langerhans. Evidence for an effector role of nitric oxide in islet dysfunction. Biochem J 1992; 287: 229-235

Corbett JA, McDaniel ML: Intraislet release of interleukin 1 inhibits beta cell function by inducing beta cell expression of inducible nitric oxide synthase. J Exp Med 1995; 181: 559-568

Crawford DR, Abramova NE, Davies KJ: Oxidative stress causes a general, calcium-dependent degradation of mitochondrial polynucleotides. Free Radic Biol Med 1998; 25: 1106-1111

da Silva Xavier G, Varadi A, Ainscow EK, Rutter GA: Regulation of gene expression by glucose in pancreatic beta -cells (MIN6) via insulin secretion and activation of phosphatidylinositol 3'-kinase. J Biol Chem 2000; 275: 36269-36277

da Silva Xavier G, Leclerc I, Varadi A, Tsuboi T, Moule SK, Rutter GA: Role for AMP-activated protein kinase in glucose-stimulated insulin secretion and preproinsulin gene expression. Biochem $\mathbf{J}$ 2003; 371: 761-774

Daneman D: Type 1 diabetes. Lancet 2006; 367: 847-858

de Andrade PB, Rubi B, Frigerio F, van den Ouweland JM, Maassen JA, Maechler P: Diabetesassociated mitochondrial DNA mutation A3243G impairs cellular metabolic pathways necessary for beta cell function. Diabetologia 2006; 49: 1816-1826

de Cavanagh EM, Inserra F, Toblli J, Stella I, Fraga CG, Ferder L: Enalapril attenuates oxidative stress in diabetic rats. Hypertension 2001; 38: 1130-1136

De Vos A, Heimberg H, Quartier E, Huypens P, Bouwens L, Pipeleers D, Schuit F: Human and rat beta cells differ in glucose transporter but not in glucokinase gene expression. J Clin Invest 1995; 96: 2489-2495

Dean PM: Ultrastructural morphometry of the pancreatic $\beta$-cell. Diabetologia 1973; 9: 115-119

Declèves AE, Mathew AV, Cunard R, Sharma K: AMPK mediates the initiation of kidney disease induced by a high-fat diet. J Am Soc Nephrol 2011; 22: 1846-1855

Degli Esposti M: Measuring mitochondrial reactive oxygen species. Methods 2002; 26: 335-340

Delaney CA, Eizirik DL: Intracellular targets for nitric oxide toxicity to pancreatic beta-cells. Braz J Med Biol Res 1996; 29: 569-579

Delaney CA, Pavlovic D, Hoorens A, Pipeleers DG, Eizirik DL: Cytokines induce deoxyribonucleic acid strand breaks and apoptosis in human pancreatic islet cells. Endocrinology 1997; 138: 2610-2614 
Detimary P, Gilon P, Nenquin M, Henquin JC: Two sites of glucose control of insulin release with distinct dependence on the energy state in pancreatic B-cells. Biochem J 1994; 297: 455-461

DeWitt DL, Day JS, Sonnenburg WK, Smith WL: Concentrations of prostaglandin endoperoxide synthase and prostaglandin 2 synthase in the endothelium and smooth muscle of bovine aorta. J Clin Invest 1983; 72: 1882-1888

Dinarello CA: Interleukin-1. Cytokine Growth Factor Rev 1997; 8: 253-265

Donath MY, Størling J, Maedler K, Mandrup-Poulsen T: Inflammatory mediators and islet betacell failure: a link between type 1 and type 2 diabetes. J Mol Med 2003; 81: 455-470

Drews G, Krippeit-Drews P, Düfer M: Oxidative stress and beta-cell dysfunction. Pflugers Arch 2010; 460: 703-718

Duchen MR, Smith PA, Ashcroft FM: Substrate-dependent changes in mitochondrial function, intracellular free calcium concentration and membrane channels in pancreatic beta-cells. Biochem $\mathbf{J}$ 1993; 294: 35-42

Duchen MR: Roles of mitochondria in health and disease. Diabetes 2004; 53: S96-102

Durruty P, Garcia de los Rios M: [Glucotoxicity and lipotoxicity: factors in the pathogenesis and evolution of type 2 diabetes]. Rev Med Chil 2001; 129: 671-679

Dyck JR, Lopaschuk GD: AMPK alterations in cardiac physiology and pathology: enemy or ally? J Physiol 2006; 574: 95-112

Eisenbarth GS, Lafferty KJ: Type I diabete : molecular, cellular, and clinical immunology. George S. Eisenbarth, Ed. New York Oxford University Press, 1996

Eisenbarth GS: Type 1 Diabetes: Cellular, Molecular \& Clinical Immunology. Online Edition Version 3.0 ed., 2006

Eizirik DL, Delaney CA, Green MH, Cunningham JM, Thorpe JR, Pipeleers DG, Hellerström

C, Green IC: Nitric oxide donors decrease the function and survival of human pancreatic islets. Mol Cell Endocrinol 1996; 118: 71-83

Eizirik DL, Pavlovic D: Is there a role for nitric oxide in beta-cell dysfunction and damage in IDDM? Diabetes Metab Rev 1997; 13: 293-307

Eizirik DL, Darville MI: beta-cell apoptosis and defense mechanisms: lessons from type 1 diabetes. Diabetes 2001; 50: S64-69

Eizirik DL, Mandrup-Poulsen T: A choice of death-the signal-transduction of immune-mediated beta-cell apoptosis. Diabetologia 2001; 44: 2115-2133

Eizirik DL, Cardozo AK, Cnop M: The role for endoplasmic reticulum stress in diabetes mellitus. Endocr Rev 2008; 29: 42-61

Eizirik DL, Colli ML, Ortis F: The role of inflammation in insulitis and beta-cell loss in type 1 diabetes. Nat Rev Endocrinol 2009; 5: 219-226

Eizirik DL, Cnop M: ER stress in pancreatic beta cells: the thin red line between adaptation and failure. Sci Signal 2010; 3: pe7

Eliasson L, Renström E, Ding WG, Proks P, Rorsman P: Rapid ATP-dependent priming of secretory granules precedes $\mathrm{Ca}^{2+}$-induced exocytosis in mouse pancreatic B-cells. J Physiol 1997; 503: $399-412$

Eliasson L, Ma X, Renström E, Barg S, Berggren PO, Galvanovskis J, Gromada J, Jing X, Lundquist I, Salehi A, Sewing S, Rorsman P: SUR1 regulates PKA-independent cAMP-induced granule priming in mouse pancreatic B-cells. J Gen Physiol 2003; 121: 181-197

Eruslanov E, Kusmartsev S: Identification of ROS using oxidized DCFDA and flow-cytometry. Methods Mol Biol 2010; 594: 57-72 
Eto K, Yamashita T, Matsui J, Terauchi Y, Noda M, Kadowaki T: Genetic manipulations of fatty acid metabolism in beta-cells are associated with dysregulated insulin secretion. Diabetes 2002; 51: S414-420

Ferber S, BeltrandelRio H, Johnson JH, Noel RJ, Cassidy LE, Clark S, Becker TC, Hughes SD, Newgard CB: GLUT-2 gene transfer into insulinoma cells confers both low and high affinity glucosestimulated insulin release. Relationship to glucokinase activity. J Biol Chem 1994; 269: 11523-11529

Flier JS: Leptin expression and action: new experimental paradigms. Proc Natl Acad Sci U S A 1997; 94: 4242-4245

Fonseca SG, Gromada J, Urano F: Endoplasmic reticulum stress and pancreatic beta-cell death. Trends Endocrinol Metab 2011; 22: 266-274

Foulis AK, Liddle CN, Farquharson MA, Richmond JA, Weir RS: The histopathology of the pancreas in type 1 (insulin-dependent) diabetes mellitus: a 25-year review of deaths in patients under 20 years of age in the United Kingdom. Diabetologia 1986; 29: 267-274

Friedman JM: Leptin, leptin receptors and the control of body weight. Eur J Med Res 1997; 2: 7-13

Friedman JM, Halaas JL: Leptin and the regulation of body weight in mammals. Nature 1998; 395: 763-770

Froguel P, Vaxillaire M, Sun F, Velho G, Zouali H, Butel MO, Lesage S, Vionnet N, Clément K, Fougerousse F, et al.: Close linkage of glucokinase locus on chromosome $7 p$ to early-onset noninsulin-dependent diabetes mellitus. Nature 1992; 356: 162-164

Frühbeck G: Intracellular signalling pathways activated by leptin. Biochem J 2006; 393: 7-20

Fryer LG, Carling D: AMP-activated protein kinase and the metabolic syndrome. Biochem Soc Trans 2005; 33: 362-366

Gardner DS, Tai ES: Clinical features and treatment of maturity onset diabetes of the young (MODY). Diabetes Metab Syndr Obes 2012; 5: 101-108

Garthwaite TL, Martinson DR, Tseng LF, Hagen TC, Menahan LA: A longitudinal hormonal profile of the genetically obese mouse. Endocrinology 1980; 107: 671-676

Gehrmann W, Elsner M, Lenzen S: Role of metabolically generated reactive oxygen species for lipotoxicity in pancreatic beta-cells. Diabetes Obes Metab 2010; 12: 149-158

Gottlieb E, Armour SM, Harris MH, Thompson CB: Mitochondrial membrane potential regulates matrix configuration and cytochrome c release during apoptosis. Cell Death Differ 2003; 10: 709-717

Grant SF, Hakonarson H, Schwartz S: Can the genetics of type 1 and type 2 diabetes shed light on the genetics of latent autoimmune diabetes in adults? Endocr Rev 2010; 31: 183-193

Green DR, Reed JC: Mitochondria and apoptosis. Science 1998; 281: 1309-1312

Green K, Brand MD, Murphy MP: Prevention of mitochondrial oxidative damage as a therapeutic strategy in diabetes. Diabetes 2004; 53: S110-118

Greenberg AS, McDaniel ML: Identifying the links between obesity, insulin resistance and beta-cell function: potential role of adipocyte-derived cytokines in the pathogenesis of type 2 diabetes. Eur $\mathbf{J}$ Clin Invest 2002; 32: 24-34

Grodsky GM, Bennett LL, Smith DF, Schmid FG: Effect of pulse administration of glucose or glucagon on insulin secretion in vitro. Metabolism 1967; 16: 222-233

Gromada J, Ding WG, Barg S, Renström E, Rorsman P: Multisite regulation of insulin secretion by cAMP-increasing agonists: evidence that glucagon-like peptide 1 and glucagon act via distinct receptors. Pflugers Arch 1997; 434: 515-524 
Grunnet LG, Aikin R, Tonnesen MF, Paraskevas S, Blaabjerg L, Storling J, Rosenberg L, Billestrup N, Maysinger D, Mandrup-Poulsen T: Proinflammatory cytokines activate the intrinsic apoptotic pathway in beta-cells. Diabetes 2009; 58: 1807-1815

Grunnet LG, Mandrup-Poulsen T: Cytokines and type 1 diabetes: a numbers game. Diabetes 2011; 60: 697-699

Guo Z, Zhao Z: Effect of N-acetylcysteine on plasma adiponectin and renal adiponectin receptors in streptozotocin-induced diabetic rats. Eur J Pharmacol 2007; 558: 208-213

Gupta S, Cuffe L, Szegezdi E, Logue SE, Neary C, Healy S, Samali A: Mechanisms of ER StressMediated Mitochondrial Membrane Permeabilization. Int J Cell Biol 2010; 2010: 170215

Gurgul-Convey E, Lenzen S: Protection against cytokine toxicity through endoplasmic reticulum and mitochondrial stress prevention by prostacyclin synthase overexpression in insulin-producing cells. J Biol Chem 2010; 285: 11121-11128

Gurgul-Convey E, Mehmeti I, Lortz S, Lenzen S: Cytokine toxicity in insulin-producing cells is mediated by nitro-oxidative stress-induced hydroxyl radical formation in mitochondria. $\mathbf{J}$ Mol Med 2011; 89: 785-798

Gurgul-Convey E, Hanzelka K, Lenzen S: Mechanism of prostacyclin-induced potentiation of glucose-induced insulin secretion. Endocrinology 2012; 153: 2612-2622

Gurgul-Convey E, Hanzelka K, Kacheva S, Jura J, Lenzen S: Die Rolle Stickstoffmonoxids für zytokin-vermittelter Mimitin Genexpression in insulin-produzierenden Zellen. In 44th Annual Meeting of German Diabetes Society (Deutschen Diabetes-Gesellschaft, DDG) Leipzig, Germany, 2009

Gurgul E, Lortz S, Tiedge M, Jörns A, Lenzen S: Mitochondrial catalase overexpression protects insulin-producing cells against toxicity of reactive oxygen species and proinflammatory cytokines. Diabetes 2004; 53: 2271-2280

Gurzov EN, Ortis F, Cunha DA, Gosset G, Li M, Cardozo AK, Eizirik DL: Signaling by IL1 beta+IFN-gamma and ER stress converge on DP5/Hrk activation: a novel mechanism for pancreatic beta-cell apoptosis. Cell Death Differ 2009; 16: 1539-1550

Halaas JL, Gajiwala KS, Maffei M, Cohen SL, Chait BT, Rabinowitz D, Lallone RL, Burley SK, Friedman JM: Weight-reducing effects of the plasma protein encoded by the obese gene. Science 1995; 269: 543-546

Hallows KR, Mount PF, Pastor-Soler NM, Power DA: Role of the energy sensor AMP-activated protein kinase in renal physiology and disease. Am J Physiol Renal Physiol 2010: 298: F1067-F1077

Hanna ST, Pigeau GM, Galvanovskis J, Clark A, Rorsman P, MacDonald PE: Kiss-and-run exocytosis and fusion pores of secretory vesicles in human beta-cells. Pflugers Arch 2009; 457: 13431350

Hanzelka K, Skalniak L, Jura J, Lenzen S, Gurgul-Convey E: Effects of the novel mitochondrial protein mimitin in insulin-secreting cells. Biochem J 2012; 445: 349-359

Hardie DG, Carling D, Carlson M: The AMP-activated/SNF1 protein kinase subfamily: metabolic sensors of the eukaryotic cell? Annu Rev Biochem 1998; 67: 821-855

Hardie DG: Sensing of energy and nutrients by AMP-activated protein kinase. Am J Clin Nutr 2011; 93: 891S-896

Häring HU, Mehnert H: Pathogenesis of type 2 (non-insulin-dependent) diabetes mellitus: candidates for a signal transmitter defect causing insulin resistance of the skeletal muscle. Diabetologia 1993; 36: 176-182

Hatae T, Wada M, Yokoyama C, Shimonishi M, Tanabe T: Prostacyclin-dependent apoptosis mediated by PPAR delta. J Biol Chem 2001; 276: 46260-46267 
Heitmeier MR, Scarim AL, Corbett JA: Double-stranded RNA inhibits beta-cell function and induces islet damage by stimulating beta-cell production of nitric oxide. J Biol Chem 1999; 274: $12531-12536$

Hellman B: Studies in obese-hyperglycemic mice. Ann N Y Acad Sci 1965; 131: 541-558

Henningsson R, Salehi A, Lundquist I: Role of nitric oxide synthase isoforms in glucose-stimulated insulin release. Am J Physiol Cell Physiol 2002; 283: C296-304

Henquin JC: ATP-sensitive $\mathrm{K}^{+}$channels may control glucose-induced electrical activity in pancreatic B-cells. Biochem Biophys Res Commun 1988; 156: 769-775

Henquin JC: Triggering and amplifying pathways of regulation of insulin secretion by glucose. Diabetes 2000; 49: 1751-1760

Henquin JC, Ishiyama N, Nenquin M, Ravier MA, Jonas JC: Signals and pools underlying biphasic insulin secretion. Diabetes 2002; 51: S60-67

Hertel JK, Johansson S, Raeder H, Midthjell K, Lyssenko V, Groop L, Molven A, Njølstad PR: Genetic analysis of recently identified type 2 diabetes loci in 1,638 unselected patients with type 2 diabetes and 1,858 control participants from a Norwegian population-based cohort (the HUNT study). Diabetologia 2008; 51: 971-977

Hill BG, Dranka BP, Bailey SM, Lancaster JR, Jr., Darley-Usmar VM: What part of NO don't you understand? Some answers to the cardinal questions in nitric oxide biology. J Biol Chem 2010; 285: 19699-19704

Hirayama I, Tamemoto H, Yokota H, Kubo SK, Wang J, Kuwano H, Nagamachi Y, Takeuchi T, Izumi T: Insulin receptor-related receptor is expressed in pancreatic beta-cells and stimulates tyrosine phosphorylation of insulin receptor substrate-1 and -2. Diabetes 1999; 48: 1237-1244

Holohan C, Szegezdi E, Ritter T, O'Brien T, Samali A: Cytokine-induced beta-cell apoptosis is NO-dependent, mitochondria-mediated and inhibited by BCL-X $\mathrm{X}_{\mathrm{L}}$. J Cell Mol Med 2008; 12: 591-606

Holst JJ: The physiology of glucagon-like peptide 1. Physiol Rev 2007; 87: 1409-1439

Horike N, Sakoda H, Kushiyama A, Ono H, Fujishiro M, Kamata H, Nishiyama K, Uchijima Y, Kurihara Y, Kurihara H, Asano T: AMP-activated protein kinase activation increases phosphorylation of glycogen synthase kinase $3 \beta$ and thereby reduces cAMP-responsive element transcriptional activity and phosphoenolpyruvate carboxykinase $\mathrm{C}$ gene expression in the liver. $\mathrm{J}$ Biol Chem 2008; 283: 33902-33910

Hotta M, Tashiro F, Ikegami H, Niwa H, Ogihara T, Yodoi J, Miyazaki J: Pancreatic beta cellspecific expression of thioredoxin, an antioxidative and antiapoptotic protein, prevents autoimmune and streptozotocin-induced diabetes. J Exp Med 1998; 188: 1445-1451

Hutton JC, Eisenbarth GS: A pancreatic beta-cell-specific homolog of glucose-6-phosphatase emerges as a major target of cell-mediated autoimmunity in diabetes. Proc Natl Acad Sci U S A 2003; 100: $8626-8628$

Ishihara H, Asano T, Tsukuda K, Katagiri H, Inukai K, Anai M, Kikuchi M, Yazaki Y, Miyazaki JI, Oka Y: Pancreatic beta cell line MIN6 exhibits characteristics of glucose metabolism and glucose-stimulated insulin secretion similar to those of normal islets. Diabetologia 1993; 36: $1139-1145$

Iynedjian PB, Pilot PR, Nouspikel T, Milburn JL, Quaade C, Hughes S, Ucla C, Newgard CB: Differential expression and regulation of the glucokinase gene in liver and islets of Langerhans. Proc Natl Acad Sci U S A 1989; 86: 7838-7842

Jacobsen ML, Rønn SG, Bruun C, Larsen CM, Eizirik DL, Mandrup-Poulsen T, Billestrup N: IL-1beta-induced chemokine and Fas expression are inhibited by suppressor of cytokine signalling-3 in insulin-producing cells. Diabetologia 2009; 52: 281-288 
Jacobson MD, Burne JF, King MP, Miyashita T, Reed JC, Raff MC: Bcl-2 blocks apoptosis in cells lacking mitochondrial DNA. Nature 1993; 361: 365-369

Jetton TL, Magnuson MA: Heterogeneous expression of glucokinase among pancreatic beta cells. Proc Natl Acad Sci U S A 1992; 89: 2619-2623

Jitrapakdee S, Wutthisathapornchai A, Wallace JC, MacDonald MJ: Regulation of insulin secretion: role of mitochondrial signalling. Diabetologia 2010; 53: 1019-1032

Johnson JH, Newgard CB, Milburn JL, Lodish HF, Thorens B: The high Km glucose transporter of islets of Langerhans is functionally similar to the low affinity transporter of liver and has an identical primary sequence. J Biol Chem 1990; 265: 6548-6551

Jörns A, Kubat B, Tiedge M, Wedekind D, Hedrich HJ, Klöppel G, Lenzen S: Pathology of the pancreas and other organs in the diabetic LEW.1AR1/Ztm- iddm rat, a new model of spontaneous insulin-dependent diabetes mellitus. Virchows Arch 2004; 444: 183-189

Jörns A, Günther A, Hedrich HJ, Wedekind D, Tiedge M, Lenzen S: Immune cell infiltration, cytokine expression, and beta-cell apoptosis during the development of type 1 diabetes in the spontaneously diabetic LEW.1AR1/Ztm-iddm rat. Diabetes 2005; 54: 2041-2052

Jun HS, Santamaria P, Lim HW, Zhang ML, Yoon JW: Absolute requirement of macrophages for the development and activation of beta-cell cytotoxic CD8+ T-cells in T-cell receptor transgenic NOD mice. Diabetes 1999; 48: 34-42

Jun HS, Yoon CS, Zbytnuik L, van Rooijen N, Yoon JW: The role of macrophages in T cellmediated autoimmune diabetes in nonobese diabetic mice. J Exp Med 1999; 189: 347-358

Jun HS, Yoon JW: The role of viruses in type I diabetes: two distinct cellular and molecular pathogenic mechanisms of virus-induced diabetes in animals. Diabetologia 2001; 44: 271-285

Kacheva S, Lenzen S, Gurgul-Convey E: Differential effects of proinflammatory cytokines on cell death and ER stress in insulin-secreting INS1E cells and the involvement of nitric oxide. Cytokine 2011; 55: 195-201

Kefas BA, Cai Y, Ling Z, Heimberg H, Hue L, Pipeleers D, Van de Casteele M: AMP-activated protein kinase can induce apoptosis of insulin-producing MIN6 cells through stimulation of c-Jun-Nterminal kinase. J Mol Endocrinol 2003; 30: 151-161

Kennedy ED, Maechler P, Wollheim CB: Effects of depletion of mitochondrial DNA in metabolism secretion coupling in INS-1 cells. Diabetes 1998; 47: 374-380

Kharroubi I, Ladrière L, Cardozo AK, Dogusan Z, Cnop M, Eizirik DL: Free fatty acids and cytokines induce pancreatic beta-cell apoptosis by different mechanisms: role of nuclear factorkappaB and endoplasmic reticulum stress. Endocrinology 2004; 145: 5087-5096

Kielgast U, Holst JJ, Madsbad S: Treatment of type 1 diabetic patients with glucagon-like peptide-1 (GLP-1) and GLP-1R agonists. Curr Diabetes Rev 2009; 5: 266-275

Kim I, Xu W, Reed JC: Cell death and endoplasmic reticulum stress: disease relevance and therapeutic opportunities. Nat Rev Drug Discov 2008; 7: 1013-1030

Kim MS, Park JY, Namkoong C, Jang PG, Ryu JW, Song HS, Yun JY, Namgoong IS, Ha J, Park IS, Lee IK, Viollet B, Youn JH, Lee HK, Lee KU: Anti-obesity effects of alpha-lipoic acid mediated by suppression of hypothalamic AMP-activated protein kinase. Nat Med 2004; 10: 727-733

Klöppel G, Löhr M, Habich K, Oberholzer M, Heitz PU: Islet pathology and the pathogenesis of type 1 and type 2 diabetes mellitus revisited. Surv Synth Pathol Res 1985; 4: 110-125

Kreuwel HT, Sherman LA: The role of Fas-FasL in CD8+ T-cell-mediated insulin-dependent diabetes mellitus (IDDM). J Clin Immunol 2001; 21: 15-18

Kumar P, Peers C: AMP-activated protein kinase: function and dysfunction in health and disease. J Physiol 2006; 574: 3-6 
Kutlu B, Cardozo AK, Darville MI, Kruhoffer M, Magnusson N, Orntoft T, Eizirik DL: Discovery of gene networks regulating cytokine-induced dysfunction and apoptosis in insulinproducing INS-1 cells. Diabetes 2003; 52: 2701-2719

Lage R, Diéguez C, Vidal-Puig A, López M: AMPK: a metabolic gauge regulating whole-body energy homeostasis. Trends Mol Med 2008; 14: 539-549

Lajoix AD, Reggio H, Chardes T, Peraldi-Roux S, Tribillac F, Roye M, Dietz S, Broca C, Manteghetti M, Ribes G, Wollheim CB, Gross R: A neuronal isoform of nitric oxide synthase expressed in pancreatic beta-cells controls insulin secretion. Diabetes 2001; 50: 1311-1323

Lakey JR, Suarez-Pinzon WL, Strynadka K, Korbutt GS, Rajotte RV, Mabley JG, Szabó C, Rabinovitch A: Peroxynitrite is a mediator of cytokine-induced destruction of human pancreatic islet beta cells. Lab Invest 2001; 81: 1683-1692

Lam NT, Cheung AT, Riedel MJ, Light PE, Cheeseman CI, Kieffer TJ: Leptin reduces glucose transport and cellular ATP levels in INS-1 beta-cells. J Mol Endocrinol 2004; 32: 415-424

Lamkanfi M, Kalai M, Vandenabeele P: Caspase-12: an overview. Cell Death Differ 2004; 11: 365368

Lang J: Molecular mechanisms and regulation of insulin exocytosis as a paradigm of endocrine secretion. Eur J Biochem 1999; 259: 3-17

Larsen L, Størling J, Darville M, Eizirik DL, Bonny C, Billestrup N, Mandrup-Poulsen T: Extracellular signal-regulated kinase is essential for interleukin-1-induced and nuclear factor kappaBmediated gene expression in insulin-producing INS-1E cells. Diabetologia 2005; 48: 2582-2590

Lartigue L, Medina C, Schembri L, Chabert P, Zanese M, Tomasello F, Dalibart R, Thoraval D, Crouzet M, Ichas F, De Giorgi F: An intracellular wave of cytochrome c propagates and precedes Bax redistribution during apoptosis. J Cell Sci 2008; 121: 3515-3523

Lawrence MC, McGlynn K, Naziruddin B, Levy MF, Cobb MH: Differential regulation of CHOP10/GADD153 gene expression by MAPK signaling in pancreatic beta-cells. Proc Natl Acad Sci U S A 2007; 104: 11518-11525

Laybutt DR, Preston AM, Akerfeldt MC, Kench JG, Busch AK, Biankin AV, Biden TJ: Endoplasmic reticulum stress contributes to beta cell apoptosis in type 2 diabetes. Diabetologia 2007; 50: $752-763$

Lazarou M, McKenzie M, Ohtake A, Thorburn DR, Ryan MT: Analysis of the assembly profiles for mitochondrial- and nuclear-DNA-encoded subunits into complex I. Mol Cell Biol 2007; 27: 42284237

Leclerc I, Woltersdorf WW, da Silva Xavier G, Rowe RL, Cross SE, Korbutt GS, Rajotte RV, Smith R, Rutter GA: Metformin, but not leptin, regulates AMP-activated protein kinase in pancreatic islets: impact on glucose-stimulated insulin secretion. Am J Physiol Endocrinol Metab 2004; 286: E1023-1031

Lee AH, Iwakoshi NN, Glimcher LH: XBP-1 regulates a subset of endoplasmic reticulum resident chaperone genes in the unfolded protein response. Mol Cell Biol 2003; 23: 7448-7459

Lee HC, Wei YH: Mitochondrial role in life and death of the cell. J Biomed Sci 2000; 7: 2-15

Lee JW, Kim WH, Yeo J, Jung MH: ER stress is implicated in mitochondrial dysfunction-induced apoptosis of pancreatic beta cells. Mol Cells 2010; 30: 545-549

Lee MJ, Feliers D, Mariappan MM, Sataranatarajan K, Mahimainathan L, Musi N, Foretz M, Viollet B, Weinberg JM, Choudhury GG, Kasinath BS: A role for AMP-activated protein kinase in diabetes-induced renal hypertrophy. Am J Physiol Renal Physiol 2007; 292: F617-627

Lenzen S: Insulin secretion by isolated perfused rat and mouse pancreas. Am J Physiol 1979; 236: E391-400 
Lenzen S, Panten U: 2-oxocarboxylic acids and function of pancreatic islets in obese-hyperglycaemic mice. Insulin secretion in relation to 45Ca uptake and metabolism. Biochem J 1980; 186: 135-144

Lenzen S, Panten U: Signal recognition by pancreatic B-cells. Biochem Pharmacol 1988; 37: 371378

Lenzen S, Drinkgern J, Tiedge M: Low antioxidant enzyme gene expression in pancreatic islets compared with various other mouse tissues. Free Radic Biol Med 1996; 20: 463-466

Lenzen S, Tiedge M, Elsner M, Lortz S, Weiss H, Jörns A, Klöppel G, Wedekind D, Prokop CM, Hedrich HJ: The LEW.1AR1/Ztm-iddm rat: a new model of spontaneous insulin-dependent diabetes mellitus. Diabetologia 2001; 44: 1189-1196

Lenzen S: Oxidative stress: the vulnerable beta-cell. Biochem Soc Trans 2008; 36: 343-347

Lenzen S: [The beta cell in diabetes]. Dtsch Med Wochenschr 2011; 136: 1123-1127

Li F, Mahato RI: iNOS gene silencing prevents inflammatory cytokine-induced beta-cell apoptosis. Mol Pharm 2008; 5: 407-417

Lindström P: The physiology of obese-hyperglycemic mice [ob/ob mice]. Scientific World Journal 2007; 7: 666-685

Linssen MM, van Raalte DH, Toonen EJ, Alkema W, van der Zon GC, Dokter WH, Diamant M, Guigas B, Ouwens DM: Prednisolone-induced beta cell dysfunction is associated with impaired endoplasmic reticulum homeostasis in INS-1E cells. Cell Signal 2011; 23: 1708-1715

Liu D, Pavlovic D, Chen MC, Flodstrom M, Sandler S, Eizirik DL: Cytokines induce apoptosis in beta-cells isolated from mice lacking the inducible isoform of nitric oxide synthase (iNOS-/-). Diabetes 2000; 49: 1116-1122

Lortz S, Tiedge M, Nachtwey T, Karlsen AE, Nerup J, Lenzen S: Protection of insulin-producing RINm5F cells against cytokine-mediated toxicity through overexpression of antioxidant enzymes. Diabetes 2000; 49: 1123-1130

Lortz S, Tiedge M: Sequential inactivation of reactive oxygen species by combined overexpression of SOD isoforms and catalase in insulin-producing cells. Free Radic Biol Med 2003; 34: 683-688

Lortz S, Gurgul-Convey E, Lenzen S, Tiedge M: Importance of mitochondrial superoxide dismutase expression in insulin-producing cells for the toxicity of reactive oxygen species and proinflammatory cytokines. Diabetologia 2005; 48: 1541-1548

Lyssenko V, Lupi R, Marchetti P, Del Guerra S, Orho-Melander M, Almgren P, Sjögren M, Ling C, Eriksson KF, Lethagen AL, Mancarella R, Berglund G, Tuomi T, Nilsson P, Del Prato S, Groop L: Mechanisms by which common variants in the TCF7L2 gene increase risk of type 2 diabetes. J Clin Invest 2007; 117: 2155-2163

MacDonald PE, Joseph JW, Rorsman P: Glucose-sensing mechanisms in pancreatic beta-cells. Philos Trans R Soc Lond B Biol Sci 2005; 360: 2211-2225

Maechler P, Wollheim CB: Mitochondrial signals in glucose-stimulated insulin secretion in the beta cell. J Physiol 2000; 529: 49-56

Maechler P, Wollheim CB: Mitochondrial function in normal and diabetic beta-cells. Nature 2001; 414: 807-812

Maechler P: Mitochondria as the conductor of metabolic signals for insulin exocytosis in pancreatic beta-cells. Cell Mol Life Sci 2002; 59: 1803-1818

Maechler P, de Andrade PB: Mitochondrial damages and the regulation of insulin secretion. Biochem Soc Trans 2006; 34: 824-827

Maechler P, Li N, Casimir M, Vetterli L, Frigerio F, Brun T: Role of mitochondria in beta-cell function and dysfunction. Adv Exp Med Biol 2010; 654: 193-216 
Maedler K, Sergeev P, Ris F, Oberholzer J, Joller-Jemelka HI, Spinas GA, Kaiser N, Halban PA, Donath MY: Glucose-induced beta cell production of IL-1beta contributes to glucotoxicity in human pancreatic islets. J Clin Invest 2002; 110: 851-860

Magnuson MA, Shelton KD: An alternate promoter in the glucokinase gene is active in the pancreatic beta cell. J Biol Chem 1989; 264: 15936-15942

Makeeva N, Myers JW, Welsh N: Role of MKK3 and p38 MAPK in cytokine-induced death of insulin-producing cells. Biochem J 2006; 393: 129-139

Malaisse WJ, Sener A, Koser M, Ravazzola M, Malaisse-Lagae F: The stimulus-secretion coupling of glucose-induced insulin release. Insulin release due to glycogenolysis in glucose-deprived islets. Biochem J 1977; 164: 447-454

Mandrup-Poulsen T, Bendtzen K, Nielsen JH, Bendixen G, Nerup J: Cytokines cause functional and structural damage to isolated islets of Langerhans. Allergy 1985; 40: 424-429

Mandrup-Poulsen T, Spinas GA, Prowse SJ, Hansen BS, Jørgensen DW, Bendtzen K, Nielsen $\mathbf{J H}$, Nerup J: Islet cytotoxicity of interleukin 1. Influence of culture conditions and islet donor characteristics. Diabetes 1987; 36: 641-647

Mandrup-Poulsen T: Cytokine-mediated beta-cell destruction-the molecular effector mechanism causing IDDM? J Autoimmun 1990; 3: 121-122

Mandrup-Poulsen T: beta-cell apoptosis: stimuli and signaling. Diabetes 2001; 50: S58-63

Mandrup-Poulsen T: Apoptotic signal transduction pathways in diabetes. Biochem Pharmacol 2003; 66: $1433-1440$

Mandrup-Poulsen T, Donath M, Korsgren O, Dragsbæk Madsen O, Rorsman P: DIAMAP Road Map Report, Chapter 2. Islets. DIAMAP, 2010, pp. 33-52

Marchetti P, Susin SA, Decaudin D, Gamen S, Castedo M, Hirsch T, Zamzami N, Naval J, Senik A, Kroemer G: Apoptosis-associated derangement of mitochondrial function in cells lacking mitochondrial DNA. Cancer Res 1996; 56: 2033-2038

Marciniak SJ, Yun CY, Oyadomari S, Novoa I, Zhang Y, Jungreis R, Nagata K, Harding HP, Ron D: CHOP induces death by promoting protein synthesis and oxidation in the stressed endoplasmic reticulum. Genes Dev 2004; 18: 3066-3077

Marsin AS, Bertrand L, Rider MH, Deprez J, Beauloye C, Vincent MF, Van den Berghe G, Carling D, Hue L: Phosphorylation and activation of heart PFK-2 by AMPK has a role in the stimulation of glycolysis during ischaemia. Curr Biol 2000; 10: 1247-1255

Matschinsky FM, Ellerman JE: Metabolism of glucose in the islets of Langerhans. J Biol Chem 1968; 243: 2730-2736

Matschinsky FM: Glucokinase as glucose sensor and metabolic signal generator in pancreatic betacells and hepatocytes. Diabetes 1990; 39: 647-652

Matschinsky FM: Banting Lecture 1995. A lesson in metabolic regulation inspired by the glucokinase glucose sensor paradigm. Diabetes 1996; 45: 223-241

Mauricio D, Mandrup-Poulsen T: Apoptosis and the pathogenesis of IDDM: a question of life and death. Diabetes 1998; 47: 1537-1543

Mayer J, Russell RE, Bates MW, Dickie MM: Metabolic, nutritional and endocrine studies of the hereditary obesity-diabetes syndrome of mice and mechanism of its development. Metabolism 1953; 2: 9-21

McCarthy MI: Genomics, type 2 diabetes, and obesity. N Engl J Med 2010; 363: 2339-2350

McCarthy MI: Dorothy Hodgkin Lecture 2010. From hype to hope? A journey through the genetics of Type 2 diabetes. Diabet Med 2011; 28: 132-140 
McCullough KD, Martindale JL, Klotz LO, Aw TY, Holbrook NJ: Gadd153 sensitizes cells to endoplasmic reticulum stress by down-regulating $\mathrm{Bcl} 2$ and perturbing the cellular redox state. Mol Cell Biol 2001; 21: 1249-1259

Mehmeti I, Gurgul-Convey E, Lenzen S, Lortz S: Induction of the intrinsic apoptosis pathway in insulin-secreting cells is dependent on oxidative damage of mitochondria but independent of caspase12 activation. Biochim Biophys Acta 2011; 1813: 1827-1835

Mehmeti I, Lenzen S, Lortz S: Modulation of Bcl-2-related protein expression in pancreatic beta cells by pro-inflammatory cytokines and its dependence on the antioxidative defense status. Mol Cell Endocrinol 2011; 332: 88-96

Minami K, Yano H, Miki T, Nagashima K, Wang CZ, Tanaka H, Miyazaki JI, Seino S: Insulin secretion and differential gene expression in glucose-responsive and -unresponsive MIN6 sublines. Am J Physiol Endocrinol Metab 2000; 279: E773-781

Minokoshi Y, Alquier T, Furukawa N, Kim YB, Lee A, Xue B, Mu J, Foufelle F, Ferré P, Birnbaum MJ, Stuck BJ, Kahn BB: AMP-kinase regulates food intake by responding to hormonal and nutrient signals in the hypothalamus. Nature 2004; 428: 569-574

Miyata M, Ueno Y, Sekine H, Ito O, Sakuma F, Koike H, Nishio S, Nishimaki T, Kasukawa R: Protective effect of beraprost sodium, a stable prostacyclin analogue, in development of monocrotaline-induced pulmonary hypertension. J Cardiovasc Pharmacol 1996; 27: 20-26

Miyazaki J, Araki K, Yamato E, Ikegami H, Asano T, Shibasaki Y, Oka Y, Yamamura K: Establishment of a pancreatic beta cell line that retains glucose-inducible insulin secretion: special reference to expression of glucose transporter isoforms. Endocrinology 1990; 127: 126-132

Mokhtari D, Myers JW, Welsh N: The MAPK kinase kinase-1 is essential for stress-induced pancreatic islet cell death. Endocrinology 2008; 149: 3046-3053

Momoi T: Caspases involved in ER stress-mediated cell death. J Chem Neuroanat 2004; 28: 101-105

Moreira JE, Hand AR, Håkan Borg LA, Sandler S, Welsh M, Welsh N, Eizirik DL: Decrease in insulin-containing secretory granules and mitochondrial gene expression in mouse pancreatic islets maintained in culture following streptozotocin exposure. Virchows Arch B Cell Pathol Incl Mol Pathol 1991; 60: 337-344

Morishima N, Nakanishi K, Takenouchi H, Shibata T, Yasuhiko Y: An endoplasmic reticulum stress-specific caspase cascade in apoptosis. Cytochrome c-independent activation of caspase- 9 by caspase-12. J Biol Chem 2002; 277: 34287-34294

Mosmann TR, Coffman RL: Heterogeneity of cytokine secretion patterns and functions of helper T cells. Adv Immunol 1989; 46: 111-147

Moukil MA, Veiga-da-Cunha M, Van Schaftingen E: Study of the regulatory properties of glucokinase by site-directed mutagenesis: conversion of glucokinase to an enzyme with high affinity for glucose. Diabetes 2000; 49: 195-201

Naik RG, Brooks-Worrell BM, Palmer JP: Latent autoimmune diabetes in adults. J Clin Endocrinol Metab 2009; 94: 4635-4644

Nakagawa T, Zhu H, Morishima N, Li E, Xu J, Yankner BA, Yuan J: Caspase-12 mediates endoplasmic-reticulum-specific apoptosis and cytotoxicity by amyloid-beta. Nature 2000; 403: 98-103

Nambam B, Aggarwal S, Jain A: Latent autoimmune diabetes in adults: A distinct but heterogeneous clinical entity. World J Diabetes 2010; 1: 111-115

Nerup J, Mandrup-Poulsen T, Mølvig J, Helqvist S, Wogensen L, Egeberg J: Mechanisms of pancreatic beta-cell destruction in type I diabetes. Diabetes Care 1988; 11: 16-23

Nerup J, Mandrup-Poulsen T, Helqvist S, Andersen HU, Pociot F, Reimers JI, Cuartero BG, Karlsen AE, Bjerre U, Lorenzen T: On the pathogenesis of IDDM. Diabetologia 1994; 37: S82-89 
Newgard CB, McGarry JD: Metabolic coupling factors in pancreatic beta-cell signal transduction. Annu Rev Biochem 1995; 64: 689-719

Newmeyer DD, Ferguson-Miller S: Mitochondria: releasing power for life and unleashing the machineries of death. Cell 2003; 112: 481-490

Newsholme P, Brennan L, Rubi B, Maechler P: New insights into amino acid metabolism, beta-cell function and diabetes. Clin Sci 2005; 108: 185-194

Ogilvie I, Kennaway NG, Shoubridge EA: A molecular chaperone for mitochondrial complex I assembly is mutated in a progressive encephalopathy. J Clin Invest 2005; 115: 2784-2792

Ortis F, Cardozo AK, Crispim D, Störling J, Mandrup-Poulsen T, Eizirik DL: Cytokine-induced proapoptotic gene expression in insulin-producing cells is related to rapid, sustained, and nonoscillatory nuclear factor-kappaB activation. Mol Endocrinol 2006; 20: 1867-1879

Ortis F, Pirot P, Naamane N, Kreins AY, Rasschaert J, Moore F, Théâttre E, Verhaeghe C, Magnusson NE, Chariot A, Orntoft TF, Eizirik DL: Induction of nuclear factor-kappaB and its downstream genes by TNF-alpha and IL-1beta has a pro-apoptotic role in pancreatic beta cells. Diabetologia 2008; 51: 1213-1225

Oslowski CM, Urano F: A switch from life to death in endoplasmic reticulum stressed beta-cells. Diabetes Obes Metab 2010; 12: 58-65

Otsuki M, Goya K, Kasayama S: Vascular endothelium as a target of beraprost sodium and fenofibrate for antiatherosclerotic therapy in type 2 diabetes mellitus. Vasc Health Risk Manag 2005; 1: $209-215$

Owerbach D, Bell GI, Rutter WJ, Shows TB: The insulin gene is located on chromosome 11 in humans. Nature 1980; 286: 82-84

Oyadomari S, Gotoh T, Aoyagi K, Araki E, Shichiri M, Mori M: Coinduction of endothelial nitric oxide synthase and arginine recycling enzymes in aorta of diabetic rats. Nitric Oxide 2001; 5: 252-260

Oyadomari S, Araki E, Mori M: Endoplasmic reticulum stress-mediated apoptosis in pancreatic beta-cells. Apoptosis 2002; 7: 335-345

Oyadomari S, Koizumi A, Takeda K, Gotoh T, Akira S, Araki E, Mori M: Targeted disruption of the Chop gene delays endoplasmic reticulum stress-mediated diabetes. J Clin Invest 2002; 109: 525532

Oyadomari S, Mori M: Roles of CHOP/GADD153 in endoplasmic reticulum stress. Cell Death Differ 2004; 11: 381-389

Panten U, Zünkler BJ, Scheit S, Kirchhoff K, Lenzen S: Regulation of energy metabolism in pancreatic islets by glucose and tolbutamide. Diabetologia 1986; 29: 648-654

Pelleymounter MA, Cullen MJ, Baker MB, Hecht R, Winters D, Boone T, Collins F: Effects of the obese gene product on body weight regulation in ob/ob mice. Science 1995; 269: 540-543

Petit PX, Susin SA, Zamzami N, Mignotte B, Kroemer G: Mitochondria and programmed cell death: back to the future. FEBS Lett 1996; 396: 7-13

Pickup JC, Crook MA: Is type II diabetes mellitus a disease of the innate immune system? Diabetologia 1998; 41: 1241-1248

Pihoker C, Gilliam LK, Hampe CS, Lernmark A: Autoantibodies in diabetes. Diabetes 2005; 54: S52-61

Pipeleers D, Hoorens A, Marichal-Pipeleers M, Van de Casteele M, Bouwens L, Ling Z: Role of pancreatic beta-cells in the process of beta-cell death. Diabetes 2001; 50: S52-57

Pirot P, Eizirik DL, Cardozo AK: Interferon-gamma potentiates endoplasmic reticulum stressinduced death by reducing pancreatic beta cell defence mechanisms. Diabetologia 2006; 49: 12291236 
Pirot P, Ortis F, Cnop M, Ma Y, Hendershot LM, Eizirik DL, Cardozo AK: Transcriptional regulation of the endoplasmic reticulum stress gene chop in pancreatic insulin-producing cells. Diabetes 2007; 56: 1069-1077

Pirot P, Cardozo AK, Eizirik DL: Mediators and mechanisms of pancreatic beta-cell death in type 1 diabetes. Arq Bras Endocrinol Metabol 2008; 52: 156-165

Pociot F, McDermott MF: Genetics of type 1 diabetes mellitus. Genes Immun 2002; 3: 235-249

Portha B, Tourrel-Cuzin C, Movassat J: Activation of the GLP-1 receptor signalling pathway: a relevant strategy to repair a deficient beta-cell mass. Exp Diabetes Res 2011; 2011: 376509

Prentki M: New insights into pancreatic beta-cell metabolic signaling in insulin secretion. Eur J Endocrinol 1996; 134: 272-286

Purrello F, Buscema M, Rabuazzo AM, Caltabiano V, Forte F, Vinci C, Vetri M, Vigneri R: Glucose modulates glucose transporter affinity, glucokinase activity, and secretory response in rat pancreatic beta-cells. Diabetes 1993; 42: 199-205

Rabinovitch A: An update on cytokines in the pathogenesis of insulin-dependent diabetes mellitus. Diabetes Metab Rev 1998; 14: 129-151

Rabinovitch A, Suarez-Pinzon WL: Cytokines and their roles in pancreatic islet beta-cell destruction and insulin-dependent diabetes mellitus. Biochem Pharmacol 1998; 55: 1139-1149

Rabinovitch A, Suarez-Pinzon W, Strynadka K, Ju Q, Edelstein D, Brownlee M, Korbutt GS, Rajotte RV: Transfection of human pancreatic islets with an anti-apoptotic gene (bcl-2) protects betacells from cytokine-induced destruction. Diabetes 1999; 48: 1223-1229

Raha S, Robinson BH: Mitochondria, oxygen free radicals, disease and ageing. Trends Biochem Sci 2000; 25: 502-508

Rath PC, Aggarwal BB: TNF-induced signaling in apoptosis. J Clin Immunol 1999; 19: 350-364

Ravier MA, Rutter GA: Isolation and culture of mouse pancreatic islets for ex vivo imaging studies with trappable or recombinant fluorescent probes. Methods Mol Biol 2010; 633: 171-184

Regazzi R, Wollheim CB, Lang J, Theler JM, Rossetto O, Montecucco C, Sadoul K, Weller U, Palmer M, Thorens B: VAMP-2 and cellubrevin are expressed in pancreatic beta-cells and are essential for $\mathrm{Ca}^{2+}$-but not for GTP gamma S-induced insulin secretion. EMBO J 1995; 14: 2723-2730

Rehm M, Düssmann H, Prehn JH: Real-time single cell analysis of Smac/DIABLO release during apoptosis. J Cell Biol 2003; 162: 1031-1043

Renström E, Eliasson L, Rorsman P: Protein kinase A-dependent and -independent stimulation of exocytosis by cAMP in mouse pancreatic B-cells. J Physiol 1997; 502: 105-118

Richards SK, Parton LE, Leclerc I, Rutter GA, Smith RM: Over-expression of AMP-activated protein kinase impairs pancreatic $\beta$-cell function in vivo. J Endocrinol 2005; 187: 225-235

Robertson RP: Successful islet transplantation for patients with diabetes-fact or fantasy? N Engl J Med 2000; 343: 289-290

Robin ED, Wong R: Mitochondrial DNA molecules and virtual number of mitochondria per cell in mammalian cells. J Cell Physiol 1988; 136: 507-513

Rodriguez Candela JL, Garcia-Fernandez MC: Stimulation of secretion of insulin by adenosinetriphosphate. Nature 1963; 197: 1210

Roep BO, De Vries RR: T-lymphocytes and the pathogenesis of type 1 (insulin-dependent) diabetes mellitus. Eur J Clin Invest 1992; 22: 697-711

Roep BO: T-cell reactivity to beta-cell antigens in human insulin-dependent (type 1) diabetes mellitus. Implications for diagnosis and therapy. Clin Rev Allergy Immunol 2000; 19: 265-275 
Ron D, Habener JF: CHOP, a novel developmentally regulated nuclear protein that dimerizes with transcription factors $\mathrm{C} / \mathrm{EBP}$ and LAP and functions as a dominant-negative inhibitor of gene transcription. Genes Dev 1992; 6: 439-453

Rorsman P, Eliasson L, Renström E, Gromada J, Barg S, Göpel S: The Cell Physiology of Biphasic Insulin Secretion. News Physiol Sci 2000; 15: 72-77

Rutter GA, Leclerc I: The AMP-regulated kinase family: enigmatic targets for diabetes therapy. Mol Cell Endocrinol 2009; 297: 41-49

Sakai K, Matsumoto K, Nishikawa T, Suefuji M, Nakamaru K, Hirashima Y, Kawashima J, Shirotani T, Ichinose K, Brownlee M, Araki E: Mitochondrial reactive oxygen species reduce insulin secretion by pancreatic beta-cells. Biochem Biophys Res Commun 2003; 300: 216-222

Saklatvala J, Dean J, Finch A: Protein kinase cascades in intracellular signalling by interleukin-I and tumour necrosis factor. Biochem Soc Symp 1999; 64: 63-77

Saldeen J: Cytokines induce both necrosis and apoptosis via a common Bcl-2-inhibitable pathway in rat insulin-producing cells. Endocrinology 2000; 141: 2003-2010

Saldeen J, Welsh N: p38 MAPK inhibits JNK2 and mediates cytokine-activated iNOS induction and apoptosis independently of NF- $\mathrm{B}$ translocation in insulin-producing cells. Eur Cytokine Netw 2004; 15: 47-52

Sandler S, Andersson A, Hellerström C: Inhibitory effects of interleukin 1 on insulin secretion, insulin biosynthesis, and oxidative metabolism of isolated rat pancreatic islets. Endocrinology 1987; 121: $1424-1431$

Sato Y, Henquin JC: The $\mathrm{K}^{+}$-ATP channel-independent pathway of regulation of insulin secretion by glucose: in search of the underlying mechanism. Diabetes 1998; 47: 1713-1721

Satoh T, Abiru N, Kobayashi M, Zhou H, Nakamura K, Kuriya G, Nakamura H, Nagayama Y, Kawasaki E, Yamasaki H, Yu L, Eisenbarth GS, Araki E, Mori M, Oyadomari S, Eguchi K: CHOP deletion does not impact the development of diabetes but suppresses the early production of insulin autoantibody in the NOD mouse. Apoptosis 2011; 16: 438-448

Schuit F, Flamez D, De Vos A, Pipeleers D: Glucose-regulated gene expression maintaining the glucose-responsive state of beta-cells. Diabetes 2002; 51: S326-332

Schuit FC, In't Veld PA, Pipeleers DG: Glucose stimulates proinsulin biosynthesis by a dosedependent recruitment of pancreatic beta cells. Proc Natl Acad Sci U S A 1988; 85: 3865-3869

Schuit FC: Is GLUT2 required for glucose sensing? Diabetologia 1997; 40: 104-111

Sharma RK, Seitz DP, Singh B, Tan Y: Localization and regulation of bovine eye calmodulindependent cyclic nucleotide phosphodiesterase by cyclic AMP-dependent protein kinase. Int J Mol Med 2002; 10: 17-23

Siegle I, Klein T, Zou MH, Fritz P, Komhoff M: Distribution and cellular localization of prostacyclin synthase in human brain. J Histochem Cytochem 2000; 48: 631-641

Sigfrid LA, Cunningham JM, Beeharry N, Lortz S, Tiedge M, Lenzen S, Carlsson C, Green IC: Cytokines and nitric oxide inhibit the enzyme activity of catalase but not its protein or mRNA expression in insulin-producing cells. J Mol Endocrinol 2003; 31: 509-518

Skulachev VP: Mitochondrial physiology and pathology; concepts of programmed death of organelles, cells and organisms. Mol Aspects Med 1999; 20: 139-184

Small CJ, Carling D, Bloom SR: Cellular energy sensor balances the scales. Nat Med 2004; 10: 681682

Soejima A, Inoue K, Takai D, Kaneko M, Ishihara H, Oka Y, Hayashi JI: Mitochondrial DNA is required for regulation of glucose-stimulated insulin secretion in a mouse pancreatic beta cell line, MIN6. J Biol Chem 1996; 271: 26194-26199 
Souza KL, Gurgul-Convey E, Elsner M, Lenzen S: Interaction between pro-inflammatory and antiinflammatory cytokines in insulin-producing cells. J Endocrinol 2008; 197: 139-150

Spinas GA, Mandrup-Poulsen T, Molvig J, Baek L, Bendtzen K, Dinarello CA, Nerup J: Low concentrations of interleukin-1 stimulate and high concentrations inhibit insulin release from isolated rat islets of Langerhans. Acta Endocrinol 1986; 113: 551-558

Sprague RS, Bowles EA, Hanson MS, DuFaux EA, Sridharan M, Adderley S, Ellsworth ML, Stephenson AH: Prostacyclin analogs stimulate receptor-mediated cAMP synthesis and ATP release from rabbit and human erythrocytes. Microcirculation 2008; 15: 461-471

Stark GR, Kerr IM, Williams BR, Silverman RH, Schreiber RD: How cells respond to interferons. Annu Rev Biochem 1998; 67: 227-264

Stenström G, Gottsäter A, Bakhtadze E, Berger B, Sundkvist G: Latent autoimmune diabetes in adults: definition, prevalence, beta-cell function, and treatment. Diabetes 2005; 54: S68-72

Stephanou A, Brar BK, Knight RA, Latchman DS: Opposing actions of STAT-1 and STAT-3 on the Bcl-2 and Bcl-x promoters. Cell Death Differ 2000; 7: 329-330

Størling J, Binzer J, Andersson AK, Züllig RA, Tonnesen M, Lehmann R, Spinas GA, Sandler S, Billestrup N, Mandrup-Poulsen T: Nitric oxide contributes to cytokine-induced apoptosis in pancreatic beta cells via potentiation of JNK activity and inhibition of Akt. Diabetologia 2005; 48: 2039-2050

Straub SG, Sharp GW: Glucose-stimulated signaling pathways in biphasic insulin secretion. Diabetes Metab Res Rev 2002; 18: 451-463

Suarez-Pinzon WL, Szabó C, Rabinovitch A: Development of autoimmune diabetes in NOD mice is associated with the formation of peroxynitrite in pancreatic islet beta-cells. Diabetes 1997; 46: 907911

Suarez-Pinzon WL, Mabley JG, Strynadka K, Power RF, Szabó C, Rabinovitch A: An inhibitor of inducible nitric oxide synthase and scavenger of peroxynitrite prevents diabetes development in NOD mice. J Autoimmun 2001; 16: 449-455

Szegezdi E, Logue SE, Gorman AM, Samali A: Mediators of endoplasmic reticulum stress-induced apoptosis. EMBO Rep 2006; 7: 880-885

Tabas I, Ron D: Integrating the mechanisms of apoptosis induced by endoplasmic reticulum stress. Nat Cell Biol 2011; 13: 184-190

Taguchi N, Aizawa T, Sato Y, Ishihara F, Hashizume K: Mechanism of glucose-induced biphasic insulin release: physiological role of adenosine triphosphate-sensitive $\mathrm{K}+$ channel-independent glucose action. Endocrinology 1995; 136: 3942-3948

Tait SW, Green DR: Mitochondria and cell death: outer membrane permeabilization and beyond. Nat Rev Mol Cell Biol 2010; 11: 621-632

Taplin CE, Barker JM: Autoantibodies in type 1 diabetes. Autoimmunity 2008; 41: 11-18

Tattersall RB, Fajans SS: A difference between the inheritance of classical juvenile-onset and maturity-onset type diabetes of young people. Diabetes 1975; 24: 44-53

Tau G, Rothman P: Biologic functions of the IFN-gamma receptors. Allergy 1999; 54: 1233-1251

Tiedge M, Lortz S, Drinkgern J, Lenzen S: Relation between antioxidant enzyme gene expression and antioxidative defense status of insulin-producing cells. Diabetes 1997; 46: 1733-1742

Tiedge M, Lortz S, Munday R, Lenzen S: Complementary action of antioxidant enzymes in the protection of bioengineered insulin-producing RINm5F cells against the toxicity of reactive oxygen species. Diabetes 1998; 47: 1578-1585 
Tonnesen MF, Grunnet LG, Friberg J, Cardozo AK, Billestrup N, Eizirik DL, Størling J, Mandrup-Poulsen T: Inhibition of nuclear factor-kappaB or Bax prevents endoplasmic reticulum stress- but not nitric oxide-mediated apoptosis in INS-1E cells. Endocrinology 2009; 150: 4094-4103

Tran PO, Gleason CE, Poitout V, Robertson RP: Prostaglandin $E_{2}$ mediates inhibition of insulin secretion by interleukin-1beta. J Biol Chem 1999; 274: 31245-31248

Trayhurn P, Hoggard N, Mercer JG, Rayner DV: Leptin: fundamental aspects. Int J Obes Relat Metab Disord 1999; 23: 22-28

Tritos NA, Mantzoros CS: Leptin: its role in obesity and beyond. Diabetologia 1997; 40: 1371-1379

Tsuneoka M, Teye K, Arima N, Soejima M, Otera H, Ohashi K, Koga Y, Fujita H, Shirouzu K, Kimura H, Koda Y: A novel Myc-target gene, mimitin, that is involved in cell proliferation of esophageal squamous cell carcinoma. J Biol Chem 2005; 280: 19977-19985

Tsuruzoe K, Araki E, Furukawa N, Shirotani T, Matsumoto K, Kaneko K, Motoshima H, Yoshizato K, Shirakami A, Kishikawa H, Miyazaki J, Shichiri M: Creation and characterization of a mitochondrial DNA-depleted pancreatic beta-cell line: impaired insulin secretion induced by glucose, leucine, and sulfonylureas. Diabetes 1998; 47: 621-631

Tuomi T, Groop LC, Zimmet PZ, Rowley MJ, Knowles W, Mackay IR: Antibodies to glutamic acid decarboxylase reveal latent autoimmune diabetes mellitus in adults with a non-insulin-dependent onset of disease. Diabetes 1993; 42: 359-362

Turrens JF: Mitochondrial formation of reactive oxygen species. J Physiol 2003; 552: 335-344

Urano F, Wang X, Bertolotti A, Zhang Y, Chung P, Harding HP, Ron D: Coupling of stress in the ER to activation of JNK protein kinases by transmembrane protein kinase IRE1. Science 2000; 287: 664-666

Verma G, Datta M: The critical role of JNK in the ER-mitochondrial crosstalk during apoptotic cell death. J Cell Physiol 2012; 227: 1791-1795

Viana AY, Sakoda H, Anai M, Fujishiro M, Ono H, Kushiyama A, Fukushima Y, Sato Y, Oshida Y, Uchijima Y, Kurihara H, Asano T: Role of hepatic AMPK activation in glucose metabolism and dexamethasone-induced regulation of AMPK expression. Diabetes Res Clin Pract 2006; 73: 135-142

Vilsbøll T, Garber AJ: Non-glycaemic effects mediated via GLP-1 receptor agonists and the potential for exploiting these for therapeutic benefit: focus on liraglutide. Diabetes Obes Metab 2012; 14: S41-49

Viollet B, Foretz M, Guigas B, Horman S, Dentin R, Bertrand L, Hue L, Andreelli F: Activation of AMP-activated protein kinase in the liver: a new strategy for the management of metabolic hepatic disorders. J Physiol 2006; 574: 41-53

Viollet B, Mounier R, Leclerc J, Yazigi A, Foretz M, Andreelli F: Targeting AMP-activated protein kinase as a novel therapeutic approach for the treatment of metabolic disorders. Diabetes Metab 2007; 33: $395-402$

Virtanen SM, Knip M: Nutritional risk predictors of beta cell autoimmunity and type 1 diabetes at a young age. Am J Clin Nutr 2003; 78: 1053-1067

Waldhäusl W, Lenzen S: Kohlenhydrate, endokrines Pankreas, Diabetes. In Pathophysiologie. Molekulare, zelluläre und systemische Grundlagen von Krankheiten Schwarz S, Förster O, Peterlik M, Schauenstein K, Wick G, (ed.) Wilhelm Maudrich-Verlag, Wien 2007, p. 15-11 - 15-20

Wallace DC: Mitochondrial diseases in man and mouse. Science 1999; 283: 1482-1488

Walter P, Ron D: The unfolded protein response: from stress pathway to homeostatic regulation. Science 2011; 334: 1081-1086 
Wang LL, Zhao XC, Yan LF, Wang YQ, Cheng X, Fu R, Zhou LH: C-jun phosphorylation contributes to down regulation of neuronal nitric oxide synthase protein and motoneurons death in injured spinal cords following root-avulsion of the brachial plexus. Neuroscience 2011; 189: 397-407

Wang X, Olberding KE, White $\mathbf{C}, \mathbf{L i} \mathbf{C}$ : $\mathrm{Bcl}-2$ proteins regulate ER membrane permeability to luminal proteins during ER stress-induced apoptosis. Cell Death Differ 2011; 18: 38-47

Wang XZ, Ron D: Stress-induced phosphorylation and activation of the transcription factor CHOP (GADD153) by p38 MAP Kinase. Science 1996; 272: 1347-1349

Wegrzyn P, Yarwood SJ, Fiegler N, Bzowska M, Koj A, Mizgalska D, Malicki S, Pajak M, Kasza A, Kachamakova-Trojanowska N, Bereta J, Jura J: Mimitin - a novel cytokine-regulated mitochondrial protein. BMC Cell Biol 2009; 10: 23

Weiss HJ, Turitto VT: Prostacyclin (prostaglandin I2, PGI2) inhibits platelet adhesion and thrombus formation on subendothelium. Blood 1979; 53: 244-250

Weksler-Zangen S, Raz I, Lenzen S, Jörns A, Ehrenfeld S, Amir G, Oprescu A, Yagil Y, Yagil C, Zangen DH, Kaiser N: Impaired glucose-stimulated insulin secretion is coupled with exocrine pancreatic lesions in the Cohen diabetic rat. Diabetes 2008; 57: 279-287

Welsh M, Scherberg N, Gilmore R, Steiner DF: Translational control of insulin biosynthesis. Evidence for regulation of elongation, initiation and signal-recognition-particle-mediated translational arrest by glucose. Biochem J 1986; 235: 459-467

West IC: Radicals and oxidative stress in diabetes. Diabet Med 2000; 17: 171-180

Wiederkehr A, Wollheim CB: Minireview: implication of mitochondria in insulin secretion and action. Endocrinology 2006; 147: 2643-2649

Wolff SP: Diabetes mellitus and free radicals. Free radicals, transition metals and oxidative stress in the aetiology of diabetes mellitus and complications. Br Med Bull 1993; 49: 642-652

Wollheim CB: Beta-cell mitochondria in the regulation of insulin secretion: a new culprit in type II diabetes. Diabetologia 2000; 43: 265-277

Wroblewski M, Gottsater A, Lindgarde F, Fernlund P, Sundkvist G: Gender, autoantibodies, and obesity in newly diagnosed diabetic patients aged 40-75 years. Diabetes Care 1998; 21: 250-255

Wu KK, Liou JY: Cellular and molecular biology of prostacyclin synthase. Biochem Biophys Res Commun 2005; 338: 45-52

Xie R, Nguyen S, McKeehan K, Wang F, McKeehan WL, Liu L: Microtubule-associated protein 1S (MAP1S) bridges autophagic components with microtubules and mitochondria to affect autophagosomal biogenesis and degradation. J Biol Chem 2011; 286: 10367-10377

Xu J, Han J, Long YS, Epstein PN, Liu YQ: The role of pyruvate carboxylase in insulin secretion and proliferation in rat pancreatic beta cells. Diabetologia 2008; 51: 2022-2030

Yegen C, Aktan AO, Dosluoglu HH, Ercan S, Yalin R: The effect of Iloprost (ZK 36374) on isolated and transplanted pancreatic islet cells. Prostaglandins Leukot Essent Fatty Acids 1994; 51: 257-262

Yoon JW, Jun HS: Cellular and molecular roles of beta cell autoantigens, macrophages and T cells in the pathogenesis of autoimmune diabetes. Arch Pharm Res 1999; 22: 437-447

Yoshida H, Matsui T, Yamamoto A, Okada T, Mori K: XBP1 mRNA is induced by ATF6 and spliced by IRE1 in response to ER stress to produce a highly active transcription factor. Cell 2001; 107: 881-891

Zhang BB, Zhou G, Li C: AMPK: an emerging drug target for diabetes and the metabolic syndrome. Cell Metab 2009; 9: 407-416

Zhang Y, Proenca R, Maffei M, Barone M, Leopold L, Friedman JM: Positional cloning of the mouse obese gene and its human homologue. Nature 1994; 372: 425-432 
Zhou G, Myers R, Li Y, Chen Y, Shen X, Fenyk-Melody J, Wu M, Ventre J, Doebber T, Fujii N, Musi N, Hirshman MF, Goodyear LJ, Moller DE: Role of AMP-activated protein kinase in mechanism of metformin action. J Clin Invest 2001; 108: 1167-1174

Zhou L, Zhu DY: Neuronal nitric oxide synthase: structure, subcellular localization, regulation, and clinical implications. Nitric Oxide 2009; 20: 223-230

Zimmet PZ, Tuomi T, Mackay IR, Rowley MJ, Knowles W, Cohen M, Lang DA: Latent autoimmune diabetes mellitus in adults (LADA): the role of antibodies to glutamic acid decarboxylase in diagnosis and prediction of insulin dependency. Diabet Med 1994; 11: 299-303

Zou T, Ouyang L, Chen L, Dong W, Qiao H, Liu Y, Qi Y: The role of microtubule-associated protein 1S in SOCS3 regulation of IL-6 signaling. FEBS Lett 2008; 582: 4015-4022 


\section{ACKNOWLEDGEMENTS}

First of all I would like to express my utmost gratitude to Prof. Dr. Sigurd Lenzen for giving me the opportunity to perform my $\mathrm{PhD}$ studies at the Institute of Clinical Biochemistry and for his supervision throughout the process. I am grateful for his guidance, tremendous knowledge, encouragement, and contribution to the progress of my work.

I wish to express my most sincere and deep gratitude to Dr. Ewa Gurgul-Convey, who provided a critical and meritorious input for my research. It was an honor and pleasure to be her PhD student. I appreciate all her contributions of time and ideas to make my $\mathrm{PhD}$ studies stimulating and productive. I am especially thankful for her continued warm encouragement, thoughtful guidance and motivation, even during the tough times in the PhD pursuit. She patiently provided the vision and advice necessary for me to complete my dissertation, for which I am truly indebted. Moreover she has been invaluable on both an academic and a personal level, for which I am also extremely grateful.

I thank her husband Martin Convey and their son Frank Convey for being a surrogate family to me during my stay in Hannover.

I am grateful to colleagues from the Institute of Clinical Biochemistry at Hannover Medical School for their hospitality and creating an amiable atmosphere of work. To all of them I express my thanks for the enjoyment and motivation they provided whilst working with them. The group has been a source of friendships. Johanna - thank you for always being there for me; Christiane, Nicole, Rebecca, Tanja, Claudio and Ulf - thank you for your care, attention, all your comforting words, for your hugs, and for all the laughter.

I am also very grateful to our group's administrative assistants Angela Steinhusen and Diana Deeke who were always ready to help.

My stay in Hannover would not be so unforgettable without all the extraordinary and amazing people I was fortunate to meet during my stay in Germany. I am particularly grateful to Katrin and Svenja for making me feel at home and for being with me through the bittersweet times.

I want to express my deeply-felt thanks to my friends Ania, Asia, Marysia and Natalia for their friendship, patience, and emotional support, despite the distance between us.

And last but not least I am forever indebted to my family, to whom I dedicate this work. To my dearest parents and to my incredible sister for their unconditional love, encouragement, support, and understanding. Thank you so much, without you none of this would have been possible. 


\section{DECLARATION OF AUTHENTICITY}

This thesis contains no material which has been accepted for the award of any other degree or diploma in any University. To the best of my knowledge and belief, this thesis contains no material previously published or written by another person, except where due reference has been made.

I hereby declare that this $\mathrm{PhD}$ thesis entitled "Effects of the novel mitochondrial protein mimitin in insulin-secreting cells" has been written independently with no other aids or sources than quoted. 


\section{CURRICULUM VITAE}

\section{Personal details}
Name:
Katarzyna Joanna Hanzelka
Date and place of birth:
27 April 1984, Cracow, Poland

\section{Education and Laboratory Experience}

- 1999-2003

- $2003-2008$

- September 2007 - March 2008

- 30 July 2008

- October 2008-2012
Bartłomiej Nowodworski’s Secondary School no.1, Kraków, Poland,

Profile: biology and chemistry, Final Exam with Honours

Master Studies at the Faculty of Biochemistry, Biophysics and Biotechnology, Jagiellonian University, Cracow, Poland; specialized in medical biotechnology

Socrates-Erasmus scholarship at the Department of Experimental Immunology, Academic Medical Center, Amsterdam, Netherlands, Master of Science in Biotechnology with Honours Thesis: "The influence of metabolic factors on chemerin expression in human HepG2 hepatoma cells",

Department of Immunology, Faculty of Biochemistry, Biophysics and Biotechnology, Jagiellonian University, Cracow, Poland

PhD studies, Leibniz University of Hannover, Scientific supervision:

Prof. Sigurd Lenzen and Dr. Ewa Gurgul-Convey, Institute of Clinical Biochemistry,

Hannover Medical School, Hannover, Germany 


\section{LIST OF PUBLICATIONS}

1. Hanzelka K., Skalniak L., Jura J., Lenzen S., Gurgul-Convey E. (2012) Effects of the novel mitochondrial protein mimitin in insulin-secreting cells. Biochem J 445: 349-359

2. Gurgul-Convey E., Hanzelka K., Lenzen S. (2012) Mechanism of prostacyclin-induced potentiation of glucose-induced insulin secretion. Endocrinology 153:2612-22.

3. Gurgul-Convey E., Hanzelka K., Lenzen S. (2012) Is there a role for neuronal nitric oxide synthase (nNOS) in cytokine toxicity to pancreatic $\beta$-cells? Nitric oxide 27: 235-241. 


\section{LIST OF ABSTRACTS}

1. Derecka M., Hanzelka K., Malara A., Banas M., Gawel K., Cichy J. (2009) The role of acute phase mediators in regulating chemerin synthesis in hepatic cells, Poster presentation at the $36^{\text {th }}$ Winter School of the Faculty of Biochemistry, Biophysics and Biotechnology of the Jagiellonian University, Zakopane, Poland

2. Hanzelka K., Gurgul-Convey E., Jura J., Lenzen S. (2009) Die Rolle von Mimitin in insulinproduzierende Zellen, Poster presentation at the $44^{\text {th }}$ Annual Meeting of the German Diabetes Association (Deutschen Diabetes-Gesellschaft, DDG), P-169, Leipzig, Germany

3. Gurgul-Convey E., Hanzelka K., Kacheva S., Jura J., Lenzen S. (2009) Die Rolle Stickstoffmonoxids für zytokin-vermittelten Mimitin Genexpression in insulinproduzierenden Zellen, Poster presentation at the $44^{\text {th }}$ Annual Meeting of the German Diabetes Association (DDG), P-284, Leipzig, Germany

4. Hanzelka K., Gurgul-Convey E., Jura J., Lenzen S. (2009) The role of mimitin in insulinproducing cells, $45^{\text {th }}$ Annual Meeting of the European Association for the Study of Diabetes (EASD), P-371, Vienna, Austria, Diabetologia 52

5. Hanzelka K., Lenzen S., Gurgul-Convey E. (2010) Mimitin Überexpression schützt gegenüber Zytokin-induzierter Apoptose durch Unterdrückung der MAP1S Wirkung, Poster presentation at the $45^{\text {th }}$ Annual Meeting of the German Diabetes Association (DDG), P-267, Stuttgart, Germany

6. Gurgul-Convey E., Hanzelka K., Lenzen S. (2010) Zytoprotektion und Erhalt der Insulinsekretion durch PGIS Überexpression in insulin-produzierenden Zellen, Poster presentation at the $45^{\text {th }}$ Annual Meeting of theGerman Diabetes Association (DDG), P-263, Stuttgart, Germany

7. Hanzelka K., Lenzen S., Gurgul-Convey E. (2010) Mimitin overexpression protects insulinproducing INS1E cells against cytokine-induced apoptosis via prevention of MAP1S action, $46^{\text {th }}$ Annual Meeting of the EASD, P-501, Stockholm, Sweden, Diabetologia 53

8. Hanzelka K., Lenzen S., Gurgul-Convey E. (2011) Mimitin Überexpression schützt insulinproduzierende Zellen vor Zytokin-induziertem ER Stress, Poster presentation at the $46^{\text {th }}$ Annual Meeting of the German Diabetes Association (DDG), P-113, Leipzig, Germany

9. Gurgul-Convey E., Hanzelka K., Lenzen S. (2011) Mechanismus der gesteigerten glucoseinduzierten Insulinsekretion durch Prostacyclin-Synthase Überexpression in insulinproduzierenden Zellen, Poster presentation at the $46^{\text {th }}$ Annual Meeting of the German Diabetes Association (DDG), P-114, Leipzig, Germany 